\title{
Review on ammonia as a potential fuel: from synthesis to economics
}

\author{
Valera-Medina A., A. ; Amer-Hatem, F. ; Azad, A.K. ; Dedoussi, I.; De Joannon, M.; Fernandes, R.X. ; \\ Glarborg, P.; Hashemi, H.; He, X. ; Mashruk, S.
}

Total number of authors:

19

Published in:

Energy \& Fuels

Link to article, DOI:

10.1021/acs.energyfuels.0c03685

Publication date:

2021

Document Version

Publisher's PDF, also known as Version of record

Link back to DTU Orbit

Citation (APA):

Valera-Medina A., A., Amer-Hatem, F., Azad, A. K., Dedoussi, I., De Joannon, M., Fernandes, R. X., Glarborg, P., Hashemi, H., He, X., Mashruk, S., McGowan, J., Mounaim-Rouselle, C., Ortiz-Prado, A., Ortiz-Valera, J. A., Rossetti, I., Shu, B., Yehia, M., Xiao, H., \& Costa, M. (2021). Review on ammonia as a potential fuel: from synthesis to economics. Energy \& Fuels, 35(9), [6964-7029]. https://doi.org/10.1021/acs.energyfuels.0c03685

\section{General rights}

Copyright and moral rights for the publications made accessible in the public portal are retained by the authors and/or other copyright owners and it is a condition of accessing publications that users recognise and abide by the legal requirements associated with these rights.

- Users may download and print one copy of any publication from the public portal for the purpose of private study or research.

- You may not further distribute the material or use it for any profit-making activity or commercial gain

- You may freely distribute the URL identifying the publication in the public portal 


\title{
Review on Ammonia as a Potential Fuel: From Synthesis to Economics
}

\author{
A. Valera-Medina,* F. Amer-Hatem, A. K. Azad, I. C. Dedoussi, M. de Joannon, R. X. Fernandes, \\ P. Glarborg, H. Hashemi, X. He, S. Mashruk, J. McGowan, C. Mounaim-Rouselle, A. Ortiz-Prado, \\ A. Ortiz-Valera, I. Rossetti, B. Shu, M. Yehia, H. Xiao, and M. Costa
}

Cite This: Energy Fuels 2021, 35, 6964-7029

Read Online

ACCESS | Lلll Metrics \& More | 回 Article Recommendations | si Supporting Information

\begin{abstract}
Ammonia, a molecule that is gaining more interest as a fueling vector, has been considered as a candidate to power transport, produce energy, and support heating applications for decades. However, the particular characteristics of the molecule always made it a chemical with low, if any, benefit once compared to conventional fossil fuels. Still, the current need to decarbonize our economy makes the search of new methods crucial to use chemicals, such as ammonia, that can be produced and employed without incurring in the emission of carbon oxides. Therefore, current efforts in this field are leading scientists, industries, and governments to seriously invest efforts in the development of holistic solutions capable of making ammonia a viable fuel for the transition toward a clean future. On that basis, this review has approached the subject gathering inputs from scientists actively working on the topic. The review starts from the importance of ammonia as an energy vector, moving through all of the steps in the production, distribution, utilization, safety, legal considerations, and economic aspects

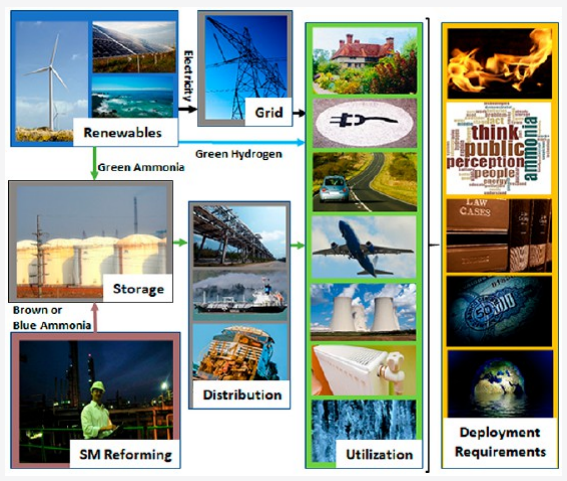
of the use of such a molecule to support the future energy mix. Fundamentals of combustion and practical cases for the recovery of energy of ammonia are also addressed, thus providing a complete view of what potentially could become a vector of crucial importance to the mitigation of carbon emissions. Different from other works, this review seeks to provide a holistic perspective of ammonia as a chemical that presents benefits and constraints for storing energy from sustainable sources. State-of-the-art knowledge provided by academics actively engaged with the topic at various fronts also enables a clear vision of the progress in each of the branches of ammonia as an energy carrier. Further, the fundamental boundaries of the use of the molecule are expanded to real technical issues for all potential technologies capable of using it for energy purposes, legal barriers that will be faced to achieve its deployment, safety and environmental considerations that impose a critical aspect for acceptance and wellbeing, and economic implications for the use of ammonia across all aspects approached for the production and implementation of this chemical as a fueling source. Herein, this work sets the principles, research, practicalities, and future views of a transition toward a future where ammonia will be a major energy player.
\end{abstract}

\section{INTRODUCTION}

Out of all of the different greenhouse gases (GHGs) that contribute to climate change, carbon dioxide $\left(\mathrm{CO}_{2}\right)$ is the $\mathrm{GHG}$ causing the largest impact on our climate by creating a greenhouse effect that traps thermal radiation into the Earth's atmosphere, raising temperatures and promoting effects such as ice caps melting with oceans rising, decrease of native vegetation, and rise in diseases, among many others. Estimates ${ }^{1}$ show a sharp rise in global temperatures, thus increasing the importance of technologies that avoid the emission of $\mathrm{CO}_{2}$ and other GHGs. Studies have projected a global average temperature increase of approximately $1.0{ }^{\circ} \mathrm{C}$, with a range between 0.8 and $1.2{ }^{\circ} \mathrm{C}$, leading to $1.5{ }^{\circ} \mathrm{C}$ if emissions continue to raise by 2050 , a situation that is highly possible.

In terms of energy generation, wind, solar, and marine technologies are the focus of research, development, and implementation. Wind energy, in particular, is one of the most commercialized renewable energy technologies across the world. Wind turbines have become bigger, with taller hub heights and larger rotor diameters. Simultaneously, the dimensions and number of units in offshore facilities keep increasing, with farms, such as Walney Extension (U.K.), that have reached capacities of $659 \mathrm{MW} .^{2}$ Forecasts predict up to an 8 -fold increase in wind power generation over the next 20 years, thus emphasizing the high impact that the technology will have by then. ${ }^{3}$ However, management of these large resources is

Special Issue: In Memory of Mario Costa

Received: November 2, 2020

Revised: January 24, 2021

Published: February 28, 2021

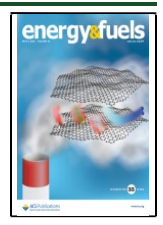




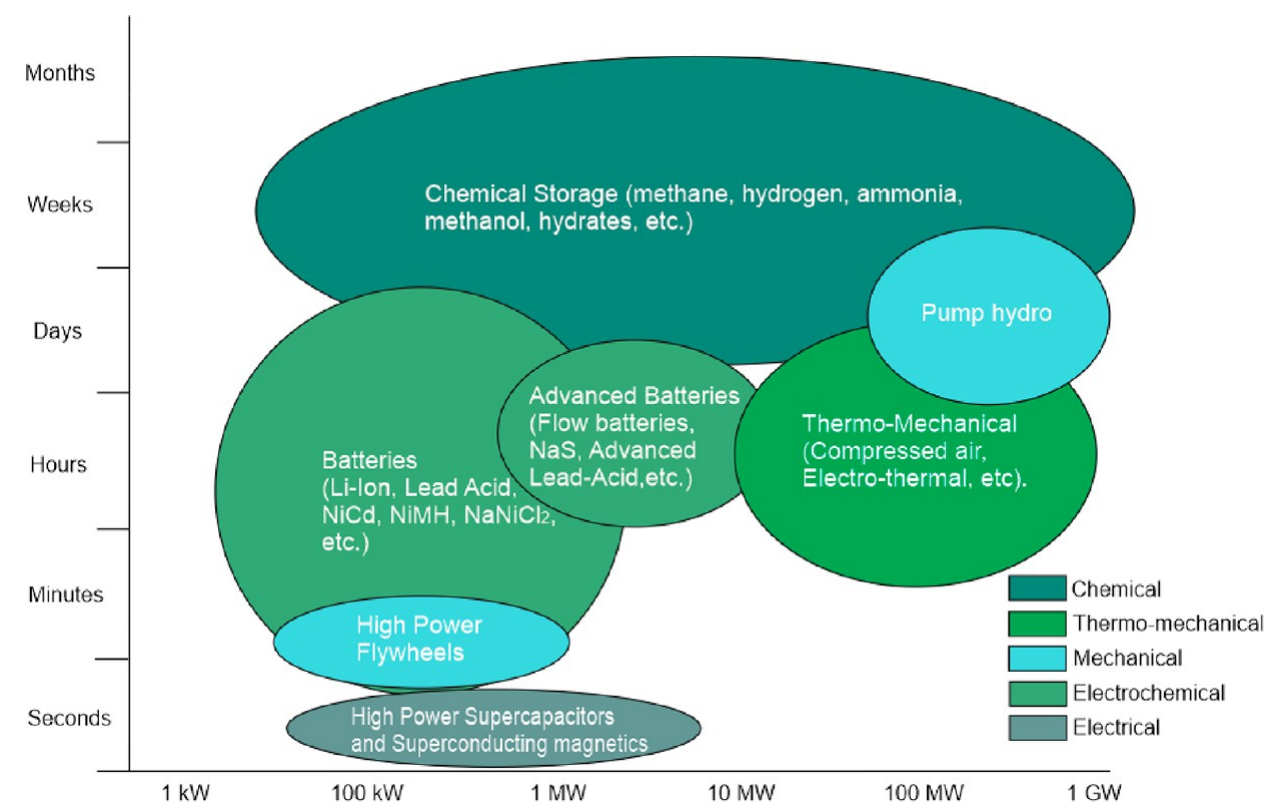

Figure 1. Comparison between different energy storage technologies. This figure was reproduced with permission from ref 11 . Copyright 2020 Elsevier.

critical to improve profitability while supporting the grid with zero-carbon energy in the long term.

Similar to wind energy, solar energy has also gained extensive attention worldwide. Solar energy has become a paramount energy source for the development of renewable energy systems. Solar photovoltaics (PVs), solar thermal electricity, and solar heating/cooling are now well-established solar technologies. ${ }^{4,5}$ For example, solar PV electricity generation increased by about 130 TWh globally in 2019 (from 440 TWh for all renewables), second only to wind in absolute terms, reaching $2.7 \%$ of the electricity supply. ${ }^{6}$

Finally, another technology that can also be considered is marine energy. However, as a result of its immature technical development compared to the previous two technologies, only a mere $0.5 \mathrm{GW}$ capacity had been installed by 2018, with $1.7 \mathrm{GW}$ under construction. ${ }^{7}$ Nevertheless, better economics and energy management could free the potential of $748 \mathrm{GW}$ power by 2050 , creating the way for 160000 direct jobs.

However, all of these technologies vary based on weather conditions, time, difficult to access locations, and seasonal periods. These facts, combined with extreme variability in some regions, can be overcome with the use of proper energy management techniques, such as energy storage, thus enabling the distribution of excess energy when and where it is needed.

There are many ways to store this energy. Concepts go from storage in high power superconductors, managing reasonable energy power $(<5 \mathrm{MW})$ over extremely limited periods (seconds), to pump hydro or chemical storage, capable of storing gigawatts of power for long periods of time (months and years) (Figure 1). However, different from mechanical devices, chemical storage presents a unique feature: flexibility. Chemicals can be moved, stored, and distributed easily, with many of them having a mature market already standing for over decades. Out of all of the zero-carbon options, those commercially assessed are mainly hydrogen, ammonia, and hydrazine as potentials for fueling the future.

Hydrazine presents several issues related to its toxicity and reactivity, making it a difficult fuel that has been relegated only to aerospace applications for auxiliary power during emergency situations. $^{8}$

Hydrogen, the most common molecule in the universe, is currently under assessment everywhere. Numerous paths for its production, distribution, and consumption present a complex variation and trade-off between costs, emissions, scalability, and requirements. ${ }^{9}$ Some scenarios ${ }^{9}$ foresee the use of hydrogen in up to $50 \%$ end-use demand applications by the middle of the 21 st century. However, the creation of a "hydrogen economy" faces several constraints that still require the development of equipment and, overall, infrastructure. In comparison to other molecules, such as ammonia, hydrogen storage can only be cheaper than the use of ammonia when salt caves are employed, ${ }^{10}$ although this only applies over limited periods of time. Thus, storage costs are between 26 and 30 times higher for hydrogen than for ammonia. ${ }^{10}$ Moreover, other barriers, such as its high diffusivity, low energy volumetric density, high flammability range, etc., still make it non-economically viable for a zero-carbon transition, thus requiring another molecule.

Ammonia has been recently presented by authors and global organizations as a zero-carbon molecule that can provide the required energy storage medium for renewable sources. As a product of nitrogen and hydrogen, ammonia can be stored under easy conditions (i.e., refrigerated at $-33{ }^{\circ} \mathrm{C}$ at atmospheric pressure or at $0.8-1.0 \mathrm{MPa}$ under atmospheric temperature), thus making it a versatile, easy to store medium. Moreover, liquid ammonia has a greater volumetric hydrogen density than liquid hydrogen itself (i.e., liquid hydrogen at $20 \mathrm{~K}$ has approximately $70 \mathrm{~kg}$ of $\mathrm{H}_{2} / \mathrm{m}^{3}$, while liquid ammonia at 300 $\mathrm{K}$ and $1.0 \mathrm{MPa}$ has $106 \mathrm{~kg}$ of $\mathrm{H}_{2} / \mathrm{m}^{312}$ ). The versatility of the molecule has led to its distribution at a commercial and global scale, with a market of 180 million tonnes produced annually worldwide, ${ }^{13}$ making it the second most commercialized chemical in the world. Therefore, infrastructure at every scale (i.e., large ports and distribution lines, medium distributors, and small users) is available for immediate implementation of an "ammonia economy" in support of a futuristic "hydrogen economy". 


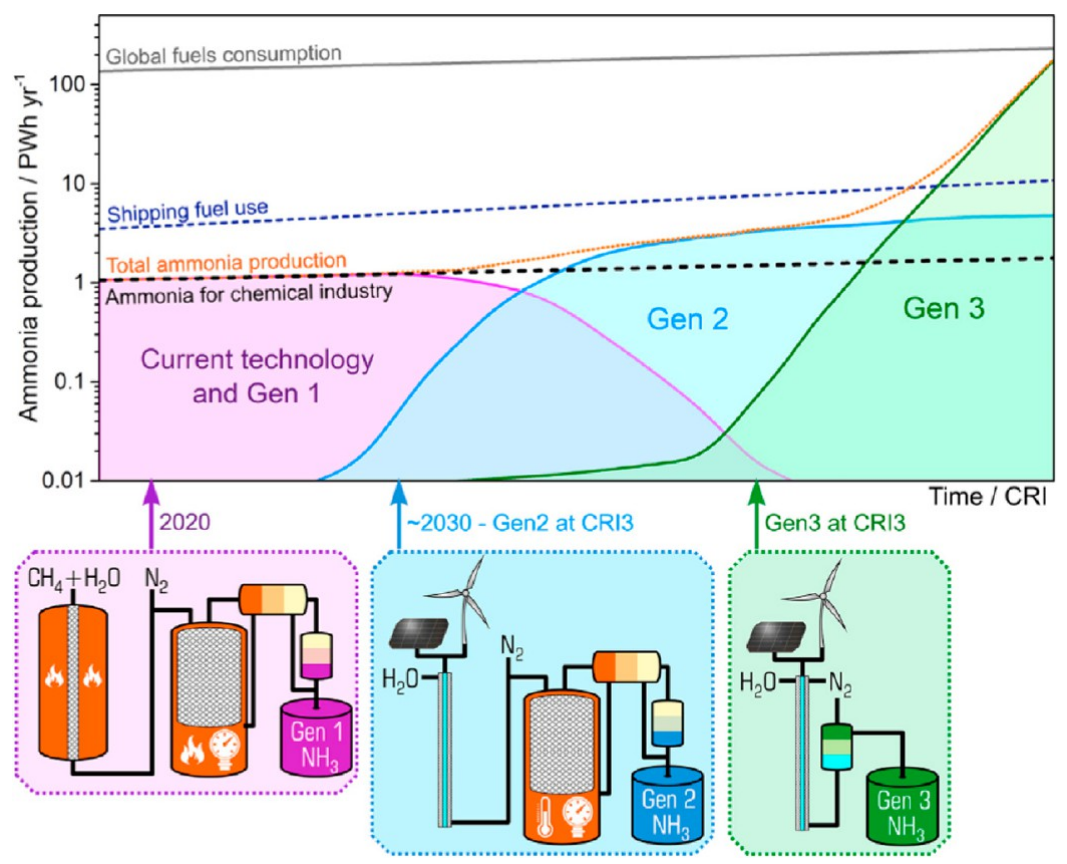

Figure 2. Ammonia economy roadmap showing current and projected contributions of the current and generation 1 (purple), generation 2 (light blue), and generation 3 (green) ammonia production technologies. This figure was reproduced with permission from ref 14 . Copyright 2020 Elsevier.

However, to reach that point and fulfill the need of a zerocarbon economy, hydrogen and ammonia need to be produced with a minor or null carbon footprint. According to MacFarlane et al., ${ }^{14}$ the transition needs to occur through the development of three types of technologies or "generations" (Figure 2). The first generation will produce "blue hydrogen" that will ensure carbon capture and storage (CCS) of $\mathrm{CO}_{2}$ produced during the manufacturing of ammonia (i.e., the easiest method to move hydrogen); a second generation will employ renewable sources to produce "green hydrogen", consequently producing "green ammonia"; and finally, a third generation of technologies will avoid producing hydrogen, delivering ammonia via electroreduction of $\mathrm{N}_{2}$, thus avoiding the well-known Haber-Bosch process, which is the method to produce ammonia at a commercial scale. ${ }^{14}$ Although costs are the main barrier for generations 1 and 2, while technological feasibility is still a constraint for commercial deployment of generation 3 , the global movement toward this path of development to an "ammonia economy" is continuously progressing. Current industrial developments have targeted the production of green ammonia in Australia in a venture between BAE and Yara, while CCS is now under consideration for ammonia plants in Norway. ${ }^{15}$

Similarly, advanced research and development is also ongoing on the different methods to use ammonia, from systems that produce less than $10 \mathrm{~W}$ to those that can potentially move transoceanic vessels and provide power at national scales. Most advances need to deal with several constraints that include emissions (principally $\mathrm{NO}_{x}$ ), corrosion, deactivation, or stability. Some of the most advanced technologies are discussed later in this review.

Finally, public acceptance and economic factors also need to be addressed if ammonia is going to be employed as a global fuel. As for public acceptance, a recent study ${ }^{11}$ denotes that it is likely that, in the countryside, people would be willing to deal with the nuisances of ammonia (i.e., its bad odor), while urban locations would be more reluctant to its use for powering/heating applications. Although safety and integrity need to be maintained in both scenarios, it was clear that there is a potential for ammonia to feed plants and processes outside of heavily populated regions.

In the same manner, various economic studies have been attempted to demonstrate the feasibility of ammonia as an energy storage medium of renewable energy. Works from Banares-Alcantara et al. ${ }^{16}$ describe profitable and feasible scenarios when ammonia is used as an energy storage medium and fertilizer, while the works of Rouwenhorst et al., ${ }^{17}$ Wang et al., ${ }^{18}$ and Bicer et al. ${ }^{19}$ present novel concepts that can make ammonia a feasible and economic candidate to decarbonize transport and power generation. Recently, Palys et al. ${ }^{20}$ performed a techno-economic analysis on an islanded system powered only with renewable sources (Figure 3). Wind turbines, solar photovoltaics, proton electrolytic membranes (PEMs) and alkaline electrolysis units, pressure swing absorbers, hydrogenfed PEM fuel cells, ammonia-fed solid oxide fuel cells (SOFCs), ammonia-fed internal combustion engines (ICEs), and gas and liquid storage are all included in the analysis.

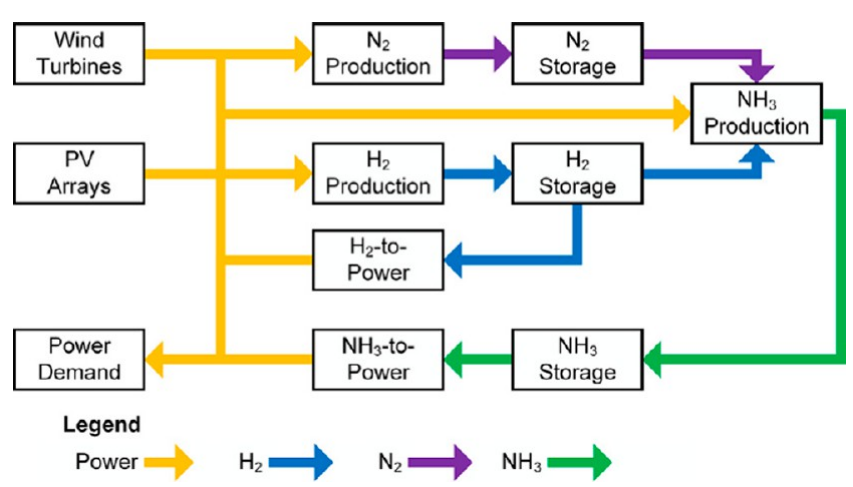

Figure 3. Conceptual superstructure of the renewable energy supply, which uses hydrogen and ammonia for energy storage. This figure was reproduced with permission from ref 20. Copyright 2020 Elsevier. 
Variable operation periods were also considered. Using a selection of various cities in the U.S.A. (with different climate regions and power demand), the results indicate that hydrogen storage is more expensive in most cities for long periods of time, while ammonia is not significantly worse for short-term energy storage. Overall, the ammonia-based levelized cost of electricity (LCOE) is never more than U.S. $\$ 0.02 / \mathrm{kWh}$ greater than the hydrogen-based LCOE. However, all studied scenarios and locations showed that a combination of both vectors is the most economically viable, with cities in which hydrogen is more economic reducing costs even further from the use of ammonia and vice versa. For example, in hydrogen-based locations, the use of ammonia leads to less investment in renewables because ammonia can store energy more economically, while ammoniabased locations also using hydrogen can reduce costs by using a hydrogen-fed power generation system that can lower the investment in ammonia synthesis units (which are expensive), with short-term hydrogen power generation being an efficient method to balance immediate energy demand. ${ }^{20}$ Further results show that seasonal storage of ammonia with short-term use of hydrogen is the most economically viable option. Simultaneously, smaller capacity SOFC and PEM can generate consistent power, while larger power units (ICE) can meet the high demand seasonal peaks. For these combined systems, the LCOE is between U.S. $\$ 0.17 / \mathrm{kWh}$ and U.S. $\$ 0.28 / \mathrm{kWh}$, including the investment in the renewables, ${ }^{20}$ feasible and competitive to even some fossil-based strategies. More details about these and other studies are detailed in the following sections. Therefore, it is evident that the potential of using ammonia is considerable, with promising economics, a reliable standing network, and the development of technologies that will reduce production costs and minimize unwanted emissions with higher reconversion efficiencies.

These aspects have led to the recognition of ammonia as a potential energy carrier. Several programs worldwide (Table 1) are now underway for the assessment of the molecule to ensure the decarbonization of our energy systems. Thus, it is clear that further understanding all aspects of this chemical as an energy source is critical to ensure its greatest penetration or limit its use, whatever is the most feasible path on the basis of current and future trends.

Thus, this review attempts to present some of the advances of the use of ammonia as an energy carrier by combining the expertise of researchers actively working in the field. Further, different from other works, this review does not intend to show only technical aspects for the use of ammonia as a fueling source but also all of the various parameters, many social and political, that are needed for the transition to the use of ammonia in the global energy mix. The review starts with some details about the current production of ammonia, followed by the presentation of combustion fundamentals and technologies to use the chemical for power, heat, and propulsion generation. Safety aspects that include environment, corrosion, legal perspective, and risks follow to enable a comprehensive and fair assessment of ammonia as an energy source. The work continues with an approach to the economic constraints of ammonia-based technologies, finishing with the assessment of future trends in all of the previously raised aspects. Conclusions are withdrawn from each section, thus ensuring that readers can make a holistic conclusion of the potential of ammonia as an energy vector.

\section{SYNTHESIS}

It is essential to recall how ammonia is produced. Ammonia production amounts to 146 million $t$ /year in the world, ${ }^{32}$ spread through China (48 Mt/year), Russia (12 Mt/year), India (11 $\mathrm{Mt} /$ year), and the U.S.A. (9 Mt/year). The main process for ammonia synthesis is the Haber-Bosch process, ${ }^{33}$ implemented in super giant plants with $2-3000 \mathrm{t}$ /day capacity, expected to increase further in future installations.

Ammonia synthesis is based on a reversible exothermal reaction (reaction $\mathrm{R} 1)$. $^{34-36}$

$$
\mathrm{N}_{2(\mathrm{~g})}+3 \mathrm{H}_{2(\mathrm{~g})} \rightleftarrows 2 \mathrm{NH}_{3(\mathrm{~g})} \quad \Delta H^{\circ}=-92 \mathrm{~kJ} \mathrm{~mol}^{-1}
$$

According to thermodynamics, a low temperature would favor the reaction, but on the basis of kinetic reasons, high operating temperatures are needed for a reasonable productivity. The reaction does not occur without a catalyst, but even with it, the operating temperature is $\sim 670 \mathrm{~K}$, imposing a high pressure $(\sim 10.0-30.0 \mathrm{MPa})$ to achieve a practically interesting conversion.

The catalysts used commercially are based on $\mathrm{Fe}$, formerly obtained from magnetite oxide $\left(\mathrm{Fe}_{3} \mathrm{O}_{4}\right)^{37-41}$ and later on wustite $\left(\mathrm{Fe}_{1-x} \mathrm{O}\right)^{39,42}$ or $\mathrm{Fe}-\mathrm{Co}$ catalysts. ${ }^{43}$ Different materials based on $\mathrm{Ru} / \mathrm{C}$ are exploited in the Kellogg advanced ammonia process (KAAP), which became popular in the 1990s as an alternative process, allowing the process to drop the operating pressure below 100 bar with huge energy and cost savings. The equilibrium constant of the reaction depends upon the temperature according to eq $1^{44}$

$$
\begin{aligned}
\log _{10} K_{\mathrm{eq}}= & -\frac{59.9024}{R}+\frac{37656}{R T}-2.691122 \log _{10} T \\
& -5.519265 \times 10^{-5} T+1.848863 \times 10^{-7} T^{2}
\end{aligned}
$$

which leads to a decreasing maximum ammonia concentration when raising the temperature, while increasing pressure boosts the conversion.

As for kinetics, different models work depending upon the catalyst. $^{44,45}$ The traditional Fe-based catalysts obey the Temkin model (eq 2), which accounts for the inhibition of Fe by the products

$$
\frac{\mathrm{d} \eta}{\mathrm{d} \tau}=k \lambda(q)\left(K_{\mathrm{a}}^{2} a_{\mathrm{N}_{2}}\left[\frac{\left(a_{\mathrm{H}_{2}}\right)^{3}}{\left(a_{\mathrm{NH}_{3}}\right)^{2}}\right]^{\alpha}-\left[\frac{\left(a_{\mathrm{NH}_{3}}\right)^{2}}{\left(a_{\mathrm{H}_{2}}\right)^{3}}\right]^{1-\alpha}\right)
$$

where $\mathrm{d} \eta / \mathrm{d} \tau$ is the consumption rate of the limiting reactant (depending upon feeding stoichiometry) expressed as mol h $\mathrm{dm}_{\text {cat }}^{-3} k$ is the kinetic constant referred to the $\mathrm{NH}_{3}$ decomposition reaction, $K_{\mathrm{a}}$ is the equilibrium constant, $a_{i}$ is the activity of species $i, \lambda(q)$ is adjusted according to the reactants feeding ratio, and $\alpha$ is an adaptive parameter, function of the catalyst, to be set at a constant value (normally 0.75 ).

$\mathrm{Ru}$-based catalysts behave differently because the key kinetic step is $\mathrm{H}_{2}$ competitive adsorption. A modified Temkin model (eq 3) with adsorption terms accounting for this point has been validated, together with a straight Langmuir-Hinshelwood approach, ${ }^{42,46,47}$ which did not fit optimally with the catalyst behavior ${ }^{48}$

$$
\frac{\mathrm{d} \eta}{\mathrm{d} \tau}=k \lambda(q) \frac{\left(a_{\mathrm{N}_{2}}\right)^{0.5}\left[\frac{\left(a_{\mathrm{H}_{2}}\right)^{0.375}}{\left(a_{\mathrm{NH}_{3}}\right)^{0.25}}\right]-\frac{1}{K_{\mathrm{a}}}\left[\frac{\left(a_{\mathrm{NH}_{3}}\right)^{0.75}}{\left(a_{\mathrm{H}_{2}}\right)^{1.125}}\right]}{1+K_{\mathrm{H}_{2}}\left(a_{\mathrm{H}_{2}}\right)^{0.3}+K_{\mathrm{NH}_{3}}\left(a_{\mathrm{NH}_{3}}\right)^{0.2}}
$$


where $k$ is instead the kinetic constant of the direct reaction. ${ }^{39}$

As a result of the exothermicity of the reaction, the temperature increases along the bed, limiting the conversion alongside the latter. Therefore, one of the key reactor issues is to set an adequate thermal management program. ${ }^{49}$ This can be achieved through different approaches, such as intra- and/or interbed cooling or feed split, with quenching of the reactor by injection of "cold" feed streams. The goal is to identify a reactor operating line joining the points of maximum rate to optimize the efficiency.

A typical ammonia synthesis loop is constituted by a reaction section containing multi-bed layers of catalyst(s), possibly coupling different catalytic systems, with cooling between the different beds. An ammonia separation system based on condensation of ammonia and the following recycle of unreacted gases is shown in Figure 4.

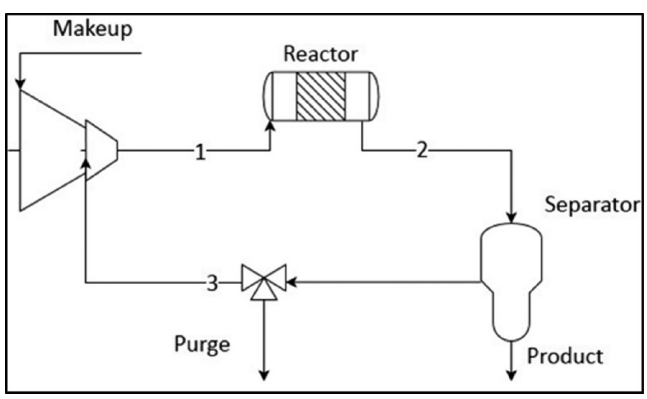

Figure 4. Concept of the reaction loop of an ammonia synthesis plant.

The ammonia synthesis loop is composed of the ammonia synthesis reactor, the ammonia separator, the compressor of the synthesis gas, and the preheater. A complex heat-exchange network is also designed to remove the reaction heat and recover it in different plant sections. However, the whole plant also includes upstream processes for the synthesis of the reacting gases, $\mathrm{N}_{2}$ from air and $\mathrm{H}_{2}$ from different fossil feedstocks, usually through reforming processes. Investigations are in progress to cover this item from renewables, at first by adapting the reforming process to the exploitation of biomass-derived raw materials (e.g., steam reforming of ethanol and gasification of biomass) or through the use of renewable electricity, such as water electrolysis sustained by renewable power. The current production of ammonia and the short-term forecasts, however, depict the main ammonia market from fossil-based reforming processes to hydrogen.

Starting from natural gas or light naphta as feedstock, the main process is based on steam reforming, followed by autothermal reforming or partial oxidation, while for heavy oil or coal, partial oxidation or gasification are the most adopted methods. The main product in every case is $\mathrm{H}_{2}$, but different oxygenate byproducts are also present (i.e., $\mathrm{CO}, \mathrm{CO}_{2}, \mathrm{H}_{2} \mathrm{O}$, and $\mathrm{O}_{2}$ ) which are noxious for the ammonia synthesis catalyst; thus, a careful gas conditioning is needed.

$\mathrm{CO}$ is usually converted through the water-gas shift reaction and to a higher conversion through methanation or methanolation, while the other gases are usually removed by adsorption (e.g., pressure swing adsorption) or condensation in liquid nitrogen. Details on the integrated hydrogen production and purification steps can be deepened elsewhere. ${ }^{50}$ An example of the block diagram for processes from natural gas is reported in Figure 5, which exemplifies a scheme based on the steam reforming of natural gas. ${ }^{40}$ In the figure, the sections for

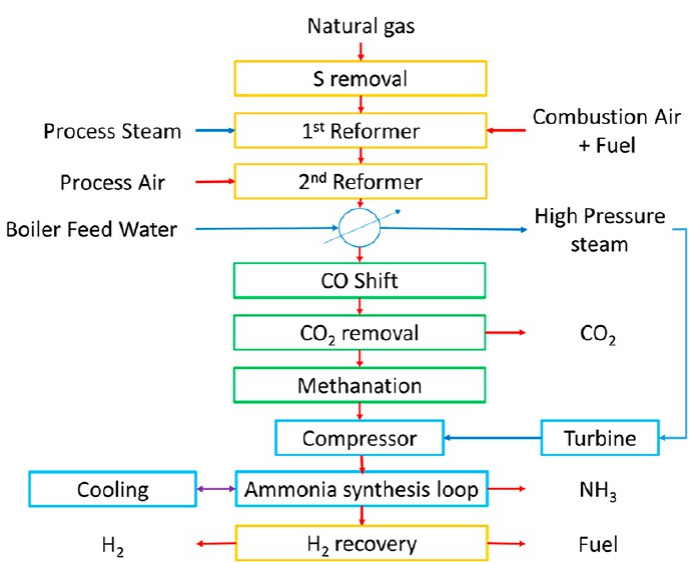

Figure 5. Block diagram of an ammonia synthesis process based on the steam reforming of natural gas. This figure was readapted with permission from ref 40. Copyright 1995 Springer-Verlag.

production and recovery of $\mathrm{H}_{2}$ are identified in yellow, those for reformate purification are identified in green, and the ammonia synthesis loop is identified in light blue. The main input/output streams are identified together with the main sections for heat recovery from the hot sections of the plant (dark blue; e.g., cooling of the reformate from the secondary reformer to the purification section and cooling of the ammonia synthesis reactors, which is not drawn for simplicity). Such energy recovery is at the basis of the process intensification. Highpressure steam is produced, which feeds a steam turbine cycle to drive the ammonia synthesis loop compressors, one of the most energy-demanding sections of the plant.

Synthesis gas compression is one of the main costly items because the reactants are made available at maximum pressures of 2.5-3.0 MPa, while the synthesis loop can be operated from 8.0 to $100.0 \mathrm{MPa}$, usually at $15.0-30.0 \mathrm{MPa}$. High-pressure loops should deal with reciprocating compressors, which are on one hand very expensive, while on the other hand they limit the flow rate exploitable (ca. $300 \mathrm{t} /$ day). The use of centrifugal compressors allows for the improvement of the feed flow rate to the current thousands $t$ /day productivity but set constraints to the maximum operating pressure $(\sim 15.0 \mathrm{MPa})$. This limits the conversion per pass in the reactor, imposing high recirculation rates and, thus, larger volumes and higher recycling costs.

The ammonia synthesis reactor is the core of the ammonia synthesis loop. Different reactor space velocities are designed, ranging from $12000 \mathrm{~h}^{-1}$ at $15.0 \mathrm{MPa}$ to $35000 \mathrm{~h}^{-1}$ at $80.0 \mathrm{MPa}$, with temperatures between 620 and $800 \mathrm{~K}$. Accordingly, the typical conversion-per-pass ranges from 12 to 16.5 vol $\% \mathrm{NH}_{3}$, rising to $19-19.5 \%$ in advanced processes. The adiabatic temperature raises these ranges between 447 and $505 \mathrm{~K}$ (up to $560{ }^{\circ} \mathrm{C}$ for the high conversion processes). As mentioned, the heat of reaction should be removed, e.g., through interbed cooling and energy recovery. In the most optimized configurations, the energy recovery can be up to $93 \%$.

Ammonia is then collected by condensation. Dependent upon the operating pressure, this step of the process can also be the object of optimization. For example, high-pressure synthesis loops can achieve condensation and significant ammonia recovery with cooling water only, while low-pressure synthesis loops need cryogenic cooling to $248 \mathrm{~K}$.

The unconverted synthesis gas must be recycled, being recompressed to the synthesis pressure (the cost depends upon the pressure loss in the cycle and the recycle flow rate) and 
purged to avoid the accumulation of inert gases in the loop. Alternative layouts placing the items of the loop with different order and connections are proposed, but the most used is the layout reported in Figure 4.

Direct heat exchange is accomplished in the converter with cooling pipes inside the catalyst bed or with a shell and tube heat-exchanger reactor. Figure 6 a describes a reactor with axial
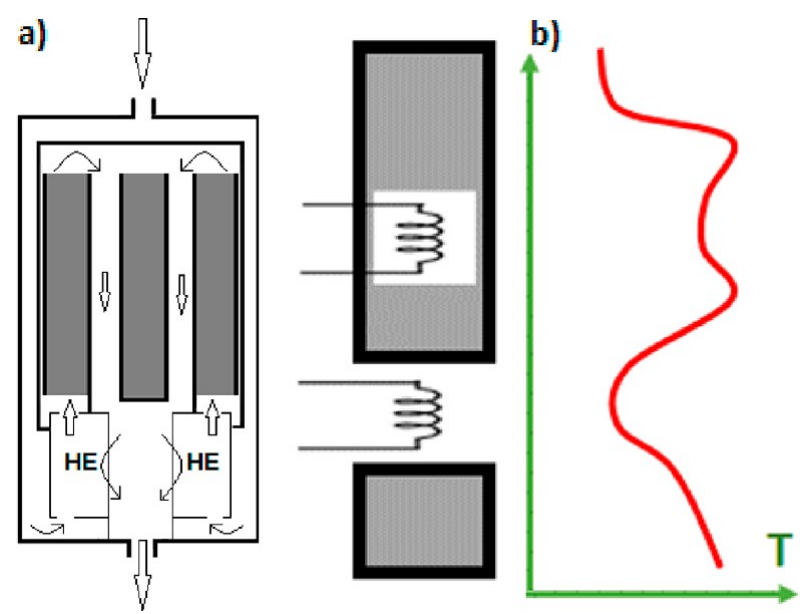

Figure 6. (a) Cold-wall axial flow converters with an internal heat exchanger (HE) and (b) qualitative description of intra- and interbed cooling, with the temperature profile (red) along the reactor length. Serpentines represent cooling heat exchangers, and gray boxes represent the catalyst bed. Cooling can be achieved with water to produce high-pressure steam.

feed split across the catalyst bed and heat recovery at the outlet, while the options of a cooling system inside the catalyst bed and between consecutive catalyst layers is reported in Figure 6b, with a schematic of the expected temperature profile along the reactor.

The cold feed may be also used to quench the catalyst bed, using feed distribution nozzles or between two adjacent adiabatic beds. ${ }^{49}$ Otherwise, the catalyst bed can be operated as adiabatic, with the heat removed between the layers.

Specific materials are needed for the converter, to stand the high pressure in the presence of $\mathrm{H}_{2}$ and $\mathrm{N}_{2}$ (i.e., embrittlement and nitridation). Alloy steels can be used below $673 \mathrm{~K}$, whereas stainless-steel, Incoloy, and Inconel materials should be used for higher temperatures. To save investment costs, a cold-wall arrangement is often employed, as in Figure 6a, with the hot catalyst bed contained in the internal cartridge, surrounded by the flow of the preheated feed $(\sim 573 \mathrm{~K})$. In this way, the pressure difference across the cartridge wall is only a few bar, with the external fluid already being pressurized. The significant pressure difference between the external environment and the internal high-pressure medium is located across the external vessel wall, which is subject to a much lower temperature, thus needing a less expensive metal for its manufacturing.

Formerly, the reactors were operated with axial flow, while the design of the first radial flow reactor was a key innovation to decrease the pressure drop across the catalyst bed, thus allowing for a lower particle size of the catalyst, with higher effectiveness and practically nil diffusional limitations. ${ }^{51,52}$ Mixed axial/radial configurations were instead proposed by Ammonia Casale, ${ }^{53}$ with an annular catalyst bed.

Ammonia synthesis is one of the most energy-consuming processes, accounting for nearly $3 \%$ of the world energy consumption. Thus, every attempt to intensify the process of decreasing the energy demand has enormous impacts on resources, savings, and globally on the environment. Different strategies are in place for this purpose, with the study of novel cycles and materials. In particular, new catalysts are needed to further decrease the ammonia synthesis loop pressure, which is now one of the key issues for the development of small-scale plants, which would be better integrated with renewable-based raw materials (e.g., biomass) and energy sources (e.g., water electrolysis supported by renewable electricity). Furthermore, key process parameters, such as the synthesis loop pressure and the gap between the hydrogen synthesis section and the utilization in the loop, become paramount in the new methods for production. Therefore, high-pressure electrolyzers should be selected to decrease the compression duty. In addition, the improvement of the thermal management within the loop and overall in the process would allow for considerable savings, especially when thermal energy utilization is envisaged (i.e., high-pressure steam production to support the compression duties). However, it is clear that, as part of a green agenda, green ammonia (product of renewable processes) will increase its influence in the production of the chemical worldwide.

\section{COMBUSTION}

Once ammonia has been produced, stored, and distributed, one method to employ the molecule is to combust it for power generation or heat release. Although there are some other methods to recover the energy from the molecule (i.e., fuel cells), it is important to acknowledge the importance and complexity of ammonia combustion in its pure form or when combined with other molecules. Therefore, this section approaches the known phenomena around ammonia combustion.

3.1. Fundamentals. Since the 1950s, fundamental investigations have been performed to understand the combustion characteristics of ammonia. The experiments include the flammability, ${ }^{54-58}$ ignition delay, ${ }^{59-78,76}$ flame propagation, ${ }^{77-94}$ and speciation. ${ }^{95-112}$ Data from those experiments serve further as validation targets for the chemical kinetics mechanisms and as references for further technical realizations. It is therefore essential here to provide a review of the measurements, which are easily accessible to peer researchers for identifying the relevant and reliable data set. An overview of investigations of the ignition delay time and laminar burning velocity that are the two most important combustion characteristics will be given in the following sections, focusing mainly on the most recent studies. Notably, in this review, only the experiments applying ammonia as the main fuel, i.e., ammonia fraction is larger than $50 \%$ in fuel mixtures, are considered.

3.1.1. Ignition Delay Time (IDT). Investigations of the IDT of ammonia mixtures can be traced back to the 1960 s, ${ }^{64,66}$ where the induction time has been used to characterize the oxidation process of ammonia. Since then, several studies ${ }^{61-63,65}$ have been performed in shock tubes that covered the oxidation of ammonia at high temperatures $(>1600 \mathrm{~K})$ and low pressures $(<1.0 \mathrm{MPa})$ for constructing comprehensive chemical kinetics mechanism for ammonia oxidation. Among those studies, ${ }^{61-66}$ only Drummond reported IDTs measured at pressures higher than 1.0 MPa $(2.72-4.44 \mathrm{MPa}){ }^{61}$ Because ammonia became a promising zero-carbon fuel, IDT data measured at high pressures are essential. The high-pressure data in Drummond's work $^{61}$ covered a broad but unclear range of pressure, leading to difficulty for the model validation. Many new experimental 
investigations of the IDT at high pressures have been reported in the last 5 years. Figure 7 depicts those experimental investigations for the IDT of ammonia mixtures on a $T-P$ diagram, where the covered and missing conditions can be directly found.

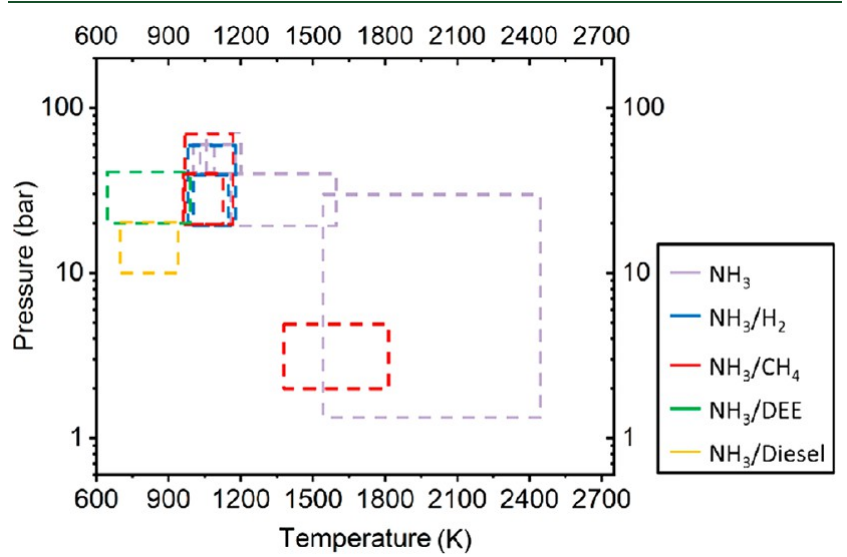

Figure 7. Summary of the conditions of IDT measurements of mixtures containing ammonia from the literature. ${ }^{59,67-71,73,74,76}$

Mathieu and Petersen reported IDT measurements that were carried out in a shock tube, covering pressures near $0.14,1.1$, and 3.0 $\mathrm{MPa}$ and temperatures of $1560-2455 \mathrm{~K}$. The mixtures applied were highly diluted by $\operatorname{Ar}$ (98-99\%) with equivalence ratios of $0.5,1.0$, and $2.0 .^{70}$ The IDTs were determined by the chemiluminescence emission of the excited hydroxyl radical $\left(\mathrm{OH}^{*}\right)$ near $307 \mathrm{~nm}$. The data demonstrated a clear dependence of IDT upon the pressure, equivalence ratio, and dilution at high temperatures. Considering the operation conditions of modern energy and transport systems, Shu et al. extended the IDT measurements to intermediate temperatures $(1100-1600 \mathrm{~K})$ at high pressures (2.0 and 4.0 MPa), applying undiluted ammonia/ air mixtures with equivalence ratios of $0.5,1.0$, and 2.0 in a highpressure shock tube. ${ }^{69}$ However, the experimental data from Mathieu and Petersen and Shu et al. are not directly comparable as a result of different mixture dilutions. Pochet and co-workers reported IDT measurements of lean ammonia mixtures in a rapid compression machine (RCM) at low-temperature combustion (LTC) conditions $(1000-1100 \mathrm{~K})$, pressures of 4.3 and $6.5 \mathrm{MPa}$, and equivalence ratios of $0.2,0.35$, and 0.5 . $^{68}$ For these lean mixtures, no clear dependence of IDT upon the equivalence ratio was identified. He et al. $^{71}$ extended the IDT measurement range further at the LTC conditions in a RCM, using diluted ammonia/oxygen mixtures ( $70 \%$ by $\mathrm{Ar}-\mathrm{N}_{2}$ ) at temperatures between 950 and $1150 \mathrm{~K}$, pressures of 2.0, 4.0, and 6.0 $\mathrm{MPa}$, and equivalence ratios from 0.5 to 2.0. No ignition was observed at $2.0 \mathrm{MPa}$, and the measurements showed that the IDT decreases as the equivalence ratio decreases at the same $T$ and $P$, consistent with the observations in the shock tube by Mathieu and Petersen. Most recently, Dai et al. ${ }^{76}$ measured the IDT of a diluted ammonia/oxygen mixture $\left(75 \% \mathrm{Ar}-\mathrm{N}_{2}\right)$ in a $\mathrm{RCM}$, further extending the pressure and equivalence ratio ranges, i.e., $2.0-7.0 \mathrm{MPa}$ and $0.5-3.0$, respectively.

The investigations on neat ammonia have shown that ammonia has a high activation energy, although it is an attractive candidate as a result of its carbon-free characteristics. Thus far, only three studies ${ }^{68,71,76}$ have reported IDT for ammonia/hydrogen mixtures under LTC conditions with ammonia as the main fuel. $\mathrm{He}$ et al. performed RCM investigations for dilute ammonia/hydrogen $\left(70 \% \mathrm{Ar}-\mathrm{N}_{2}\right)$ at 2.0 and $4.0 \mathrm{MPa}$ and $960-11130 \mathrm{~K}$, with the ammonia/ hydrogen ratio varying from $0.99 / 0.01$ to $0.8 / 0.2 .^{71}$ A clear enhancement of the ammonia ignition by adding hydrogen was observed; the autoignition temperature was lowered $100 \mathrm{~K}$ by adding only $5 \%$ hydrogen in the fuel mixture. Very recently, Dai and co-workers reported RCM results for dilute ammonia/ hydrogen mixtures investigated at pressures of 2.0-7.0 MPa, temperatures of $950-1200 \mathrm{~K}$, and equivalence ratios of 0.5 and 1.0 , with 5 and $10 \%$ hydrogen addition to the fuel mixture. ${ }^{76} \mathrm{~A}$ significant enhancement of the IDT by $5 \%$ hydrogen addition was found (a factor of 10), whereas 10\% hydrogen addition further shortened the IDT by a factor of 2 . These findings are consistent with those of $\mathrm{He}$ et al. ${ }^{71}$

Several studies have been carried out applying hydrocarbons, such as methane and diethyl ether (DEE), as the ignition promoter for ammonia. Dai et al. ${ }^{74}$ reported the first IDT measurements of ammonia/methane mixtures at a high pressure measured in a RCM. The methane fraction varied as $0,5,10$, and $50 \%$. At reported conditions (2.0-7.0 MPa and 930-1140 K) and equivalence ratios of $0.5-2.0$, respectively, methane shows a strong enhancing effect on ammonia that levels off at high methane fractions, similar to what was observed for hydrogen addition. This effect was confirmed by Shu et al. ${ }^{67}$ in their RCM investigation, covering equivalence ratios of 1.0 and 2.0 and methane fractions of 10 and $20 \%$. Most recently, Issayev et al. investigated the combustion behavior of ammonia/DEE mixtures in a RCM over a temperature range of 620-942 K, pressures near 2.0 and $4.0 \mathrm{MPa}$, and equivalence ratios of 0.5 and $1.0 .^{73}$ The DEE fraction varied from 0.05 to 0.2 . A $10 \%$ addition of DEE was found to strongly enhance the ignition delay of pure ammonia at $900 \mathrm{~K}$ and $2.0 \mathrm{MPa}$ by a factor of 10 . A 20\% DEE addition caused the IDT to approach that of pure DEE, indicating that DEE could be a promising igniter in engines.

3.1.2. Laminar Burning Velocity (LBV). The characterization of the LBV (also known as laminar flame speed) of ammonia mixtures started in the $1950 \mathrm{~s},{ }^{58,82-85}$ where the measurements were conducted in burners and the LBVs were determined using the Bunsen flame area method. Further investigations were conducted in the 1970s and 1980s, ${ }^{55,57}$ applying cylindrical-tube methods to obtain an understanding of the flammability and explosion characteristics of ammonia/air mixtures. Zakaznov et al. $^{57}$ and Ronney ${ }^{55}$ report LBVs of fuel-lean to fuel-rich ammonia/air mixtures $(\varphi=0.7-1.5)$ at pressures from 0.06 to $0.2 \mathrm{MPa}$. The measured LBVs show good agreement for fuellean and stoichiometric mixtures, whereas the LBVs of fuel-rich mixtures measured by Ronney ${ }^{55}$ under microgravity conditions are $30 \%$ faster than those reported by Zakaznov et al. ${ }^{57}$ The maximum LBV of ammonia/air mixture was found to be $0.08 \mathrm{~m} /$ $\mathrm{s}$ in a microgravity environment and $0.07 \mathrm{~m} / \mathrm{s}$ under gravity conditions. To evaluate the explosion hazards of ammonia/air mixtures as byproducts of nuclear wastes, LBV measurements were carried out by Pfahl and co-workers at $0.1 \mathrm{MPa}$ and $295 \mathrm{~K}$, applying a constant volume combustion vessel and video recordings of schlieren visualization. ${ }^{56}$ Their results are consistent with those of Zakaznov et al. Takizawa and coworkers obtained LBV data for ammonia/air mixtures applying both the spherical-vessel method and schlieren photography. The two methods provided almost identical results, and the data are consistent with the results of Zakaznov et al. and Pfahl et al. $^{56,57}$

Because ammonia has emerged as a promising alternative fuel, further investigations on the unstretched LBVs and the burned 
gas Markstein length of ammonia mixtures are required. Hayakawa et al. ${ }^{86}$ carried out measurements for ammonia mixtures at pressures up to $0.5 \mathrm{MPa}$ and equivalence ratios from 0.7 to 1.3 , applying a constant volume combustion chamber with high-speed schlieren photography. The unstretched LBVs at 0.1 $\mathrm{MPa}$ and $295 \mathrm{~K}$ showed good agreement with the literature data, even though the stretch effect was not considered in the old measurements, ${ }^{55-57}$ and the maximum LBV was found at an equation ratio $(\varphi)$ of 1.1 . As the initial pressure increases, the LBV decreases, and the maximum LBV is only $0.048 \mathrm{~m} / \mathrm{s}$ at $\varphi=$ 1.1 under $0.5 \mathrm{MPa}$. The burned gas Markstein length of ammonia/air mixtures increases with increasing equivalence ratio, the same as for methane/air and hydrogen/air flames. Moreover, the burned gas Markstein length decreases as the pressure increases, and the values at 0.3 and $0.5 \mathrm{MPa}$ are identical. Very recently, Han et al. $^{81}$ reported LBV measurements applying the heat flux method, which should be more accurate than the traditional constant volume combustion chamber or spherical tube methods. The obtained LBVs from this work are generally $1 \mathrm{~cm} / \mathrm{s}$ slower than those of previous work; ${ }^{56,57,79,86}$ the maximum LBV of ammonia/air mixtures at $0.1 \mathrm{MPa}$ and $295 \mathrm{~K}$ was reported to be $0.06 \mathrm{~m} / \mathrm{s}$ at $\varphi=1.05$.

The efforts to determine accurately the LBV of ammonia/air mixtures show that ammonia has a much slower flame speed than hydrogen or methane. Therefore, work has been performed to characterize the LBV of ammonia/additive mixtures. Hydrogen is the most preferred promoter as a result of its unique ignition features (wide flammability limits and high reactivity) and non-carbon characteristics. Lee et al. ${ }^{78}$ reported the first LBV measurements on ammonia/hydrogen/air flames at atmosphere pressure and room temperature, applying the outwardly propagating spherical flame method. They observed that the presence of hydrogen strongly enhances the flame speed but also leads to higher NO formation. However, for fuel-rich mixtures, hydrogen improves the burning performance while keeping the $\mathrm{NO}$ emission low. As a drawback, adding hydrogen tends to enhance flame sensitivity to stretch. Ichikawa and coworkers followed up the investigation by extending to an elevated pressure, i.e., up to $0.5 \mathrm{MPa}{ }^{77}$ Nonlinear increased unstretched LBVs have been observed by increasing the hydrogen substitution in their work. The burned gas Markstein length varies non-monotonically with the hydrogen ratio. The value decreases as the pressure increases, leveling out at $0.3-0.5$ $\mathrm{MPa}$, similar to the findings by Hayakawa et al. for ammonia/air mixtures. ${ }^{86}$ Han et al. ${ }^{81}$ reported new measurements on the LBV of ammonia/hydrogen mixtures at $0.1 \mathrm{MPa}$ and $295 \mathrm{~K}$, applying the thermal flux method. Their results show very good consistency with the literature data but with improved accuracy. Wang et al. ${ }^{113}$ extended the measurements to elevated pressures, namely, 0.3 and $0.5 \mathrm{MPa}$, where a drastic decrease of LBVs has been observed, i.e., with a factor of 2 and 3 slower at 0.3 and 0.5 $\mathrm{MPa}$, respectively, than at $0.1 \mathrm{MPa}$. Moreover, Lhuilier et al. ${ }^{88}$ extended the measurements to elevated temperatures, i.e., up to $473 \mathrm{~K}$ at $0.1 \mathrm{MPa}$ using the outwardly propagating spherical flame method. Their results at $0.1 \mathrm{MPa}$ and $295 \mathrm{~K}$ agree well with the literature data. As expected, the LBVs of ammonia/ hydrogen mixtures increase with the inlet gas temperature.

Investigations on ammonia/methane mixtures (ammonia as the main fuel) are presently very limited. Han et al. ${ }^{81}$ used the heat flux method to obtain results in excellent agreement with those reported by Okafor et al., ${ }^{92,93}$ where methane was applied as the main fuel. Unlike ammonia/hydrogen mixtures, the addition of methane increases the LBV linearly to the mixture content of methane.

Very recently, studies ${ }^{80,81,90,94,113}$ have been reported on oxygen-enriched ammonia mixtures and ammonia/CO mixtures. The presence of $\mathrm{CO}$ strongly enhances the flame speed, with an efficiency between those of hydrogen and methane. ${ }^{80}$ However, the enhancement of $\mathrm{CO}$ shows a non-monotonic behavior, with a maximum efficiency at $X_{\mathrm{CO}}=0.85 .^{80}$ Oxygenenriched ammonia/oxygen/nitrogen mixtures show a strongly improved flame propagation and a reduced buoyancy effect, resulting in enhanced LBVs. ${ }^{90,91,94}$ By substitution of nitrogen fully by oxygen, the $\mathrm{LBV}$ can reach $1.20 \mathrm{~m} / \mathrm{s}$ at room temperature and $0.1 \mathrm{MPa}$. However, the maximum LBV was found to be at different equivalence ratios for different oxygen fractions; i.e., the maximum LBV is located at a leaner mixture for higher oxygen fractions. Increased inlet gas temperatures also promote the LBV strongly; the LBVs measured at $390 \mathrm{~K}$ are generally $30 \%$ faster than those at $303 \mathrm{~K}$. The stoichiometric ammonia/oxygen mixture has LBVs of 1.60 and $1.20 \mathrm{~m} / \mathrm{s}$ at 390 and $303 \mathrm{~K}$, respectively. ${ }^{94}$

Figure 8 summarizes the recently measured LBVs of ammonia and ammonia/promoter mixtures where the enhancement from

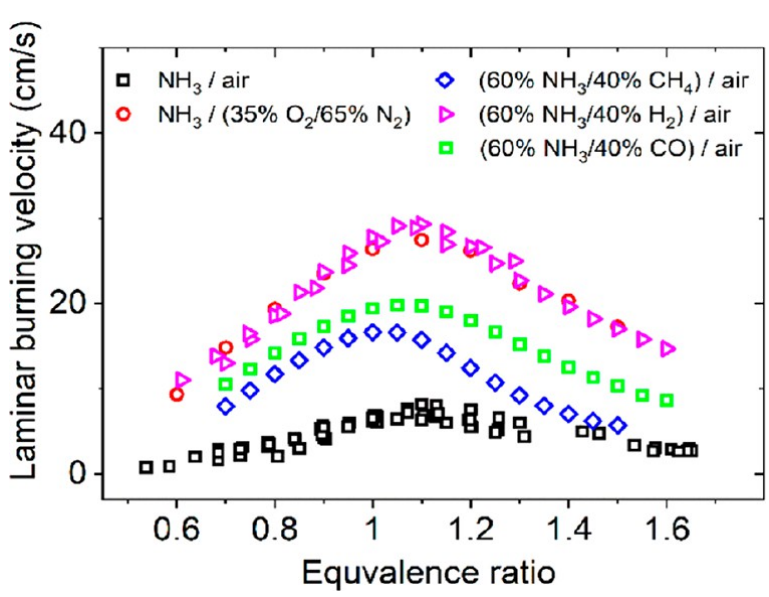

Figure 8. Summary of the LBV of mixtures containing ammonia from the literature. ${ }^{81,90-92,114}$

different burning promoters (hydrogen, methane, carbon monoxide, and oxygen) are directly compared. A further comparison including an ammonia/oxygen mixture (which has much higher LBVs and, therefore, depresses the details of other mixtures) can be found in Figure S1 of the Supporting Information.

3.2. Kinetics. Modeling of ammonia oxidation has attracted the interest of the combustion community because ammonia is the key volatile $\mathrm{N}$ species in combustion. ${ }^{115}$ In addition to its role as an important intermediate during the devolatilization of solid fuels or the conversion of cyanides at high temperatures, ${ }^{116-118}$ ammonia has also been used as the reducing agent in the selective non-catalytic reduction (SNCR) of NO, also known as thermal deNO $x^{*}{ }^{119,120}$ The SNCR method has been widely applied in combustion of fuels, such as biomass and waste. Modeling the oxidation of ammonia as well as thermal deNO $\mathrm{N}_{x}$ has been extensively studied in the past few decades. ${ }^{116,117,118-130}$ Chemical kinetics mechanisms were developed first targeting the chemistry at high temperatures, where ammonia is considered as a combustion intermediate or a SNCR agent for NO reduction. ${ }^{61,62,116,131-133}$ Now that 
ammonia attracts attention as an alternative fuel for future energy and transportation applications, researchers have turned their focus on the chemistry of ammonia oxidation at low to intermediate temperatures $(800-1600 \mathrm{~K})$ and elevated pressures $(>2 \mathrm{MPa})$ that are the relevant conditions in modern combustion devices, such as internal combustion engines and gas turbines. Considering both focal points of a SNCR agent and an independent fuel, a complete scheme of the conversion chemistry of ammonia can be obtained by combining the chemistry between ammonia and $\mathrm{NO}_{x}$ and the elementary reactions of ammonia combustion, e.g., $\mathrm{H}$-abstraction reactions and the cross reactions in the case of a binary fuel system.

Validation of detailed reaction mechanisms requires reliable experiment data covering a wide range of global parameters, such as the laminar burning velocity, ignition delay time, and speciation. In section 3.1, the reported experimental investigations were discussed, focusing on low to intermediate temperatures and elevated pressures. In addition to the comprehensive experimental data sets available in the 1 i t e r a -

ture, ${ }^{54,59,60,67-74,76,77,80,81,86-88,90-94,96,99-103,106,115,134-136}$ quite a few reaction mechanisms have been reported in the past

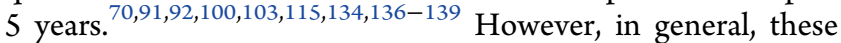
mechanisms have been evaluated only against a limited subset of the experimental data. In the present review, selected recent models are evaluated against experimental investigations for neat ammonia, ammonia-hydrogen mixtures, and ammoniahydrocarbon mixtures. We limit the comparison to data for IDTs and laminar flame speeds (LFSs), while validation against speciation data obtained in flow or jet-stirred reactors or laminar flames is considered outside the scope of this review.

3.2.1. Chemical Kinetics Mechanisms. In the last few decades, numerous chemical kinetics mechanisms $^{70,91,92,100,103,104,115,116,122,126,127,134,136,139-141}$ have been developed for ammonia oxidation under a wide range of conditions. However, as a result of the limited experimental data or different application focus, none of these mechanisms demonstrates satisfactory predictions covering all of the relevant conditions. For instance, Tian et al. ${ }^{104}$ reported an ammonia$\mathrm{C}_{1}$ mechanism (the Tian mechanism) including 84 species and 703 reactions for modeling premixed $\mathrm{NH}_{3} / \mathrm{CH}_{4} / \mathrm{O}_{2} / \mathrm{Ar}$ flames at low pressures. The ammonia sub-mechanism was drawn mainly from the work of Skreiberg et al., ${ }^{126}$ adding 108 additional $\mathrm{C}$ and $\mathrm{N}$ species cross reactions. The Tian mechanism generally demonstrates a satisfactory performance for speciation in laminar flames but shows limited accuracy in simulating ignition delay times, especially for measurements at high pressures. ${ }^{68,71,76,126}$ Mathieu and Petersen proposed an $\mathrm{NH}_{3}$ mechanism (the Mathieu mechanism) with 35 species and 159 elementary reactions for simulating ammonia oxidation at pressures above $1.0 \mathrm{MPa}$. The Mathieu mechanism was mainly based on the mechanism reported by Dagaut et al., ${ }^{140}$ updating the sub-mechanisms for $\mathrm{H}_{2} / \mathrm{O}_{2}, \mathrm{H}_{2} / \mathrm{N}_{2} \mathrm{O}$, and $\mathrm{HCN}$. ${ }^{122,142-145}$ This mechanism demonstrated good performance against ignition delay measurements of ammonia-oxygen mixtures at elevated temperatures and high pressures and speciation of $\mathrm{H}_{2}$ / $\mathrm{O}_{2}$ mixtures with $\mathrm{NO} / \mathrm{NO}_{2}$ addition at intermediate temperatures and high pressures. However, for the most recent ignition delay measurements of ammonia mixtures at elevated pressures and intermediate temperatures, the Mathieu mechanism shows less satisfactory agreement. ${ }^{71,76}$ Shrestha et al. ${ }^{136}$ presented a detailed kinetic mechanism (the Shrestha mechanism) for the oxidation of $\mathrm{NH}_{3}$ containing 34 species and 264 reactions, including $\mathrm{H}_{2} / \mathrm{CO}$ and $\mathrm{NH}_{3} / \mathrm{NO}_{x}$ subsets. The Shrestha mechanism showed good performance against selected data from shock tubes, ${ }^{70,146}$ jet-stirred/flow reactors, ${ }^{142,147}$ and premixed flames. $^{77,86}$ In further evaluation by other authors, the Shrestha mechanism shows limited accuracy, however, especially for ammonia/promoter mixtures. ${ }^{7,76}$

It is outside the scope of the present review to evaluate a large fraction of the literature mechanisms against experimental data. However, five recent mechanisms were selected for evaluation, i.e., Glarborg-2018, ${ }^{115}$ Li-2019, ${ }^{137}$ Mei-2019, ${ }^{91}$ Jiang-2019, ${ }^{138}$ and Stagni-2020. ${ }^{103}$ For each of these models, the predictive capability in simulating ignition delay times and flame speeds for ammonia, ammonia/hydrogen, and ammonia/methane mixtures is evaluated. Because ammonia chemistry is less complex than hydrocarbon chemistry, the most recent elementary reaction models for ammonia oxidation in different studies are generally fairly compatible; differences are largely limited to the choice of rate constants or branching ratios for specific elementary reactions. Details of the development of the five mechanisms can be found in the literature; here, only a brief summary for each mechanism is offered.

The Glarborg-2018 model was reported by Glarborg et al. ${ }^{115}$ as part of a review on nitrogen chemistry relevant for combustion processes. It contains sub-mechanisms for $\mathrm{H}_{2} /$ $\mathrm{CO}, \mathrm{C}_{1}$ hydrocarbons, $\mathrm{NO}_{x} / \mathrm{NNH}, \mathrm{HCN} / \mathrm{HNCO}$, and $\mathrm{NH}_{3}$. Glarborg-2018 is based mainly on the work of Glarborg and coworkers since 1998, ${ }^{117,122,126,127,129,140}$ and the features of many central reactions can be traced back to the work performed in 1980s. ${ }^{116,125}$ The thermodynamic properties of selected key species, such as $\mathrm{NH}_{x}, \mathrm{NO}_{x}$, and $\mathrm{CH}_{x}$, were re-evaluated via the active thermochemical tables approach. ${ }^{148}$ The mechanism has been validated against a wide range of experimental data obtained in shock tubes, premixed flames, and jet-stirred reactors. ${ }^{70,149-153}$ As a non-optimized mechanism, Glarborg2018 showed very good performance for simulating the speciation in flames and jet-stirred reactors. However, it was developed for trace concentrations of amines, and the performance for predicting ignition delay time measured at high temperatures and low pressures is less satisfactory. Glarborg and co-workers pointed to the necessity of extending the validation to high pressures encountered in engines and gas turbines where ammonia is considered as the main fuel for the systems.

The Li-2019 model was proposed by $\mathrm{Li}$ and co-workers ${ }^{137}$ with the aim to construct a comprehensive ammonia/hydrogen/ methane mechanism that could then be reduced for computational fluid dynamic (CFD) simulation of advanced combustion concepts, such as moderate or intense low-oxygen dilution (MILD) combustion. The mechanism merges the ammonia subset from the Shrestha mechanism ${ }^{136}$ and the hydrogen $/ C_{1}-$ $\mathrm{C}_{2}$ subset from AramcoMech 2.0, ${ }^{154}$ adding some complemental ammonia $-\mathrm{C}_{1}$ species and reactions from the Tian mechanism. $^{104}$

The full version of Li-2019 has total 128 species and 957 elementary reactions, while the skeletal mechanisms include a 51 species version for ammonia/hydrogen/methane mixtures and a 26 species version for ammonia/hydrogen mixtures. The comprehensive mechanism and the reduced versions have been validated by the authors against ignition delay times, ${ }^{69,70}$ laminar burning velocities, ${ }^{77,86,91,106,128}$ and non-premixed flames. ${ }^{155}$ Both the full and reduced schemes provided an overall satisfactory performance, with a strongly reduced 
Table 2. Overview of the Evaluations of the Five Selected Literature Mechanisms

\begin{tabular}{|c|c|c|c|c|c|c|c|c|}
\hline & \multirow[b]{2}{*}{$\begin{array}{l}\text { number of } \\
\text { species }\end{array}$} & \multirow[b]{2}{*}{$\begin{array}{c}\text { number of } \\
\text { reactions }\end{array}$} & \multirow[b]{2}{*}{ subsets } & \multicolumn{5}{|c|}{ performed validation in the literature } \\
\hline & & & & system & $\begin{array}{l}\text { experiment } \\
\text { type }^{a}\end{array}$ & $T(\mathrm{~K})$ & $P$ (bar) & $\begin{array}{l}\text { equivalence } \\
\text { ratio }\end{array}$ \\
\hline \multirow[t]{5}{*}{ Glarborg-2018 } & \multirow[t]{5}{*}{151} & \multirow[t]{5}{*}{1395} & \multirow{5}{*}{$\begin{array}{l}\mathrm{H}_{2} / \mathrm{CO}, \mathrm{C}_{1}-\mathrm{C}_{2} \text {, } \\
\text { hydrocarbon/nitrogen, and } \\
\text { amine }\end{array}$} & $\mathrm{NH}_{3} / \mathrm{O}_{2}$ & flame spec & room & 0.046 & 0.71 \\
\hline & & & & $\mathrm{NH}_{3} / \mathrm{O}_{2}$ & ST IDT & $1560-2500$ & $1.4,10,30$ & $0.5,1.0,2.0$ \\
\hline & & & & $\mathrm{NH}_{3} / \mathrm{CH}_{4} / \mathrm{O}_{2}$ & FR spec & $900-1400$ & 1.06 & $\begin{array}{l}0.13,1.07 \\
1.55\end{array}$ \\
\hline & & & & $\mathrm{NH}_{3} / \mathrm{H}_{2} / \mathrm{O}_{2}$ & RCM IDT & $950-1200$ & $20-70$ & $\begin{array}{l}0.5,1.0,2.0 \text {, } \\
\quad 3.0\end{array}$ \\
\hline & & & & $\mathrm{NH}_{3} / \mathrm{CH}_{4} / \mathrm{O}_{2}$ & RCM IDT & $900-1140$ & $20-70$ & $0.5,1.0,2.0$ \\
\hline \multirow[t]{5}{*}{ Jiang-2019 } & \multirow[t]{5}{*}{68} & \multirow[t]{5}{*}{311} & \multirow[t]{5}{*}{$\mathrm{H}_{2} / \mathrm{CO}, \mathrm{C}_{1}-\mathrm{C}_{2}$, and amine } & $\mathrm{NH}_{3} / \mathrm{H}_{2}$ & RCM IDT & $980-1087$ & 43.4 & 0.35 \\
\hline & & & & $\mathrm{NH}_{3} / \mathrm{O}_{2}$ & ST IDT & $1560-2500$ & $1.4,10,30$ & $0.5,1.0,2$ \\
\hline & & & & $\mathrm{NH}_{3} / \mathrm{H}_{2} /$ air & flame LBV & room & 1 & $0.6-1.4$ \\
\hline & & & & $\mathrm{NH}_{3} /$ air & flame LBV & room & $1.0,5.0$ & $0.7-1.3$ \\
\hline & & & & $\mathrm{NH}_{3} / \mathrm{H}_{2} / \mathrm{O}_{2}$ & flame spec & room & $\begin{array}{r}0.05,0.06 \\
0.09,0.12\end{array}$ & $0.9,1.0,1.1$ \\
\hline \multirow[t]{8}{*}{ Li-2019 } & \multirow[t]{8}{*}{128} & \multirow[t]{8}{*}{957} & \multirow{8}{*}{$\begin{array}{l}\mathrm{H}_{2} / \mathrm{CO}, \mathrm{C}_{1}-\mathrm{C}_{2}, \\
\text { hydrocarbon/nitrogen, and } \\
\text { amine }\end{array}$} & $\mathrm{NH}_{3} / \mathrm{O}_{2}$ & ST IDT & $1560-2500$ & $1.4,10,30$ & $0.5,1.0,2.0$ \\
\hline & & & & $\mathrm{NH}_{3} / \mathrm{H}_{2} / \mathrm{O}_{2}$ & RCM IDT & $960-1130$ & $20,40,60$ & $0.5,1.0,1.5$ \\
\hline & & & & $\mathrm{NH}_{3} /$ air & ST IDT & $1100-1600$ & 20,40 & $0.5,1.0,2.0$ \\
\hline & & & & $\mathrm{NH}_{3} / \mathrm{CH}_{4} / \mathrm{H}_{2} / \mathrm{CO}$ & ST IDT & $950-2000$ & $\begin{array}{l}1.5,12.1 \\
30.4\end{array}$ & 0.5 \\
\hline & & & & $\mathrm{NH}_{3} / \mathrm{CH}_{4} / \mathrm{O}_{2}$ & RCM IDT & $900-1140$ & $20-70$ & $0.5,1.0,2.0$ \\
\hline & & & & $\mathrm{NH}_{3} /$ air & flame LBV & 298 & 1.0 & $0.7-1.3$ \\
\hline & & & & $\mathrm{NH}_{3} / \mathrm{H}_{2} /$ air & flame LBV & 298 & $1.0,3.0,5.0$ & $0.6-1.6$ \\
\hline & & & & $\mathrm{NH}_{3} / \mathrm{CH}_{4} /$ air & flame LBV & 298 & $1.0,3.0,5.0$ & $0.7-1.5$ \\
\hline \multirow[t]{3}{*}{ Mei-2019 } & \multirow[t]{3}{*}{38} & \multirow[t]{3}{*}{265} & \multirow[t]{3}{*}{$\mathrm{H}_{2}$ and amine } & $\mathrm{NH}_{3} /$ air & flame LBV & 298 & 1.0 & $0.7-1.3$ \\
\hline & & & & $\mathrm{NH}_{3} / \mathrm{O}_{2} / \mathrm{N}_{2}$ & flame LBV & 298 & $1.0,2.0,5.0$ & $0.6-1.5$ \\
\hline & & & & $\mathrm{NH}_{3} / \mathrm{O}_{2}$ & ST IDT & $1560-2500$ & $1.4,10,30$ & $0.5,1.0,2.0$ \\
\hline \multirow[t]{7}{*}{ Stagni-2020 } & \multirow[t]{7}{*}{31} & \multirow[t]{7}{*}{203} & \multirow[t]{7}{*}{$\mathrm{H}_{2}$ and amine } & $\mathrm{NH}_{3} / \mathrm{O}_{2}$ & $\begin{array}{l}\text { JSR/FR } \\
\text { spec }\end{array}$ & $500-2000$ & 1.0 & $0.01-0.375$ \\
\hline & & & & $\mathrm{NH}_{3} / \mathrm{NO} / \mathrm{O}_{2}$ & JSR spec & $950-1450$ & 1 & $0.1-2$ \\
\hline & & & & $\mathrm{NH}_{3} / \mathrm{O}_{2} / \mathrm{N}_{2}$ & FR spec & $450-925$ & $30-100$ & 1.23 \\
\hline & & & & $\mathrm{NH}_{3} / \mathrm{O}_{2}$ & ST IDT & $1560-2500$ & $1.4,10,30$ & $0.5,1.0,2.0$ \\
\hline & & & & $\mathrm{NH}_{3} /$ air & ST IDT & $1100-1600$ & 20,40 & $0.5,1.0,2.0$ \\
\hline & & & & $\mathrm{NH}_{3} / \mathrm{O}_{2}$ & RCM IDT & $1000-1130$ & $37-75$ & $\begin{array}{l}0.5,1.0,1.5 \\
2.0\end{array}$ \\
\hline & & & & $\mathrm{NH}_{3} / \mathrm{N}_{2} / \mathrm{O}_{2}$ & flame LBV & 298 & $1.0,2.0,5.0$ & $0.2-2$ \\
\hline
\end{tabular}

${ }^{a}$ ST, shock tube; RCM, rapid compression machine; JSR, jet-stirred reactor; FR, flow reactor; IDT, ignition delay time; spec, speciation; and LBV, laminar burning velocity.

computational time for CFD simulations when applying the reduced mechanisms.

The Mei-2019 model were developed by Mei et al. ${ }^{91}$ for predicting laminar burning velocities and laminar flame propagation of pure ammonia at elevated pressures. The model includes 38 species and 265 elementary reactions. It was constructed based on previous models; i.e., the $\mathrm{H}_{2}$ subset was adopted from Hashemi et al., ${ }^{156}$ and the ammonia subset was mainly adopted from the Shrestha mechanism, ${ }^{136}$ replacing the rate constants of reactions $\mathrm{NH}_{2}+\mathrm{H}=\mathrm{NH}+\mathrm{H}_{2}, \mathrm{~N}_{2} \mathrm{H}_{2}+\mathrm{H}=$ $\mathrm{NNH}+\mathrm{H}_{2}$, and $\mathrm{N}_{2} \mathrm{H}_{2}+\mathrm{M}=\mathrm{NNH}+\mathrm{H}+\mathrm{M}$ with more recent values. ${ }^{116,156,157}$ The authors demonstrated the good performance of this mechanism for predicting the laminar burning velocity of ammonia mixtures under $0.1,0.2$, and $0.5 \mathrm{MPa}$. The mechanism also shows satisfactory performance for the ignition delay times measured in a shock tube (high temperatures and low to high pressures) by Mathieu and Petersen. ${ }^{70}$

The Jiang-2019 model $^{138}$ is an updated version of the hydrogen/oxygen/nitrogen mechanism originally developed at the University of San Diego, also known as the San Diego mechanism, which has not been updated since 2004. Jiang and co-workers expanded the mechanism to 19 species and 60 elementary reactions, taking ammonia combustion into account by including 40 nitrogen-related elementary reactions. The resulting reduced mechanism was validated against literature results, including laminar burning velocities and ignition delay times, ${ }^{56,70,77,78,86,114}$ with good results.

The Stagni-2020 model is a very recent comprehensive ammonia mechanism, proposed by Stagni and co-workers ${ }^{103}$ to improve modeling of ammonia oxidation and pyrolysis at low temperatures and dilute conditions. It contains $\mathrm{H}_{2} / \mathrm{O}_{2}$ and ammonia subsets with a total of 31 species and 203 reactions. The $\mathrm{H}_{2} / \mathrm{O}_{2}$ mechanism was adopted after the work of Metcalfe et al., ${ }^{158}$ and the $\mathrm{NO}_{x} / \mathrm{NH}_{3}$ chemistry was taken from Song et al., ${ }^{134}$ re-evaluating rate constants for $\mathrm{H}$-abstraction reactions of $\mathrm{NH}_{3}$ by $a b$ initio calculations. Moreover, the most sensitive reactions at low temperatures involving $\mathrm{H}_{2} \mathrm{NO}$ and $\mathrm{HNO}$ were carefully evaluated, taking the rate constants from Dean and Bozzelli $^{121}$ and Glarborg et al. ${ }^{115}$ Stagni et al. validated the mechanism against a novel speciation data set from jet-stirred and flow reactors, obtaining good agreement. Also, simulations for ignition delay times of neat ammonia mixtures measured in a shock tube $e^{70}$ and a rapid compression machine ${ }^{71}$ as well as for laminar burning velocities of ammonia/air mixtures at $0.1 \mathrm{MPa}$ and $298 \mathrm{~K}^{91}$ were satisfactory. 

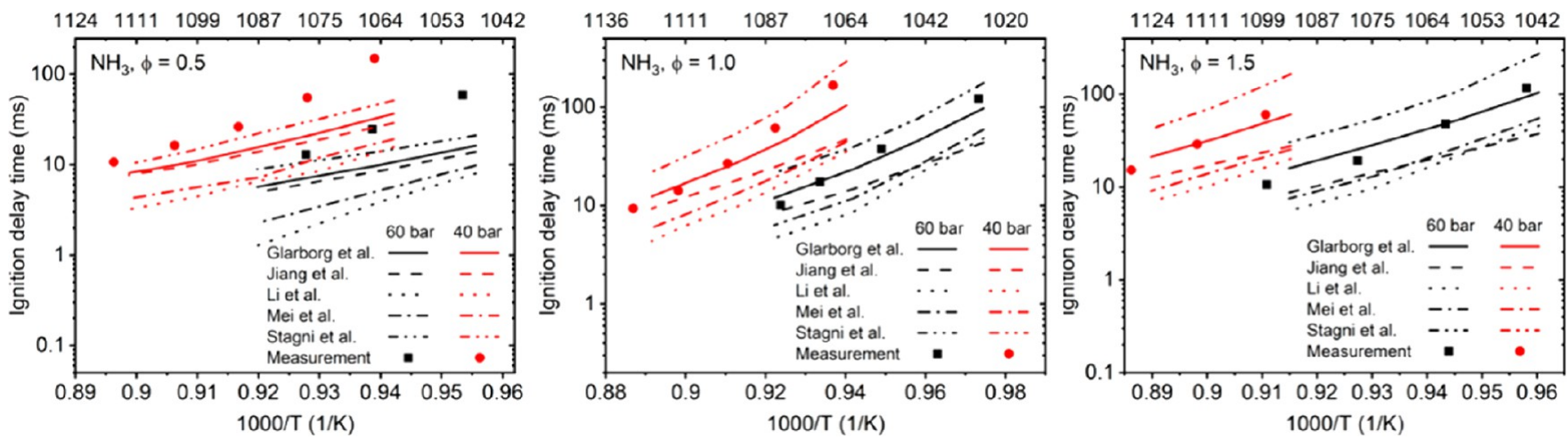

Figure 9. Comparison between simulation results with the selected mechanisms and the measurements from He et al. ${ }^{71}$ for ignition delay times of $\mathrm{NH}_{3} / \mathrm{O}_{2} / \mathrm{N}_{2} / \mathrm{Ar}$ mixtures with $70 \%$ dilution at RCM conditions. Lines, simulation; symbols, measurement.
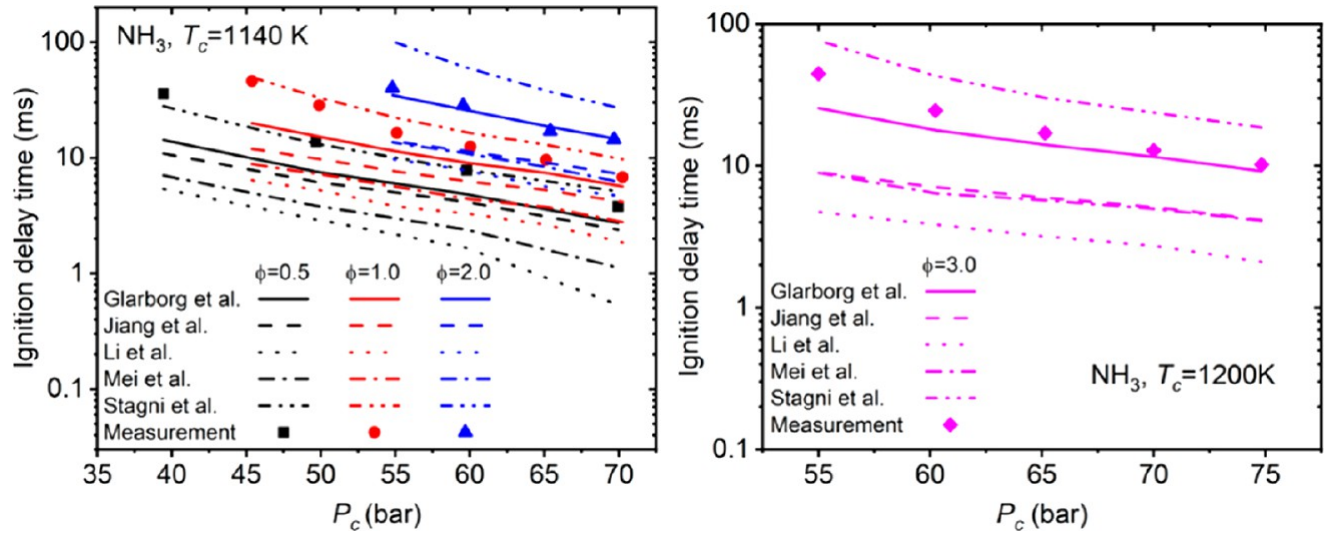

Figure 10. Comparison between simulation results with different mechanisms and the measurements from Dai et al. ${ }^{76}$ for ignition delay times of $\mathrm{NH}_{3} /$ $\mathrm{O}_{2} / \mathrm{N}_{2} / \mathrm{Ar}$ mixtures (75\% dilution for $\phi=0.5,1.0$, and 2.0 in the left panel and $80 \%$ dilution for $\phi=3.0$ in the right panel) at RCM conditions. Lines, simulation; symbols, measurement.

In several recent studies, ${ }^{59,67,68,71,74,76,80,101,106}$ some of these five selected mechanisms have been further evaluated, applying newly obtained experimental data, such as ignition delays and speciation of ammonia mixtures, at intermediate temperatures and high pressures. These studies have highlighted some strengths and shortcomings of the selected mechanisms, but a wider comparison has not been reported; an overview of the validation of the five mechanisms can be found in Table 2 . In the following sections, the performance of the five mechanisms will be compared and discussed for ignition delays and flame speeds of neat ammonia, ammonia/hydrogen, and ammonia/methane.

3.3. Evaluation against Ignition Delay Time. In this section, ignition delay times of different mixtures measured at high pressures in shock tubes and rapid compression machines, covering the relevant conditions for internal combustion engines and gas turbines, have been selected from the literature for validation of the performance of the chosen mechanisms. To ensure clarity of the figures, data demonstrated in the following sections were selected as representative for the specific conditions (mixtures, pressures, temperatures, and equivalence ratios); more comparisons between simulations and experiments can be found in Figures S2-S11 of the Supporting Information.

The simulations for ignition delay time were conducted by an in-house Cantera program based on an assumption of a homogeneous reactor with a constrained volume. The nonideal effects of RCM measurements were taken into consideration, i.e., the perturbation from the compression process and the heat loss from core gas to reaction chamber walls, by applying the volume profiles generated from the measured pressure traces of non-reactive mixtures. The ignition delay time under RCM conditions was defined as the time interval between the end of compression (EOC) and the time point, where the derivative of the pressure rise as a result of combustion reaches the peak.

The simulations for shock tube conditions at high temperatures were based on a homogeneous reactor with a constant volume. However, at intermediate temperatures, non-ideal $\mathrm{d} P$ / $\mathrm{d} t$ effects cannot be neglected. In this case, the measured pressure trace between the time point of arrival of the reflected shock wave and the one at $90 \%$ of the measured ignition delay time was converted into a volume profile. After that, the volume was kept constant until the end of simulation. The ignition delay time in shock tube conditions was defined as the time interval between the passage of the reflected shock wave and the intersection of the line drawn along the steepest rate of $\mathrm{OH}$ generation and a horizontal line, which defines the no $\mathrm{OH}$ generation level.

After comparison of the simulation results to measured data, brute force sensitivity analyses were conducted to identify the key reactions for predicting ignition delay times of different mixtures. The rate coefficient of each reaction $\left(k_{i}\right)$ was individually doubled. The resulting relative variation in the ignition delay time $(\tau)$ as $\left[\tau\left(2 k_{i}\right)-\tau\left(k_{i}\right)\right] / \tau\left(k_{i}\right)$ was then taken as the sensitivity coefficient of that reaction. Finally, the 
sensitivity coefficient was normalized to the maximum value, which is plotted in the following figures.

3.3.1. Neat Ammonia. To validate model performances for neat ammonia ignition delay times under rapid compression machine conditions, two sets of IDT measurements were adopted: the temperature-dependent IDT measurements from He et al. ${ }^{71}$ for equivalence ratios of $0.5,1.0$, and 1.5 at pressures of 4.0 and $6.0 \mathrm{MPa}$ (as shown in Figure 9) and the pressuredependent measurement from Dai et al. ${ }^{76}$ for the equivalence ratio from 0.5 to 3.0 at 1140 and $1200 \mathrm{~K}$ (as shown in Figure 10). As seen in both figures, the mechanisms Jiang-2019, ${ }^{138} \mathrm{Li}$ $2019,{ }^{137}$ and Mei-2019 ${ }^{91}$ underestimate the ignition delay time with a factor of 1.5-4 for most conditions, except the case at $\varphi=$ 3 and $T_{c}=1200 \mathrm{~K}$, where they underestimate the IDT with a factor larger than 5. Dai et al. ${ }^{76}$ found that Jiang-2019 predicted well the ignition delay times of a lean $\mathrm{NH}_{3}$ mixture with $70 \%$ argon dilution but failed to reproduce the IDTs at other conditions satisfactorily. Glarborg-2018 ${ }^{115}$ predicts well results under fuel-rich and stochiometric conditions but underestimates IDT under lean conditions with a factor of 5 and 2 for the measurements of $\mathrm{He}$ et al. ${ }^{71}$ and Dai et al., ${ }^{76}$ respectively. Stagni$2020^{103}$ estimates overall lower reactivity of neat ammonia mixtures than Glarborg-2018. Therefore, it presents smaller discrepancy between simulated and measured IDTs in the fuellean conditions but overestimates the IDTs in stochiometric and fuel-rich conditions within a factor of 1.5 and 3 , respectively.

The measurements from Mathieu and Petersen ${ }^{70}$ were adopted to validate the high-temperature performance of the mechanisms as shown in Figure 11, because these data cover a

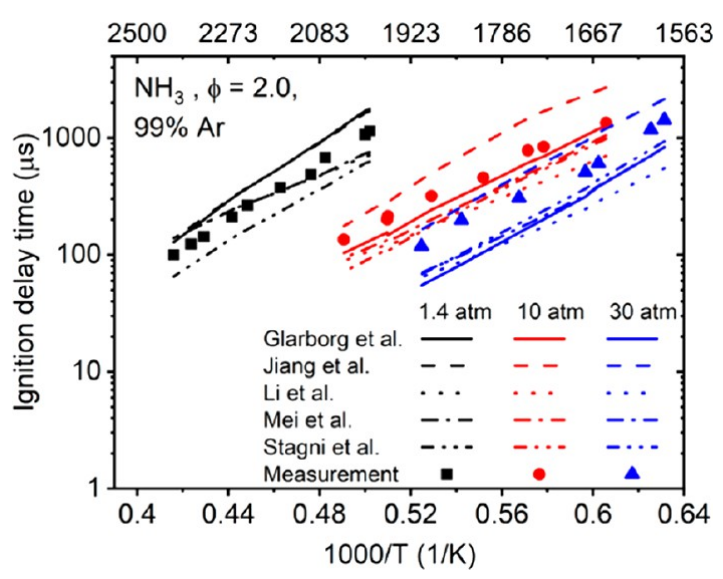

Figure 11. Comparison between simulation results with the selected mechanisms and the measurements from Mathieu and Petersen ${ }^{70}$ for ignition delay times of fuel-rich $\mathrm{NH}_{3} / \mathrm{O}_{2} /$ Ar mixtures with $99 \%$ dilution at shock tube conditions. Lines, simulation; symbols, measurement.

wide range of temperatures $(1500-2500 \mathrm{~K})$, pressures $(0.14$, 1.0 , and 3.0 $\mathrm{MPa})$, and equivalence ratios (0.5, 1.0, and 2.0). Jiang- $2019^{138}$ overestimates the ignition delay time under all conditions with a factor of around 2 , while the simulation results with other mechanisms have good agreement with measurements in fuel-lean and stochiometric conditions. Under fuel-rich conditions, the calculated IDTs by Stagni- $2020^{103}$ are shorter than the measurement with a factor of 1.5 at all three pressures. This prediction is not consistent with the simulation results in their study, ${ }^{103}$ possibly because the definition of the simulated IDT is different between this study and ref 103. Glarborg-2018 overestimates the IDT at $0.14 \mathrm{MPa}$ and underestimates it at 3.0 $\mathrm{MPa}$, while the simulation results of Mei-2019 lie between
Glarborg-2018 and Stagni-2020. Li-2019 predicts slightly higher reactivity of ammonia mixtures than Stagni-2020.

Overall, Glarborg-2018 ${ }^{115}$ and Stagni-2020 $0^{103}$ perform better than the other mechanisms under both RCM and shock tube conditions, even though they have short-comings at fuel-lean and fuel-rich conditions, respectively. Sensitivity analyses of both models were conducted at 1050 and $1700 \mathrm{~K}$ to represent RCM (left panel of Figure 12) and shock tube (right panel of Figure 12) conditions, respectively. In the lower temperature case, the product channel branching ratios of $\mathrm{NH}_{2}+\mathrm{NO} / \mathrm{NO}_{2}$ play important roles in both mechanisms. However, the $\mathrm{HO}_{2}$ radical chemistry is different in the two mechanisms. The reactions of $\mathrm{HO}_{2}+\mathrm{NH}_{2}$ and $\mathrm{HO}_{2}+\mathrm{NO}$ have almost no influence on the simulation results of Glarborg-2018, while they are relatively important in Stagni-2020. It is worth noting that the rate coefficient of $\mathrm{HO}_{2}+\mathrm{NH}_{2}=\mathrm{NH}_{3}+\mathrm{O}_{2}$ was recalculated by Stagni et al. ${ }^{103}$ In the higher temperature case, the pyrolysis reactions involving $\mathrm{NH}_{2}, \mathrm{NNH}$, and $\mathrm{N}_{2} \mathrm{H}_{2}$ become dominant. Also, here, the two mechanisms have slight differences. The reaction $\mathrm{H}_{2} \mathrm{NN}=\mathrm{H}_{2}+\mathrm{N}_{2}$ inhibits the reactivity in Glarborg2018, while it is not included in Stagni-2020. The initiation reaction of $\mathrm{NH}_{2}+\mathrm{O}_{2}=\mathrm{NH}_{2}+\mathrm{HO}_{2}$ promotes reactivity more strongly in Stagni-2020 than in Glarborg-2018.

3.3.2. Ammonia/Hydrogen. The IDT measurements of two mixtures with different $\mathrm{NH}_{3} / \mathrm{H}_{2}$ ratios from Dai et al. ${ }^{76}$ were adopted to validate the ignition properties of $\mathrm{NH}_{3} / \mathrm{H}_{2}$ mixtures in RCM conditions, as shown in Figure 13. The mixtures with 5 and $10 \% \mathrm{H}_{2}$ in fuel have an equivalence ratio of 1.0 and 0.5 , respectively. Jiang-2019 ${ }^{138}$ overestimates the ignition delay time with factors of 5 and 2 for 6.0 and $4.0 \mathrm{MPa}$, respectively, while for the 2.0 MPa case, the simulated IDT curve has a much steeper slope than the measurements. The other four mechanisms capture the main characteristics of the measurements at 4.0 and 6.0 MPa. Among them, Glarborg-2018 and Stagni-2020 present a better performance than the other two mechanisms, ${ }^{91,137}$ which both underestimate the ignition delay with a factor of 2 . It is worth noting that, at the pressure condition of 2.0 MPa, only the simulated IDTs with Stagni-2020 have good agreement with the measurements, while the other mechanisms overestimate the reactivity with a factor larger than 3 , which is consistent to the observation by Dai et al. ${ }^{76}$

In comparison to the measured ignition delay time of the mixture with a higher $\mathrm{H}_{2}$ content, i.e., $20 \% \mathrm{H}_{2}$ in fuel, at $2.0 \mathrm{MPa}$ and a equivalence ratio of 0.5 from $\mathrm{He}$ et al., ${ }^{71}$ as shown in Figure 14 , the calculated value with Jiang-2019 is higher and the curve slope is steeper, while the other four mechanisms present similar results, underestimating the IDTs by a factor of 2 .

Glarborg-2018 ${ }^{115}$ and Stagni-2020 $0^{103}$ perform better than the other mechanisms for predicting the ignition delay time of $\mathrm{NH}_{3} /$ $\mathrm{H}_{2}$ mixtures under RCM conditions. According to the sensitivity analysis in the left panel of Figure 15 for the condition with 5\% $\mathrm{H}_{2}$ at $2.0 \mathrm{MPa}$, the two production channels of $\mathrm{NH}_{2}+\mathrm{NO}$, the reactions $\mathrm{H}+\mathrm{O}_{2}=\mathrm{O}+\mathrm{OH}$ and $\mathrm{H}_{2} \mathrm{O}_{2}(+\mathrm{M})=2 \mathrm{OH}(+\mathrm{M})$, play important roles in the ignition process simulated by Glarborg2018. However, according to Stagni-2020, $\mathrm{NH}_{3}+\mathrm{O}_{2}=\mathrm{HO}_{2}+$ $\mathrm{NH}_{2}$ and the product ratio of $\mathrm{NH}_{2}+\mathrm{NO}_{2}$ are more important. For the other condition with $10 \% \mathrm{H}_{2}$ at $6.0 \mathrm{MPa}$ in the right panel of Figure 15, the important reactions remain mostly the same. With the increased pressure, the reaction $\mathrm{H}+\mathrm{O}_{2}=\mathrm{O}+$ $\mathrm{OH}$ becomes much less important in both mechanisms. As the $\mathrm{H}_{2}$ content increases, analysis of Glarborg-2018 indicates that $\mathrm{H}$ $+\mathrm{H}_{2} \mathrm{O}_{2}=\mathrm{H}_{2}+\mathrm{HO}_{2}$ and $2 \mathrm{HO}_{2}=\mathrm{H}_{2} \mathrm{O}_{2}+\mathrm{O}_{2}$ become dominant, 

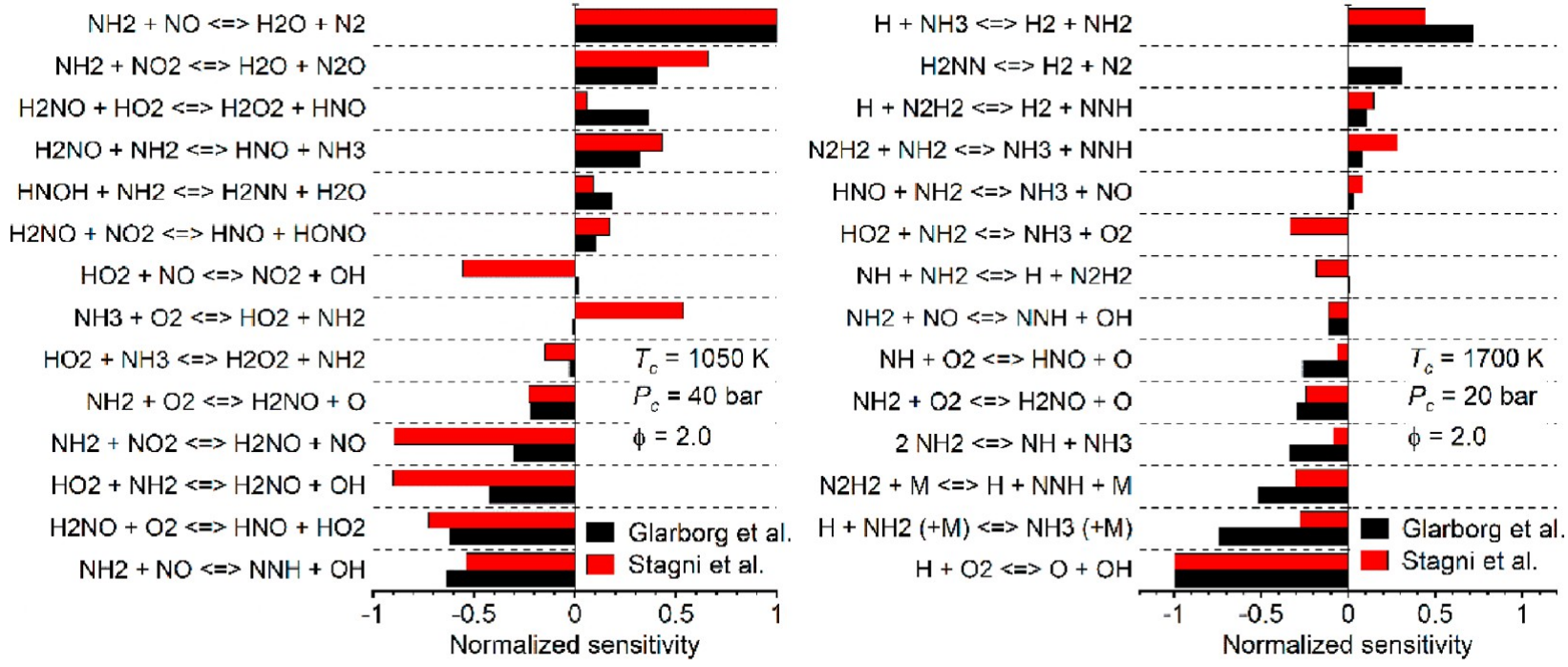

Figure 12. Normalized sensitive analysis on the ignition delay times of neat ammonia mixtures at RCM (70\% dilution, left panel) and shock tube (99\% dilution, right panel) conditions for Glarborg-2018 ${ }^{115}$ and Stagni-2020. ${ }^{103}$
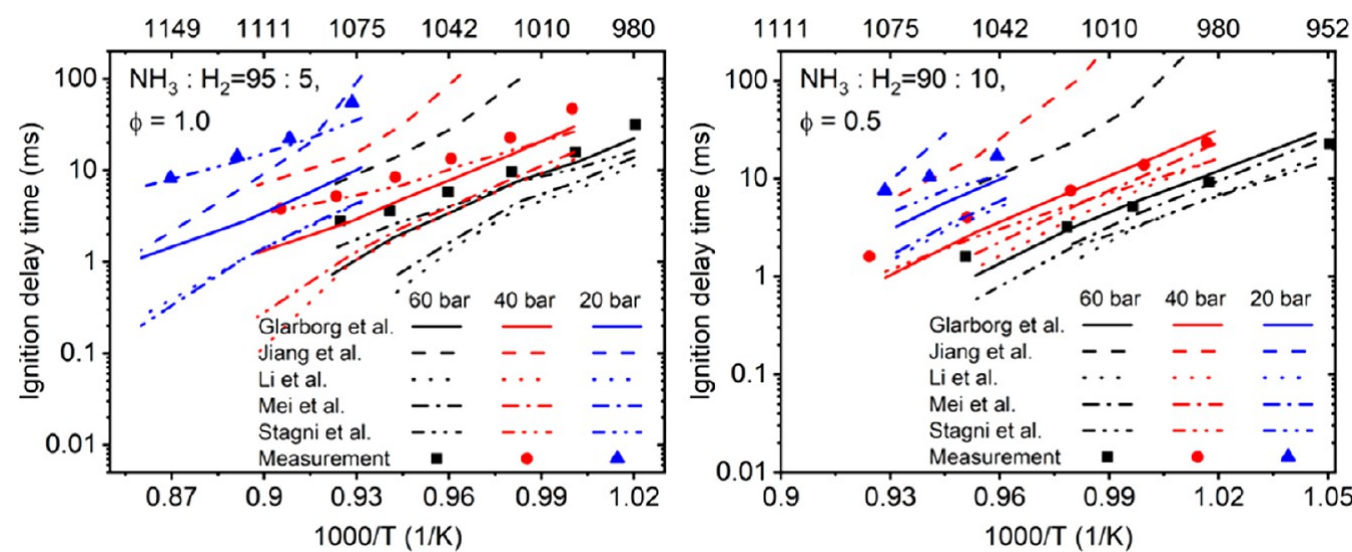

Figure 13. Comparison between simulation results with the selected mechanisms and the measurements from Dai et al. ${ }^{76}$ for ignition delay times of $\mathrm{NH}_{3} / \mathrm{H}_{2} / \mathrm{O}_{2} / \mathrm{N}_{2} /$ Ar mixtures, namely, the stochiometric mixture with $5 \% \mathrm{H}_{2}$ in fuel and $75 \%$ dilution for $\varphi=1.0$ in the left panel and the fuel-lean mixture with $10 \% \mathrm{H}_{2}$ in fuel in the right panel at RCM conditions. Lines, simulation; symbols, measurement.
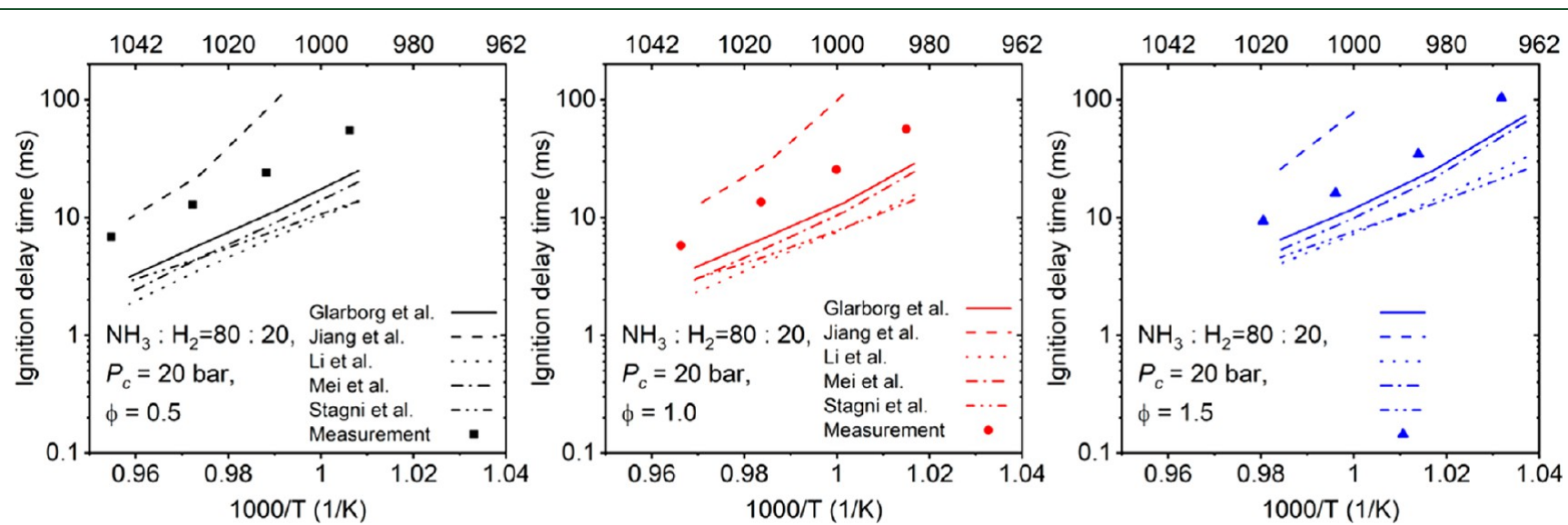

Figure 14. Comparison between simulation results with different mechanisms and the measurements from $\mathrm{He}_{\text {et al. }}{ }^{71}$ for ignition delay times of $\mathrm{NH}_{3} /$ $\mathrm{H}_{2} / \mathrm{O}_{2} / \mathrm{N}_{2} /$ Ar mixtures with $20 \% \mathrm{H}_{2}$ in fuel and $70 \%$ dilution at RCM conditions. Lines, simulation; symbols, measurement.

while these two reactions only have a minor influence according to Stagni-2020.

3.3.3. Ammonia/Methane. Because Stagni-2020 and Mei2019 do not include the species containing carbon, ${ }^{91,103}$ the mechanisms Glarborg-2018, Li-2019, and Jiang-2019 were validated with the measured IDTs of fuel-lean $\mathrm{NH}_{3} / \mathrm{CH}_{4}$ mixtures with different $\mathrm{CH}_{4}$ percentages in fuel, i.e., 5,10 , and $50 \%$, at 60 bar from Dai et al. ${ }^{74}$ in RCM conditions, as shown in 

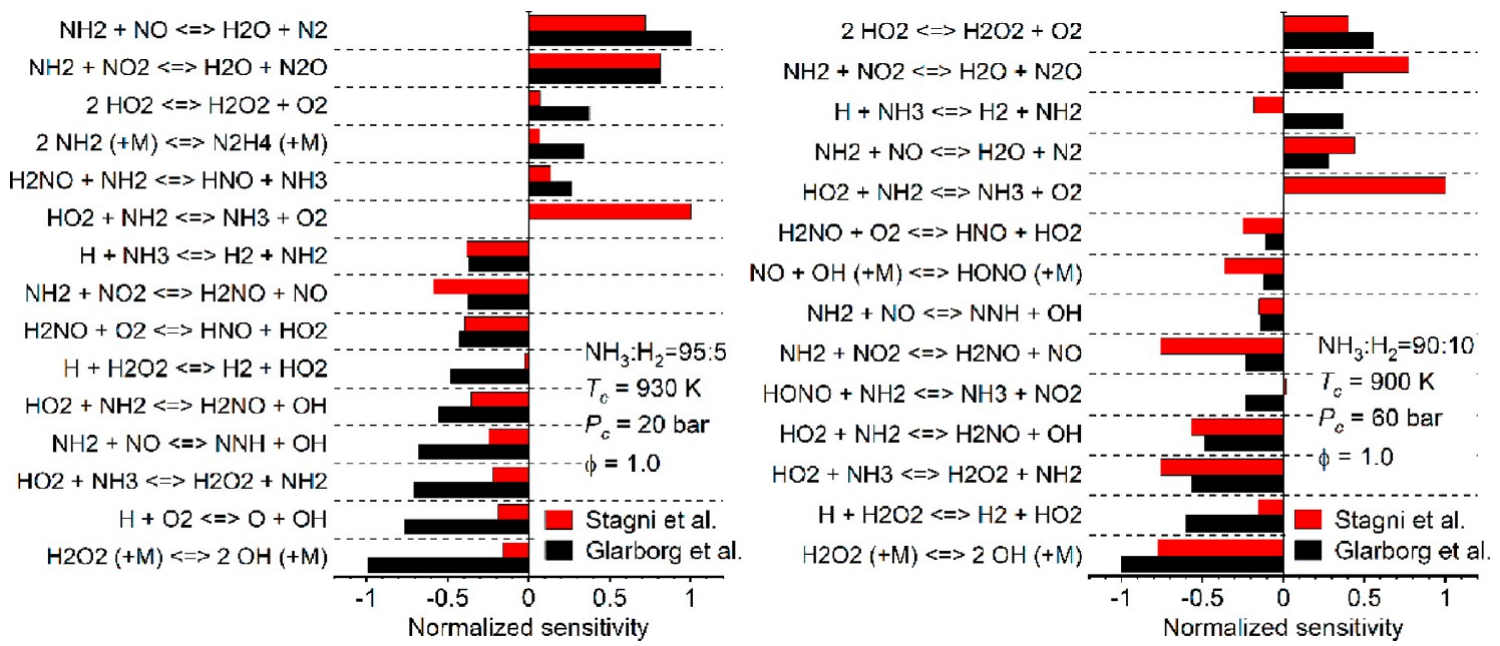

Figure 15. Normalized sensitive analysis on the ignition delay times of $\mathrm{NH}_{3} / \mathrm{H}_{2}$ mixtures with $70 \%$ dilution at $\mathrm{RCM}$ conditions for Glarborg-2018 ${ }^{115}$ and Stagni-2020. ${ }^{103}$
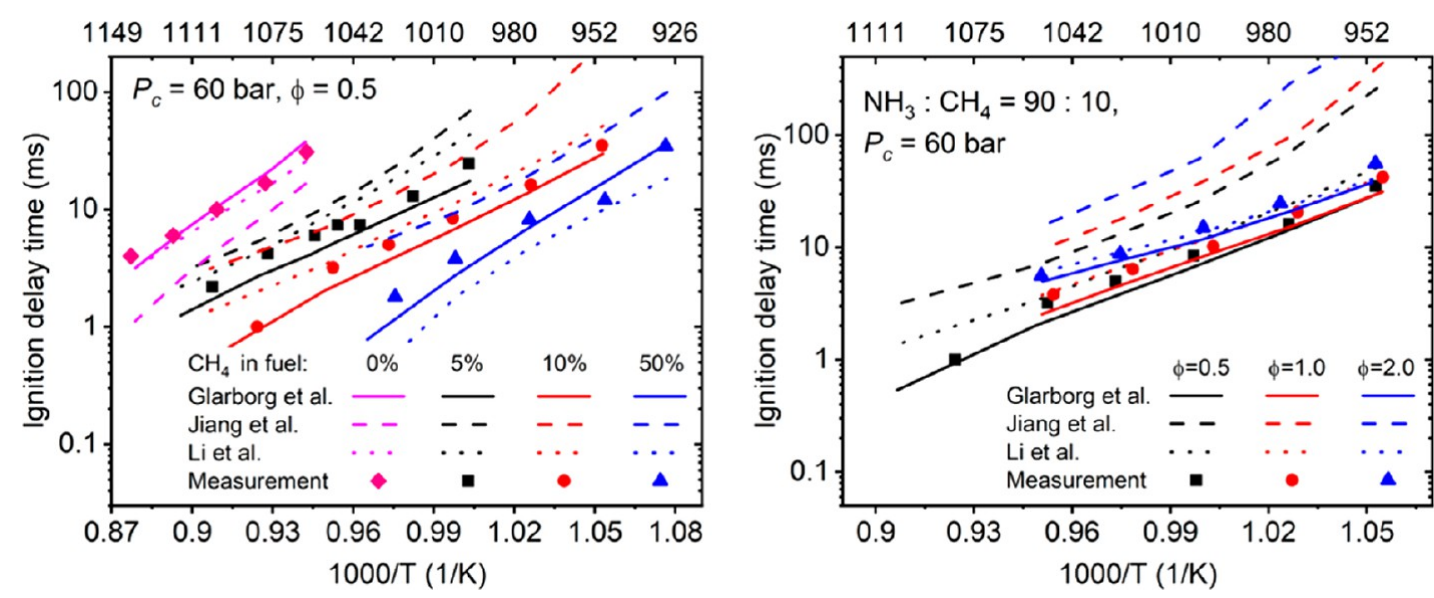

Figure 16. Comparison between simulation results with the selected mechanisms and the measurements from Dai et al. ${ }^{74}$ for ignition delay times of $\mathrm{NH}_{3} / \mathrm{CH}_{4} / \mathrm{O}_{2} / \mathrm{N}_{2} /$ Ar mixtures with $70 \%$ dilution at RCM conditions. Lines, simulation; symbols, measurement.

Figure 16. In addition, stochiometric and fuel-rich mixtures with $10 \% \mathrm{CH}_{4}$ in fuel were reported. Jiang-2019 underestimates the reactivity of all mixtures with a factor of $2-4$. The simulated IDTs with Glarborg-2018 are slightly shorter than the measurements within a factor of 1.5 . $\mathrm{Li}-2019$ overestimates the IDTs for the mixture with 5 and $10 \% \mathrm{CH}_{4}$ within a factor of 1.5 , while it underestimates the IDTs of the mixture containing $50 \% \mathrm{CH}_{4}$ in fuel with a factor of 2 . These findings are consistent with the observations by Dai et al. ${ }^{74}$ On the other hand, as shown in Figure 17, all three mechanisms predict well IDTs reported for mixtures with $40 \% \mathrm{CH}_{4}$ in fuel at high temperatures and low pressures, measured by Xiao et al. ${ }^{59}$ in a shock tube. It is worth noting to note here that the mechanisms Glarborg-2018 and Li2019 were also validated by Shu et al. ${ }^{67}$ in their most recent work as well; there, $\mathrm{Li}$-2019 demonstrated overall better performance than Glarborg-2018. By updating several reaction rate coefficients of Li-2019, its performance for fuel-rich mixtures was further improved. ${ }^{67}$

Since Jiang-2019 ${ }^{138}$ performed well for the shock tube measurements but not satisfactorily for RCM conditions, it is worth finding out the difference between the key reactions for these two conditions. The sensitivity analyses for Jiang-2019 and $\mathrm{Li}-2019$ are compared in the left panel of Figure 18 for the shock tube conditions. Jiang-2019 contained most of the important

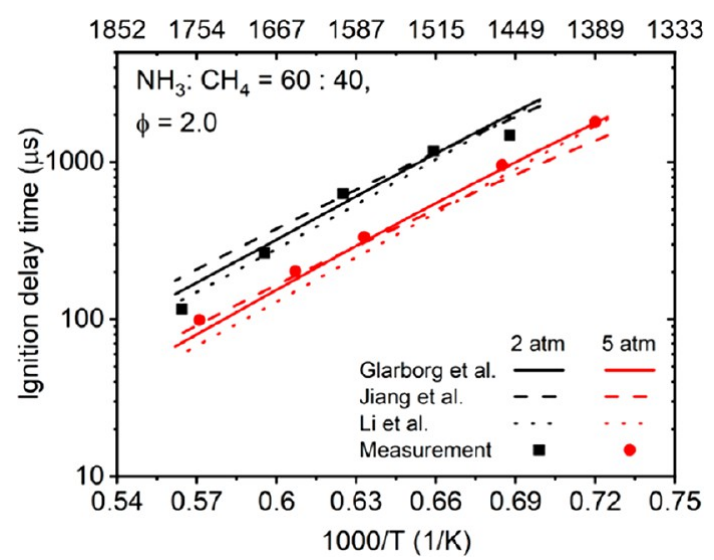

Figure 17. Comparison between simulation results with the selected mechanisms and the measurements from Xiao et al. ${ }^{59}$ for ignition delay times of $\mathrm{NH}_{3} / \mathrm{CH}_{4} /$ air mixtures with $40 \% \mathrm{CH}_{4}$ in fuel at shock tube conditions. Lines, simulation; symbols, measurement.

reactions in Li-2019, although the relative importance of different reactions varies. However, for the RCM conditions in the right panel of Figure 18, some of the important reactions in $\mathrm{Li}-2019$, e.g., the reactions related to $\mathrm{N}_{2} \mathrm{H}_{4}, \mathrm{NH}_{2}+\mathrm{NO}_{2}$, 

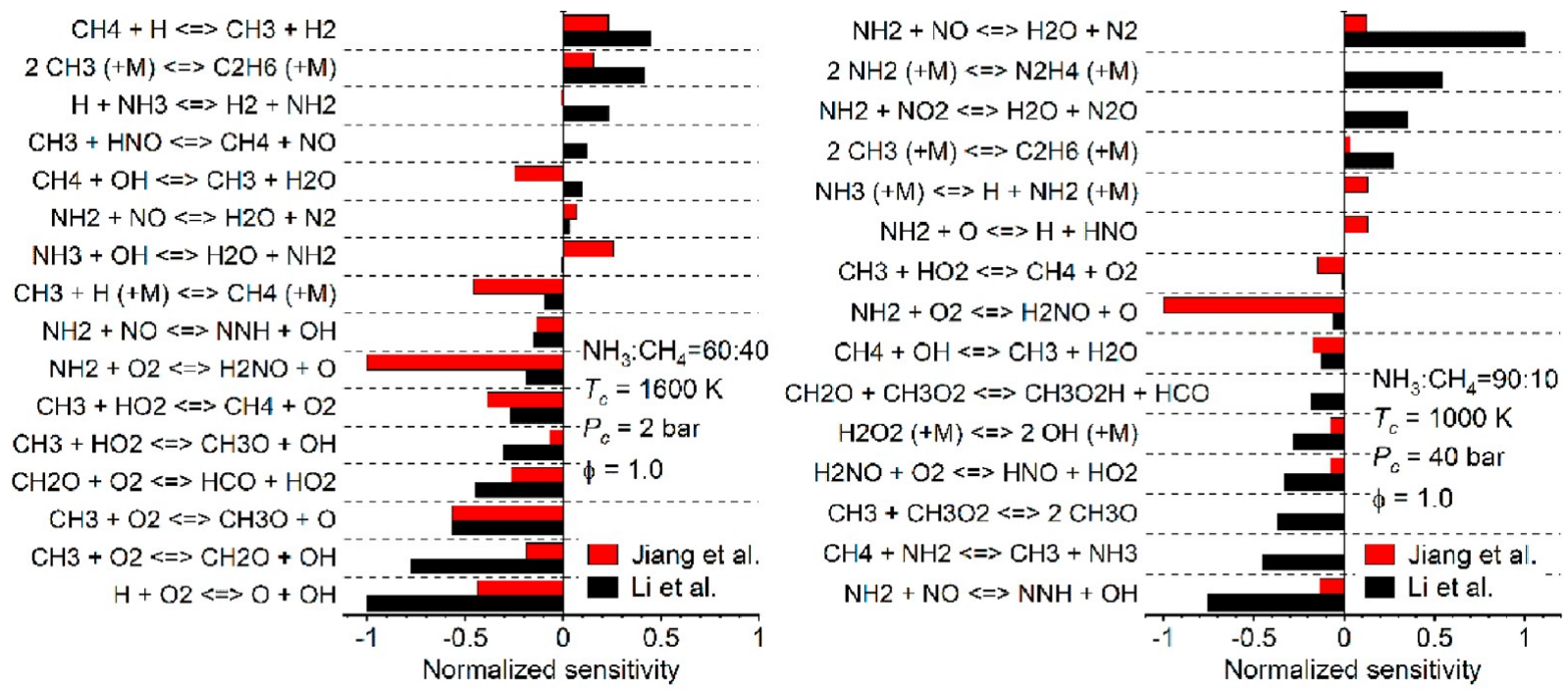

Figure 18. Normalized sensitive analysis on the ignition delay times of $\mathrm{NH}_{3} / \mathrm{CH}_{4}$ mixtures at shock tube (left panel) and RCM (right panel) conditions.

$\mathrm{CH}_{3} \mathrm{OO}$, and amine/carbon interactivity, are not included in Jiang-2019, possibly contributing to the discrepancy under RCM conditions.

3.4. Validation against Laminar Burning Velocity. As discussed in section 3.1.2, the laminar burning velocity of ammonia/air mixtures has been measured extensively using different experimental approaches, including constant-volume cylindrical combustion vessels ${ }^{57,91}$ and spherical vessels. ${ }^{79}$ Hayakawa et al. $^{86}$ measured the flame speed of ammonia/air mixtures at pressures of $0.1-0.5 \mathrm{MPa}$ using a constant-volume combustion chamber. Han et al. ${ }^{81}$ used the heat-flux method to measure the burning velocities of $\mathrm{NH}_{3} /$ air, $\mathrm{NH}_{3} / \mathrm{H}_{2} /$ air, $\mathrm{NH}_{3}$ / $\mathrm{CO} /$ air, and $\mathrm{NH}_{3} / \mathrm{CH}_{4} /$ air. Lhuillier et al. ${ }^{88}$ explored the effect of the initial temperature $(298-473 \mathrm{~K})$ and hydrogen addition on the ammonia flame speed.

Figure 19 compares predictions of the selected models with a broad range of the available flame speed measurements for $\mathrm{NH}_{3}$ /air mixtures. There is a considerable disparity between literature data, partly as a result of the larger uncertainty in

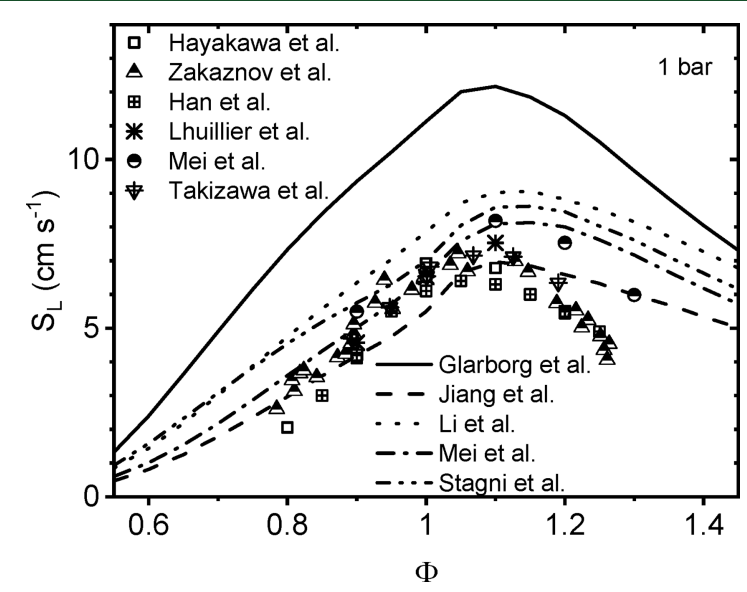

Figure 19. Comparison between simulation results with the selected mechanisms and the measurements from Hayakawa et al., ${ }^{86}$ Zakaznov et al., ${ }^{57}$ Han et al., ${ }^{81}$ Lhuillier et al., ${ }^{88}$ Mei et al., ${ }^{91}$ and Takizawa et al. ${ }^{79}$ for laminar burning velocities of $\mathrm{NH}_{3}$ /air mixtures at $0.1 \mathrm{MPa}$ and an initial temperature of $298 \mathrm{~K}$. measuring low flame speeds. ${ }^{91}$ Among the investigated models, those advocated by Jiang-2019 and Mei-2019 compare better to the experimental data, while Glarborg-2018 overestimates the flame speeds considerably. Under fuel-rich conditions, all models predict faster burning velocities than the average of the experimental data.

Data measured at elevated pressure $(0.3-0.5 \mathrm{MPa})$ are shown in Figure 20. Here, Jiang-2019 provides a good prediction of the

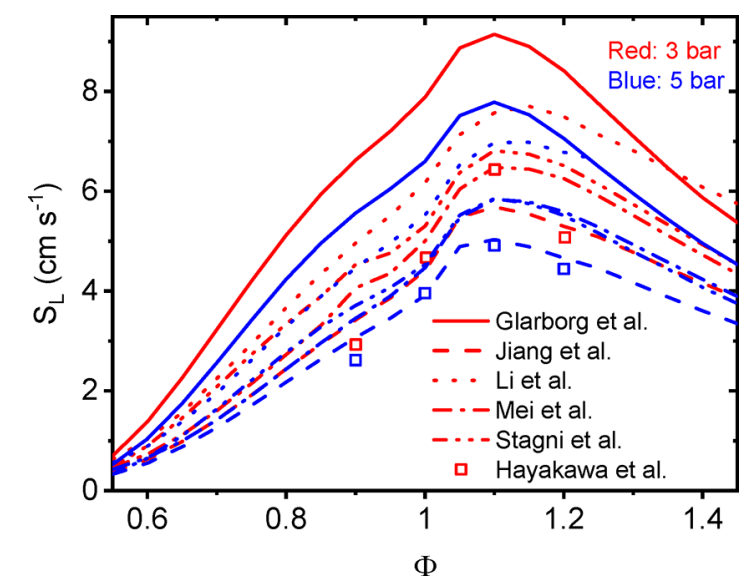

Figure 20. Comparison between simulation results with the selected mechanisms and the measurements from Hayakawa et al. ${ }^{86}$ for laminar burning velocities of $\mathrm{NH}_{3}$ /air mixtures at 0.3 and $0.5 \mathrm{MPa}$ pressure and an initial temperature of $298 \mathrm{~K}$.

flame speed, while the other models are less accurate. In particular, Glarborg-2018 overpredicts the LBV, even though the absolute differences are mostly within $0.03 \mathrm{~m} / \mathrm{s}$.

To promote further utilization of ammonia as a fuel, the burning velocity of ammonia-based fuels should be improved; therefore, several studies have been dedicated to find an efficient fuel additive. The effect of hydrogen addition on the LBV has been investigated extensively. ${ }^{77,81,88,113,114,159}$ Notably, Ichikawa et al. $^{77}$ used a constant volume combustion chamber to measure the burning velocity when the hydrogen fraction in the fuel was varied from 0 to $100 \%$ at pressures of $0.1-0.5 \mathrm{MPa}$, and 
Wang et al. ${ }^{113}$ used the heat flux method to measure the burning velocity of $\mathrm{NH}_{3} / \mathrm{H}_{2} /$ air at $0.1-0.5 \mathrm{MPa}$.

Figure 21 compares selected experimental LBVs for ammonia/hydrogen mixtures with modeling predictions. The

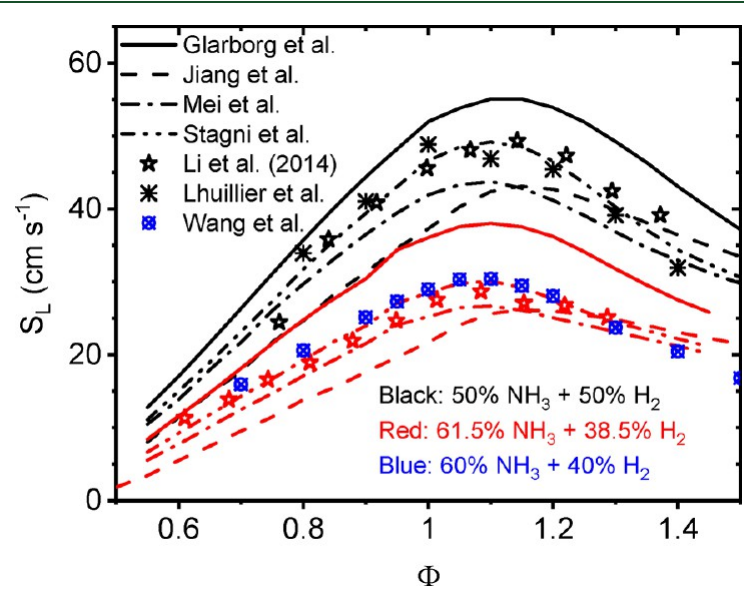

Figure 21. Comparison between simulation results with the selected mechanisms and the measurements from $\mathrm{Li}$ et al., ${ }^{114}$ Lhuillier et al., ${ }^{88}$ and Wang et al. ${ }^{113}$ for laminar burning velocities of $\mathrm{NH}_{3} / \mathrm{H}_{2} /$ air mixtures at $0.1 \mathrm{MPa}$ pressure and an initial temperature of $298 \mathrm{~K}$.

predictions of Mei-19 and Stagni-20 agree well with the measured data. Jiang-2019 tends to underpredict the LBVs, while they are overpredicted by Glarborg-2018. The results of the model by Li et al. ${ }^{137}$ are not shown as a result of difficulties in obtaining convergence.

Han et al. ${ }^{81}$ and Okafor et al. ${ }^{92,93}$ have measured laminar burning velocities for $\mathrm{NH}_{3} / \mathrm{CH}_{4} /$ air mixtures. Because the data were collected at different $\mathrm{CH}_{4} / \mathrm{NH}_{3}$ ratios, Figure 22 is limited

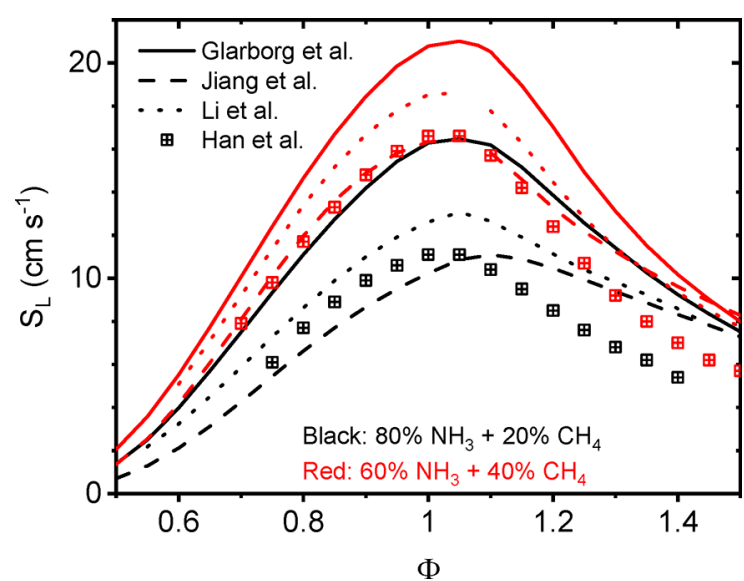

Figure 22. Comparison between simulation results with the selected mechanisms and the measurements from Han et al. ${ }^{81}$ for laminar burning velocities of $\mathrm{NH}_{3} / \mathrm{CH}_{4}$ /air mixtures at 1 bar pressure and an initial temperature of $298 \mathrm{~K}$.

to the experiments by Han et al. ${ }^{81}$ Among the investigated models, only Glarborg-2018, Jiang-2019, and Li-2019 included an oxidation subset for methane. Jiang-2019 predicts the burning velocity more accurately, but all three mechanisms overpredict the LBV for fuel-rich mixtures.

The Jiang-2019 model is selected for further investigation as a result of its better overall performance. Figure 23 shows the sensitivity of the burning velocity to reaction rate constants for

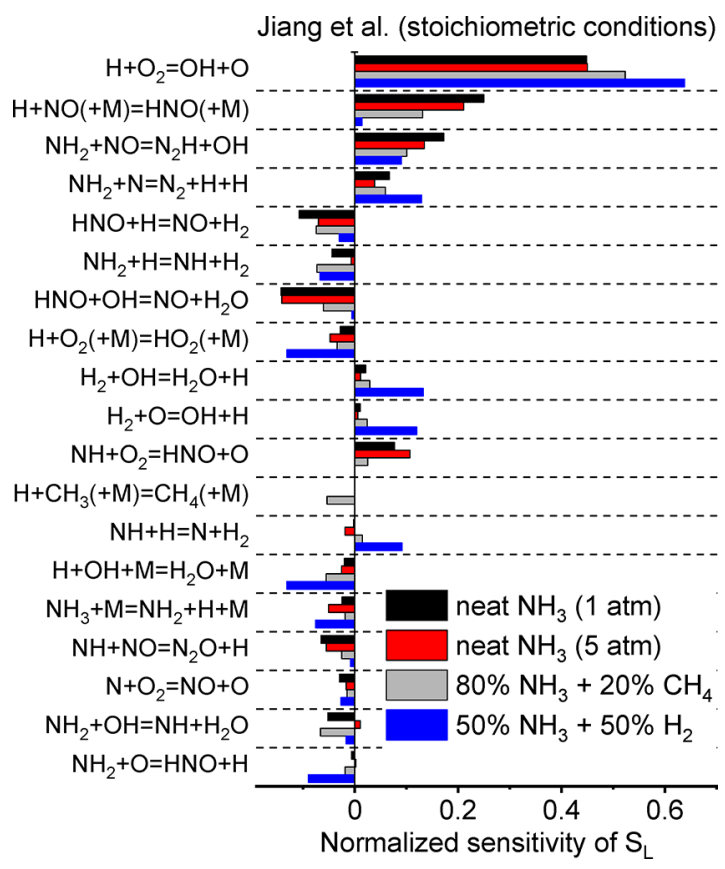

Figure 23. Sensitivity of burning velocity prediction to reaction rate constants for different stoichiometric mixtures of ammonia/ $\mathrm{H}_{2} / \mathrm{CH}_{4} /$ air with an initial temperature of $298 \mathrm{~K}$ and $1 \mathrm{~atm}$ pressure (unless stated). Calculations were conducted using the Jiang-2019 mechanism. ${ }^{138}$

different mixtures. The reaction $\mathrm{H}+\mathrm{NO}(+\mathrm{M})=\mathrm{HNO}(+\mathrm{M})$ increases the flame speed considerably, except when hydrogen is added to the fuel mixture. The reactions $\mathrm{NH}_{2}+\mathrm{NO}=\mathrm{NNH}+$ $\mathrm{OH}$ and $\mathrm{NH}_{2}+\mathrm{N}=\mathrm{N}_{2}+\mathrm{H}+\mathrm{H}$ also accelerate flame propagation, while $\mathrm{HNO}+\mathrm{H}=\mathrm{NO}+\mathrm{H}_{2}, \mathrm{NH}_{2}+\mathrm{H}=\mathrm{NH}+\mathrm{H}_{2}$, and $\mathrm{HNO}+\mathrm{OH}=\mathrm{NO}+\mathrm{H}_{2} \mathrm{O}$ reduce the burning velocity. The flame propagation is mainly controlled by reactions in the hydrogen and amine subsets, even when methane is added to the fuel.

3.5. Ammonia as a Fuel Using Co-firing Strategies. Generally and as presented, ammonia is considered to have a relatively low combustion speed, high ignition energy, narrow flammability range, and low flame temperature. Therefore, the use of ammonia faces several problems in practical combustion applications; e.g., limitations are exhibited in internal combustion engine speed and engine power compared to conventional fuels. ${ }^{160}$ Thus, co-firing dual-fuel approaches are often a choice in combustion devices to overcome the weakness of using pure ammonia.

An excellent promoter for this task is hydrogen, which not only can be obtained from cracked ammonia but also does not contain carbon. Carbon-free hydrogen is considered an ideal promoter to improve the combustion of ammonia, whose burning velocity is relatively much higher with a greater flammability range. Generally, co-firing hydrogen with ammonia can improve the burning performance of ammonia, achieving moderate burning velocity and lower $\mathrm{NO}_{x}$ emissions. ${ }^{161}$ It was found that the unstretched laminar burning velocity increases nonlinearly with an increase of hydrogen addition, while the Markstein length varies non-monotonically with an increase of hydrogen addition. With an increase in initial pressure, the burning velocity and Markstein length will decrease. ${ }^{86}$ Also, an improvement of stability limits with hydrogen substitution was demonstrated for various ammonia flames. ${ }^{162}$ Particularly, 
under fuel-rich conditions, a substantial increase of laminar burning velocities with hydrogen substitution can be observed as a result of the increased amount of hydrogen atoms, suggesting the potential of hydrogen as a promoter for improving the burning performance with low $\mathrm{NO}_{x}$ and $\mathrm{N}_{2} \mathrm{O}$ emissions in fuelrich flames. ${ }^{78}$ Actually, in the tests of practical combustion devices, it was demonstrated that a fuel composition of $80 \%$ $\mathrm{NH}_{3}$ and $20 \% \mathrm{H}_{2}$ produces a comparable magnitude of $\mathrm{NO}$ emissions to that of gasoline as a result of lower flame temperatures. ${ }^{163}$ In addition, a $10 \%$ hydrogen addition showed efficiencies and power comparable to gasoline as a result of higher compression ratios. ${ }^{164}$ Stable combustion operation was also demonstrated in gas turbines with a $70 \% \mathrm{NH}_{3} / 30 \% \mathrm{H}_{2}$ (mole \%) fuel blend. Moreover, to use hydrogen as promoter enables the use of hydrogen obtained from pre-cracking of ammonia. Some experiments have found that the flammability in ammonia/air mixtures increases as a result of dissociated ammonia that leads to traces of hydrogen in the blend. ${ }^{165}$ It was demonstrated that ammonia dissociation can effectively enhance the combustion performance and emissions of $\mathrm{NH}_{3}$ and $\mathrm{NO}_{x}$ can be reduced considerably. ${ }^{166}$

As for the high resistance of ammonia to autoignition, adding hydrogen to air-ammonia mixtures can help improve ignition and increase combustion velocity. ${ }^{167}$ Under low-temperature conditions $(1000-1100 \mathrm{~K})$, the hydrogen addition must be greater than $10 \%$ in volume, which shows a significant promotion in the ignition delay time. ${ }^{68}$ Specifically, when the fuel mixtures contain $20 \% \mathrm{H}_{2}$, ignition delay times tend to be shorter for fuel-richer mixtures, while for 1 and $0 \% \mathrm{H}_{2}$ in fuel mixtures, the equivalence ratio dependence is reversed. ${ }^{71}$

As the main ingredient of natural gas, co-firing $\mathrm{CH}_{4}$ with $\mathrm{NH}_{3}$ blends also has the potential as a cleaner solution compared to pure fossils, with a remarkable reduction of $\mathrm{CO}_{2}$ emissions. In comparison to methane, non-premixed $\mathrm{CH}_{4} / \mathrm{NH}_{3}$ /air flames showed much lower $\mathrm{CO}_{2}$ emissions with moderate reduction of combustion stability limits and flame temperature. ${ }^{168}$ When the ammonia fraction is small in the fuel mixture, $\mathrm{NO}_{x}$ emissions were found to be increased monotonically with the ratio of ammonia. ${ }^{169}$ Because methane-ammonia mixtures contain significant fuel-bound nitrogen, the addition of more $\mathrm{NH}_{3}$ leads to higher $\mathrm{N}_{2}$ concentrations rather than NO. ${ }^{170} \cdot{ }^{171}$ Detailed measurements for premixed $\mathrm{CH}_{4} / \mathrm{NH}_{3}$ /air combustion showed that, for stoichiometric mixtures, with ammonia fractions increasing, the mole fractions of $\mathrm{H}_{2} \mathrm{O}, \mathrm{NO}$, and $\mathrm{N}_{2}$ will increase monotonically, while those of $\mathrm{H}_{2}, \mathrm{CO}, \mathrm{CO}_{2}$, and $\mathrm{NO}_{2}$ have reverse tendencies. ${ }^{104}$ Several studies have shown significant improvement on ammonia ignition, ${ }^{59}$ flame propagation, ${ }^{92}$ and other flame features with the addition of methane as an additive under various conditions, indicating the promising potential of such fuel blends.

Implementing diesel/ammonia mixtures as a fuel is also a route to use ammonia. Replacing diesel in engines showed promising results a decade ago. When energy substitution by ammonia did not exceed $60 \%,{ }^{172}$ the use of diesel and ammonia fuel mixtures produced lower levels of $\mathrm{NO}_{x}$ emissions than with pure diesel, a result speculated to be a consequence of lower combustion temperatures. However, if ammonia is employed as the main molecule in the fuel blends, $\mathrm{NO}_{x}$ emissions will increase significantly as a result of fuel-bound nitrogen. Other emissions, such as carbon monoxide and hydrocarbon emissions, were found to be higher than those of pure diesel at the same power output in these diesel engines. Specifically, relatively high exhaust ammonia emissions (1000-3000 ppmv) were also a key issue requiring further after treatment as a result of a less effective combustion.

Just like diesel, gasoline has also been attempted to enhance ammonia combustion in engines. Although energy density and heating values of ammonia are lower compared to gasoline, combustion of gaseous ammonia with gasoline is proven feasible in those engines analyzed. ${ }^{173}$ It was found that energy efficiency is comparable to that of using gasoline, while $\mathrm{CO}$ emissions are decreased. However, $\mathrm{NO}_{x}$ and $\mathrm{HC}$ were found to increase when ammonia was added. ${ }^{174}$ The use of ammonia with gasoline allowed for knock-free operation at higher compression ratios and higher loads than using gasoline alone.

A lot of other fuels, such as dimethyl ether (DME), ${ }^{175}$ ethanol, ${ }^{176}$ kerosene, ${ }^{177}$ etc., are also potential promoters, which can be used for ammonia combustion. However, in previous attempts, it was shown that, as a result of the low combustion temperature of ammonia, higher $\mathrm{CO}$ and $\mathrm{HC}$ emissions are the main problem still needed to be settled.

3.6. Laboratory-Scale Experiments and Computational Fluid Dynamics toward Larger Ammonia-Power Units. Laboratory- and utility-scale experiments and their CFD simulations are eventually guiding the industrial emergence of ammonia-fueled heat engines that include internal combustion systems, land gas turbines, and even aerospace devices. Therefore, it is necessary to demonstrate the main variations in these systems and concepts to guarantee stable combustion over a wide range of operating conditions with stringent control on non-carbon pollutant emissions. The inherent challenges presented in fundamental studies regarding IDT, LBV, ignition energy, and flame extinction discussed in the previous section are further studied in the presence of the realistic complexities arising from parameters, such as details of complex mechanisms during mixing of fuel and oxidant, varying turbulence levels and temperature distributions, finite residence times, and variation of mass fractions resulting from the oxidation of ammonia in combination with simultaneous oxidation of other species while burning whether in the pure form or blended with methane, hydrogen, etc. at various equivalence numbers and pressure levels.

In terms of gas turbines, recent studies from various research centers, including Cardiff University's Gas Turbine Research Centre (GTRC) utility-scale gas turbine with its high-pressure optical chamber (HPOC), King Abdullah University of Science and Technology (KAUST) in Saudi Arabia with high-pressure operating facilities and unique measuring techniques, and Tohoko University in collaboration with the National Institute of Advanced Industrial Science and Technology (AIST) involving a micro gas turbine (MGT), and others, are continuously shedding light to problems related to the technologies of ammonia combustion in gas turbines and suggesting practical remedies. Tackling practical challenges to facilitate the transition from using fossil fuels to ammonia in power generation machines is the main objective of all of these studies. Those range from accounting for the fundamental unknown behavior of radicals at the core of the flame to practical corrosive studies of ammonia impact requiring the exchange of brass and other material susceptible parts exposed to the molecule. ${ }^{178}$ Thus, this subsection focuses on the fundamental studies, either numerical or experimental, to determine the impact of these complex phenomena in laboratory-based rigs.

One of the purposes of laboratory research was to recognize images of flames produced when burning ammonia at different conditions as well as comparing ammonia flames images to other 

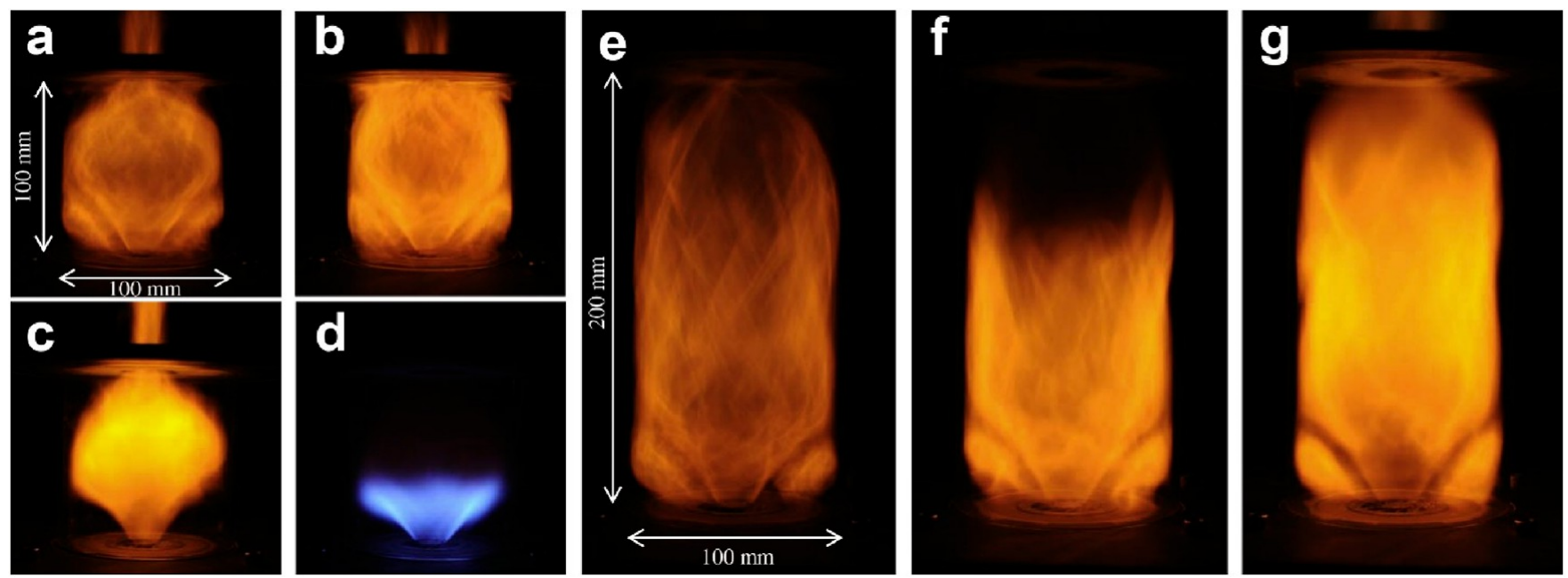

Figure 24. Flames images in the swirl burner with cylindrical liners: (a) ammonia/air flame, $\varphi=1.0, h=100 \mathrm{~mm}$, and $U_{\text {in }}=3.14 \mathrm{~m} / \mathrm{s}$; $(\mathrm{b})$ ammonia/air flame, $\varphi=1.2, h=100 \mathrm{~mm}$, and $U_{\text {in }}=3.14 \mathrm{~m} / \mathrm{s}$; (c) ammonia/air flame, $\varphi=1.2, h=100 \mathrm{~mm}$, and $U_{\text {in }}=3.35 \mathrm{~m} / \mathrm{s} ;(\mathrm{d})$ methane $/$ air flame, $\varphi=1.0, h=$ $100 \mathrm{~mm}$, and $U_{\text {in }}=3.14 \mathrm{~m} / \mathrm{s} ;(\mathrm{e})$ ammonia/air flame, $\varphi=0.8, h=200 \mathrm{~mm}$, and $U_{\text {in }}=3.14 \mathrm{~m} / \mathrm{s} ;(\mathrm{f})$ ammonia/air flame, $\varphi=1.0, h=200 \mathrm{~mm}$, and $U_{\text {in }}=$ $3.14 \mathrm{~m} / \mathrm{s}$; and $(\mathrm{g})$ ammonia/air flame, $\varphi=1.2, h=200 \mathrm{~mm}$, and $U_{\mathrm{in}}=3.14 \mathrm{~m} / \mathrm{s}$. This figure was reproduced with permission from ref 179 . Copyright 2017 Elsevier.

fuels, like methane. Hayakawa et al. ${ }^{179}$ experimentally investigated the stability limits and the emission characteristics with different swirlers from 0.736 to 1.27 Swirl number $(S)$. Stabilized flames were obtained for a heating value of $13.2 \mathrm{~kW}$, and a demonstration was given to the images of various flames by recording the $\mathrm{NH}_{2} \alpha$ band chemiluminescence spectrum and the superheated water vapor spectrum as indicated from the quartz lining. Figure 24 shows images of $\mathrm{NH}_{3}$ flames at different operating conditions as well as a comparison to a typical methane flame produced at the same burner. The shorter flame length in the case of methane, which is also bluish in color, is due to the much higher LBV, while the presence of superheated steam is more prominent in the rich mixtures. The effect of altering the equivalence number and inlet velocity on ammonia flames is also indicated in the images taken. It is observed that the rich mixture of ammonia is more compact and its orange color is brighter. This is thought to be the result of the presence of more $\mathrm{NH}_{2} \alpha$ band chemiluminescence spectrum and superheated steam in the combustion products. All of the images of flames shown in the figure indicate the aerodynamic features. Both the central recirculation zone (CRZ) and external recirculation zone (ERZ) are clear. Panels a-c of Figure 24 are $\mathrm{NH}_{3}$ flames, where panels a and b of Figure 24 demonstrate the difference between stoichiometric and rich $\mathrm{NH}_{3}$ flames and panels $b$ and $c$ of Figure 24 demonstrate the effect brought about by increasing the momentum ratio of the injected charge, which is shown to alter the aerodynamic configuration. The greatest contrast in the figure is between panels a and d of Figure 24, which is emanating from the difference between burning $\mathrm{NH}_{3}$ and burning $\mathrm{CH}_{4}$, as discussed above. Comparing panels e, $\mathrm{f}$, and $\mathrm{g}$ of Figure 24 for $\varphi=0.8,1$, and 1.2, respectively, shows the shortest flame length to be that corresponding to stoichiometric flames (Figure 24f) compared to the rich and lean flames (panels e and $g$ of Figure 24). This is probably due to the fact that the stoichiometric condition corresponds to the highest LBV of the three flames shown.

The performance and emission characteristics of nonpremixed combustion at a high pressure for ammonia-air and methane-air were then compared in rich-lean non-premixed environments to account for the main differences between the two fuels in operating a gas turbine combustor. ${ }^{180}$ Although both fuels produce stable flames, there are opposite features between the characteristics of both chemicals. For example, while maximum $\mathrm{NO}$ was registered at a global equivalence ratios of $\varphi_{\text {global, premixed }}=1.0$ when using $\mathrm{CH}_{4}$, a minimum $\mathrm{NO}$ was obtained for $\varphi_{\text {global, premixed }}=1.1$ for $\mathrm{NH}_{3}$. Furthermore, while the local NO in the case of ammonia depends upon the level of $\mathrm{OH}$, which is assumed to depend upon the local $\varphi$, it largely depends upon the local temperature in the case of methane.

Further experiments and findings were supported by the utilization of a high-pressure optical chamber (HPOC) that is fitted with a generic lean premixed swirl burner. Experimental facilities included $\mathrm{OH}$ chemiluminescence measurements, with a Dantec Dynamics Hi Sense MK II charge-coupled device (CCD) camera with $1.3 \mathrm{~m}$ megapixel resolution coupled with Hamamatsu C9546-03 L image intensifier. A bespoke $0.078 \mathrm{~m}$ focal length lens capable of capturing light in the ultraviolet (UV) wavelength range was used. The Abel deconvolution methodology was used to enable spatial resolution, and an Avigilon $5 \mathrm{Mp} \mathrm{H.264} \mathrm{high-definition} \mathrm{camera} \mathrm{was} \mathrm{used} \mathrm{in}$ capturing various ammonia flames for investigating their stability. Gas analyses were performed using integrated signal instruments, identifying $\mathrm{NO}_{x}$ and $\mathrm{NH}_{3}$ in the flue gases.

The works performed at the GTRC were also expanded to numerical analyses that enabled further insights into the progression of emissions and stability at higher pressures and inlet temperatures. Xiao et al. ${ }^{181}$ presented a lean premixed ammonia flame that was simulated using OpenFOAM with a reduced mechanism for chemical kinetics. The chemical source term was introduced through the partially stirred reactor (PaSR) accounting for the turbulence-chemistry interaction. In this framework, the computational cell is split into reacting and nonreacting zones. The fuel used was a 50-50 ammonia-hydrogen mixture at atmospheric pressure introduced at ambient temperature for a power of $30 \mathrm{~kW}$. The equivalence ratio was varied between 0.433 and 0.5 . NO emission resulted in values between 300 and $3000 \mathrm{ppmv}$, increasing with the equivalence ratio in the studied range. The flame structure was demonstrated through depicting flow fields, temperatures, $\mathrm{OH}$, and NO. The formation and destruction of $\mathrm{NO}$ for the conditions studied was 


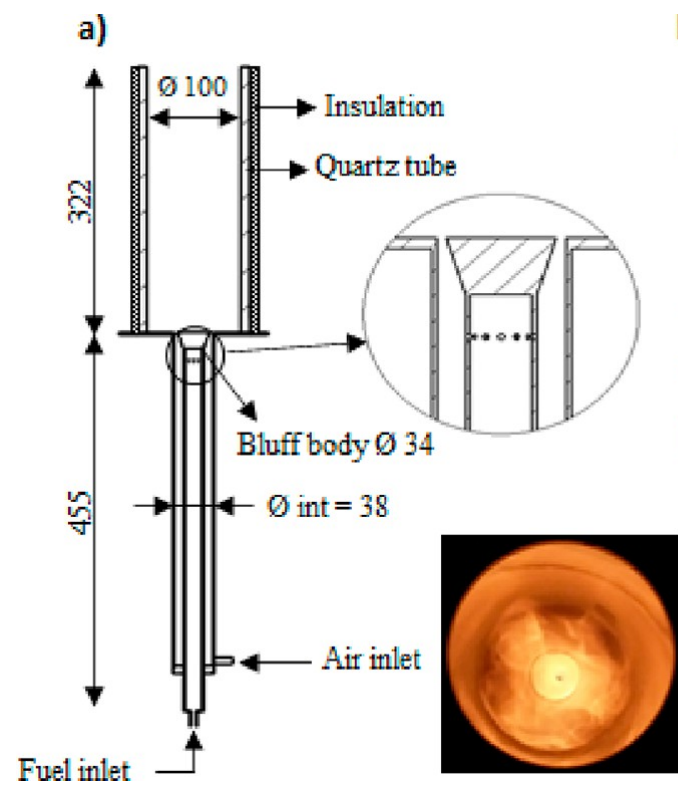

b)

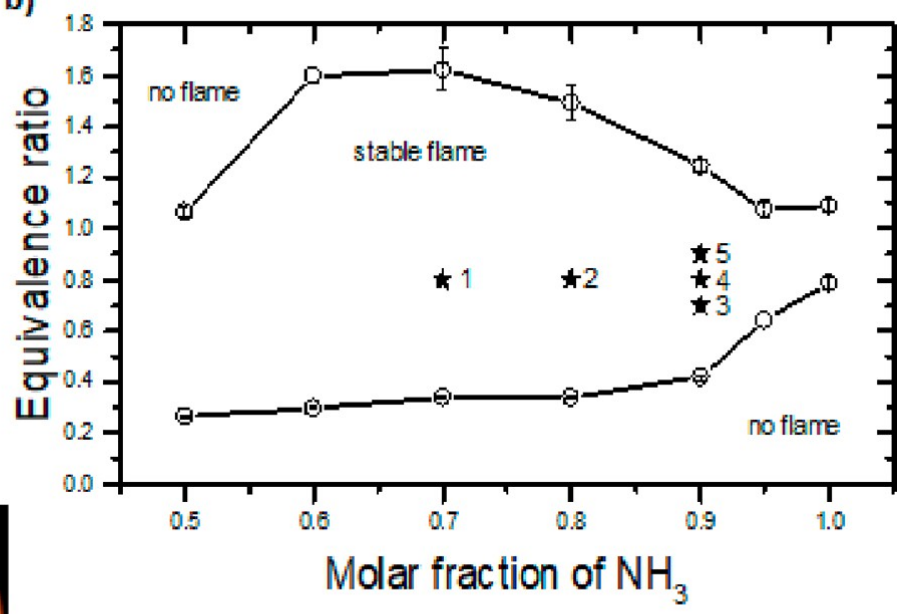

Figure 25. (a) Schematic details of a novel burner design for $\mathrm{NH}_{3}-\mathrm{H}_{2}$-air mixtures and (b) stability map for various fuel molar fractions and equivalence ratios. This figure was reproduced with permission from ref 187 . Copyright 2020 Elsevier.

linked to the $\mathrm{OH}$ and $\mathrm{HNO}$ formation and various production/ destruction mechanisms.

The same experimental facility was used to study ammoniamethane combustion at 0.1 and $0.2 \mathrm{MPa}$ pressure for varying $\mathrm{NH}_{3}$ and $\mathrm{CH}_{4}$ fractions and at different equivalences ranging from lean to rich mixtures with the aid of one-dimensional (1D) analyses. ${ }^{182}$ The study aimed at determining the flame stability and NO emissions for different equivalence numbers. The numerical calculations involved the utilization of GASEQ and CHEMKIN-PRO. The study demonstrated the extremely low concentration of $\mathrm{NO}$ emissions at rich equivalence numbers ranging between 1.15 and 1.25 , although unacceptable levels of $\mathrm{CO}$ were observed. The effect of the swirl number on the aerodynamics of the flow pattern and, thus, the residence time of radicals in the internal recirculation zone was pointed out. Generally, the study concluded that the sole injection of the fuel air mixture is not adequate for the methane ammonia mixture, a problem that was later resolved by ref 101 .

Rich ammonia-hydrogen blends at an equivalence number of 1.2 at an inlet temperature of $657 \mathrm{~K}$ of a variety of blends from 10 to $50 \%$ hydrogen were then studied in ref 183 . This work demonstrated that the burner design can affect the flame topology and, hence, the emission levels as a result of the cracking of ammonia into hydrogen, nitrogen, and $\mathrm{NH}_{3}$. It was proposed to inject a further fraction of $\mathrm{NH}_{3}$ and $\mathrm{H}_{2}$ in a postflame region, which resulted in a further reduction of $\mathrm{NO}_{x}$ levels. The combination that brought about the optimum results for the specific burner design and operating conditions was 40-60 hydrogen-ammonia with a further $4 \%$ injection in the postflame region.

Supporting data produced using Star-CCM+ version 19.3 applying RANS $k-\omega$ SST modeling with a clustering technique for chemistry resolution was used in ref 184 . The predicted levels of $\mathrm{NO}, \mathrm{NH}_{3}$, and $\mathrm{H}_{2}$ were compared to the experimental measurements. Only ammonia emissions agreed reasonably, while discrepancies were experienced for NO and hydrogen. This is normally due to the vast variation between chemical kinetic mechanisms available, and it requires further investigation. ${ }^{71}$ Computational results obtained at various ambient conditions and confinements showed the variance in emissions based on the temperature and pressure, with a predicted reduction of $\mathrm{NO}$ at higher values. Moreover, hydrogen that was produced at the expense of $\mathrm{NH}_{3}$ cracking was observed to be rising in concentration in post-flame regions. The wall condition, whether adiabatic or isothermal, resulted in different radial distributions of radicals at the exhaust plane. Those included $\mathrm{H}_{2}, \mathrm{H}_{2} \mathrm{O}, \mathrm{H}, \mathrm{NH}_{2}, \mathrm{NH}_{3}, \mathrm{NO}, \mathrm{O}, \mathrm{NH}, \mathrm{OH}$, and $\mathrm{N}_{2}$. Although the parameters changed brought significant changes in the combustion characteristics, the overall conclusion demonstrates that the burning of ammonia and ammonia blends in gasturbine-like combustors requires a dedicated burner design. Further, the generic burner that was initially designed to meet natural gas characteristics would not result in adequate emission levels, thus needing a different injection philosophy to reach lower $\mathrm{NO}$ and unburned $\mathrm{NH}_{3}$ emissions.

Similarly, when Somarathne et al. ${ }^{185}$ addressed the burning of pure ammonia in a turbulent premixed environment with air, they highlighted the fact that $\mathrm{NH}_{3} \mathrm{LBV}$ is very low and the production of fuel $\mathrm{NO}$ is considerable. Large eddy simulation (LES) investigations with the inspection of streamlines and velocity distribution, turbulence intensity $u^{\prime}$ and isosurfaces of the second invariant gradient tensor $Q$ shaded with the mass fraction of $\mathrm{NH}_{3}$, and $\mathrm{Y}_{\mathrm{NH}_{3}}$ indicated that a careful design of the swirl burner results in the formation of an inner recirculation zone and small eddies, enhancing the turbulent mixing of burnt and unburnt gases. This finding leads to the conclusion that it is possible to eliminate stability problems arising from the low burning velocity. However, the investigation of $\mathrm{NO}$ emissions at an inlet temperature of $500 \mathrm{~K}$ and stoichiometric mixture showed that the levels of NO produced locally exceeded 10000 ppmv. This agrees with other investigations of NO emissions for pure ammonia combustion ${ }^{181}$ with an inlet temperature of 500 $\mathrm{K}$ and stoichiometric mixtures that showed that the levels of NO produced locally exceeded 10000 ppmv. Furthermore, 1D flame simulation using CHEMKIN-PRO at the initial temperature of $500 \mathrm{~K}$ for lean and rich mixtures showed that $\mathrm{NO}$ emission has a maximum value around the equivalence ratio of 0.9 and then decreased with a further increase of the equivalence ratio until 
$\mathrm{NO}$ is minimal at values of 1.25 , where both $\mathrm{NO}$ and unburnt $\mathrm{NH}_{3}$ mole fractions are less than $300 \times 10^{-6}$, with space and time averaged emission (STAE) values of $\sim 203 \times 10^{-6}$. Threedimensional (3D) modeling validated these results and also indicated alarming levels of $\mathrm{H}_{2}$ under these rich conditions, suggesting that the welcome disappearance of unburnt $\mathrm{NH}_{3}$ was only due to its cracking into hydrogen at the combustor exit.

All of these results lead to the need of further modifications required when burning ammonia and ammonia blends instead of hydrocarbons. However, as part of the challenges that laboratory-based systems are resolving, the problem of flame stability is of a more fundamental nature. The $\mathrm{LBV}$ of $\mathrm{NH}_{3} /$ air flames, of around $7 \mathrm{~cm} / \mathrm{s}$ under the stoichiometric condition and at ambient conditions, produces less flame stability and higher levels of NO generation than that of combustion of conventional hydrocarbons, as a consequence of nitrogen embedded in the ammonia molecule, restricting the direct $\mathrm{NH}_{3}$-air combustion in conventional applications. Using generic gas turbine swirl burners designed for the purpose of burning conventional hydrocarbons has resulted on stability problems, whether when burning ammonia solely or even when mixing it with $\mathrm{CH}_{4}$, as reported by ref 182 . Studies that have covered burning of pure ammonia in premixed and diffusion forms of admitting the fuel and air to the combustor (see for example refs 186 and 187) have involved modifications in techniques for the injection of fuel and oxidant. Flame stability is achieved through a careful burner design that allows for the creation of an adequate CRZ associated with vortex breakdown shearing that entrains fresh reactants, thus enhancing mixing between free radicals and hot upstream combustion products, leading to continuous chemical reactions. This is combined with more ERZs that meet the distinctive burning properties of ammonia. Attempts have been performed to increase the operating range of equivalence ratios from lean to rich mixtures while obtaining a stable flame through blending with either methane or hydrogen. For example, ref 187 used a swirling bluff body burner shown in Figure 25a to burn a blend of $\mathrm{NH}_{3}-\mathrm{H}_{2}$-air at inlet ambient temperature and pressure that resulted in a reasonable range of operating conditions, mapped by a stability diagram shown in Figure 25b. As seen, the equivalence ratio range for pure ammonia oxidation obtained for that burner was between 0.8 and 1.1. This was found expanded to a range between 0.34 and 1.62 when reducing the $\mathrm{NH}_{3}$ content in the fuel mixture to $70 \%$ with hydrogen.

The high NO emissions resulting from ammonia and ammonia blend flames remain to be the main challenge hindering the application of the clean molecule in industrial applications. Detailed kinetics shown above indicated that the oxidation of $\mathrm{NH}_{3}, \mathrm{NH}_{2}$, and $\mathrm{NH}$ in the presence of $\mathrm{OH}, \mathrm{H}$, and $\mathrm{O}$ results in the formation of $\mathrm{NO}$ through a $\mathrm{HNO}$ intermediate. It is necessary to minimize the cost of manufacturing and maintaining large-size SCR systems for ammonia-fired engines in practice. Because both fundamental one-dimensional studies as well as laboratory investigations have shown that a minimum NO production is achieved for rich mixtures of equivalence ratio of around 1.2, CFD studies have demonstrated the possibility of $\mathrm{NO}_{x}$ control through the design of combustors involving twostage zones. Laboratory-scale experiments and CFD upstream of the combustor involve a CRZ with a rich flame condition, and additional air is admitted downstream of the CRZ to consume any unburnt fuel and to reduce the exiting temperatures meeting turbine requirements. A series of laboratory experiments were conducted to examine the effect of rich-lean combustion on the firing of pure ammonia and ammonia-hydrogen at different pressures for premixed and non-premixed combustion. ${ }^{180,188}$ Results demonstrate the reduction in both $\mathrm{NO}$ and $\mathrm{NH}_{3}$ at the exit of the combustor as a result of following such a strategy. ${ }^{188}$

Somarathne et al. investigated the effect of operating in a rich/ lean condition through applying a mixture with a high equivalence ratio in the primary burner and allowing further aerodynamic stabilization. Then, secondary air was introduced downstream to study the possibility of burning any unburnt $\mathrm{NH}_{3}$ or $\mathrm{H}_{2}$ and allowing for the exit temperature to be lower than the $1300 \mathrm{~K}$ limit for the protection of turbine blades against thermal stresses. The secondary air was thus introduced at a length of $0.10 \mathrm{~m}$ of the total length of $0.15 \mathrm{~m}$ combustor. The operating conditions studied included pressures of $0.1,0.2$, and $0.5 \mathrm{MPa}$. The effect of primary and secondary equivalence ratios was numerically studied. The results showed the positive effect of pressure increases in decreasing $\mathrm{NO}$ and $\mathrm{NH}_{3}$ without secondary air at all equivalence numbers studied. However, the introduction of secondary air leads to further formation of $\mathrm{NO}$ as a result of the presence of unburnt $\mathrm{NH}_{3}$ that would burn in lean conditions.

It is suggested that a fully premixed injection strategy is not appropriate for optimized ammonia combustion and that high flame instabilities can be produced at medium swirl numbers; hence, lower swirl and a different injection strategy for optimized power generation using ammonia fuel blends are needed. Because it was acknowledged that the majority of gas turbine combustors have been operated in a non-premixed mode, this was attempted. It was found obvious to reiterate the study in a non-premixed environment and compare the performance and level of emissions produced between both premixed and nonpremixed flames. ${ }^{186}$ STAE NO was observed to follow a similar behavior to that displayed for the premixed flow because it behaves similarly with the change of the global equivalence ratio. However, the local NO distribution showed the presence of higher levels of emissions near the combustor walls, while the center was almost free from emissions. This was attributed to the local value of $\varphi$. The effect of pressure on the level of emissions was shown to be independent of the combustion injection type. STAE NO was higher than that in the premixed flow as a result of non-uniformity of mass fractions and local $\varphi$, a negative effect that could be reduced by careful engineering the admission details of the fuel according to the detailed combustor and burner configurations.

Moreover, the research in ref 189 found that the effect of pressure must be taken into account to reduce $\mathrm{NO}$ and unburnt $\mathrm{NH}_{3}$ emissions and that increasing the operating pressure from 0.1 to $0.5 \mathrm{MPa}$ lowers the $\mathrm{NO}$ and unburnt $\mathrm{NH}_{3}$ emissions from approximately 700 to $200 \mathrm{ppmv}$ at $\varphi=1.2$. This same work also demonstrated that the NO emission reduction results from a significant decrease in the $\mathrm{OH}$ radical concentration at high pressures because these radicals play an important role during the oxidation of the amidogen radical $\left(\mathrm{NH}_{2}\right)$ to $\mathrm{NO}$ via nitroxyl $\left(\mathrm{HNO}\right.$ ) in the reaction sequence $\mathrm{NH}_{2} \rightarrow \mathrm{HNO}, \mathrm{NH} \rightarrow \mathrm{HNO}$, and $\mathrm{HNO} \rightarrow \mathrm{NO}$. The reduction in the $\mathrm{OH}$ radical concentration at high pressures is related to the third body reaction $\mathrm{OH}+\mathrm{H}+(\mathrm{M}) \leftrightarrow \mathrm{H}_{2} \mathrm{O}+\mathrm{M}$, which is highly sensitive for the forward direction at high pressures.

Co-firing of $\mathrm{CH}_{4}$ and $\mathrm{NH}_{3}$ was thus addressed in ref 101 for single- and two-stage combustion of premixed and nonpremixed conditions at varying ambient pressures, primary and overall equivalence, and ammonia content in the mixture up to $30 \%$ ammonia by heat fraction. The investigation included 
both experimental and LES analyses. The comparison of $\mathrm{OH}$ PLIF shots for instantaneous and averaged intensities of flames obtained at premixed and non-premixed conditions of the mixture burnt at $\varphi=1.2$ demonstrated the interesting distinctive features between the two flames. The premixed single-stage combustion produced excessive amounts of NO for both the lean and rich mixtures up to $\varphi \sim 1.35$, indicating the need to reduce emissions via two-stage combustion. The non-premixed case problem was less pronounced. The LES analysis of the twostage combustion of methane-ammonia-air mixtures indicates the possibility of achieving environmentally acceptable levels of emissions and combustor outlet temperatures under stringent conditions of ambient pressure, blending fractions of ammonia and methane, or through the splitting between primary and secondary equivalence numbers. To find out whether the referred values of these parameters are unique features of the configuration studies, further studies are required.

$\mathrm{NO}_{x}$ emissions were also reduced through the humidification of reactants in $\mathrm{NH}_{3}-\mathrm{H}_{2}$ blends. ${ }^{190}$ The reduction was a result of the combined effect of the decrease of the flame temperature as well as enhanced $\mathrm{O}$ consumption through the reaction $\mathrm{O}+\mathrm{H}_{2} \mathrm{O}$ $\leftrightarrow \mathrm{OH}+\mathrm{OH}$, to limit $\mathrm{N}_{2}+\mathrm{O} \leftrightarrow \mathrm{NO}+\mathrm{N}$. Further details are given in the next subsections. It is notable to mention that excessive temperature reduction in the flame zone, although inhibiting the formation of NO, might also lead the loss of flame stability; thus, it would be a question of optimization.

As mentioned, considerable work is taking place at KAUST as well to determine further parameters and features in the use of ammonia. Works have been presented around the stability of ammonia flames, showing interesting results for the use of very lean conditions at which hydrogen-ammonia flames produce negligible NO emissions (although there is still a question about unburned ammonia). ${ }^{191}$ Further, Khateeb et al. ${ }^{192}$ recently conducted stability mapping for premixed ammonia-hydrogen-nitrogen-air swirl flames. The results indicated that flashback occurrence can be eliminated when the ammonia fuel fraction exceeds a critical value, which is dependent upon the Reynolds number, thus widening the stability region. In terms of emission results, the study found consistent data with previous studies, with a lean ammonia/hydrogen flame producing a large amount of $\mathrm{NO}$, whereas good $\mathrm{NO}$ performance at slightly rich conditions. Interestingly, adding nitrogen in the mixture to mimic ammonia cracking did not influence the stability regions but marginally decreased NO emissions.

Recent work by Bennett et al. ${ }^{96}$ to show the reduction of soot formation in co-combustion of ammonia with other fuels using a non-premixed counterflow flame configuration is the first of its kind. Results from the study indicated that the addition of ammonia with conventional fuels has a chemical effect in reducing soot formation. However, this effect was not apparent during initial polycyclic aromatic hydrocarbon (PAH) formation processes because PAHs of 2-3 rings were not affected, but soot reduction was initiated for PAHs larger than 2-3 rings.

Therefore, active research is currently taking place to understand not only the combustion fundamentals behind the use of ammonia and all of its potential blends for engines and large power generation systems, but also there is a great interest to develop and implement these technologies in robust systems capable of using ammonia with high power release and low emissions. The work has led to interesting concepts that now are under scrutiny at small-, medium-, and large-scale sizes.

\section{APPLICATIONS}

4.1. Furnaces/Boilers. Energy used in industrial and residential sectors is a relevant part of the total energy, accounting for more than 50\% of total world energy consumption. ${ }^{193}$ This percentage grows through the years with the continuous increase of energy-intense material demand. In industrial sectors, the primary energy sources are still coal, petroleum, and natural gas; only a very small percentage comes from renewable energy. Therefore, decarbonization of the industrial sector is a key step for meeting the $\mathrm{CO}_{2}$ net zero emission in the near future. Once again, ammonia is among the best candidates as a new carbon-free energy carrier to be used as a fuel.

Various solutions have been tested depending upon what type of facility has been considered, which, in turn, poses different issues in terms of ammonia utilization, purpose, etc. In general, the difficulties to be faced in furnaces and boilers are those related to ammonia combustion characteristics, already discussed thus far, e.g., flame stability, pollutant emissions, structural integrity, etc. However, in those cases, where furnaces are conceived for material treatment, the effects of evaluation of gas composition are also a priority.

In relation to flame stability and $\mathrm{NO}_{x}$ formation, co-firing with different fuels, the use of staged combustion as well as oxygenenriched or diluted oxidant streams have been evaluated thus far for practical solutions, depending upon the combustion strategy that needs to be implemented.

In coal-fired thermal power plants, ammonia co-firing has been explored in various configurations ${ }^{194-196}$ both experimentally and numerically. However, a detailed interpretation of the effects of ammonia on each single stage of coal combustion, independent of the furnace configuration, is very difficult to be pointed out as a result of the well-known complexity of solid fuel combustion. For example, ammonia can interfere with gas and gas-solid reactions as well as with heat transfer in the furnace.

It was shown that, keeping the thermal power, it is possible to reduce $\mathrm{CO}_{2}$ emission by substituting coal with ammonia in different concentrations depending upon the system requirements. An effort in this direction was carried out by Tamura et al., ${ }^{194}$ which characterized coal/ammonia co-combustion in a 1.2 $\mathrm{MW}_{\mathrm{th}}$ furnace. They demonstrated the relevance of coal/ ammonia mixing and staged combustion on $\mathrm{NO}_{x}$ formation. Although the combustion behavior strongly depends upon the furnace configuration, the authors highlighted main features that are relevant for the process in general.

As is well-known, coal combustion occurs through different steps, which span from heating and devolatilization of coal particles and char formation to oxidation of products of devolatilization and char oxidation (Figure 26). On this basis, $\mathrm{NH}_{3}$ injection strongly affects the flue gas composition and ash based on its position in the furnace. Ammonia can play the role of a reducing agent or $\mathrm{NO}_{x}$ source depending upon the coal combustion condition in the zone where the interaction with $\mathrm{NH}_{3}$ occurs. In terms of $\mathrm{NO}_{x}$, in ammonia/coal co-combustion, the target is to keep the $\mathrm{NO}_{x}$ level similar to those of pure coal combustion, avoiding as much as possible its further increase while decreasing $\mathrm{CO}_{2}$ emissions.

In Figure 26, a qualitative scheme of pulverized coal combustion was reported to highlight the possible region where the injection of $\mathrm{NH}_{3}$ is not detrimental for $\mathrm{NO}_{x}$ formation. ${ }^{196}$ 


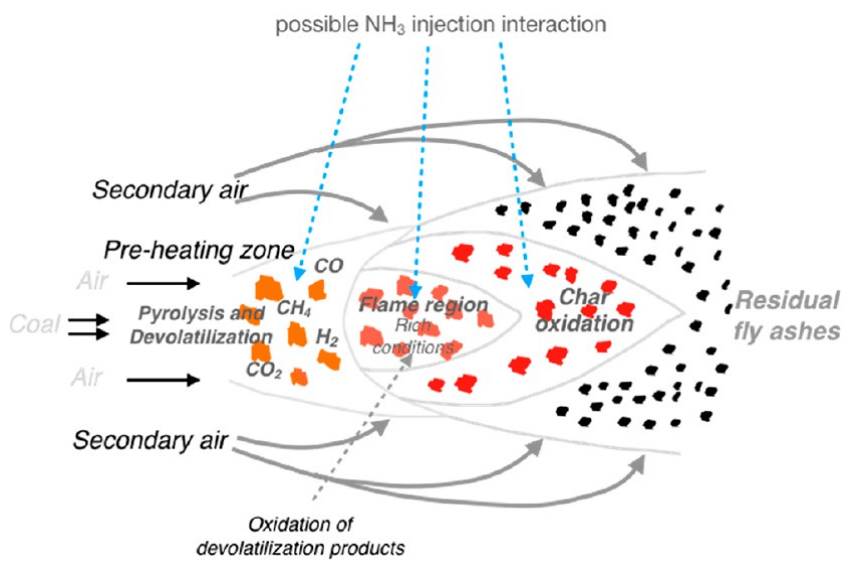

Figure 26. Schematization of coal combustion and possible $\mathrm{NH}_{3}$ interaction.

Tamura et al. ${ }^{194}$ and Ishiara et al. ${ }^{196}$ demonstrated that the injection in the combustion region, where devolatilization products oxidize, i.e., in flame region, leads to almost the same level of $\mathrm{NO}_{x}$ emission as the coal combustion. More specifically, Ishiara et al. ${ }^{196}$ pointed out that, because of the air staging, the flame region is in rich conditions and becomes richer with ammonia injection. This reduces the NO production with respect to what is usually expected without ammonia injection. In addition, the slight reduction in the flame temperature during ammonia injection also has a positive effect on NO formation. However, the flame temperature is high enough to convert $\mathrm{NH}_{3}$ before the region where char oxidation starts. On the contrary, the authors showed that $\mathrm{NH}_{3}$ injection in the coal heating and devolatilization region or in the region where char oxidation occurs causes a significant increase of $\mathrm{NO}_{x}$ with respect to coal combustion. A different behavior is reported by Tamura et al. that experimentally showed in their configuration the effectiveness of injection of ammonia mixed with coal through the coal nozzle with respect to separate downstream injection. It is clear that the effectiveness of ammonia injection before the post-flame zone depends upon the air-staging strategy. The higher the airstaging ratio, the higher the equivalence ratio in the flame zone and the lower the $\mathrm{NO}_{x}$ production.

As expected, ammonia/coal co-combustion also has an effect on other species, which has to be taken into account. In general, $\mathrm{NH}_{3}$ or NO compete with other species and char present in the reaction volume. The interaction among them can heavily affect $\mathrm{NO}_{x}$ emissions. In general, as a result of the high flame temperature, $\mathrm{NH}_{3}$ is converted before the region where char oxidation starts. There is scarce information in the literature about the effect of ammonia on volatilization products at the flame zone, and further studies are needed. In the temperature range typical of the flame region, where the high-temperature reaction branching is active, it is expected that the presence of $\mathrm{H}_{2}$ and $\mathrm{CH}_{4}$ could enhance ammonia oxidation. It is interesting to note that $\mathrm{NH}_{3}$ co-firing causes a decrease of $\mathrm{CO}$ emission and an increase in unburned carbon in the ashes. ${ }^{194}$ The authors hypothesize that the $\mathrm{CO}$ decrease is related to not only the decrease of the coal amount, as for $\mathrm{CO}_{2}$, but also the gas shift reaction (i.e., $\mathrm{H}_{2} \mathrm{O}+\mathrm{CO} \rightarrow \mathrm{H}_{2}+\mathrm{CO}_{2}$ ), which takes place in the burned gases. This reaction is favored in the presence of ammonia because, in $\mathrm{NH}_{3}$ co-combustion, the amount of water formed during oxidation is higher than that formed in coal combustion.
A potential drawback of ammonia co-firing is the increase of carbon in fly ashes. In this regard, different results were reported by refs 194 and 195 . Indeed, while the authors of ref 194 report a decrease of unburned carbon in fly ashes with respect to coal combustion, which is in agreement with ref 197 , in ref 195 , the opposite trend was found numerically. As a common result, no ammonia slip was experimentally or numerically found in any of the fed conditions considered.

A relevant parameter to consider for the evaluation of the effectiveness of co-firing is the heat transfer. In the case of coal furnaces, it is mainly based on the radiative mechanism as a result of the presence of coal and char particles. Ammonia addition decreases the concentration of coal particles. Also, the final effects depend upon the co-firing strategy, as previously mentioned. It has been shown ${ }^{196}$ that up to $35 \%$ ammonia cofiring the concentration of coal particles is high enough to keep the heat transfer unchanged. Tamura et al. ${ }^{194}$ showed that, with $60 \%$ co-firing, the radiative component decreases significantly. Despite that, the heat transfer to the wall does not reduce accordingly, although the heat transfer to the wall is only $3 \%$ lower than in the case of pure coal firing. The authors relate this effect to the change in the flame shape. While increasing $\mathrm{NH}_{3}$, the flame becomes thinner and longer, causing an increase of convective components of heat transfer. In this case, also, the design of the injection nozzle is relevant because of its impact on the flame shape.

Energy-intensive material production activities, such as iron, steel, and cement production, alone account for about $50 \%$ of energy consumption in industry. In this case, the strategies for $\mathrm{CO}_{2}$ emission reduction related to the use of alternative fuels have to take into account all constraints as a result of the effect of an oxidative atmosphere or combustion residuals on the material itself. In the cement industry, the use of alternative fuels in the pyro-processing of raw material, which leads to clinker production, is a common practice, especially in terms of coprocessing of waste materials in rotary kilns. The combustion process in kilns is considered almost an incineration process whose residuals become part of the clinker itself. Nevertheless, the temperature profile along the kiln axis is crucial for the final quality of the clinker, affecting the clinker microstructure in terms of porosity as well as size and distribution of crystals in the clinker phase. Thus, the temperature along the kiln axis has to be high enough, and the heat transfer to the material has to be efficient, to guarantee the separation of heating, melting, nodule formation, and burning processes along the kiln axis appropriately. Gaseous flows are counter-current with respect to the material, so that the flame temperature has to reach 2300 $\mathrm{K}$ to allow the material temperature to reach about $1720 \mathrm{~K}$ in the burning stage. Also, in these furnaces, the heat transfer essentially occurs through radiative mechanisms.

On the basis of these considerations, it is clear that the use of pure ammonia as well as other low-calorific-value fuels for clinker production in conventional kilns, without a precalciner, is not feasible. Nevertheless, as a result of the huge amount of energy consumed in the process, the use of a few percentages of such fuels has a significant impact on $\mathrm{CO}_{2}$ emissions. Kujiraoka et al. ${ }^{198}$ demonstrated that the use of $30 \%$ ammonia in heavy oil co-firing does not alter the compression characteristics of the clinker with respect to that produced with heavy oil. As for the precalciner kiln, it is possible to use up to $65 \%$ of fuel in the calciner, which works at much lower gas temperatures (between 1200 and $1400 \mathrm{~K}$ ), which correspond to a maximum material temperature of $1200 \mathrm{~K}$. In this case, the fuel quality is less 
(b)

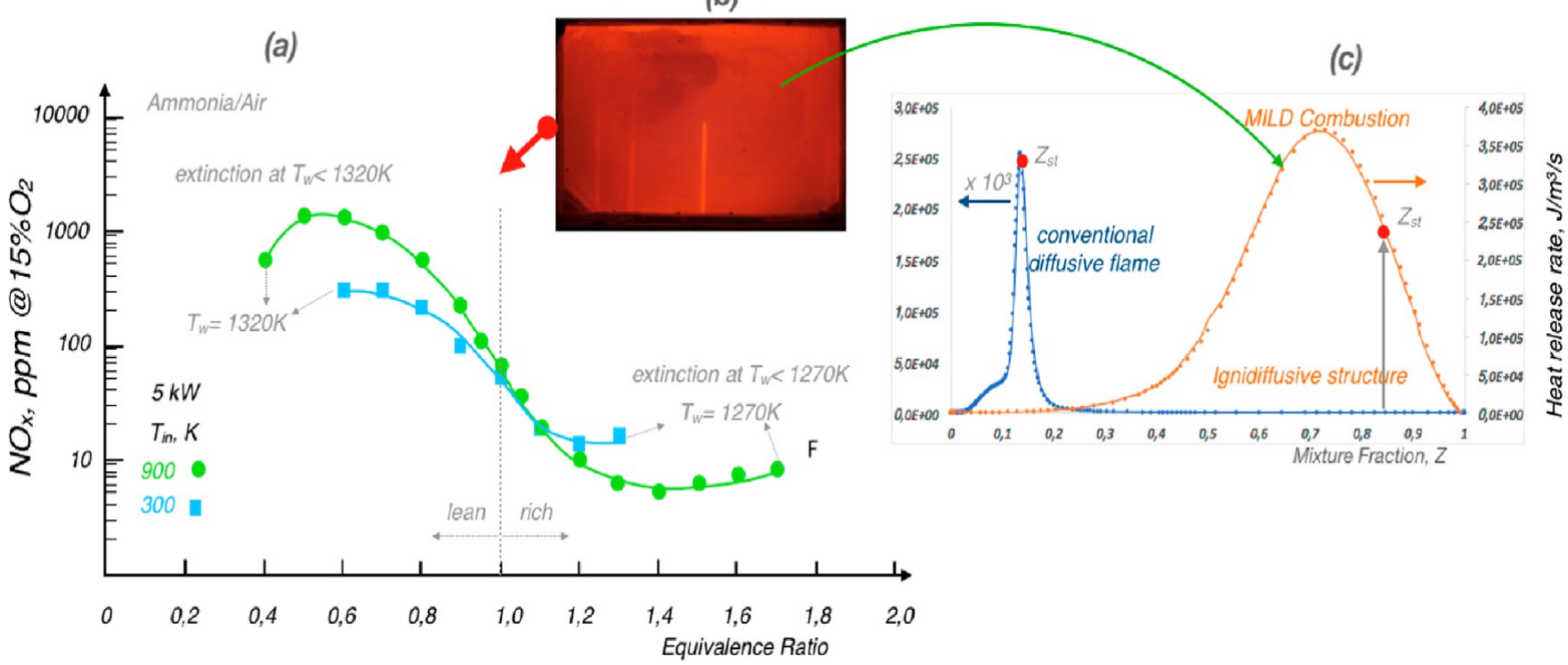

Figure 27. Ammonia MILD combustion: (a) $\mathrm{NO}_{x}$ emission, (b) example of no visible flame, and (c) example of an igni-diffusive structure.

relevant, and waste are largely used in this part of the plant. Therefore, also, ammonia as a fuel in these sections of the plant is attractive, also keeping in mind that it is necessary to use selective non-catalytic reduction for $\mathrm{NO}_{x}$ abatement. However, no studies have been carried out yet for the use of ammonia in calciners and preheaters.

As discussed, the characteristics of ammonia do not make it a good fit for use in combustors with standard configurations. Indeed, the low calorific value and the low burning velocity do not stabilize either a premixed or diffusion flame without using appropriate strategies. In the past decade, solicited by the need to meet new targets in terms of efficiency and emissions, innovative, fuel-flexible combustion technologies have been developed. This is the case of MILD combustion characterized by a different stabilization mechanism with respect to the feedback-stabilized conventional combustion processes. MILD combustion occurs when the reactants are locally preheated at a temperature higher than the autoignition temperature $\left(T_{\text {ign }}\right)$, and the local composition allows for a temperature increase (DT) lower than $T_{\mathrm{ign}}$ as a result of dilution or the low calorific value of the fuel used. These conditions make the combustion process evolve without the stabilization of a common premixed or diffusion flame structure but through so-called igni-diffusive structures $^{199}$ (Figure 27c), where heat release rate profiles related to conventional and MILD combustion were reported. Igni-diffusive structures cover a wider mixture fraction range with respect to conventional diffusion structures, and their maximum heat release is not correlated to the stoichiometric mixture fraction. In combustion chambers, igni-diffusive structures derive from the pockets of the mixture of different compositions that progress on the microscale by means of ignition, oxidation, and annihilation with no propagative mechanisms. Moreover, these are nearly homogeneously distributed in time and space in the entire volume of the combustion chamber. Independent of the fuel used, no visible flame structure is present in the combustion chamber. The local conditions for igni-diffusive structures are reached by a very high level of internal heat and mass recirculation, which makes the MILD combustion process really fuel flexible, as assessed by plenty of papers published in the field.
In the last few years, MILD combustion has gained more and more relevance because of the increasing number of new molecules used as energy carriers, with combustion characteristics very different from those of fossil fuels. Different configurations have been considered, from laboratory to domestic to industrial scale. A very effective configuration is the one based on a cyclonic flow configuration on a small scale. ${ }^{200,201}$ The authors deeply studied ammonia MILD combustion in this burner, identifying the range of stability in terms of the equivalence ratio, initial temperature, and power intensity. It has been proven that, in this condition, ammonia combustion can be stabilized in a wide range of equivalence ratios, from 0.4 up to 1.8. At the same time, very low $\mathrm{NO}_{x}$ emissions, in comparison to that usually measured using ammonia in standard combustion configuration, were detected, as shown in Figure 27a. More specifically, under this condition, it is possible to have a $\mathrm{NO}_{x}$ emission of about $70 \mathrm{ppm}$ in stoichiometric-fed conditions and only a few part per million (ppm) in rich conditions. Dependent upon feed conditions, the emissions can be further decreased by adding water in the oxidant stream. ${ }^{202}$

The local temperature value at which ammonia MILD combustion can stabilize at the limit of the equivalence ratio range is remarkable and represents a threshold value. Independent of the inlet temperature, ammonia MILD combustion stabilizes when local temperatures are higher than $1300 \mathrm{~K}$ in lean/stoichiometric conditions. ${ }^{200,202}$ It has been demonstrated in elementary reactors ${ }^{99,102}$ that this temperature is the threshold to make the high-temperature oxidation mechanism of ammonia start as a result of the onset of hightemperature branching reactions of $\mathrm{H}_{2} / \mathrm{O}_{2}$. For temperatures lower than $1300 \mathrm{~K}$, the ammonia oxidation occurs through the low and intermediate reaction channels, which do not yield an $\mathrm{OH}$ concentration high enough to sustain the combustion process in the burner. The threshold temperature of $1300 \mathrm{~K}$ can be decreased by co-firing with methane or hydrogen. In the case of methane, the temperature can decrease to about $1150 \mathrm{~K}$ in dependence of the co-firing level. This threshold value is also affected by the composition of the recirculation flow as a result of the high third body efficiency of recirculated species, such as 
Table 3. Energy Content and Energy Density at Storage Conditions

\begin{tabular}{|c|c|c|c|c|c|c|c|c|}
\hline & $\mathrm{H}_{2}$ & $\mathrm{CH}_{4}$ & $\mathrm{C}_{2} \mathrm{H}_{5} \mathrm{OH}$ & DME & gasoline & diesel & heavy oil & $\mathrm{NH}_{3}$ \\
\hline energy content $(\mathrm{MJ} / \mathrm{kg})$ & 120.0 & 49.0 & 26.9 & 28.0 & 44.0 & 42.4 & 40.2 & 18.8 \\
\hline stoichiometric air/fuel & 2.4 & 9.6 & 14.3 & 2.3 & 15.3 & 14.3 & & 6.05 \\
\hline energy density $(\mathrm{MJ} / \mathrm{L})$ & 4.8 & 9.7 & 21.3 & 18.7 & 32.0 & 35.2 & 36.6 & 11.5 \\
\hline laminar flame speed $(\mathrm{cm} / \mathrm{s})^{a}$ & 218 & 35 & 41 & 45 & 34 & & & 7 \\
\hline ignition delay time $(\mathrm{ms})^{b}$ & 51.43 & 72.2 & 6.6 & 0.76 & 10 & 1.12 & & 1383 \\
\hline
\end{tabular}

${ }^{a}$ Experimental measured data from the literature at initial conditions: $P=1 \mathrm{~atm}, T \approx 298 \mathrm{~K}$, and $\varphi=1.0 .{ }^{86,207-211}{ }^{b}$ Under conditions of a homogeneous constant volume reactor at $P=20 \mathrm{bar}, T=900 \mathrm{~K}$, and $\varphi=1.0$.

water. $^{203,204}$ For example, in MILD combustion, the third body efficiency has great relevance in the kinetics of three molecular reactions and strongly affects ignition and branching mechanisms.

Results on MILD combustion in cyclonic configurations have been obtained thus far on a laboratory scale, but it is not difficult to consider a scale up of the system in terms of power for domestic or small-scale applications. In fact, it is possible to increase the number of units working in parallel and/or increase their operative pressure while keeping the cyclonic configuration and their efficiency.

4.2. Internal Combustion Engines. Green ammonia, which requires less storage volume than hydrogen and is cheaper to make than other synthetic carbon fuels, seems to be the best candidate as electrofuels for transportation because the greenhouse gas emissions from an ammonia-driven vehicle could be less than one-third of gasoline or diesel. In the case of heavy freight, because the production sites of the hydrogen carrier (the hydrogen itself or ammonia) will certainly be located far from the consumers, long-distance freight transport with ammonia as fuel is an advantage with a volume density of liquid ammonia more than 2.5 times higher than that of compressed hydrogen at a high pressure. Ammonia can also be a suitable fuel for auxiliary power units because there is less challenge on storage and the load range is more limited. Reducing the total greenhouse gas emissions from marine transportation is possible using hydrogen and ammonia directly as supplementary fuels or individual fuels. Using ammonia as a dual fuel in marine engines can decrease total greenhouse gas emissions up to $33.5 \%$ per ton kilometer, whereas this number increases to $69 \%$ if only ammonia is used in the engines, as underlined in ref 205 based on life cycle analyses. Actually, as for heavy-duty trucks, in the case of marine transportations (tankers, super trawlers, or cargo ships), the size of the fuel tanks needed for hydrogen would be too large, too onerous, and impossible if the refueling is not easily possible. Although more energy-dense than hydrogen, ammonia still occupies significantly more space than diesel for the same amount of propulsion, as underlined de Vries. ${ }^{206}$ Nevertheless, ammonia has many advantages to other fossil fuels, for example, to liquefied natural gas (LNG), because it is already produced and transported in large quantities around the world. However and as pointed out through the use of other fuel sources (Table 3), ammonia can be competitive to other alternatives but still presents a disadvantage to fossil sources, thus requiring more ingenious methods to use all of its properties while raising power and efficiency.

The idea of using ammonia as fuel is nothing new, with the first well-known Belgium use of buses fleet during World War II. Several further studies performed during the mid-1960s ${ }^{212-214}$ were focused on evaluating the potential of ammonia as fuel in internal combustion engines. Currently, ammonia-based combustion engine fueling methods are not ready to be marketed because the use of the molecule still poses major problems not only because of supply and safety issues but also because of its physical characteristics compared to conventional fuels. Therefore, for many applications, two strategies have been considered for the use of ammonia fuel: supply ammonia either partially in standard engines to limit the carbon footprint or employ it mainly in dedicated engines to reach zero footprint. Another example consists of using ammonia as a reducing agent for $\mathrm{NO}_{x}$ mitigation by direct injection in diesel engines to avoid the use of selective catalytic reactors at the exhaust. ${ }^{215}$

In the following subsections, main conclusions about state-ofthe-art ammonia fueling methods for internal combustion engines are highlighted.

4.2.1. Automotive Application. As a result of the specific features of ammonia as a fuel, i.e., its narrow flammability limits, high autoignition temperature, and low combustion speed, even in spark-ignition (SI) or compression-ignition (CI) engines, the feasibility to consider pure $\mathrm{NH}_{3}$ requires some adaptations to achieve favorable ignition conditions, by either increasing the compression ratio or using a turbocharger or dedicated ignition system or using a more reactive quantity of fuel, as summarized recently in an International Energy Agency (IEA) report. ${ }^{216,217}$

As a result of its high autoignition temperature and its narrow flammability limits, as summarized by Dimitriou et al. ${ }^{218}$ in their recent review focused on CI engines, dual-fuel modes are the most attractive way to use ammonia as a fuel in a CI engine, thus feeding the engine with a pilot injection of more reactive fuels, such as diesel, acetylene, butane, LNG, liquefied petroleum gas (LPG), DME, etc. In most cases, the port-fuel injection of ammonia is better than direct liquid injection of ammonia, which is very limited in conventional diesel mode, as highlighted recently by Lesmana et al. ${ }^{219}$ Analogously, in SI engines, the ignition is easier thanks to the ignition device, making possible the combustion at a load range with pure ammonia and its blends with another fuel (such as hydrogen or standard or alternative gasoline fuels), thus enhancing the combustion process $^{217,220}$ with reasonable compression ratios.

Bearing in mind the 2050 energy transition target, zerocarbon emission fuels will be the only fuels to be considered, either ammonia alone or ammonia with hydrogen, for both SI engines or CI engines (in spark-assisted or dual-fuel modes). However, as underlined in ref 217 , most studies during the past decade have been carried out on cooperative fuel research (CFR) engines and not the usual engines installed in current vehicles. Moreover, only a few attempts of ammonia-fueled vehicles have been made thus far [i.e., the Marangoni Toyota project (https://nh3fuelassociation.org/2013/04/25/ ammonia-fuel-marangoni-eco-explorer/) or the AmVeh Korean project (https://nh3fuelassociation.org/2013/06/20/theamveh-an-ammonia-fueled-car-from-south-korea/ $)^{221}$ ], which only use ammonia as a partial substitute of standard fuels, mainly limited because of the toxicity of possible ammonia leaks. 


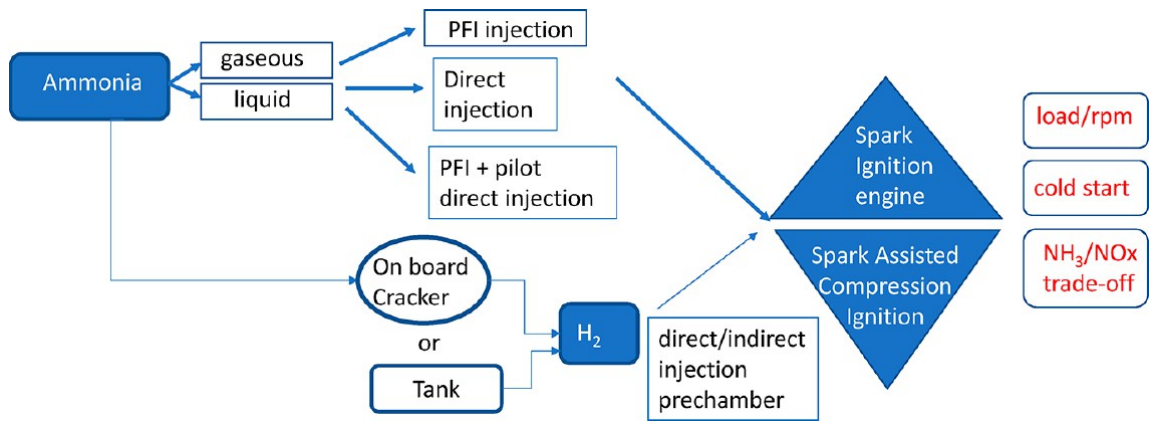

Figure 28. Different possible paths for suitable use of ammonia as fuel in an internal combustion engine.

Only a few studies have explored the possibility of fueling an engine with neat ammonia. ${ }^{222,223}$ Koike et al. ${ }^{224}$ first proved that, for a 14:1 compression ratio, an engine under boosted conditions can run with ammonia with acceptable cyclic variations at high load but only at $800 \mathrm{rpm}$. Lhuillier et al. ${ }^{225}$ confirmed the use of the chemical in a current SI engine (10.5:1 compression ratio) at $1500 \mathrm{rpm}$ at full load. As summarized by Mounaï-Rousselle et al., ${ }^{216}$ operating an engine with pure ammonia at a lower load (i.e., intake pressures lower than atmospheric conditions) is also possible. However, a drastic heating of the combustion chamber is required to enhance stable conditions. It must be noted that, thus far, no operating tests have been carried out on vehicles under these conditions. Lee and Song ${ }^{226}$ also studied a partial premixed charge combustion strategy with a very high compression ratio of $35: 1$ and a intake gas temperature suitable for ammonia combustion without the need of another fuel. They only added a direct pilot ammonia injection during the compression.

Figure 28 schematizes the different possible solutions already tested to consider ammonia as a fuel, mixed or not mixed with hydrogen. The indicated efficiency and the output energy decrease with the $\mathrm{H}_{2}$ increase. The highest efficiency is reached for lean equivalence ratios, but highest output energy can be obtained near stoichiometry, even under slightly rich mixtures. Even if small contents [less than $10 \% \mathrm{H}_{2}$ (vol)] are enough to guarantee engine stability at different loads, to maintain similar output energies with acceptable stability, high-temperature conditions are needed, guaranteeing ammonia ignition provided either at higher compression ratios or by boosted intake pressures.

To enable $\mathrm{H}_{2}$ to support ammonia combustion, the solution of making hydrogen on board using the heat contained in the exhaust gases seems to be the best as long as the production of sufficient hydrogen under startup conditions is guaranteed. ${ }^{223}$ Several current works are underway to determine efficiencies and the potential of using hydrogen from cracked ammonia employing waste heat in automotive systems. ${ }^{227-229}$ Table 4 summarizes the main conclusions for the use of hydrogen as a doping agent.

Most studies were based on the injection of gaseous ammonia inside the intake port [port fuel injection (PFI)] by means of dedicated injectors or LPG types, because ammonia is gaseous below 10 bar and ambient temperature. Moreover and as indicated in Figure 28, different injection strategies can be explored (gaseous phase directly inside the combustion chamber $^{230}$ or liquid injection inside the intake port ${ }^{223}$ or inside the combustion chamber ${ }^{226}$ ). Direct injection has to be considered seriously because the injection strategy (injection duration, phasing, and splitting) can be adjusted as a function of
Table 4. Main Conclusions for Ammonia with $\mathrm{H}_{2}$ as a Promoter

\begin{tabular}{|c|c|c|c|}
\hline $\begin{array}{l}\text { minimum } \mathrm{H}_{2} \text { for } \\
\text { combustion } \\
\text { stability }\end{array}$ & efficiency & output energy & $\begin{array}{l}\text { open-ended } \\
\text { considerations }\end{array}$ \\
\hline $5-10 \%(\mathrm{vol})$ & $\begin{array}{l}\text { higher for } \\
\text { stoichiometric and } \\
\text { slightly rich mixture }\end{array}$ & $\begin{array}{l}\text { less than } \\
\text { standard } \\
\text { engine fuels }\end{array}$ & $\begin{array}{l}\text { cold start } \\
\text { conditions }\end{array}$ \\
\hline $\begin{array}{l}\text { decrease with } \\
\text { load increase }\end{array}$ & $\begin{array}{l}\text { higher than standard } \\
\text { fuels }\end{array}$ & $\begin{array}{l}\text { increase with } \\
\text { compression } \\
\text { ratio }\end{array}$ & pure ammonia \\
\hline $\begin{array}{l}\text { increase with } \\
\text { engine speed }\end{array}$ & $\begin{array}{l}\text { decrease with } \mathrm{H}_{2} \\
\text { increase }\end{array}$ & $\begin{array}{l}\text { increase with } \\
\text { engine speed }\end{array}$ & \\
\hline
\end{tabular}

the load to favor higher efficiency. However, from available literature studies, no systematic experimental or simulation studies have been carried out to draw up recommendations. An injector concept for direct liquid injection was developed by Sasaki et al. ${ }^{231}$ with also the possibility to fill up $\mathrm{H}_{2}$ simultaneously but without any results available in open access.

Main conclusions about pollutant species at the exhaust can be drawn as the opposite trend of $\mathrm{NO}_{x}$ and $\mathrm{NH}_{3}$. Indeed, $\mathrm{NO}_{x}$ emissions are at a maximum at around 0.8 equivalence ratio and $\mathrm{NH}_{3}$ for rich mixtures (up to $2 \mathrm{vol} \%$ of wet gases). Even if one part of $\mathrm{NO}_{x}$ formation is due to the $\mathrm{N}$ content in $\mathrm{NH}_{3}$ itself, $\mathrm{NO}$ increases with $\mathrm{H}_{2}$ addition. $\mathrm{NO}_{2}$ is less than half the concentration of that of $\mathrm{NO}_{x}$ emissions, and very low levels of $\mathrm{N}_{2} \mathrm{O}$ emissions were also found in all of these studies, i.e., less than 50-100 ppmv, inducing low footprint global potential impact. Furthermore, the effect of crevice traps has to be evaluated, especially during boosted conditions, as underlined by Westlye et al. ${ }^{163}$ Finding appropriate and optimal solutions to avoid pollutant emissions remains a key issue, especially as a result of the exhaust gas temperature available for catalytic after treatment, which can vary considerable depending upon the operating conditions of the engines. Recent tests ${ }^{224}$ showed the application of a redox catalyst and concluded that the coolant temperature, the spark timing, and the amount of $\mathrm{H}_{2}$ will affect $\mathrm{NH}_{3}$ and $\mathrm{NO}_{x}$ emissions and the efficiency of this exhaust posttreatment. In a recent European project, Advanced materials and Reactors for ENergy storage tHrough Ammonia (ARENHA), the potential of ammonia as a possible fuel for internal combustion engines (SI engines) and solid oxide fuel cells for passenger cars will be compared to the use of ammonia as a hydrogen carrier.

Up to now, no experimental results are available about ammonia as fuel in mid- or heavy-duty engines, although there are current works in the U.S. going on to deliver novel data that will support further developments. ${ }^{232}$ Only some prospective numerical studies are available. ${ }^{233,234}$ They concluded that the 
critical component in the development of these units will be a high-pressure $\mathrm{NH}_{3}$ injector to deliver sufficiently high flow rates and good atomization, especially as a result of the physical specificities of ammonia (smaller density, different lubricity, corrosivity, etc.).

4.2.2. Marine Sector. In 2018, the International Maritime Organization (http://www.imo.org) defined as a target the reduction of GHG emissions from international shipping by at least $50 \%$ by 2050 compared to 2008 . For this goal, several reports have been released supporting the proposal [for example, those produced by DNV GL (https://www.dnvgl. $\mathrm{com} / \mathrm{maritime} /$ publications/alternative-fuel-assessmentdownload.html), Haldor Topsøe (https://www.topsoe.com/ hubfs / Ammonfuel\%2 0 Report \% 20 Version $\% 2009$. $9 \% 20$ August $\% 203$ update.pdf), etc.]. Conclusions ${ }^{235}$ were drawn on the basis that ammonia will be part of the solution to the decarbonization problem for the shipping industry, mainly as a result of its storage and distribution advantages in comparison to hydrogen (which are based on energy density compared to compressed hydrogen and liquid hydrogen and its volume energy storage). Another advantage for marine applications is that ammonia can be burned in internal combustion engines without $\mathrm{SO}_{x}$ or particulate emissions and limited $\mathrm{N}_{2} \mathrm{O} / \mathrm{NO}_{x}$ emissions in comparison to heavy oils. As a result of these announcements and reports, several maritime companies (such as Man Energy Solutions, Wärtsilä, NYK, Ricardo, etc.) have all started important development projects to help bring ammonia-fueled ships to market for tanker and cruise ships.

Similar to automotive applications, dual-fuel or SI engines are the two main options. Dual-fuel operation modes will be certainly the first to power dual-fuel maritime engines on the basis of previously developed liquid petroleum gas systems. ${ }^{236}$ The main advantages are that the liquid fuel (the more reactive fuel) can be easily adjusted to find the best balance between $\mathrm{CO}_{2}$ reduction, costs, and fuel availability.

However, there are also other technical considerations that need to be addressed when using ammonia. As part of the developments, for example, Man Energy Solutions, which has chosen to have a two-stroke ammonia engine ready by early 2024, will include implementation of selective catalytic reactors to resolve the $\mathrm{NO}_{x}$ emission problem. ${ }^{237}$ Meanwhile, Wärtsilä, who has also announced its support to the zero emission energy distribution at sea (ZEED) program, has plans for initial tests using dual-fuel and spark-ignited gas engines aiming at a release of these systems by 2022. In 2017, C-Job Naval Architecture, Proton Ventures, and Enviu established a consortium to further investigate ammonia as marine fuel through to lab testing, pilot, and evaluation. Initial analyses through a first stage using a dualfuel compression ignition with diesel have been conceived. It is expected that a two-stroke engine and low-speed diesel blends will be optimized using ammonia/hydrogen. Another interesting project for full electrical propulsion ships is based on an ammonia linear engine generator fed with small amounts of hydrogen as the pilot fuel. The project, launched in January 2020 by Newcastle University (Innovate UK TS/P010431/1, EPSRC Impact Acceleration Awards), presents a new concept supported by the cruise ship manufacturer Meyer Werft.

Another alternative to the use of conventional combustion methods when ammonia is employed is homogeneous combustion compression ignition (HCCI). The concept is based on the injection of well-mixed fuel and oxidizer (typically air) streams that are compressed to the point of autoignition. For the use of ammonia, HCCI has been considered in a free-piston linear engine generator with compression ratios (CRs) higher than $22: 1,{ }^{68,238,239}$ and even at CR as high as $40: 1,{ }^{240}$ producing results that denoted the potential of the technique with relatively low emissions.

It must be noted that the HCCI configuration is more attractive for auxiliary power units (APUs) or range extender engine units as a result of their limited load range requirements as a consequence of their fixed engine regimes. For example, under HCCI conditions, it is not possible to use this combustion mode for high loads as a result of the strong pressure peaks generated when hydrocarbon-based fuels are employed. However, for APUs or range extenders, the load can be chosen to provide stable and controllable conditions. In the case of ammonia, as a result of its high ignition delay and limited flammability limits, the problem dissipates for medium-charge conditions with stable, pre-selected configurations, e.g., at very lean mixtures (equivalence ratios of $\sim 0.5$ ). Besides, the use of ammonia will not generate emissions, such as $\mathrm{CO}_{2}, \mathrm{CO}$, unburned hydrocarbons, or soot, making it a very promising technology for these applications.

Further units with various configurations have been recently tested to improve ammonia combustion. Some results from simulation studies concluded that aqueous ammonia can burn in HCCI operating mode as anhydrous ammonia with only a slightly higher compression ratio. Aqueous ammonia solutions may be able to improve health and safety concerns for ammonia as well as remove the need for pressurized tanks, as underlined. $^{241}$ Therefore, further research and development are still required in this field, with the potential of mitigating unburned fuel while reaching high efficiencies with low emissions.

4.2.3. Auxiliary Power. Frigo and Gentili ${ }^{167}$ carried out a study in a small twin engine to evaluate the minimum $\mathrm{H}_{2}$ required at half and full load as a function of the engine regime, with $11-12$ and $6-7 \%$ of $\mathrm{H}_{2}$ (vol \%), respectively. They have been the only research team (known to the authors of this review) to have explored cold-start modes. They, unfortunately, concluded that $75 \% \mathrm{H}_{2}$ is needed at idle speed (identified in their studies at $1880 \mathrm{rpm}$ ), an amount impossible to reach with an on-board ammonia autothermal cracker. This study was performed to consider ammonia as fuel for range extender applications. $^{242}$

Finally, further works were conducted by Cardiff University as part of the program "Green Energy Decoupled" led by Siemens and in collaboration with the Science and Technology Facility Council (STFC) and Oxford University. The program sought to demonstrate the integration of all components into the concept "power-to-ammonia-to-power (P2A2P)", from the use of wind energy to produce green ammonia to the production of energy back to the grid with an IC engine. The program, detailed elsewhere, ${ }^{11}$ enabled Cardiff University to convert a natural gas engine from Mayphil into a hydrogen/ammonia system. The unit operated with blends of $70-30 \%$ (vol) ammoniahydrogen, providing power outputs up to $16 \mathrm{~kW}$ under loaded conditions. $\mathrm{NO}_{x}$ emissions were mitigated to less than 100 ppmv, while $\mathrm{CO}_{2}$ was completely eliminated. It needs to be emphasized that the unit was started with methane to reach hot, stable conditions before adding $\mathrm{H}_{2}$ and $\mathrm{NH}_{3}$. In addition, further improvements in the injection and ignition system were observed, with large amounts of unburned ammonia coming from the exhaust. The research team highlighted the need for better delivery systems, mainly based on the delivery of liquid 
ammonia, to reduce operative problems during cold months. Further works are still ongoing at the facility with the support from other U.K. universities.

It is clear that ammonia-based internal combustion engines will have a major role to play in the following years for the delivery of power using the chemical. Major investment is taking place with considerable research to tackle emissions while reaching high efficiencies and power outputs. It is likely that novel methods of injection and control and a variety of conditions will be implemented in combination with integration with other concepts to commercially deploy these technologies across the globe.

4.3. Gas Turbines. Gas turbines have been employed for many years in the production of energy and propulsion systems. They are mainly composed of three main components, namely, compressor, combustor, and turbine. Dependent upon the application, the compressor pressure ratio (PR) and turbine entry temperature (TET) can vary significantly. For instance, jet engines have considerably higher PR and TET compared to the gas turbines developed for power generation. ${ }^{243}$ Thus, it is important to define the differences between the application and how ammonia can be employed in each case.

4.3.1. Jet Engines. Ammonia was initially considered as a fuel for jet engines by the U.S. Army back in the 1960s. ${ }^{244}$ Subsequently, Verkamp et al., ${ }^{245}$ Pratt, $^{246}$ and Newhall and Starkman $^{247}$ studied various parameters of the ignition and combustion of ammonia in representative gas turbine combustor geometries employed during the 1960s. These studies demonstrated ammonia requiring considerably higher ignition energy compared to the other fuels as well as longer quenching distance and narrower operability limits. ${ }^{246}$ Even though ammonia displayed a slow chemical reaction rate, it was also found that hydrogen embedded in ammonia could enhance flame speeds. It was discovered from these early studies that $28 \%$ dissociation of ammonia to $\mathrm{N}_{2}$ and $\mathrm{H}_{2}$ would deliver the required flame properties to substitute conventional hydrocarbon fuels in gas turbine combustion systems. These early findings propelled the U.S. Army to work with Solar to conduct a feasibility study of new ammonia fueling methods, in terms of liquid injection, vapor, and catalytic combustor. ${ }^{248}$

Liquid ammonia was on trial at the initial phase to replace liquid kerosene in the jet engines. However, this liquid injection trial was immediately disregarded as a result of extremely poor results with respect to combustion performance and power output. The vaporized and catalytic combustion passed the initial phase and were assessed further with regard to highaltitude conditions and various combustor sizes. Multi-staged combustion techniques were also proposed for the first time during this study. Annular combustors were selected for ammonia combustion as a result of their size and ease in fuel flexibility. Different combustor sizes were found to have an impact on the flame shapes as a result of the surface-to-volume ratio quenching. This effect was understood to be mitigatable with a higher wall temperature. The vaporized ammonia combustion technique was evaluated by injecting ammonia vapors upstream and downstream, with the former being superior to maintain the high wall temperature and delivered almost constant efficiencies, ranging from 93.5 to $94.5 \%{ }^{248}$ The catalytic ammonia combustor burned some ammonia and cracked the rest of them to nitrogen and hydrogen and thus needed to be kept at a high temperature, providing efficiencies between 92 and $96 \%{ }^{248}$ Moreover, the catalyst was found to be deteriorated after $30 \mathrm{~h}$ of experiment. These two concepts were further examined using a $250 \mathrm{hp}$ Solar T-350 engine. The major issues of these designs were related to the high ignition temperature requirements of ammonia, and the ignition problem was even severe for the case of vaporized ammonia as a result of the large size of the system and slow chemical reaction rate of ammonia with air. The catalyst in the catalytic converter needed to be preheated to operate optimally; thus, a complete temperature control system was incorporated into the catalytic combustor. Inconel 600 showed no deterioration when used as a catalyst at nozzles, scrolls, or liners in this phase of testing, while Inconel $\mathrm{X}$ and $713 \mathrm{C}$ displayed satisfactory resistance. At the final stage of this study, performances of these two systems fueled by ammonia were compared against JP-4 hydrocarbon fuel. Even at 2.35 times higher flow rate than JP-4, ammonia displayed cooler TET, resulting in a power output gain of between 9 and $13 \%$ for the vapor and catalytic systems, respectively. Moreover, thermal efficiency of these systems displayed about $2.5 \%$ improvement compared to diesel equivalent fuel flow. Another interesting observation of this study was that $\mathrm{NO}_{x}$ formation was found to be directly related to the calorific value of the ammonia blend. The study concluded that ammonia is a satisfactory substitute for the conventional hydrocarbon fuels in simple cycle gas turbines, without any substantial increase in cost or complexity of the pre-existing designs.

The results from these aforementioned studies were employed by the U.S. Army in a UH-1D helicopter and in the CV-7A fixed-wing aircraft. ${ }^{244}$ Different operating weights were evaluated along with multi-fuel capabilities (ammonia and hydrocarbons). Fiberglass and steel-based materials were used to build small and large fuel storage tanks, respectively. Inconel 600 vessels were used as a result of their higher strength and lower corrosive properties, thus suitable for long-distance missions. Low- and high-pressure tank designs with cylindrical and spheric geometry were also studied. Spherical tanks denoted superior capacity with lower gross tank weights, and the fuel/ weight ratio at high pressures and cylindrical tanks were found to be more suitable at a low pressure as a result of their tight insulation, which is vital at cold initial conditions. T53-L-11 and T64-GE-10 engines powered by ammonia showed an encouraging maximum power increase of $15 \%$, a consequence of the required higher flow rates and increased heat capacities of combustion products, mainly hydrogen. Regeneration was also recommended for ammonia, owing to its lower heating value. However, the use of regeneration only decreased the specific fuel consumption of ammonia by $7.7 \%$, compared to a $28.1 \%$ reduction for hydrocarbon fuels at the maximum power. With regard to specific range values, regenerative ammonia showed $34 \%$ lower value than hydrocarbon fuels without regenerative systems. Low-pressure cylindrical tanks displayed 29\% better range than a high-pressure spherical tank system with regenerative ammonia but still only half of the non-regenerative hydrocarbon system. As a result of all of these performance issues as well as complexity in control and fueling systems and predicted higher costs related to development, procurement, and installation, the ammonia-powered jet engine project was withdrawn, recommending further research in several areas.

The NASA Langley Research Center (then NACA Langley Aeronautical Laboratory) also investigated anhydrous ammonia and liquid oxygen fuel blend for the X-15, single-seat, mid-wing monoplane powered by an XLR-99 engine back in 1959. This engine provided up to $\sim 250500 \mathrm{~N}$ thrust. ${ }^{249-251}$ The fuel, stable and with reasonable volumetric energy density, was relatively easy to store under the required working conditions, 

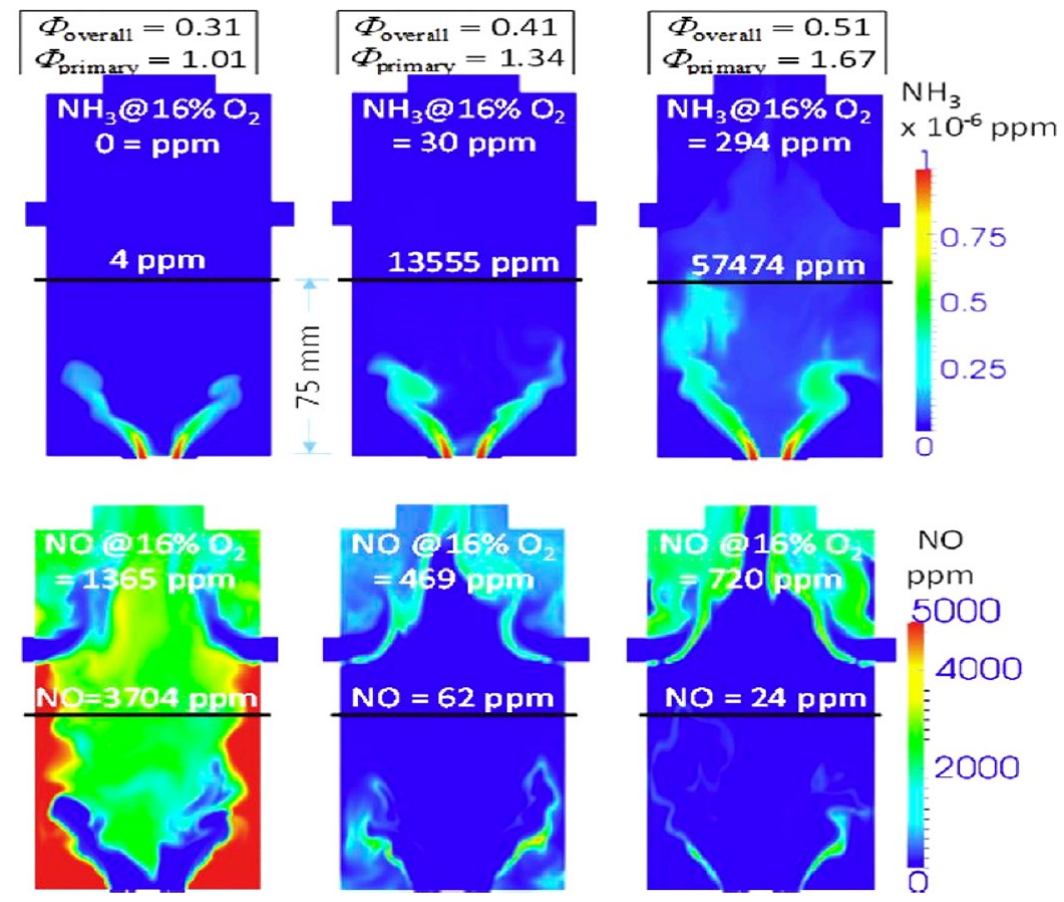

Figure 29. $\mathrm{NH}_{3}$ and $\mathrm{NO}$ distribution in terms of global equivalence ratio in non-premixed $\mathrm{NH}_{3}$ /air flames. This figure was reproduced with permission from ref 188. Copyright 2019 Elsevier.

while cooling from the liquids improved the engine performance. The X-15 powered by three rocket engines flew a total of 199 times at high supersonic speeds (up to 6.7 Mach). This speed was unmatched until the launch of the space shuttle.

To summarize, in the early days, the U.S. Army conducted a substantial amount of research regarding ammonia as an alternative fuel source for jet propulsion. Liquid ammonia was deemed to be non-viable as a result of major drops in combustion efficiency and power output. Vaporized and catalytic ammonia combustion showed promising results in the pursuit of replacing fossil fuels. However, since then, no further application to aerospace applications has been implemented in either military or civil aviation. Some studies currently propose the use of ammonia as a fuel, although the approach is basically numerical, ${ }^{252}$ thus requiring further demonstration.

4.3.2. Stationary Gas Turbines. Ammonia can be stored for long periods without degradation and can also be used as a hydrogen carrier, thus contributing significantly to the hydrogen economy. ${ }^{253,254}$ Several organizations and research groups have recognized the importance of ammonia as an energy vector for future power applications. Research from ENEL in 1991 discovered that enough power could be obtained using ammonia as a fuel with a corresponding high level of $\mathrm{NO}_{x}$ production from fuel-bound $\mathrm{N}_{2}$ pathways. ${ }^{235}$ Several challenges and shortcomings were found by organizations working toward developing ammonia-based combustors, namely, slow kinetics, narrow range of stability, vaporization, and pre-cracking of ammonia. ${ }^{256,257}$ Since then, several studies have been carried out to address these issues, which are summarized in the following subsections.

4.3.2.1. Microscale. Several studies have been conducted by Tohoku University and the National Institute of Advanced Industrial Science and Technology (AIST) in collaboration with industry leaders to demonstrate validity of ammonia as a solo fuel and co-firing with other fuels in micro gas turbine (MGT) power applications. ${ }^{101,177,188,258,259}$ Early research by Iki et al. ${ }^{260}$ looked at the co-firing of kerosene and ammonia in MGT with a diffusion combustion system to enhance stability. The study reported $21 \mathrm{~kW}$ power generation with a 70:30 kerosene/ ammonia blend and proposed the use of selective catalytic reduction (SCR) technology at the post-combustion zone to reduce $\mathrm{NO}_{x}$. Further research ${ }^{258}$ from this group showed 41.8 $\mathrm{kW}$ power output by firing ammonia gas only. 3D simulation studies using LES observed that ammonia/air mixtures can be stabilized over a wide range of conditions of equivalence ratios, pressures, and turbulence intensities up to $39.1 \mathrm{~m} / \mathrm{s}^{261}$ On the basis of these simulation results (Figure 29), the study proposed the use of a two-staged rich-lean combustion system to control $\mathrm{NO}_{x}$ emissions from ammonia-air combustion. ${ }^{188,261}$ Ammonia burning and $\mathrm{NO}_{x}$ productions were found to be related inversely. In the two-staged rich-lean combustors, the primary zone is usually kept in the rich condition, resulting in low $\mathrm{NO}_{x}$ production but a substantial amount of unburned ammonia and hydrogen passing through to the lean zone, where excess air is injected to burn them out, thereby reducing the overall emissions and unburned fuel fraction.

Okafor et al. ${ }^{188}$ developed a low $\mathrm{NO}_{x}$ prototype MGT swirl combustor for two-staged pure ammonia combustion. Numerical modeling conducted in this study showed better stability and lower $\mathrm{NO}_{x}$ and $\mathrm{NH}_{3}$ emissions with inclined ammonia injection. The study reported successful combustion of pure ammonia with $99.5 \%$ combustion efficiency and 42 ppmv $\mathrm{NO}_{x}$ emissions at $31.44 \mathrm{~kW}$. A recent study by Okafor et al. ${ }^{101}$ showed $99.8 \%$ combustion efficiency in a 70:30 (by heat fraction) methane/ammonia blend with 49 ppmv $\mathrm{NO}_{x}, 2$ ppmv $\mathrm{CO}$, and $\approx 0$ ppmv $\mathrm{N}_{2} \mathrm{O}, \mathrm{HCN}$, and $\mathrm{NH}_{3}$ emissions at the same twostaged MGT combustor. The study also observed that co-firing of ammonia and hydrocarbons with the ammonia mole fraction in the binary fuel varying from 0.30 to 0.50 in a single-staged combustor results in double $\mathrm{NO}$ production compared to pure 
ammonia combustion. The production of $\mathrm{O}, \mathrm{H}$, and $\mathrm{OH}$ radicals from hydrocarbons enhanced $\mathrm{NO}$ productions.

To summarize the advancement of microscale stationary gas turbines to date, progresses have been made in terms of ammonia as a solo fuel and co-firing with conventional fossil fuels in various power ratings and turbulence intensities. Twostaged rich-lean combustion systems have been proposed and demonstrated to reduce $\mathrm{NO}_{x}$ emissions and the unburned fuel fraction. Further investigation is necessary regarding liquid ammonia injection to reduce the cost and startup time for gas turbines at this scale.

4.3.2.2. Utility Scale. Cardiff University's research group has been heavily engaged with the application of ammonia blends in industry-representative swirl burners for several years. ${ }^{161,182,262-264}$ Ammonia was assessed initially by co-firing with methane and hydrogen. ${ }^{182,262}$ The complex nature of premixed ammonia blends was seen from the initial results, highlighting the intricate patterns of ammonia oxidation in the presence of carbon molecules and the flame speed dependency upon the equivalence ratio, eventually leading to the full extinction of the flame. The study concluded that the lowest $\mathrm{NO}_{x}$ and $\mathrm{CO}$ production was at an equivalence ratio of $\sim 1.10$. $^{182}$ Later on, Xiao et al. ${ }^{265,266}$ carried out the reduction of pre-existing ammonia/hydrocarbon mechanisms to have good accuracy with the experimental results and reduce the computational time at the same time. The LES work by Honzawa et al. ${ }^{267}$ demonstrated the use of these novel models, enabling the use of non-adiabatic conditions, which delivered more representative and realistic results than those obtained in the literature.

Because ammonia has a considerably low flame speed and hydrogen has quite a high flame speed compared to natural gas flames and hydrogen can be obtained from the cracking of ammonia, hydrogen was doped with ammonia to increase the flame speed and stabilize the flame. Results from this study ${ }^{269}$ demonstrated that a high hydrogen content in an ammoniahydrogen blend is highly unstable, with a very narrow operability range as a consequence of the high reactivity of hydrogen. Eventually, the hydrogen concentration was reduced to $30 \%$ (vol) at $40 \mathrm{~kW}$ power to operate at fuel-rich stable conditions with wide operability limits and combustion performance. On the basis of these findings, further investigations ${ }^{268}$ were conducted both numerically and experimentally to obtain the optimum equivalence ratio of $\sim 1.2$ for a 70:30 (vol \%) ammonia/hydrogen blend with low $\mathrm{NO}_{x}$ and unburnt fuel emissions. The results from numerical calculations depicted a direct correlation between $\mathrm{OH}$ radicals and $\mathrm{NO}_{x}$ formation, with a high presence of amidogen $\left(\mathrm{NH}_{2}\right)$ radicals at the post-flame zone, thus decreasing $\mathrm{NO}_{x}$ formations under elevated inlet temperature conditions. The results also showed enhancement of the chain-terminating reaction $\mathrm{NH}_{2}+\mathrm{NO} \rightarrow \mathrm{H}_{2} \mathrm{O}+\mathrm{N}_{2}$ at rich conditions and high inlet temperature conditions. Recently, Pugh et al. ${ }^{270}$ showed $\mathrm{NH}_{2}$ radicals to be a good marker for NO consumption in rich ammonia flames. However, elevated inlet temperature conditions increase $\mathrm{NO}_{x}$ formation through the thermal pathways (Figure 30), leading the study to recommend further studies to find a balance between thermal and fuel $\mathrm{NO}_{x}$ production and to ensure that unburnt ammonia is dissociated at the post-flame zone. Further numerical work by Xiao et al. ${ }^{161}$ revealed inverse relationships between pressure and $\mathrm{NO}_{x}$ production, which led the experimental work ${ }^{190}$ to be carried out at elevated pressure conditions. The results agreed with the numerical results, ${ }^{161,181,263}$ and thickening of the reaction zone

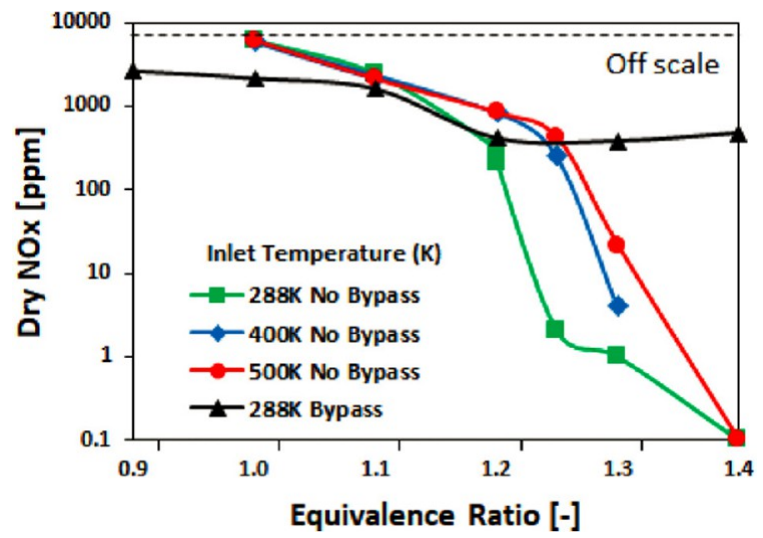

Figure 30. Dry $\mathrm{NO}_{x}$ productions with an increasing temperature. This figure was reproduced with permission from ref 268. Copyright 2018 Elsevier.

at the high pressure conditions was observed, which led to a further increase in reactivity and reduction in $\mathrm{NO}_{x}$ formations. However, the downside of elevated pressure conditions were found to be an increase in unburned ammonia concentrations by a few hundred ppmv.

High thermal $\mathrm{NO}_{x}$ production at the elevated temperature conditions led Pugh et al. ${ }^{190}$ to investigate the impact of humidification on $\mathrm{NO}_{x}$ formation via the reduction of the temperature and further $\mathrm{OH}$ radical productions while consuming the $\mathrm{O}$ radical via the reaction $\mathrm{O}+\mathrm{H}_{2} \mathrm{O} \leftrightarrow 2 \mathrm{OH}$, thereby restricting thermal NO production via $\mathrm{N}_{2}+\mathrm{O} \leftrightarrow \mathrm{NO}+$ $\mathrm{N}$, as observed by Law. ${ }^{271}$ However, the increase in $\mathrm{OH}$ and $\mathrm{N}$ productions can also enhance the formation of $\mathrm{NO},{ }^{272}$ while reduction in $\mathrm{O}$ radicals may also decrease $\mathrm{NO}$ formation by limiting $\mathrm{NH}_{2}$ radical oxidation to $\mathrm{HNO}$ and $\mathrm{NH}$ to $\mathrm{NO}$. The results from this campaign showed a reduction in $\mathrm{NO}$ formation, owing to the decrease in temperature $(\sim 150 \mathrm{~K})$ and increased production of $\mathrm{NH}_{2}$ radicals as a result of the presence of $\mathrm{OH}$ radicals at the post-flame zone. Furthermore, high hydrogen concentrations were observed in the process, giving opportunities to consume the molecule in a second lean combustion stage, thereby raising efficiency and power output. Recent work by Pugh et al. ${ }^{264}$ investigated the effect of reactant humidification for $\mathrm{NO}_{x}$ reduction in both premixed and diffusion ammonia-air flames. The authors reported limited possible humidification ( $3 \% \mathrm{vol}_{\mathrm{vo}} \mathrm{H}_{2} \mathrm{O}$ of reactant composition) and reduction in $\mathrm{NO}$ with increased $\mathrm{H}_{2} \mathrm{O}$ for the premixed case. However, both flame configurations provided increased $\mathrm{NH}_{3}$ concentrations at the exhaust, thereby increased $\mathrm{NO}$ production in staged combustion configuration.

Xiao et al. ${ }^{273}$ also looked at changes in ammonia flame behavior with oxy-combustion by carrying out some numerical simulation. No major changes in NO production were found under elevated pressures $(\sim 1.7 \mathrm{MPa})$ as the oxygen content was increased from 21 to $40 \%$, with a slight increase in NO emissions mainly as a result of the increase in the temperature. The study observed increasing pressure having an inhibiting effect on $\mathrm{NO}$ productions under oxygen-enriched conditions, predicting below 7 ppmv NO productions by all of the mechanisms under highly pressurized oxygen-enriched conditions. The study opened up another possible combustion mode of ammoniabased systems, requiring further research.

Positive results from the staged combustion research in MGT by Okafor et al. ${ }^{101,188}$ described earlier led to studies looking at rich-quench-lean (RQL) combustion systems for power 
generation. Recent work by Pugh et al. ${ }^{270}$ suggested the efficacy of secondary air staging and its sensitivity to the primary flame behavior. Ammonia-hydrogen-air blends were found to produce most favorable results under rich conditions $(\varphi=$ 1.2), employing hydrogen as a pilot. However, non-premixed ammonia-air flames running at elevated inlet temperature and pressure conditions also produced low $\mathrm{NO}$ and unburnt ammonia at the exhaust (Figure 31). Mashruk et al. ${ }^{274}$

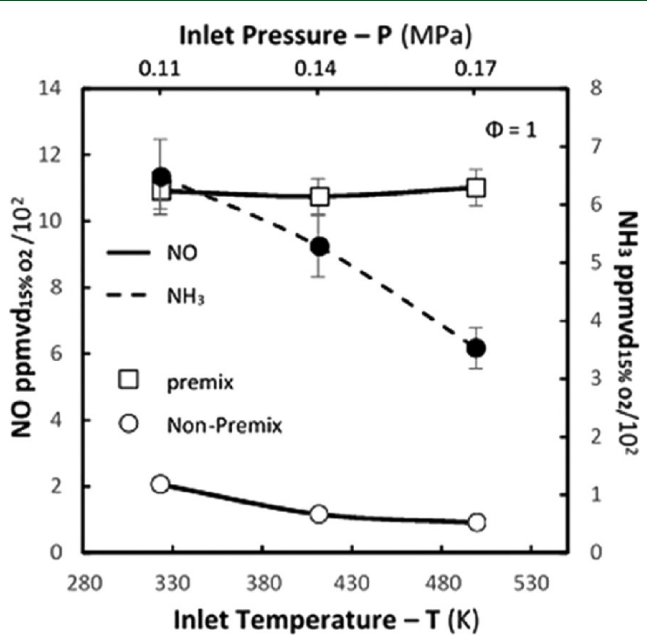

Figure 31. Sampled $\mathrm{NO}$ (empty) and $\mathrm{NH}_{3}$ (filled) emissions for each $\mathrm{NH}_{3}$-air flame with increasing inlet conditions. This figure was reproduced with permission from ref 270. Copyright 2020 Elsevier.

investigated an industry-scale humidified RQL system $(\sim 10$ MW power) numerically using five different mechanisms from the literature to assess the differences in results (Table 5). The study theoretically demonstrated that the use of the humidified RQL system fueled with ammonia-hydrogen (70:30 in vol \%) can produce flue gases consisting of $99.97 \%$ water, nitrogen, and oxygen, with the consumption of most reactive emissions and $\mathrm{NO}_{x}$ emissions, and $15 \% \mathrm{O}_{2} \sim 100$ ppmv at industrial large power generation.

Very recently, Okafor et al. ${ }^{275}$ successfully carried out direct stable combustion of liquid ammonia spray for the first time as both a sole fuel source and co-combustion with methane in a novel single-stage swirl combustor with preheated air at $500 \mathrm{~K}$. Stable spray formation was maintained by cooling the liquid ammonia, while flame stability was enhanced by preheating swirling air. Combustion efficiency and flame stability were further improved by co-firing with methane, giving a wider range of stability $(\Phi=0.66-1.37)$ when the heat percentage of liquid ammonia based on LHV in the fuel was fixed to $70 \%$. Emission results for liquid ammonia and methane co-combustion displayed trends similar to those in gaseous $\mathrm{CH}_{4}-\mathrm{NH}_{3}-$ air combustion, opening the possibility of two-staged combustion employment for liquid ammonia spray.

Overall, preliminary investigations of $\mathrm{CH}_{4}-\mathrm{NH}_{3}$ co-combustion showed the lowest emission production at slightly rich conditions. To eradicate $\mathrm{CO}_{2}$ emissions, $\mathrm{NH}_{3}$ was blended with $\mathrm{H}_{2}$ to match up the flame speed of conventional fossil fuels, leading to the determination of the $70: 30_{\mathrm{vol}} \% \mathrm{NH}_{3} / \mathrm{H}_{2}$ blend with a wide stability range and low emissions. Later on, inverse relationships between pressure and $\mathrm{NO}_{x}$ production were found, prompting investigations at elevated conditions where reaction zones thickened to allow for increased reactivity, thus lowering $\mathrm{NO}_{x}$ formation. Humidified conditions for reactants have also

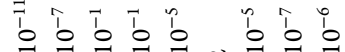

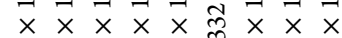

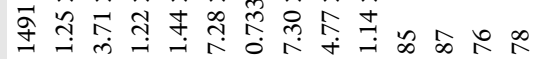

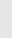

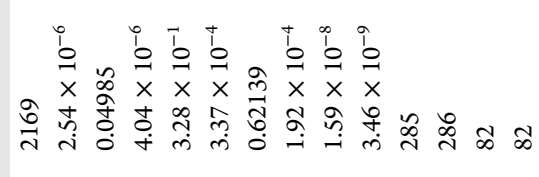

후의

$x \times \vec{x} \times \vec{m} \times \vec{x}$

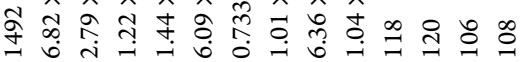

io

$x a x \times x m^{2} \times x \times$

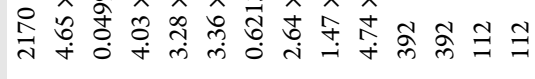

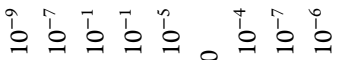

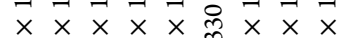

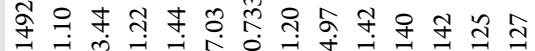



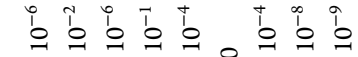

$x \times \bar{x} \times \dot{x} \times x$

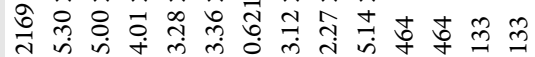

인

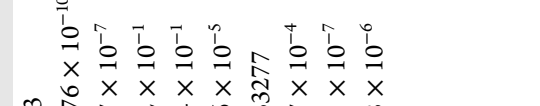

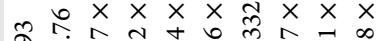

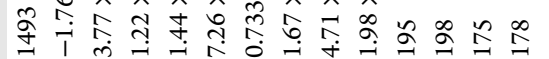

(1)

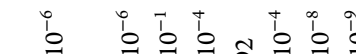

$x \quad \vec{x} \times \vec{x} \cong \vec{x} x \vec{x}$

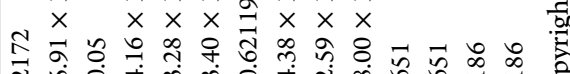

视

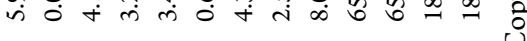

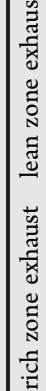

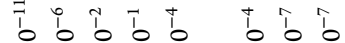

$\times \times \times \times \times \cong \times x \times$

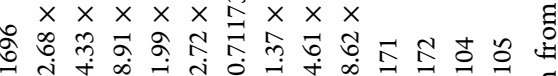

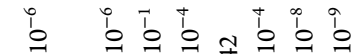

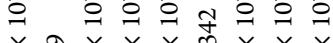

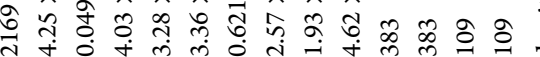

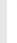

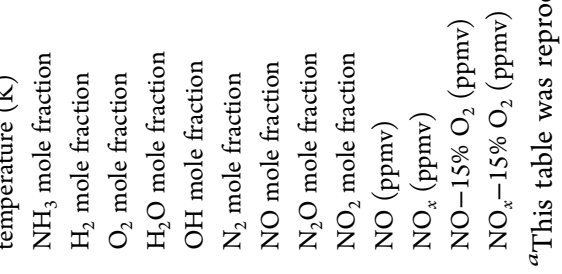




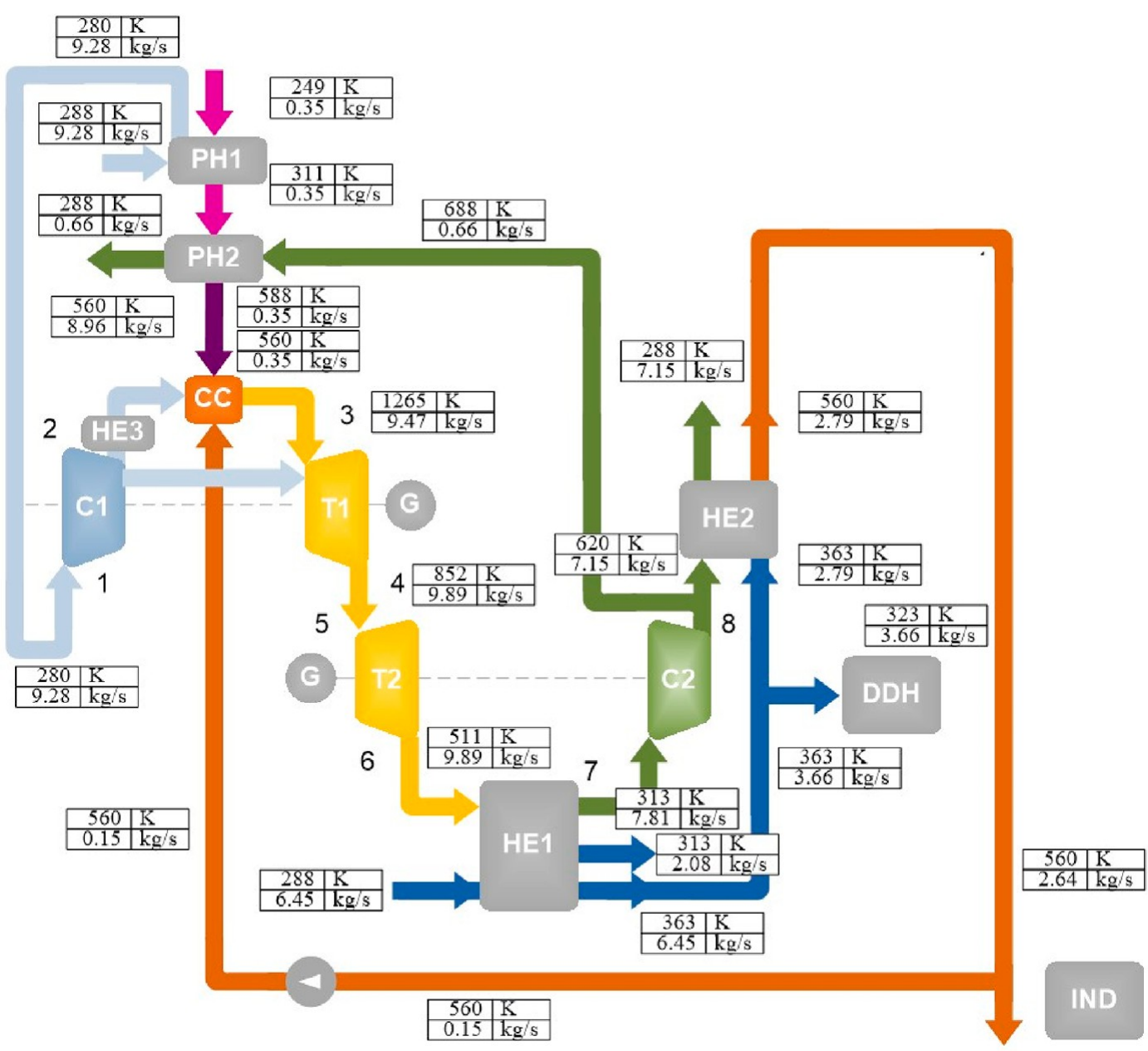

Figure 32. Ammonia trigeneration cycle with thermodynamic parameters. This figure was reproduced with permission from ref 278 . Copyright 2020 Elsevier.

been introduced to reduce thermal $\mathrm{NO}_{x}$ productions at elevated inlet temperatures by reducing the production of $\mathrm{O}$ radicals. $\mathrm{H}_{2}$ production increased as a byproduct of humidified conditions, leading to the possibility of two-staged combustion system employment in these types of $\mathrm{NH}_{3} / \mathrm{H}_{2}$ combustion. Finally, recent advancement in the liquid ammonia combustion has shown to reduce cost and startup times required for gas turbines fueled with otherwise gaseous ammonia. Considerable amounts of investigations by different research organisations are ongoing for further improvements of ammonia combustion in terms of better understandings of fundamental flame properties, emission reductions, and combustion efficiency improvement.

4.3.2.3. Cycle Analyses. Keller et al. ${ }^{276}$ performed cycle analyses using rich ammonia-fueled combined cycles using a gas turbine and a heat-recovery heat exchanger via exhaust gas recirculation (EGR). Hydrogen produced at the exhaust of a gas turbine was used to produce extra power in a boiler with heat recuperation that increases steam production for a combined steam cycle. The cycle demonstrated $\sim 64 \%$ efficiencies at $\varphi=$ 1.0, but lower $\mathrm{NO}_{x}$ production at slightly rich conditions with a cycle efficiency of $61 \%$ was achieved. However, this analysis did not consider the heating and preparation of the fuel, which would require high energy quantities and would thus reduce the cycle efficiency. ${ }^{277}$ Valera-Medina et al. ${ }^{268}$ initially assessed the impact of Brayton cycles using a Rolls-Royce Allison 501-KB5 engine. Calibration results from this study were in good agreement with the underpinning data, with relative errors for power and cycle efficiency both below $1 \%$.

Further work by Gutesa-Bozo et al. ${ }^{277}$ observed a decrease in dilution by decreasing the airflow rates, raising the final efficiencies of a single Brayton cycle very close to a single methane-fueled unit, 29 and $30 \%$, respectively. This study also raised the awareness of the potential impact of flue gases $(\mathrm{pH}$ values of $\sim 8.5$ ) on materials using ammonia/hydrogen blends. Later on, the research group ${ }^{279}$ demonstrated efficiencies above $55 \%$ by incorporating a humidified ammonia/hydrogen blend in a combined cooling, heating, and power (CCHP) cycle. Calculations for this cycle considered fuel preheating, steam preparation, and compressed air precooling. Very recently, Gutesa-Bozo et al. ${ }^{278}$ incorporated the CCHP cycle in an industry-scale system (Figure 32), fueled by 70:30 (vol \%) ammonia/hydrogen in a humidified RQL combustion system, running at $9.67 \mathrm{bar}$ and $960 \mathrm{~K}$ inlet conditions with $\varphi=1.2$. The study generated cycle efficiency of $\sim 60 \%$ with $\sim 4970 \mathrm{~kW}_{\text {th }}$ excess heat power after preparation of fuel and steam. Although this efficiency does not match current fossil-fueled similar cycle efficiencies, it shows the way forward toward $\mathrm{CO}_{2}$-free power generation.

In terms of large demonstrable projects, IHI Corporation, Japan, used an IM270 simple cycle gas turbine to evaluate the use of ammonia co-fired with natural gas. ${ }^{280}$ A two-stage combustion system was applied, incorporated with SCR 
technology to reduce $\mathrm{NO}_{x}$ production. Experiments produced up to $2 \mathrm{MW}_{\mathrm{e}}$ power using a $20 \%$ mixing ratio of ammonia. $\mathrm{CO}_{2}$ emissions decreased linearly with an increase of ammonia, while $\mathrm{NO}_{x}$ emissions were raised up to $287 \mathrm{ppmv}$, which was brought down to 10 ppmv by the SCR unit. Overall, the system required less natural gas with an increase of 5\% ammonia injection to keep the required power output and generator-end efficiency. Further works on the applicability of the concept and its demonstration can be found elsewhere, ${ }^{11}$ where more details of similar attempts show that ammonia can be effectively employed for the production of power at a large scale without incurring larger than permitted emission profiles.

To conclude, cycle efficiencies reduced slightly to accommodate lower $\mathrm{NO}_{x}$ productions for ammonia-powered systems, but a single-stage Brayton cycle was shown to have similar efficiencies for both $\mathrm{CH}_{4}$ and $\mathrm{NH}_{3} / \mathrm{H}_{2}$ blends. Further, cycle efficiencies improved significantly by incorporating CCHP cycle philosophies in an industry-scale system powered by a humidified $\mathrm{NH}_{3} / \mathrm{H}_{2}$ blend. Demonstration of ammoniamethane co-combustion displayed promising results by maintaining competitive power outputs and efficiencies as fossil-based fuels while reducing emissions.

4.4. Fuel Cells. Fuel cells have a high potential to generate electricity from electrochemical reactions of hydrogen and oxygen supplied from external sources continuously. ${ }^{281,282}$ Fuel cells show very high electrical efficiency $(\sim 60 \%)$, which can be increased using combined heat and power (CHP) systems. Although they do not employ combustion processes for the release of energy, chemical reactions, in some cases similar to those previously presented, take place in these devices, thus deserving a special place in the study of ammonia as an energy vector.

Fuel cells are categorized mainly on the type of electrolytes, e.g., polymer electrolyte membrane fuel cell (PEMFC), solid oxide fuel cell (SOFC), molten carbonate fuel cell (MCFC), alkaline fuel cell (AFC), etc. Among the different types of fuel cells, proton-conducting fuel cells (PCFCs), SOFCs, and AFCs can be used for power generation from ammonia.

Hydrogen is the most used fuel for the fuel cells, but it has a low volumetric density of $0.0813 \mathrm{~g} \mathrm{~L}^{-1}$ at ambient temperature and pressure $(300 \mathrm{~K}$ and $0.1 \mathrm{MPa}) .{ }^{283,284}$ Thus, hydrogen needs high-pressure storage. The alternative solution can be to store and transport the molecule in the liquid state, which will increase its volumetric energy density as well as transportability. Carbonbased fuels, e.g., methanol and ethanol, are the most common hydrogen-rich alcohols, where hydrogen is chemically bonded with carbon. ${ }^{285,286}$ Because the carbon-based fuels generate carbon dioxide during the synthesis process and in the power conversion, these fuels are not very attactive for fuel cell applications. As previously stated, ammonia is an interesting alternative to the use of carbon-based fuels as a result of the absence of carbon in its molecules. Ammonia generates nitrogen during the three-phase reaction in fuel cell anodes with an additional loop around the $\mathrm{N}_{2}$ cycle. Nitrogen can be easily generated from air to feed the chemical process, usually employing the Haber-Bosch process, as presented in section 2. After energy consumption, $\mathrm{N}_{2}$ is released back to the atmosphere, which makes the overall system completely carbonfree. ${ }^{287}$ Another advantage to use ammonia $\left(\mathrm{NH}_{3}\right)$ as a fuel for electricity generation using fuel cells is based on its relatively low cost and reduced flammability when compared to other fuels. Any leakage of $\mathrm{NH}_{3}$ is easily detectable from its odors, making it safer than hydrogen, ${ }^{288-290}$ a point discussed in posterior sections.

Ammonia can be used directly in SOFCs and direct ammonia fuel cells (DAFCs). Polymer electrolyte membrane fuel cells (PEMFCs) need reforming of the gas into nitrogen and hydrogen before hydrogen is fed into the fuel chamber. As a result of the operation principle of fuel cells, the presence of nitrogen in the fuel stream only acts as a diluent of hydrogen and does not generate any pollutant nor cause significant performance decay, which allows fuel cells to operate with ammonia.

4.4.1. Proton-Conducting Fuel Cells (PCFCs). PCFCs can be categorized in two different types, i.e., PEMFCs and protonconducting solid oxide fuel cells (PC-SOFCs). PEMFCs work at low temperature ranges $(360-490 \mathrm{~K})$ using pure hydrogen as fuel. The problem in using ammonia is that it may poison the $\mathrm{Pt} /$ $\mathrm{C}$ anode catalyst and react with the acidic membrane electrolytes. Therefore, ammonia itself may not be a suitable fuel for PEMFCs but can be used as the source for hydrogen production. Produced hydrogen can be used as PEMFC fuel for power generation. ${ }^{291}$ Usually, hydrogen from methane reforming is employed in most of these units.

Concurrently, the overall cost of the production of ammonia could be reduced using alternative hydrogen sources. $\mathrm{NH}_{3}$ can be produced from $\mathrm{N}_{2}$ and $\mathrm{HO}$ using Nafion membranes as the proton-conducting electrolyte and $\mathrm{Ru} / \mathrm{C}$ as the cathode at 360 K. ${ }^{292}$ Unfortunately, during the industrial production of $\mathrm{NH}_{3}$, the used catalyst can be easily poisoned by oxygen and sulfur, which increases the cost of preparation and purification of the feeding gas. Thus, further research exists in this area.

4.4.1.1. Polymer Electrolyte Membrane Fuel Cell (PEMFC). Ammonia can be used as a hydrogen source for some of fuel cells. For example, it can be employed in vehicles. In PEMFC vehicles, the acceptable ammonia concentration in hydrogen is about 0.1 ppmv. Li-exchange X-type zeolite ( $\mathrm{Li}-\mathrm{X})$ can be used for high-purity hydrogen production. ${ }^{293}$ Promising results were reported using $\mathrm{NH}_{3}$ fuel in both $\mathrm{H}^{+}$and $\mathrm{O}^{2-}$ solid electrolyte cells. ${ }^{294}$ High-temperature polymer electrolyte fuel cells (HTPEMFCs) also show promising results using ammonia fuel. Furthermore, low-temperature polymer electrolyte membrane fuel cells (LT-PEMFCs) use the traditional Nafion membrane electrolyte previously mentioned. Nafion can be substituted with a phosphoric-acid-doped polybenzimidazole (PBI) membrane, which operates at moderate temperature, i.e., in the temperature range of $490-470 \mathrm{~K}^{295}$

Tolerance to impurities normally increases with the temperature; e.g., CO tolerance in LT-PEMFC is only a few parts per million volume (ppmv), a level that increases up to $3 \%$ in HTPEMFCs. HT-PEMFCs are an interesting technology that can employ methanol reforming as a result of this higher tolerance to impurities. The effects of different impurities (i.e., $\mathrm{CO}, \mathrm{CO}_{2}$, and $\mathrm{CH}_{3} \mathrm{OH}$ ) have been found to provide satisfactory tolerances for single cells and stacks. ${ }^{296,297}$ However, HT-PEMFCs were not very popular with ammonia as a fuel. Recently, technological developments have led to strong interest in HT-PEMFCs as a result of the possibility of using ammonia as a fuel. ${ }^{298}$

4.4.1.2. Proton-Conducting Solid Oxide Fuel Cell (PCSOFC). In PC-SOFC, hydrogen moves through the porous anode to the anode-electrolyte interface, where oxidation reactions occur to generate protons. ${ }^{299-301}$ In PC-SOFC, $\mathrm{NH}_{3}$ decomposes to hydrogen and nitrogen in the anode side according to thermodynamic equilibrium at specific temperatures and pressures. Nitrogen acts as an inert diluent. Protons move from the anode to cathode through the dense electrolyte 


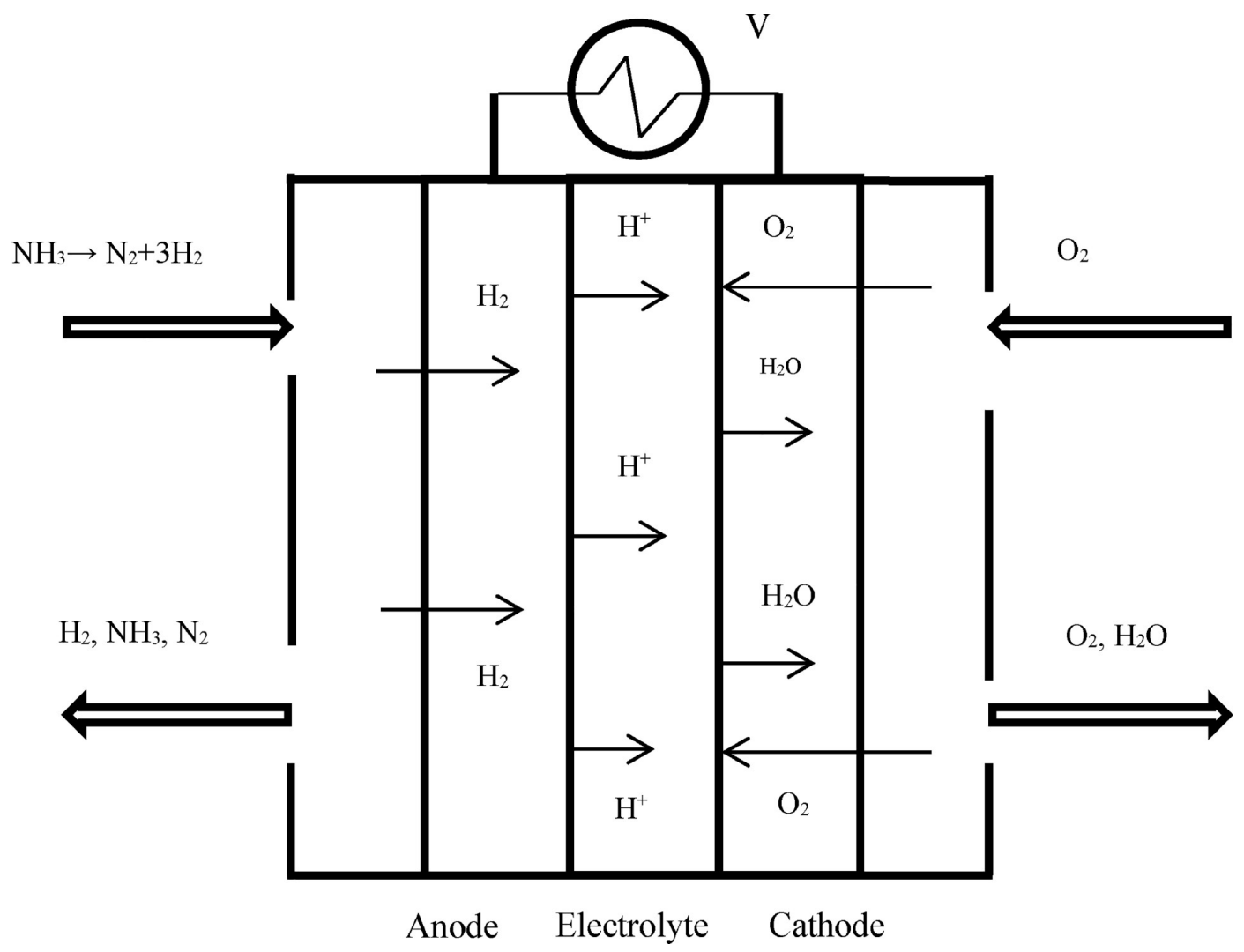

Figure 33. Schematic diagram of the ammonia-fed PC-SOFC. This figure was reproduced with permission from ref 288 . Copyright 2016 Elsevier.

and react with oxygen in the cathode compartment. Water is produced in the cathode side, where it exits the cell as steam.

This is a major advantage of proton-conducting fuel cells because hydrogen is not produced at the anode side and is not diluted by the steam. For example, gadolinium-doped barium cerate, a proton-conducting solid electrolyte, was used in an intermediate-temperature direct ammonia fuel cell reported by Pelletier et al. ${ }^{302}$ A schematic diagram of the direct ammonia-fed SOFC with a proton-conducting electrolyte is shown in Figure 33. Various materials have been found to improve the process. For example, doped-barium cerate or doped-barium zirconate have been found to be high proton conducting at intermediate temperature ranges with good stability in carbon dioxide and humidified environments. ${ }^{288}$ Fuel cells using these electrolytes conduct protons as well as prevent oxygen mobility from the cathode to the anode while stopping the contact with the anode fuel or catalysts, thereby inhibiting $\mathrm{NO}_{x}$ formation. The direct oxidation of ammonia to produce nitric acid with co-production of electricity in a high-temperature SOFC was first reported by Farr and Vayenas, ${ }^{303}$ work that is still ongoing elsewhere.

Doped $\mathrm{BaCeO}_{3}$ - and $\mathrm{BaZrO}_{3}$-based PC-SOFCs are good options to avoid the formation of nitric oxide ${ }^{304,305}$ when using ammonia. The anodic reaction for this is as follows:

$$
2 \mathrm{NH}_{3}-6 \mathrm{e}^{-} \rightarrow \mathrm{N}_{2}+6 \mathrm{H}^{+}
$$

Thermodynamic analyses on PC-SOFC and oxide-ion-conducting SOFC show that the theoretical performance of the ammonia-fed PC-SOFC is a superior choice for the current generation. ${ }^{306}$ However, the high operating temperatures and long startup time is not suitable to use direct ammonia SOFC for power in electrical vehicles, although it might be used as an auxiliary power unit for lorries, coaches, planes, or ships. Oxide- ion-conducting SOFCs operate indirectly oxidizing fuel by thermally decomposing ammonia to extract hydrogen, which will be electrochemically oxidized in the fuel cell. In these units, the concentration of nitrogen gas will depend upon the thermodynamic equilibrium of the ammonia decomposition reaction at the given temperature and pressure. The reversible potential can also be reduced as a result of the dilution of the hydrogen concentration by inert nitrogen, which will impact this parameter. Furthermore, oxygen from air can move across the cathode layers to the cathode-electrolyte interface, thus reducing the oxygen ion. Then, the oxygen ions moves through the electrolyte to react with hydrogen located at the anode, hence producing a cycle to generate electricity continuously until ammonia and oxygen are supplied.

4.4.2. Alkaline Fuel Cell (AFC). Alkaline membrane fuel cells transfer hydroxide ions through the electrolyte during the fuel cell operation. ${ }^{307}$ The most common type, $\mathrm{KOH}$ solution electrolyte ammonia fuel cells, were first discovered in $1968 .^{308}$ The working temperature of molten hydroxide $\mathrm{NaOH} / \mathrm{KOH}$ fuel cells using ammonia fuel is between 470 and $720 \mathrm{~K}$. The highest power density of these units, i.e., $40 \mathrm{~mW} \mathrm{~cm}^{-2}$ at $720 \mathrm{~K}$, was observed using a nickel catalyst on both cathode and anode sides. ${ }^{309,310}$ However, the durability of direct ammonia alkaline fuel cells (operating with $\mathrm{KOH}$-based electrolytes) is a major issue as a result of the reaction between hydroxide electrolytes and $\mathrm{CO}_{2} \cdot{ }^{311}$ Ammonia has also been tested as a fuel for alkaline membrane fuel cells using a nickel anode and $\mathrm{MnO}_{2}$ cathode.

Similar to other fuel cells, these ammonia fuel cells also have three main sections: cathode, electrolyte, and anode. The cathode section is fed with oxygen, mainly from air, which combines with water $\left(\mathrm{H}_{2} \mathrm{O}\right)$ and electrons $\left(\mathrm{e}^{-}\right)$to produce hydroxides $\left(\mathrm{OH}^{-}\right)$that move through the electrolyte, as shown 
in reaction $\mathrm{R} 3$. In the anode section, the supplied ammonia $\left(\mathrm{NH}_{3}\right)$ reacts with hydroxides $\left(\mathrm{OH}^{-}\right)$producing nitrogen, water, and electrons. These electrons move through electrical load to provide power, as shown in reaction $\mathrm{R} 4$. The overall reaction of the ammonia fuel call system is shown in reaction $\mathrm{R} 5$.

$$
\begin{aligned}
& \mathrm{O}_{2}+2 \mathrm{H}_{2} \mathrm{O}+4 \mathrm{e}^{-} \rightarrow 4 \mathrm{OH}^{-} \\
& 2 \mathrm{NH}_{3}+6 \mathrm{OH}^{-} \rightarrow \mathrm{N}_{2}+6 \mathrm{H}_{2} \mathrm{O}+6 \mathrm{e}^{-} \\
& 4 \mathrm{NH}_{3}+3 \mathrm{O}_{2} \rightarrow 2 \mathrm{~N}_{2}+6 \mathrm{H}_{2} \mathrm{O}
\end{aligned}
$$

Interestingly, at room-temperature operation, the power density observed in these units has been very low as a result of the low catalytic activity of the electrode materials. The catalytic activity of $\mathrm{Pt} / \mathrm{C}$ was found to be better than $\mathrm{Pt}-\mathrm{Ru} / \mathrm{C}$ and $\mathrm{Ru} / \mathrm{C}$ in alkaline membrane fuel cells.

One of the drawbacks of the alkaline fuel cell is the reaction between alkaline membranes with $\mathrm{CO}_{2}$ to form $\mathrm{CO}_{3}{ }^{2-}$ ions, which reduce the $\mathrm{OH}^{-}$ion conductivity. Moreover, $\mathrm{K}_{2} \mathrm{CO}_{3}$ or $\mathrm{Na}_{2} \mathrm{CO}_{3}$ precipitates can also form as a result of the reaction with $\mathrm{CO}$ in air. The crossover of ammonia through the polymeric membrane electrolyte may reduce the open-circuit voltage and efficiency. Furthermore, the oxidation of diffused ammonia in the cathode section may generate toxic NO. ${ }^{312}$ Other materials and electrolytes have also been assessed to improve these effects. For example, direct $\mathrm{NH}_{3} \mathrm{BH}_{3}$ fuel cells based on a $\mathrm{NaOH}$ electrolyte were first reported by Zhang et al. ${ }^{313}$ Direct ammonia borane fuel cells based on an alkaline membrane electrolyte have also been demonstrated by Zhang et al. ${ }^{314}$ A study of the use of ammonia borane as a fuel in an alkaline fuel cell showed a power density of $315 \mathrm{~mW} \mathrm{~cm}^{-2}$ at ambient pressure and near ambient temperature, $^{315}$ thus showing continuous improvement and promise for the use of these fuel cells employing ammonia as a fuel.

4.4.3. Direct Ammonia Solid Oxide Fuel Cell (DA-SOFC). DA-SOFCs using YSZ electrolytes and platinum electrodes were first introduced by Wojcik et al., which showed a maximum power density of $50 \mathrm{~mW} \mathrm{~cm}{ }^{-2}$ at $1070 \mathrm{~K}^{316}$ When these units are employed, it is possible to avoid the formation of $\mathrm{NO}_{x}$ in DASOFC systems producing only $\mathrm{N}_{2}$ gas as the nitrogen-containing product. $\mathrm{NO}_{x}$ are not produced by the decomposition of ammonia at the Ni-YSZ anode. ${ }^{317}$ However, there are still many unanswered questions requiring further research to improve the YSZ-based fuel cell performance before full commercialization.

Unfortunately, the ionic conductivity of YSZ decreases considerably and is not suitable as an electrolyte at moderate temperatures. Therefore, different electrolytes have been tried to overcome the obstacles and for better overall performance and stability at intermediate temperatures. ${ }^{318-320}$ High-temperature SOFCs show the best performance for DA-SOFC because ammonia can be used directly. The anodic reaction in SOFC using ammonia as a fuel follows the reactions below

$$
\begin{aligned}
& 2 \mathrm{NH}_{3}+5 \mathrm{O}_{2}^{-} \rightarrow 2 \mathrm{NO}+3 \mathrm{H}_{2} \mathrm{O}+10 \mathrm{e}^{-} \\
& 2 \mathrm{NH}_{3}+3 \mathrm{NO} \rightarrow 5 / 2 \mathrm{~N}_{2}+3 \mathrm{H}_{2} \mathrm{O}
\end{aligned}
$$

Among these reactions, reaction R5 is the rate-limiting step because of the slow diffusion of $\mathrm{O}_{2}$ through the electrolyte; therefore, a small amount of $\mathrm{NO}$ will be produced at the anode side. These $\mathrm{NO}_{x}$ can exceed $60 \%$ concentration. ${ }^{321}$

Furthemore, DA-SOFC based on an oxide-ion-conducting $\mathrm{Ce}_{0.8} \mathrm{Sm}_{0.2} \mathrm{O}_{1.9}$ electrolyte can be used at intermediate temperature ranges while showing high conductivity. The difference in power density is very small between SOFC with ammonia or hydrogen as fuels.

4.4.4. Equilibrium Potential and Efficiency of the Ammonia-Fed SOFC. Under open-circuit conditions, the equilibrium potential (voltage) of any fuel cell is related to the partial pressures of the species involved in the electrochemical reaction, which can be written as

$$
E=E^{\circ}+\frac{R T}{2 F} \ln \left[\frac{P_{\mathrm{H}_{2}}\left(P_{\mathrm{O}_{2}}\right)^{1 / 2}}{P_{\mathrm{H}_{2} \mathrm{O}}}\right]
$$

where

$$
E^{\circ}=-\frac{\Delta G}{n F}
$$

where $n$ is the number of electrons involved per electrochemical reaction, $F$ is the Faraday constant, $G$ is the change in Gibbs free energy, $E^{\circ}$ is the voltage at standard pressures, and $P_{\mathrm{H}_{2}}, P_{\mathrm{H}_{2} \mathrm{O}}$, and $P_{\mathrm{O}_{2}}$ are the partial pressures of hydrogen, steam, and oxygen, respectively. $P_{\mathrm{H}_{2} \mathrm{O}}$ refers to the partial pressure of $\mathrm{H}_{2} \mathrm{O}$ at the anode side of an oxide-ion-conducting SOFC, while the parameters refer to the cathode side for PC-SOFC.

During the operation of SOFC, the maximum electrical work $(W)$ can be calculated as

$$
W=q E
$$

where $q$ is the electrical charge passing through the outer circuit to give electric power. The efficiency of the ammonia-fed SOFC can be calculated as the ratio of the maximum electrical work $(W)$ extracted from the SOFC to the maximum conversion of the chemical energy of the fuel fed to the SOFC 322,323

$$
\eta(\%)=\frac{W}{-\Delta H^{\circ}} \times 100
$$

where $H^{\circ}$ is the lower heating value of the fed ammonia under standard conditions $\left(320.1 \mathrm{~kJ} \mathrm{~mol}^{-1}\right)$. The fuel utilization is the ratio of consumed fuel (ammonia) and oxidant (oxygen), whereas the oxygen utilization is based on the ratio of the feeding fuel and oxidant.

4.4.5. Effects of Electrode/Electrolyte Thickness and Operation Temperature. The conductivity of a solid electrolyte is inversely proportional to the thickness of the electrolyte but increases exponentially with the temperature. Therefore, when the electrolyte thickness is reduced, the same proton or oxide ion flux is attainable at a lower temperature. Reducing the thickness, on the other hand, may reduce mechanical strength and stability. An electrode material should also provide an acceptable high electronic conductivity. The catalytic reaction rate normally increases with the temperature. At high temperatures, the catalytic activity and, thus, the Faradaic efficiency also increase.

Ammonia has been used in various laboratories all over the world under a wide range of operating temperatures (670-1170 K) and with different types of electrolytes. ${ }^{287,288}$ For example, current efforts demonstrate that the performance of ammoniafed SOFCs will approach that of hydrogen-fed SOFCs if it is possible to decompose ammonia very quickly to hydrogen and nitrogen, which will, in turn, increase the temperature. High operating temperatures will also allow for complete decomposition of ammonia and, hence, high fuel utilization because the rate of ammonia decomposition varies with the temperature. For example, the reaction rate increases from about $1.0 \mathrm{~mol} \mathrm{~m}^{-3} \mathrm{~s}^{-1}$ at a temperature of $670 \mathrm{~K}$ to $3.6 \times 10^{7} \mathrm{~mol} \mathrm{~m}^{-3} \mathrm{~s}^{-1}$ at a 
temperature of $\sim 1170 \mathrm{~K}^{324,325}$ This effect is a consequence of the slow decomposition rates of ammonia at $670 \mathrm{~K}$, converting only $10 \%$ of ammonia in the anode chamber. Thus, the operation at these conditions is too low, and unless a very active catalyst can be developed, this will be detrimental for these units at those conditions. However, a considerable amount of $\mathrm{NH}_{3}$ can decompose at $770 \mathrm{~K}$, which might be a suitable operation point for PC-SOFCs. Full decomposition of ammonia has been proven at $870 \mathrm{~K}^{289}$

However, the drawback is that SOFCs show lower efficiency and equilibrium potential as the temperature increases. The reduced equilibrium potential results in lower theoretical efficiency. It should be mentioned that the overpotentials of SOFC decrease with increasing temperature. Thus, the optimal operating temperature depends upon both the reversible potential and the overpotentials. Hence, electrochemical modeling is critical for the quantification of the overpotentials involved in the operation of ammonia-fed SOFCs.

In comparison, the equilibrium potential of the SOFC $-\mathrm{H}$ is much greater than that of the SOFC-O when various electrolytes are used in ammonia-fed SOFCs. Therefore, the efficiency of PC-SOFCs becomes higher than that of the oxideion-conducting SOFC. The difference in efficiency between the PC-SOFC and oxide-ion-conducting SOFC also becomes larger as the fuel utilization increases. At typical fuel utilization of about $80-90 \%$, the efficiency of the ammonia-fed PC-SOFC is $\sim 10 \%$ higher than that of the oxide-ion-conducting SOFC. ${ }^{322,326}$ High current densities can be achieved by employing an anodesupported arrangement of the fuel cell for direct ammonia-fed SOFC operating at high temperatures (i.e., $1070 \mathrm{~K}$ ) and atmospheric pressure. This can explain the decrease in ohmic overpotential as a result of a reduction in the electrolyte thickness.

Thermodynamic analyses indicate that the peak power density of ammonia-fed SOFCs based on proton-conducting electrolytes is $20-30 \%$ higher than that of SOFCs based on $\mathrm{O}^{2-}$ conducting electrolytes, which is mainly attributed to the higher concentration of hydrogen at the anode in all cases. ${ }^{327}$ It is believed that the durability of the ammonia-fed SOFC can be improved if a redox-stable anode is employed in the SOFC stack. The voltage decreases rapidly for both types of fuel cells at high current densities, owing to the low concentrations of reactants at the triple-phase boundary.

Thus, as observed, there are still many points that require further research in terms of durability, power capacity, material treatment, purity of the feeding stream, etc. Although the future will clearly have a niche for ammonia-fed fuel cells, research in the area needs to ensure that flexibility, low emissions, and durability are prioritized for fast deployment of these devices.

\section{SAFETY ASPECTS}

5.1. Corrosion. This section presents the problems that ammonia generates on corrosion and material wearing. Metals, alloys, plastics, rubber, etc. are addressed in this section. For the analysis, ammonia has been considered as an energy vector, thus requiring storage, distribution, and utilization at medium/high temperatures, thus ensuring that the chemical energy of the molecule is fully employed. Because the background on the use of ammonia for fueling and energy distribution is very recent and incipient, this work has taken as a reference the expertise gained in other industries, combined with the reference that ammonia products can be produced in these materials, leading to some meaningful conclusions.
Ammonia, as previously depicted, is mainly produced for fertilizing applications. However, the chemical is also used in the production of textiles, cleaning products, plastics and explosives, refrigerant, deNO $\mathrm{N}_{x}$ ing and decarbonizing agents, and, now, as a potential fuel. ${ }^{8}$ Also, it has been previously stated that ammonia can be either gaseous or liquid, with the latter being the most common for distribution and storage purposes.

When ammonia is directly injected into the soil as a fertilizer, the equipment complexity increases. However, it is also clear that the efficiency of the process increases, with much lower losses caused by cleaning or evaporation of the chemical to produce amonium or urea. Thus, this application has led to vast quantities of information and data relevant to the solution of problems inherent to its storage and distribution.

Vast amounts of this work, most of it produced in the U.S., where ammonia has been directly employed for such purposes, detail materials and practices for the proper handling of ammonia. For example, storage tanks are usually manufactured using carbon steels, which are also employed in ducts, connections, and valves, hence working as modular systems. In terms of sealings, the material employed is usually Buna $\mathrm{N}$ instead of conventional rubber, which suffers degradation when in contact with ammonia. ${ }^{328}$ It is feasible to also protect steel using dip coating, usually recommended with alloys, such as $\mathrm{ZnAlMg}$. Given the high sensitivity of corrosion under low stress, copper and its alloys are usually forbidden when ammonia is employed. Thus, brass components should be avoided, even at ammonia concentrations as low as 50 ppmv.

Ammonia, in both its liquid and gaseous phases, is not particularly corrosive to ferrous materials because its $\mathrm{pH}$ fluctuates between 9.0 and 9.4. However, it is appropriate to emphasize that these materials passivate under alkaline conditions (Figure 34).

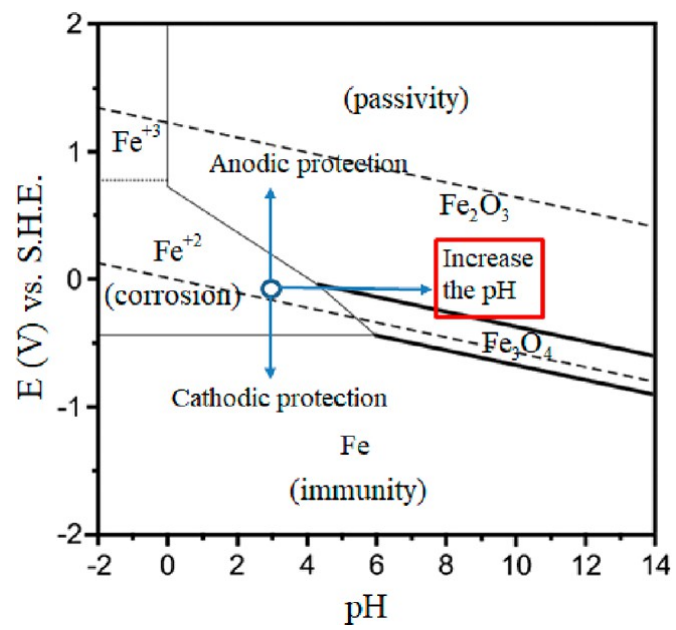

Figure 34. Pourbaix diagram, with passive conditions that iron can reach with a $\mathrm{pH}$ increase. This figure was reproduced with permission from ref 329. Copyright 2019 IOP.

Actually, it has been common practice to employ ammonia, which is highly soluble in water and forms an alcaline solution of ammonium hydroxide, ${ }^{330}$ in boilers to increase $\mathrm{pH}$, thus decreasing corrosion in these systems. Ammonia, usually injected into the water-steam circuit increases $\mathrm{pH}$, which usually tends to be around 7.0-7.6. Furthermore, solutions that include ammonia limit the dissolution of metal ions produced during corrosion, hence drastically decreasing the equilibrium potential 


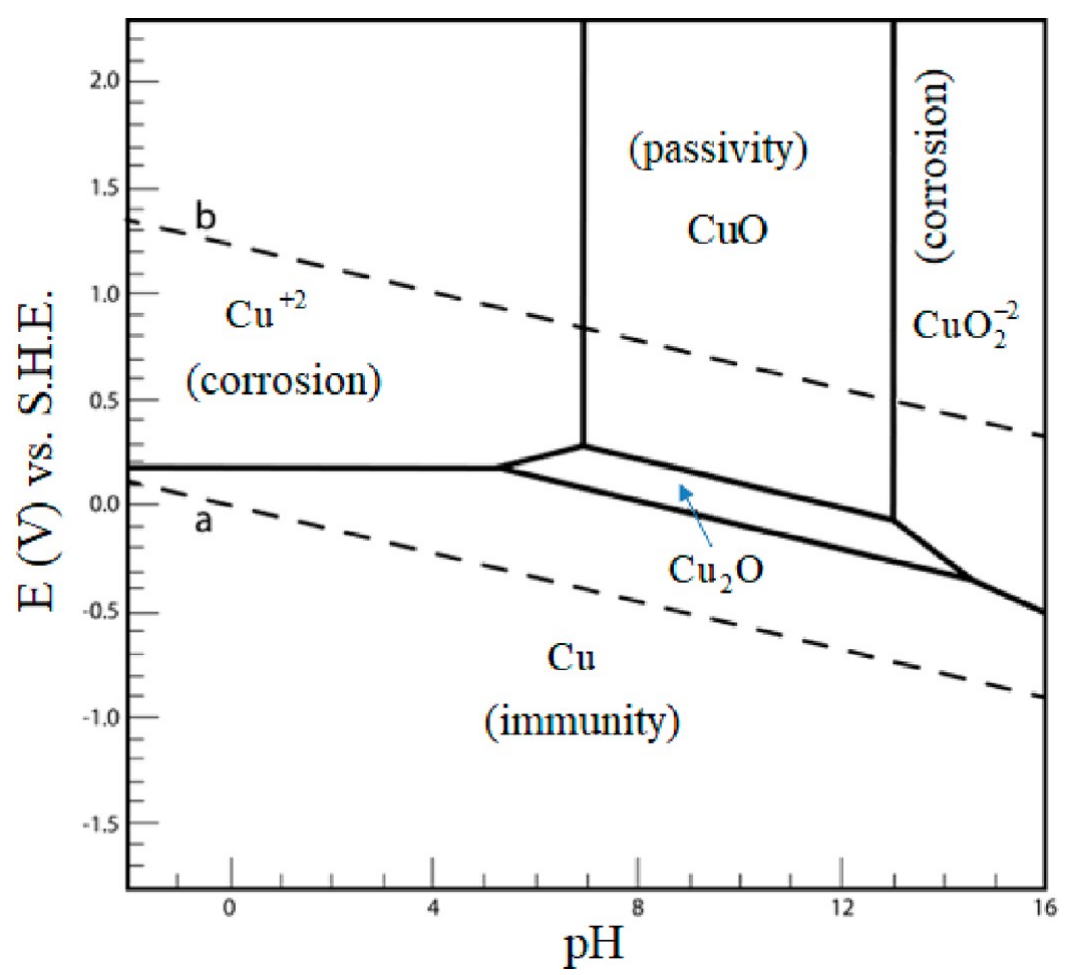

Figure 35. Pourbaix diagram for copper. It is clear that passivity can be reached by incrementing $\mathrm{pH}$, even under conditions where corrosion can occur. This figure was reproduced with permission from ref 333. Copyright 2021 Elsevier.

with respect to the standard potential, changing thermodynamic conditions within the system. ${ }^{331}$

Interestingly, liquid or diluted ammonia in water would be seen as a minor corrosion inconvenience. However and according to the analyzed material, this condition can change, potentially showing different types of corrosion that can range from uniform corrosion, galvanic corrosion, cracks, intergranular fracture, cavitation, corrosion under stress, hydrogen embrittlement, etc. Therefore, each case will depend upon the operating conditions and the material under consideration.

Gaseous ammonia and its corrosion is a very important topic when the chemical is in the presence of carbon oxides. This is a consequence of its impact on these materials, because just 5 ppmv can start forming amonium carbonate, which has severe corrosion effects. This phenomenon can lead to hydrogen embrittlement at high pressures $(15.0-20.0 \mathrm{MPa})$ and temperatures $(>770 \mathrm{~K})$. However, as a result of the lower corrosivity at ambient temperature, carbon steels are conventionally used with microalloys for the manufacturing process of ammonia storage tanks. However, it has been shown that some corrosion tends to apper under low stress. The problem manifests in welding joints, which usually present residual stress, a situation that is commonly produced during solidification and cooling of the material. Furthermore, high hardness and the presence of impurities favor corrosion failures under stress. The problem can be effectively mitigated by alleviating residual stresses (via a thermal process $)$ and adding small quantities of water $(\sim 0.2 \%)$, which inhibit the corrosion process. Moreover, under cold temperatures $(240 \mathrm{~K})$ usually employed for storage, steel presents some minor tendency to corrosion under low stress, a problem known as stress corrosion cracking (SCC). ${ }^{11}$ This corrosion occurs as a consequence of the anodic dissolution caused by the rupture of thin layers of iron oxides. This happens at very specific eletrochemical potentials, which lead to cracks that contain many materials and corrosion products, increasing the problem. Furthermore, oxygen under these conditions modifies the corrosion potential, leading to larger cracks. ${ }^{332}$ Dynamic loads and the fatigue that they cause can also influence the growth of these cracks.

Because the presence of $\mathrm{CO}_{2}$ also favors corrosive processes, it is usual to employ inhibitors that remove poisonous $\mathrm{CO}_{2}$ as well as biocides, enabling the use of coatings based on epoxic resins on both metallic and non-metallic surfaces.

Ammonia storage can be conducted at low temperatures $(240$ $\mathrm{K}$ ) or medium pressures of 1.0-2.0 $\mathrm{MPa}$ (depending upon atmospheric temperatures), thus enabling the use of ammonia as a fuel. Usually, handling of ammonia at low temperatures is easier, with good material behavior. Also, even at higher pressures (i.e., $1.12 \mathrm{MPa}$ at $300 \mathrm{~K}$ ), liquid ammonia is easy to handle, with pressures similar those of car tires. Thus, its use as a potential fuel has been gaining more followers. Although not much is known about the use of ammonia at high temperatures (i.e., combustion temperatures of $\sim 1900 \mathrm{~K}$ ), some works conducted by the U.S. Army during the 1960s showed that materials, such as Inconel, were capable of withstanding those atmospheres, thus increasing the versatility of the molecule as a fueling vector. ${ }^{11}$

However, there are cases where ammonia can be contaminated by other molecules. Should an ammonia tank be contaminated with $\mathrm{HCl}$, the corrosion attack would be severe, leading to pitting toward the material. ${ }^{330}$ As mentioned, ammonia can act as protector for some steels while being detrimental to copper alloys. Furthermore, ammonia is not corrosive to carbon steels under atmospheric conditions, although its behavior can change with the addition of $\mathrm{CO}_{2}$, $\mathrm{H}_{2} \mathrm{O}, \mathrm{O}_{2}$, etc., as previously depicted.

Interestingly, under ideal conditions, copper alloys would not be attacked by some ammonia solutions, because $\mathrm{pH}$ values 
higher than 7.0 lead to passivity of the material (Figures 35 and 36). Copper has the characteristic of being a noble material,

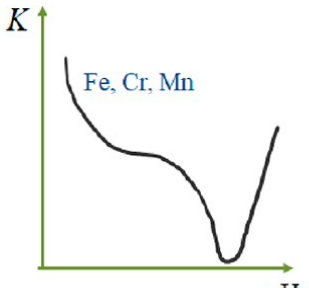

$\mathrm{pH}$

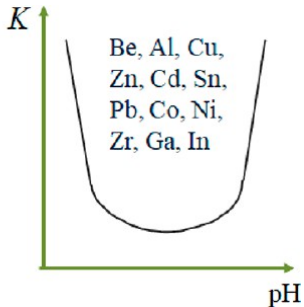

$\mathrm{pH}$
Figure 36. $\mathrm{pH}$ influence on corrosion resistance of different materials. $K$ $=$ relative corrosion velocity. This figure was readapted with permission from ref 330. Copyright 2017 Technion.

highly resistant to many atmospheres. However, as any other material, there are situations in which the right condition can detonate aggresive corrosion. According to Pourbaix diagrams, which are static and consider $\mathrm{pH}$ without considering the type of solution, it is seen that copper at relatively basic $\mathrm{pH}$ and the right potential that could start corroding it accesses a passivity zone. This zone is characterized by very stable corrosion; thus, oxides will form slowly without fast material detachment. These oxides can actually protect some materials.

However, most conditions between ammonia and copper are unfavorable to the latter. The effect is caused by ions that detach from the material as a corrosion product. These ions are highly soluble in ammonia and oxygen within the solution, thus leading to the increase in corrosion speed and the aggresive attack to the material. The reaction is as follows:

$$
\begin{gathered}
4 \mathrm{Cu}_{(\mathrm{s})}+8 \mathrm{NH}_{3(\mathrm{aq})}+\mathrm{O}_{2(\mathrm{~g})}+2 \mathrm{H}_{2} \mathrm{O}_{(\mathrm{l})} \\
\rightarrow 4\left[\mathrm{Cu}\left(\mathrm{NH}_{3}\right)_{2}\right]_{(\mathrm{aq})}^{+}+4 \mathrm{OH}^{-}{ }_{(\mathrm{aq})}
\end{gathered}
$$

In a great variety of cases, the presence of water (i.e., from atmosphere) or $\mathrm{NH}_{4} \mathrm{OH}$ leads to an aggresive corrosion attack of copper materials, creating these compounds that are soluble in water, as previously stated. Furthermore, the presence of stress under humidified conditions also leads to SCC seasonal cracking. For example, solutions with 1 ppmv can produce seasonal cracking in brass components. This problem can be eliminated by alleviating residual stresses through annealing after the manufacturing process.

Similar to copper alloys, zinc tends to be attacked by ammonia, which is the reason for recommending the use of $\mathrm{ZnAlMg}$ alloys for dip galvanizing of steels that are in contact with ammonia. In the case of aluminum, as long as copper is not present, the material shows good resistance, which has been quantified in $<0.0013 \mathrm{~mm} /$ year wearing. ${ }^{331}$

Another important parameter to consider is that steel can present corrosion when storing ammonia if it has been coldformed or welded without posterior stress release. Similarly, SCC can appear in air contaminated with ammonia. Although this problem is known and can be controlled inmediately after inspection, this has not been a continuous barrier for both human and material safety, a point that needs to be carefully addressed when thinking about ammonia as a potential fuel.

The main contaminant for ammonia is oxygen. Only 1 ppmv of oxygen is enough to start corrosion under low stress. These phenomena are intensified when high resistance steel $(>450$ $\mathrm{MPa})$ is employed and the pieces are cold-formed or welded. Steel with $\mathrm{Ni}$ and CrMo is also very susceptible to this effect.
Thus, the areas of the tank or storage elements in contact with gaseous ammonia can be attacked. Concurrently, the presence of $0.1 \%$ (weight) of water can reduce the problem, inhibiting the presence of oxygen in concentrations up to $200 \mathrm{ppmv}$.

For non-metallic materials, like rubber or plastics, ammonia in its liquid state can attack them, causing wearing. Therefore, it is common to employ Buta N (neoprene) for sealings where ammonia is used.

As previously stated, although there are other applications, fuel-based systems are still under scrutiny to determine the impact of ammonia blends (e.g., with methane, hydrogen, and syngases) in combustion systems at high temperatures or fuel cells, with a great variety of materials that may react differently to different ammonia concentrations (as previously stated in section 4). Therefore, further research is required before ammonia is fully employed as a fuel, thus enabling high integrity in future systems.

5.2. Fuel: Risks. One of the biggest concerns of using ammonia is its toxicity. The point is constantly raised as majorly detrimental for the use of the molecule as a commercial fuel, especially considering that ammonia is directly compared to other fuels, such as gasoline or diesel, i.e., largerly available and handled easily by untrained people. In comparison to these fuel sources, ammonia presents several constraints at the conditions that would economically and efficiently supply energy for vehicles and industrial processes. The vapor pressure of ammonia makes it highly volatile at atmospheric conditions, thus leading to unwanted effects of health and safety purposes when coming in contact with it. Furthermore, fast release of compressed ammonia can lead to condensation and droplet formation, forming clouds of cold ammonia at the ground level that are a critical concern to distributors and users.

However, the industry has worked with ammonia for more than 150 years since the development of Mond complexes capable of producing ammonia at a large, industrial scale. ${ }^{334}$ Furthermore, the total amount of deaths related to ammonia are usually in the single digits in countries with strict regulations, ${ }^{8}$ with incidents that can be controlled with appropriate training and support from emergency services. Thus, the question to answer is "would ammonia be (or not be) a safe molecule to be used as a fuel for automotive, aerospace, marine, and power purposes?”.

Ammonia exposure limits are regularly set between $25 \mathrm{ppmv}$ ( $8 \mathrm{~h}$ long-term exposure) and $35 \mathrm{ppmv}$ [short-term exposure; the U.S. usually specifies a $30 \mathrm{ppmv}$ value based on United States Environmental Protection Agency (U.S. EPA) acute exposure guideline level (AEGL) guidelines]. ${ }^{335}$ However, there are certain regulations like the U.S. EPA AEGL that have also set a series of values at which the exposure to ammonia can be lifethreating (i.e., 2700 ppmv for a 10 min exposure), establishing some guidance for industrial purposes. The problem with some of these numbers is that once converted to shorter periods, the values reach thousands of parts per million in concentration. An example is presented in the literature citing the emergency response planning guideline (ERPG) values used by the American Industrial Hygiene Association. ${ }^{336}$ The particular value used for the case study, set at $1500 \mathrm{ppm}$ for life-treatening exposure to most individuals over $1 \mathrm{~h}$, can be recalculated to a value of $12000 \mathrm{ppm}$ in a 5 min exposure window using methodologies such as that proposed by Michaels in 1999. ${ }^{337}$ The likelihood of an individual to be exposed in a controlled environment to those massive concentrations is extremely low, thus posing the issue of how these numbers really can be applied 
to regular situations. Michaels recognized that risk acceptability is a subjective judgment and is very difficult to define scientifically, although science can inform on the matter.

Further studies perfomed with animals have also confirmed these assertions, with thresholds that are sublethal to humans. The use of mice, cats, guinea pigs, etc. ${ }^{338,339}$ have all been tried to correlate the human response to ammonia exposure, showing values that can reach up to $35957 \mathrm{ppm}$ over 5 min exposures, values that are extremely difficult, if not impossible, to assess with human individuals. Moreover, it has been recognized that, different from some of these species, humans are unlikely to cannulate in the respiratory tracts, thus reverting to nose breathing to scrub ammonia or use wet cloths to ameliorate the toxic atmosphere. ${ }^{337}$

To address these issues, regulations and safety guidelines keep progressing. For example, the ERPG values have been refined using some Wistar rats, ${ }^{340}$ showing departure points of 1500 or $500 \mathrm{ppm} / \mathrm{h}$ (for non-lethal and medium values, respectively). However, as stated, legislation values are still well below these limits, denoting the gap of understanding in terms of the real impact that ammonia can have on humans (i.e., healthy, with disabilities, presenting pulmonary issues, etc.). Thus, further research is required on the matter, perhaps similar to studies that have approached it with voluntary candidates to provide further data on the subject. ${ }^{341}$

Impacts that also have to be considered are those to potential users when filling up tanks. Although emissions of ammonia can be smelled, thus alerting individuals, spills can be more damaging in the immediate scenario. Skin impacts, also important to notice, are a critical matter while handling ammonia. Ammonia evaporates at fast rates under atmospheric conditions. Thus, contact with liquid ammonia can cause severe freezing burns, adding to the already damaging impact that ammonia has on cells as a result of its high affinity to water (hence dehydrating and killing living tissue) ${ }^{342}$ (Figure 37).

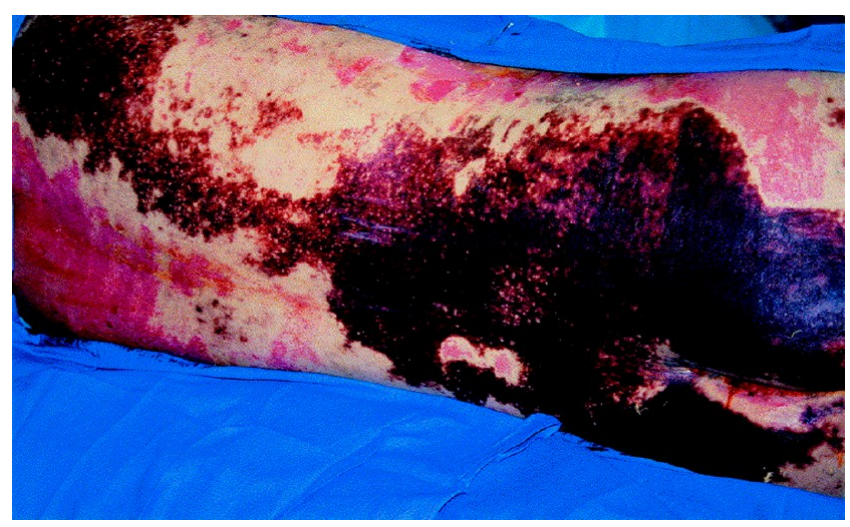

Figure 37. Exposure of skin to anhydrous ammonia. This figure was reproduced with permission from ref 342 . Copyright 2000 Elsevier.

Further precautions need to be taken regarding the impact on marine life. The threshold level of harm varies by organism but is generally measured in milligrams per liter (parts per million). The second reality is that the relationship between the gross quantity of ammonia released in a spill and the harm that is inflicted is far from straightforward. The phenomenon is caused by the different forms that ammonia can have in water: native, un-ionized ammonia $\left(\mathrm{NH}_{3}{ }^{0}\right)$, and ammonium ion $\left(\mathrm{NH}_{4}{ }^{+}\right)$. The primary vector of harm is $\mathrm{NH}_{3}{ }^{0}$. This is because living cells are set up to exchange ions with their environment. They are not equipped to manage the small, neutral (non-ionic) $\mathrm{NH}_{3}{ }^{0}$ molecule, which can passively diffuse across the membranes of, for example, fish gills. ${ }^{335}$ This will become an important parameter, especially in marine applications that are currently looking to use $\mathrm{NH}_{3}$ as a fueling source.

On this basis, it must also be emphasized that ammonia handling has improved over the years, with developing economies following more advanced guidances that have reduced incidents and that can potentially lead to a real global deployment of ammonia as an energy vector. As an example, comparisons have also been drawn with hydrogen. As previously stated, one of the main issues with hydrogen is its handling. Although it is common practice to handle hydrogen at high pressures and low temperatures, these practices are mainly employed in facilities with vast knowledge and under very strict regulations. Thus, the use of ammonia, a chemical with a highly developed distribution infrastructure, presents an easier scenario than hydrogen for fueling purposes.

A recent case study developed by Crolius et al. ${ }^{335}$ shows a comparison for the use of ammonia and hydrogen in power applications. The study approaches the extension denoting the impact of indoor clouds through small $\left(0.25 \mathrm{~mm}^{2}\right)$ and large $\left(2.5 \mathrm{~mm}^{2}\right)$ leaks (Figure 38). It is evident that ammonia has a smaller distribution, with hydrogen even showing high peaks of concentration with high ventilation rates. Thus, the basis of the "pure hydrogen" economy exposes a critical challenge in terms of health and safety, with the release of a molecule with such a high diffusivity. Furthermore and as stated previously, the broad flammability limit of hydrogen compared to ammonia emphasizes this fact. Therefore, ammonia presents an interesting case to support hydrogen replacement, although some other parameters need to be taken into consideration.

Further precautions that also need to be considered relate to $\mathrm{NO}_{x}$ and particulate matter. Nitrogen oxides play a major role in the pollution of the planet, with a greenhouse warming potential (GWP) of almost 300 that of $\mathrm{CO}_{2} \cdot{ }^{343}$ Thus, this pollutant is not only one of the biggests concerns in using ammonia for its impacts toward equipment and cycle efficiency but mainly as a large contributor to climate change. Also, $\mathrm{NO}_{x}$ can lead to the formation of ozone $\left(\mathrm{O}_{3}\right)$ at the ground level, acid rain (via formation of nitric acid), and particulate matter (via formation of secondary particulates, such as ammonium nitrate), increasing eutrophication and deteriorating health and agriculture. $^{344} \mathrm{NO}_{x}$ have also detrimental impacts on human health, causing problems ranging from allergic responses to respiratory issues. Estimates suggest that $\sim 23500$ premature deaths are caused by the release of these emissions in the U.K. alone, $^{345}$ with higher concentrations even being lethal. As for particulate matter, the topic has been addressed extensively by envornmental scientists and geophysicists. The primary problem with fine particles $(<2.5 \mu \mathrm{m})$ is that these can diffuse through skin and lungs, reaching organs and bloodstreams in animals and humans. From the formation of ammonium nitrate $\left(\mathrm{NH}_{4} \mathrm{NO}_{3}\right)$ and ammonium sulfate $\left[\left(\mathrm{NH}_{4}\right)_{2} \mathrm{SO}_{4}\right]$, ammonia plays a critical role in the formation of these species, thus contributing to the reduced air quality in regions where ammonia emissions are extensive. ${ }^{346}$ The topic not only concerns fertilizing applications but also $\mathrm{NO}_{x}$ abatement technologies in catalytic systems employed primarily in diesel engine exhaust devices. Further discussions are detailed in the next section.

5.3. Emissions and Environmental Impact. Besides the corrosion and fuel safety aspects, there are several other safety aspects that need to be considered, including the environmental 

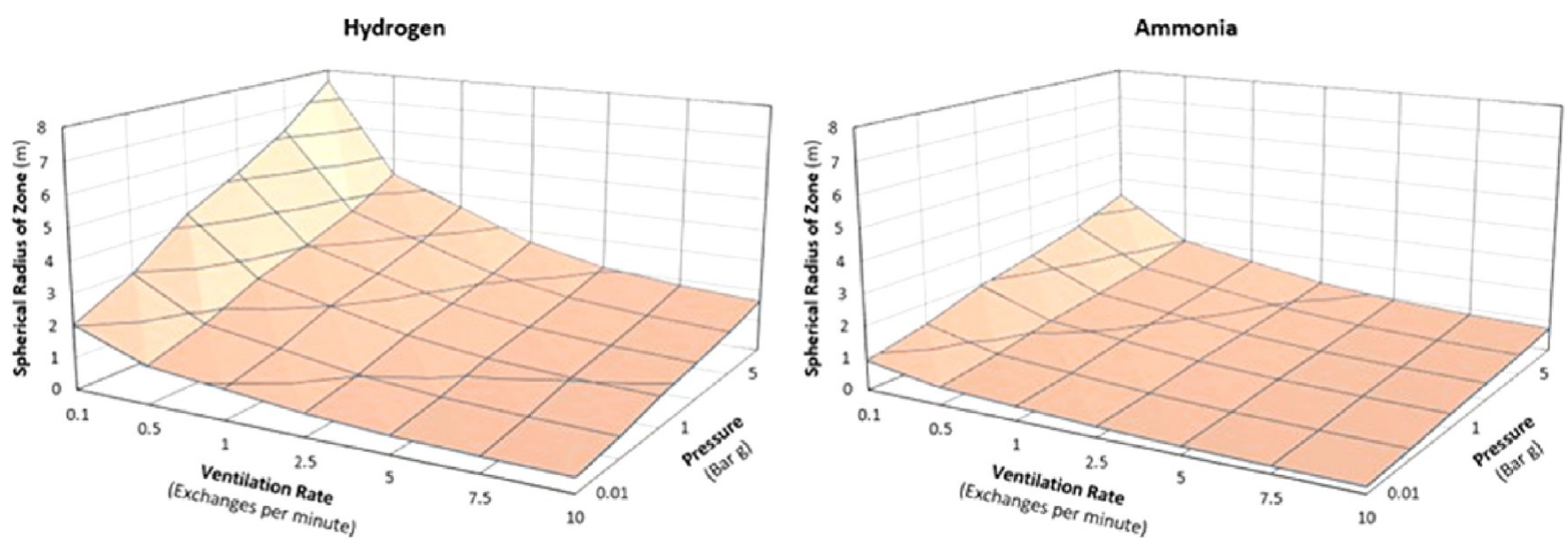

Figure 38. Comparison of zonal extents for "secondary" leaks, indoors, from a $2.50 \mathrm{~mm}^{2}$ orifice into a $200 \mathrm{~m}^{3}$ room with poor ventilation efficiency. This figure was reproduced with permission from ref 11 . Copyright 2020 Elsevier.

impact of the potential introduction of ammonia as a fuel. Albeit ammonia being, on the one hand, environmentally attractive because it provides a carbon-free fuel alternative for energy generation, on the other hand, there are environmental implications associated with the byproducts of ammonia as a fuel. These are associated with air quality and climate effects as well as nitrogen deposition effects. Here, we provide a summary of each of these pathways, with the implications of ammonia as a fuel.

5.3.1. Air Quality. Globally, outdoor air pollution (air quality) is estimated to result in over 3 million premature mortalities annually. ${ }^{347,348}$ Combustion sources are responsible for a large percentage of these premature mortalities, with residential energy, power generation, industry, and land traffic accounting for $31,14,7$, and $5 \%$, respectively. 347

Degraded air quality primarily refers to increased concentrations of fine particulate matter $\left(\mathrm{PM}_{2.5}\right)$ and ozone in the atmosphere, because these are the most prominent known causes of early deaths associated with outdoor air pollution. They both form primarily through atmospheric reactions of emissions. $\mathrm{PM}_{2.5}$ is a group of small particles or liquid droplets with a diameter of $2.5 \mu \mathrm{m}$ or less. Gaseous emissions of nitrogen oxides $\left(\mathrm{NO}_{x}\right)$, sulfur oxides $\left(\mathrm{SO}_{x}\right)$, ammonia $\left(\mathrm{NH}_{3}\right)$, and others lead to $\mathrm{PM}_{2.5}$ formation. Specifically, oxidized products of $\mathrm{NO}_{x}$ and $\mathrm{SO}_{2}$ react with $\mathrm{NH}_{3}$ to form $\mathrm{PM}_{2.5}$ (referred to as secondary $\mathrm{PM}_{2.5}$ ). However, $\mathrm{PM}_{2.5}$ can also be emitted directly, e.g., black carbon (BC) or some forms of organic carbon (OC) (referred to as primary $\left.\mathrm{PM}_{2.5}\right)$. Gaseous emissions of $\mathrm{NO}_{x}$ and volatile organic compounds (VOCs) lead to ozone formation. While $\mathrm{PM}_{2.5}$ and ozone are the predominant pollutants for quantifying air quality, ${ }^{349}$ some epidemiological studies also link the direct exposure to $\mathrm{NO}_{2}$ to adverse human health impacts, ${ }^{350}$ although this pathway is yet to be included in most studies that quantify the human health impacts of combustion emissions.

Emissions from the combustion of hydrocarbon-based fuels result in a set of combustion byproducts, primarily including $\mathrm{NO}_{x}, \mathrm{SO}_{2}$ (if there is sulfur in the fuel), $\mathrm{CO}$, and unburnt hydrocarbons as well as primary particulate matter (of different sizes, including UFP, $\mathrm{PM}_{2.5}$, and $\mathrm{PM}_{10}$ ). Additional emission species are in some cases introduced as a result of postcombustion control. For example, while $\mathrm{NH}_{3}$ is currently primarily emitted by agricultural activities, the three-way catalysts (TWCs) in gasoline vehicles ${ }^{351}$ as well as SCR systems in recent diesel vehicles result in $\mathrm{NH}_{3}$ emissions from road transportation vehicles. ${ }^{352}$ Dependent upon the combustion sector studied, the attribution of health impacts to each combustion emission species varies. This depends upon the emission mass of each but also the spatiotemporal distribution of these emissions. ${ }^{353}$ For example, in the U.S., road transportation $\mathrm{NO}_{x}$ and $\mathrm{NH}_{3}$ emissions are each responsible for $30 \%$ human health impacts associated with the sector, with implications on the effectiveness of post-combustion control. ${ }^{353}$ This pathway from emissions to impact is nonlinear and depends upon, among other things, background concentrations of other pollutants as well as meteorology. ${ }^{354,355}$ For example, a mass unit of $\mathrm{NO}_{x}$ emissions in Europe is found to lead to a higher population exposed to pollution than the same mass unit in the U.S., even when normalized by population. ${ }^{356,357}$

Because $\mathrm{NH}_{3}$ plays a key role in the formation of $\mathrm{PM}_{2.5}, \mathrm{NH}_{3}$ emissions are increasingly being highlighted as an area of which control would yield air quality improvements, ${ }^{353,358-362}$ especially in the proximity to emission sources of $\mathrm{NO}_{x}$ and $\mathrm{SO}_{2}$. Similar to $\mathrm{NO}_{x}$ and $\mathrm{SO}_{2}$, the efficiency of $\mathrm{NH}_{3}$ controls is dependent upon atmospheric conditions (e.g., acidity), with the additional challenge that $\mathrm{NH}_{3}$ is difficult to measure as a result of its semi-volatile nature. ${ }^{363}$

The aforementioned dependencies between emission species and the resulting formation of air pollution have implications for the introduction of $\mathrm{NH}_{3}$ as a fuel. Using $\mathrm{NH}_{3}$ to replace (or partially replace through blending) hydrocarbon-based fuels will (partially) eliminate carbon-based emission byproducts. In the U.S., these are estimated to lead to $\sim 37000$ early deaths annually. ${ }^{355}$ However, remaining or increased emissions of $\mathrm{NO}_{x}$ as well as likely increased emissions of (in this case, unburnt) $\mathrm{NH}_{3}$ would still result in higher adverse air quality impacts from these two species, highlighting the need for post-combustion control in $\mathrm{NH}_{3}$-fired engines. This trade-off remains an active area of research that merits further investigation.

5.3.2. Climate Impacts. Besides air quality impacts, combustion products also result in climate impacts, by altering the radiative budget of the atmosphere. While long-lived $\mathrm{CO}_{2}$ emissions are the driver of the warming effects, shorter lived non- $\mathrm{CO}_{2}$ emissions are also known to contribute, albeit to a lesser extent. ${ }^{364,365}$ Specifically, $\mathrm{NO}_{x}$ and $\mathrm{NH}_{3}$ induce both positive and negative radiative forcing changes (e.g., through the tropospheric ozone and methane responses, respectively, for $\mathrm{NO}_{x}$ ), which in some cases may cancel out net globally but can still result in regional impacts. ${ }^{366}$ The introduction of $\mathrm{NH}_{3}$ fuel 
eliminates $\mathrm{CO}_{2}$ effects, making $\mathrm{NH}_{3}$ very promising in terms of climate impacts. $^{367}$ However, studies that quantify the total societal cost of emissions, taking into account monetized air quality and climate effects, pinpoint that the combined societal cost of the combustion byproducts might result in multiple times higher cost than that of $\mathrm{CO}_{2}$ impacts. ${ }^{368-372}$ Therefore, technologies that employ ammonia need to be carefully designed to minimize these byproducts, leading only to water and nitrogen formation while capturing or consuming in the process remnants of nitrogen oxides, unburned ammonia, or any other detrimental species.

5.3.3. Nitrogen Deposition. Nitrogen deposition characterizes the intake of reactive nitrogen $(\mathrm{Nr})$ from the atmosphere to the biosphere through either dry (gravitational settling) or wet deposition (precipitation). Increased nitrogen deposition, a result of a perturbed nitrogen biochemical cycle, ${ }^{373}$ disturbs plant ecosystem function and affects biodiversity. ${ }^{374}$ Human activity sources are the drivers of reactive nitrogen emissions, ${ }^{375}$ specifically agriculture (primarily in the form of $\mathrm{NH}_{3}$ ) and combustion (primarily in the form of $\mathrm{NO}_{x}$ ). Both $\mathrm{NO}_{x}$ and $\mathrm{NH}_{3}$ emission control provide a potential way for reducing nitrogen deposition, with the quantification of the latter still bearing larger uncertainties. ${ }^{376,377}$ Finally, while nitrogen deposition is of strong interest in areas of high ecosystem value, in specific nitrogen deposition hotspots, such as the Netherlands, nitrogen deposition is increasingly becoming a major societal and political topic, with potential future socio-economic challenges for the introduction of $\mathrm{NH}_{3}$ as a fuel. ${ }^{378,379}$

5.3.4. Emission Implications from Ammonia-Fueled Engines. Because ammonia-fired engines are still an active area of research, estimates of the resulting emissions vary depending upon test setup and conditions, the combustor temperature, and amount of $\mathrm{H}_{2}$ provided and, in many cases, are traded against engine performance and combustion efficiency. ${ }^{8,222,272}$ Further research is required to make these estimates uniform across different engine setups. Overall, $\mathrm{NO}_{x}$ emissions, higher at higher temperatures, need to be balanced against unburnt $\mathrm{NH}_{3}$ emissions, more prevalent at lower temperatures and richer mixtures. What the appropriate balance should be is linked to the aforementioned environmental nonlinearities between $\mathrm{NO}_{x}$ and $\mathrm{NH}_{3}$ emissions and merits further investigation. Valera-Medina et al. ${ }^{11}$ and others note the potential of using unburned $\mathrm{NH}_{3}$ for decomposing $\mathrm{NO}_{x}$ emissions as a form of post-combustion control. ${ }^{163,268}$ Ways of addressing unburnt $\mathrm{NH}_{3}$ from the exhaust during cold start have also been shown by others. ${ }^{24}$

Socioeconomic cost-benefit analyses on the introduction of $\mathrm{NH}_{3}$ as a fuel replacing fossil-fuel-based combustion need to account for life cycle emissions during the production of $\mathrm{NH}_{3}$. Existing estimates vary between 0.5 and $14 \mathrm{~kg}$ of $\mathrm{CO}_{2} / \mathrm{kg}$ of $\mathrm{NH}_{3}$ produced, depending upon the production route. ${ }^{380}$ Carbonfree synthesis of ammonia has been demonstrated, but it is presently unclear if that process can be sufficiently scaled up to meet the demand. ${ }^{381}$

It can be concluded that, although ammonia will mitigate carbon-containing emissions, several considerations need to be taken before employing this chemical as a fueling source, for example, the production of other unwanted emissions (like $\mathrm{NO}_{x}$ ) and the overall impact of slip ammonia toward the atmosphere if systems are not clean enough. Particulate matter is another detriment to the use of ammonia. Although safety needs to be also always considered and properly addressed when using ammonia, it is clear that the history and safety record of the chemical are promising for its utilization at a global scale for fueling purposes. However, it must be remembered that ammonia will be useful for many applications but will also fall within the barriers that public perception will impose at the time of its introduction into the fueling market.

5.4. Legislation. Using ammonia for different industrial purposes and especially as a fuel for combustion systems is relatively new-fangled in comparison to traditional energy resources. The chemical compound has many potential risks regarding safe operation. For example, it can be explosive when mixed with air at a certain mixing ratio. Therefore, formal regulations cannot fulfill a feasible placement for ammonia. Thus, to achieve a fully secure and safe employment of this molecule for different applications to those currently in use, it is crucial to adopt clear and attainable legislations. These legislations must be implemented during storage, handling, and use of $\mathrm{NH}_{3}$.

The legislation scenarios are different from one place to another. Different economics adopting different legislation base their codes on many parameters, such as views of governments, people awareness, and labor laws. A recent literature review performed by Valera-Medina and Banares-Alcantara ${ }^{11}$ compares three major legislations, namely, European, American, and Chinese. The views from each region are different, with focus on health and safety, pragmatism, and risk perception. Therefore, it is important to also raise some of these differences, thus setting the path for potentially new legislations that will come into practice once ammonia is accepted as a fuel source.

For example, ammonia has been used over decades in the U.S. for different applications, such as increasing crop productivity, refringent in cooling systems, cleaning products, pharmaceutical applications, and cloth manufacturing. Thus, the established regulations and legislations of ammonia are based on four primary issues: occupational safety, public security, transportation, and environmental protection. These legislations are implemented and controlled under the supervision of the U.S. federal government. The regulations and legislations organize and rule the use, storage, and transportation of ammonia. Meanwhile, the European Union (EU) has developed its legislation and regulations that rule the production, storage, mobility, and use of ammonia. Different from the U.S., the EU is based on a legal framework where directives and regulations are presented at a European level. Each member of the block then applies the legislation based on their best understanding of such a framework. Finally, China's main party works on legislations that support growth, development, and integrity of both industry and population. Because China is the biggest producer of ammonia worldwide, the implications of their legislation in such a context need to be part of the list of countries where regulations are of relevance on a global scale.

In terms of occupational health, the U.S. established in 1970 the Occupational Health and Safety Administration (OSHA), which is a part of the United States Department of Labor. ${ }^{382}$ It covers most private sector employers and their workers, in addition to some public sector employers and workers in the 50 states and certain territories and jurisdictions under federal authority. OSHA has issued many standards that rule over different employment conditions, such as general industry, construction, maritime, agriculture, etc. Therefore, ammonia as a chemical product also has its own standards and regulations set up by OSHA. Some of these are depicted as follows. Storage and handling of anhydrous ammonia (standard number 1910.111): ${ }^{383}$ This standard is intended to control the design, 
Table 6. Projected Emissions of $\mathrm{NH}_{3}$ Based on Selected National Activity Projections and Current Legislation Compared to the National Emission Ceilings for 2010 and Beyond ${ }^{a}$

\begin{tabular}{|c|c|c|c|c|c|}
\hline Country & 1990 & 2000 & 2010 & 2020 & Ceiling \\
\hline \multicolumn{6}{|c|}{ Ratified countries ( 21 in total - 8 selected) } \\
\hline Bulgaria & 134 & 69 & 67 & 68 & 108 \\
\hline Czech Republic & 127 & 84 & 79 & 77 & 101 \\
\hline France & 687 & 702 & 655 & 651 & 780 \\
\hline Germany & 712 & 601 & 471 & 448 & 550 \\
\hline Netherlands & 209 & 149 & 123 & 138 & 128 \\
\hline Slovenia & 26 & 20 & 21 & 21 & 20 \\
\hline Spain & 335 & 390 & 360 & 368 & 353 \\
\hline United Kingdom & 369 & 323 & 270 & 267 & 297 \\
\hline Total for all ratified & 3531 & 2976 & 2666 & 2665 & 3171 \\
\hline \multicolumn{6}{|c|}{ Other signatories ( 8 in total -3 selected) } \\
\hline Austria & 65 & 60 & 58 & 59 & 66 \\
\hline Belgium & 85 & 84 & 80 & 77 & 74 \\
\hline Rep. of Moldova & 45 & 37 & 45 & 45 & 42 \\
\hline \multicolumn{6}{|c|}{ Other parties (10 in total -4 selected) } \\
\hline Malta & 2 & 2 & 3 & 3 & 3 \\
\hline Russia & 1200 & 551 & 509 & 524 & 894 \\
\hline Turkey & 397 & 422 & 449 & 491 & 241 \\
\hline Ukraine & 709 & 292 & 246 & 253 & 592 \\
\hline
\end{tabular}

${ }^{a}$ Units in kilotons. Highlighted in blue are those surpassing their ceiling. Data were from ref 394.

construction, location, installation, and operation of anhydrous ammonia systems, including refrigerated ammonia storage systems. According to this standard, materials, operating pressures, distance between containers and buildings, storage areas, etc. are defined to enable the appropriate use of the chemical. The approach is very holistic and practical, a point that is evident on the basis of the successful ammonia market in the U.S. Process safety management of highly hazardous chemicals (standard number 1910.119): ${ }^{384}$ This standard aims to prevent or minimize the consequences of catastrophic releases of toxic, reactive, flammable, or explosive chemicals. The standard only applies to users that possess ammonia quantities greater than $4535.9 \mathrm{~kg}$ (thus, if a tank of less than $1000 \mathrm{~kg}$ is employed, like in an automotive system, the legislation does not apply, a point that reiterates the fact that ammonia for fueling would require another set of legislations). Air contaminants (standard number 1910.1000): This standard limits the exposure of an employee to any substance. Ammonia is found in tables of the standard with an air contamination limit of $50 \mathrm{ppm}$ or $35 \mathrm{mg} / \mathrm{m}^{3}$. According to the standard, employees are required to "not exceed in any $8 \mathrm{~h}$ work shift of a $40 \mathrm{~h}$ work week" with this threshold. ${ }^{385}$

Simultaneously, in 2012, the European Union established an amendment to Directive 96/82/EC. ${ }^{386}$ The new Directive, SEVESO III (2012/18/EU), was set up as a response to the change in classification of dangerous substances, which has been enforced since 2015. The implementation comes as a three-part strategy to minimize and control major accident hazards involving hazardous substances. Simultaneously, the Council Directive 2000/39/EC, established on June 8, 2000 and based on Directive $98 / 24 / E C$, ensures the protection of the health and safety of workers from the risks related to chemical agents at work. $^{387}$ The Directive establishes values for a reference period of an $8 \mathrm{~h}$ time weighted average and sets short-term periods of 15 min for 60 chemicals, including ammonia. Like in the U.S., directives and regulations are intended to minimize risks associated with the use of ammonia. Formal risk assessments combined with adequate training and well-established procedures for incident investigations are well-documented in European legislations. The regulations are also concerned about the release of chemicals, such as ammonia, and their explosive potential. To control risks from explosions and fires, the legislation establishes safety features that must be present in the working environment. Adherence to this legislation and the presence of safety features protect employees from hazards, thus ensuring safe operation and handling of the chemical even in the event of leaks.

As for the Chinese, the approach also sets guidelines about storage, handling, and safety limits. According to the China's standard GBZ 2.1-2007 occupational exposure limits for hazardous agents in the workplace/chemical hazardous agents, the limits for exposure of the ammonia concentration at the workplace should not be higher than $20 \mathrm{mg} / \mathrm{m}^{3}$ of permissible concentration-time weight average (PC-TWA) and $30 \mathrm{mg} / \mathrm{m}^{3}$ of permissible concentration-short limit (PC-STEL). ${ }^{388}$ Both ammonia storage facilities and place of utilization should be equipped with ammonia leakage detection alarms. Also, the GB 50016 code for fire protection design of buildings specifies the fire separation distance between ammonia stored in a cylinder and buildings. ${ }^{389}$

Thus, a brief comparison between models denotes a pragmatic approach from the Americans, while the Europeans concentrate the legislation around personnel safety through tough regulations. Finally, the Chinese deal with the situation with practical considerations, which sometimes, unfortunately, are not followed, thus increasing injuries and fatalities in such a country. The last statement, better discussed by others, ${ }^{11}$ could be improved by training programs that increase awareness of personnel to the dangerous features of ammonia.

In terms of the environment, the approach from these economies is different. For example, in the U.S., the EPA has several regulations in place that control the use and production of ammonia. Thus, the agency has issued risk management plan (RMP) and the significant new alternatives policy (SNAP) programs, ${ }^{390,391}$ thus ensuring continuous revision of procedures and risk assessments combined with the promotion of acceptable substances that can reduce ozone depletion. However, the legislative bodies are still debating around ammonia emissions toward the environment from sectors such 

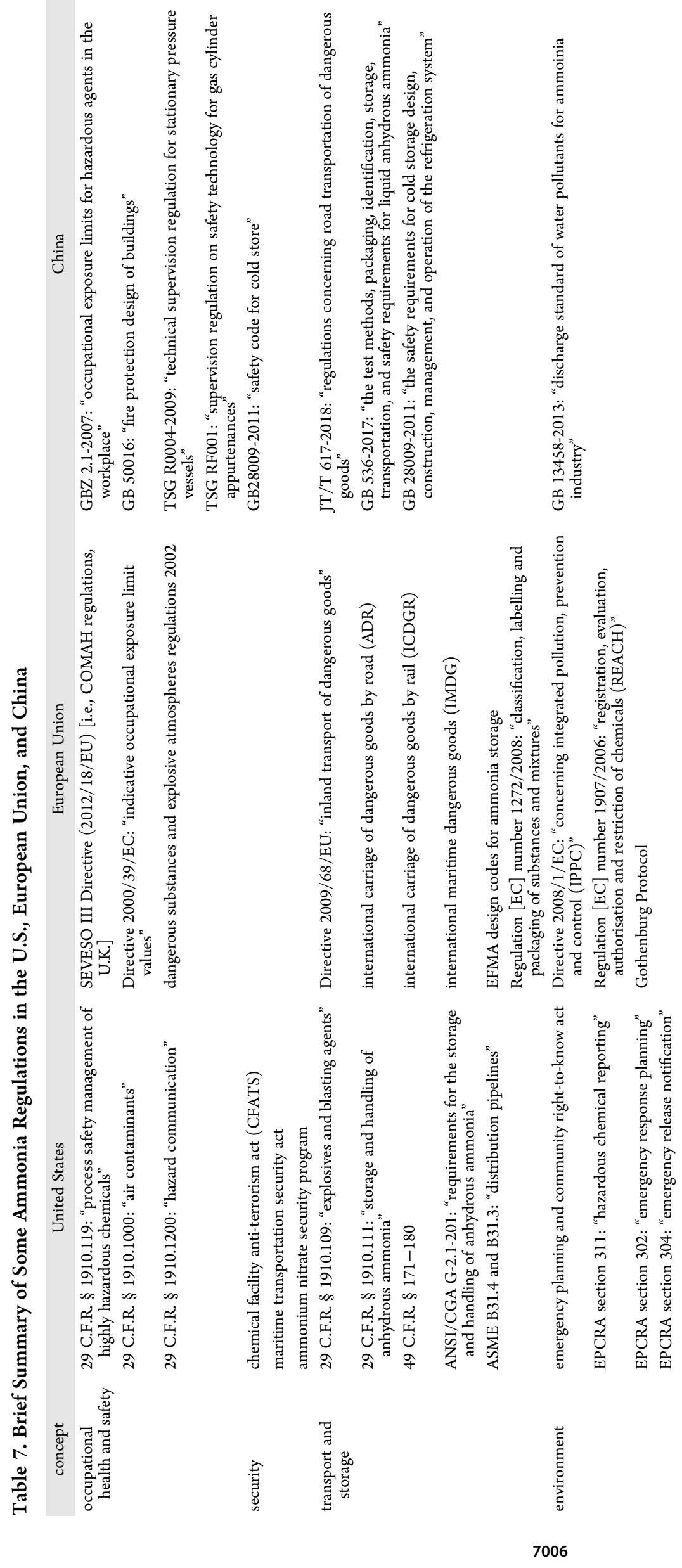
agriculture. This is an important case, because ammonia emissions tend to vary as a consequence of seasonal changes. Furthermore, any legislation would have direct impacts to such an industry. Ammonia emissions, as previously raised, are a major detriment for pollution in cities while impacting the nitrogen cycle. Thus, although regulations in the use of ammonia for several applications are well-established, it is evident that the pragmatic approach from the U.S. economy enables the progression of the use of ammonia toward other disciplines (i.e., power) while still lacking a more conservationist, environmental policy.

On the contrary, the EU has set a ceiling for these emissions via directives, such as Directive 2008/1/EC, concerning integrated pollution, prevention, and control (IPPC). ${ }^{392}$ The purpose of this directive is to achieve integrated prevention and control of pollution arising from activities concerning the use of hazardous substances and their effects on greenhouse gases. It lays down measures designed to prevent or, where that is not practical, to reduce emissions in the air, water, and land from the activities above, including measures concerning waste. Moreover, the legislation seeks to achieve a high level of protection of the environment, without prejudice to Directive 85/337/EEC and other relevant community provisions. The directive also states the use of best available techniques to mitigate the pollution. This is accompanied by the Gothenburg Protocol, a protocol implemented to reduce acidification, eutrophication, and ground-level ozone by setting up emission ceilings by all of its members (Table 6). Interestingly and different from the U.S., the protocol establishes limits of overall emissions from each country, whereas in the U.S., there is not yet such a limit.

Simultaneously, the Chinese regulations are heavily concerned with the impact that ammonia can have in water bodies, a point that is of high concern in regions where nitrogenated molecules contaminate drinking water for human activities. The pollutants discharged in water bodies of the ammonia industry are regulated by a specific standard, the GB 13458-2013 discharge standard of water pollutants for ammonia industry, issued by the China's Ministry of Ecology and Environment (MEE). ${ }^{393}$ According to this standard, the pollution level is measured by measuring the amount of solid bodies discharged to water from ammonia. However, being a chemical crucial for fertilizing, ammonia ceiling emissions are not defined.

Other legislations in areas such as tranport, distribution, refrigeration sites, appliances, etc., are in place in these three contexts, all of which are similar, being technical in nature. Furthermore, the globalization of the ammonia market makes it essential for many of these codes to be in agreement, thus reducing retrofitting costs or the loss of potential markets between these large economic blocks. However, as pointed out, the deployment of an ammonia-based economy would require not only agreement in technical codes but also progression toward a pragmatic approach (similar to the approach in the U.S.) with a clear sense of risks and environmental aspects (similar to Europe) with an attainable, easy to implement view (similar to China) to enable this ammonia-based future. Table 7 summarizes some of the regulations in place between regions. Furhter information can be found elsewhere. ${ }^{11}$

\section{ECONOMICS}

6.1. Background. In reviewing the economics of ammonia as a fuel, one has to consider more than just the costs for the chemical production of ammonia. That is, the following economic areas have to be examined for their part of the cost for ammonia as a fuel: (1) source/location/grid connection of energy input system for fuel production, (2) chemical production systems, (3) storage and fuel transportation, and (4) end use and energy conversion systems.

In this section of the review, the overall economics for each of these areas will be reviewed. Note that, as a result of the scope of this review, the economic cost variables stated here will not be adjusted for the time value of money nor will these variables be adjusted to a common currency value.

6.1.1. Source/Location/Grid Connection of Energy for Ammonia Production. Thomas and Parks ${ }^{395}$ reviewed the conventional means of production of ammonia (using natural gas) based on efficiency or from economic considerations. They noted that production costs from other fossil fuels (heavy oil or coal) could cause a production cost increase of as much as $70 \%$.

Bartels $^{396}$ carried out a feasibility study, which treated ammonia as an alternative fuel and energy storage system. His work determined costs for production, storage, and transportation of ammonia fuel. The cost of the main feedstock for ammonia production, hydrogen, was first determined for both fossil fuel and alternative energy sources. Capital costs and operating parameters of an ammonia synthesis plant were then used in an economic model to calculate the cost of ammonia from various other energy sources (including renewables). In addition, the energy use and cost for both hydrogen and ammonia fuels were then compared for fuel storage and transportation. At the time of this work, ${ }^{396}$ the results showed that the lowest cost ammonia source was coal, with a production cost of about 150-430 U.S. \$/ton or a gasoline equivalent of 0.96-2.83 U.S. \$/gallon. Other alternative ammonia sources (such as renewable-energy-powered sources) had higher costs; however, Bartels noted that they could become economical as fossil fuel costs increase and technological advances are made.

Leighty and Holbrook ${ }^{397}$ used a renewable energy source, wind-generated electricity, as a source for a proposed GW-scale hydrogen and ammonia fuel production system. Their economic analysis included the costs for storage and transmission of the produced fuel. On the basis of their assumptions, the delivered ammonia fuel costs would range from 450 to 650 U.S. \$/ton. They noted that these costs were competitive with the year 2007 U.S. cornbelt prices.

A concept note by Philibert ${ }^{398}$ emphasized the point that, as a result of future cost reductions in renewable energy technologies, ammonia production in large-scale plants based on electrolysis of water could compete with ammonia production based on natural gas in sites with excellent renewable energy resources. A detailed report by the Institute for Sustainable Process Technology ${ }^{399}$ investigated the technoeconomic aspects of the feasibility of producing ammonia using renewable energy resources. On the basis of their economic analysis, they concluded that the production of ammonia using (excess) renewable energy could not compete with existing fossil-based ammonia production. They stated, however, that this conclusion could change with major changes in the production cost of electrolyzers, increased availability of renewable energy, and a major increase in $\mathrm{CO}_{2}$ emission costs.

An industry-based perspective paper on the use of ammonia as a $\mathrm{CO}_{2}$-free fuel was given by authors from Mitsubishi Heavy Industries ${ }^{400}$ in 2019 . They did not review the economics of ammonia production but did conclude that their company had established the production technology for it, and it was much more expensive than state-of-the-art no $\mathrm{CO}_{2}$-free methods. Furthermore, they concluded that, for $\mathrm{CO}_{2}$-free ammonia fuel 


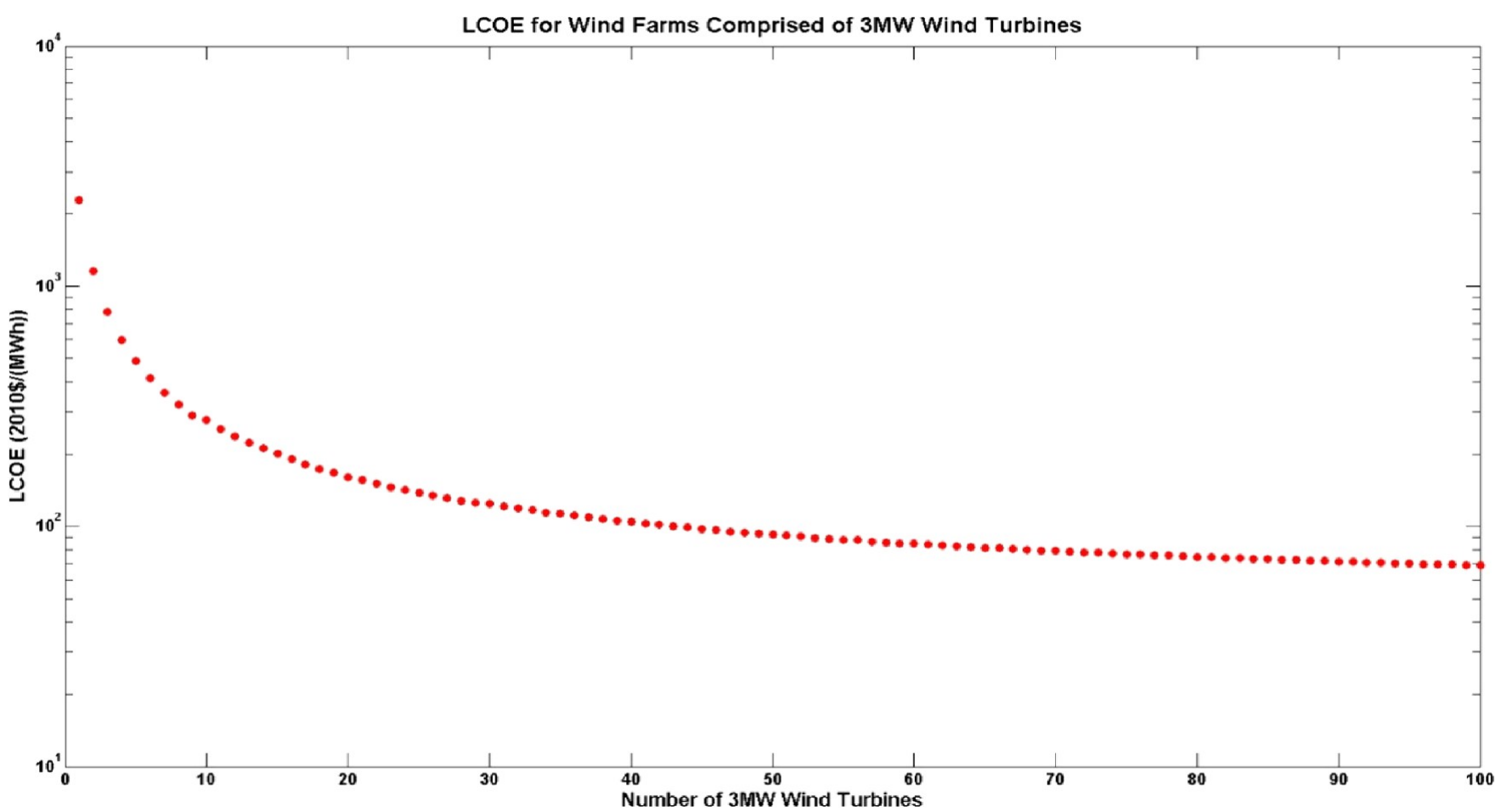

Figure 39. Ammonia LCOE for offshore wind farms of varying size.

production, political incentives would be necessary in its initial production stages.

Some researchers have noted that fossil fuels for ammonia production can be replaced with renewable energy in the manufacturing process to improve sustainability. As summarized by Morgan, ${ }^{401}$ several of the earliest ammonia plants used only hydroelectric power to produce ammonia from water and air. A number of large-scale electrolytic hydrogen facilities have been built since 1928 when hydrogen was first produced via hydroelectric power in Norway. By the 1970s, plants in India, Egypt, Zimbabwe, Peru, Iceland, and Canada were also producing ammonia fertilizer from electrolytic hydrogen. By 1998, however, only seven hydroelectric ammonia facilities were still active in the world, accounting for roughly $0.5 \%$ of the total worldwide ammonia production. ${ }^{402}$

The use of different wind energy systems to produce ammonia fuel has been investigated in a number of University of Massachusetts studies. (1) Offshore wind: ${ }^{401,403}$ In this work, a case study for a grid-connected all-electric ammonia plant in the Gulf of Maine was used to assess the lifetime economics of such a system. Utility grid prices and an offshore wind resource were incorporated in a detailed component level simulation and economics model for this type of system. The levelized cost of ammonia (LCOA) was calculated to be highly relative to ammonia produced with natural gas but was noted to be not as susceptible to major variations in ammonia feedstock prices. As shown in Figure 39, this research demonstrated the economics of scale for the levelized cost of electricity (LCOE) for ammonia-producing offshore wind farms. (2) Floating nongrid offshore systems: ${ }^{404}$ The technical and economic feasibility of a floating offshore wind-driven ammonia production system was investigated in this work. The all-electric ammonia plant was located on a non-grid-connected floating plant ship that had 4.5 MW wind turbines. Their results showed that ammonia was produced at a much lower capacity and at a cost of about U.S. $\$ 350 /$ ton higher than a land-based grid-connected system.
Future work recommended the use of larger sized wind turbines and cost reductions in the ammonia plant and efficiency increases in the auxiliary ammonia-powered gas turbine system. (3) Non-grid-connected island systems: ${ }^{405}$ A detailed system model was used to simulate the production of carbon-free ammonia fuel directly from water and air using traditional air separation units, alkaline electrolyzers, mechanical vapor compression desalination, and a Haber-Bosch synthesis loop. Mohegan Island in Maine was used as a case study, and actual wind data and electrical load data from the island were incorporated to determine the expected ammonia production and economic results. Total lifetime system costs were calculated, with the results normalized such that the windammonia system could be directly compared to a conventional diesel-only system.

Islanded (non-grid-connected) ammonia power systems have been investigated by Vrijenhoef ${ }^{406}$ and Rouwenhorst et al. ${ }^{17}$ Vrijenhoef's project goal was to develop and implement sustainable, decentralized, and small-scale ammonia production plants and/or energy storage systems. His work produced the production, transport, and storage costs for ammonia and hydrogen for a Netherlands-based non-grid-connected system. Rouwenhorst et al. reviewed recent technology advances for a non-grid, islanded ammonia energy system with an emphasis on storage systems sized 1-10 MW. Their work featured a conceptual process design based on the optimization of temperature and pressure levels of existing and proposed future technologies. This process design consisted of wind turbines and solar panels for electricity generation, a battery for short-term energy storage, an electrolyzer for hydrogen production, a pressure swing adsorption unit for nitrogen production, a novel ruthenium-based catalyst for ammonia synthesis, a supported metal halide for ammonia separation and storage, and an ammonia-fueled solid oxide fuel cell for electricity generation. They concluded, for a generic location in northern Europe, the 
islanded energy system had a round-trip efficiency of $61 \%$ and a power cost of about $0.30-0.35 € / \mathrm{kWh}$.

6.1.2. Chemical Production Systems. Thomas and Parks 395 noted that the basic chemistry of ammonia production was based on a process developed by Haber and Bosch in the early 1900s. They gave estimated ammonia production costs (from natural gas) and noted that they were directly influenced by the price of natural gas. Bicer et al. ${ }^{407}$ gave a detailed life cycle assessment of four different ammonia production methods. Their proposed production system was based on an electrolyzer for hydrogen production coupled with a Haber-Bosch plant. Their analysis did not review the economic aspects of the four different production methods; however, it could provide a good background for future economic studies.

Ammonia production costs (along with methanol and light olefins) in the European Union and other countries (U.S., Russia, Ukraine, and Saudi Arabia) were reviewed by Boulamanti and Moya. ${ }^{408}$ They considered the differences in the technologies and co-products and presented the costs based on six components: (1) feedstock, (2) credits (as a result of coproducts), (3) electricity, (4) thermal energy, (5) other materials (chemicals, catalysts, etc.), and (6) labor and other costs.

Shiozawa summarized the economics of $\mathrm{CO}_{2}$-free ammonia via chemical production systems under a research program sponsored by Japan's Institute of Energy Economics. ${ }^{409}$ On the basis of this work, he arrived at two economic-based conclusions: (1) The 2030 cost of ammonia produced via a combination of natural gas and carbon capture and sequestration (CCS) will be about U.S. \$350/ton. (2) The cost of $\mathrm{CO}_{2^{-}}$ free ammonia produced from renewable hydrogen in Australia and exported to Japan will be about U.S. \$750/ton.

His paper also noted that the International Energy Agency (IEA) predicted that ammonia production costs will eventually decrease to less than half of their 2030 levels. ${ }^{410}$

To investigate renewable energy (wind)-powered ammonia fuel systems, a detailed economic model for an all-electric ammonia fuel production system was given in the work of Morgan $^{401}$ and Morgan et al. ${ }^{403}$ On the basis of the requirements of conventional ammonia production subsystems, an electricity-driven system using current technologies was designed and cost-estimated. This all-electric ammonia plant included the hydrogen production electrolyzers, air separation, water purification, synthesis loop, and ammonia storage. Also, the effect of scaling of electrolyers to reduce capital costs (see ref 411) was found to be an important economic variable.

Recent work on the economics of smaller scale ammonia production systems was carried out by Lin et al. ${ }^{412}$ They presented a techno-economic analysis of a $20000 \mathrm{t}$ all-electric production facility that was much smaller than convention ammonia production facilities. They considered two different configurations of the Haber-Bosch process and simulated the system using Aspen Plus. Their model results were then used to estimate the total capital and operating economic costs. The economic analysis showed that the small-scale Haber-Bosch process ammonia fuel cost was about twice the value of conventional ammonia process plants. They also performed a sensitivity analysis that considered areas with local ammonia demand with access to excess renewable energy. For such cases, the cost of ammonia fuel could be comparable to that of conventional ammonia production plants.

6.1.3. Storage and Fuel Transportation Systems. An economic comparison of the storage and transportation costs of ammonia and hydrogen fuel was carried out by Bartels. ${ }^{396}$ This work, assuming 182 days of storage, concluded that ammonia had a large cost advantage over hydrogen (from 0.51 to 14.83 U.S. $\$ / \mathrm{kg}$ of $\mathrm{H}_{2}$ ). Furthermore, on the basis of a transport distance of $1610 \mathrm{~km}$, the pipeline transportation costs for ammonia were lower than those for hydrogen (from 0.034 to 0.7-3.22 U.S. \$/kg). Leighty and Holbrook ${ }^{397}$ also considered the economics of ammonia storage and transportation for their proposed GW-scale hydrogen and ammonia fuel production system.

In two reviews for ammonia storage costs, Rouwenhorst ${ }^{413}$ and Rouwenhorst et al. ${ }^{17}$ presented costs for ammonia storage of about $0.02 € / \mathrm{kWh}$. In addition, in comparison to hydrogen and ammonia storage, they noted that the storage cost for hydrogen increases significantly with storage time, while the cost of ammonia storage remains fairly constant.

A number of researchers have considered integrated ammonia storage with renewable energy sources. Wang et al. ${ }^{414}$ proposed an energy system that was based on the use of excess renewable energy (PV) for conversion into ammonia. Their analysis, including technical and economic feasibility, concluded that ammonia was a promising medium for the large-scale storage of renewable energy. Siddiqui and Dincer ${ }^{415}$ investigated a renewable energy system based on the combination of wind and solar renewable energy sources coupled with ammonia production and storage. In their system, the ammonia fuel was used to power solid oxide fuel cells. They presented economic data for the levelized cost of energy for the individual components of the hybrid system and recommended work on a techno-economic analysis of the proposed system.

Other investigators ${ }^{416,417}$ have proposed and investigated ammonia production and storage systems that use fuel cells as a source of power. More details of this work will be summarized in a following section (Fuel Cells) of this review.

6.1.4. Ammonia Fuel End Use and Energy Conversion Systems. MacFarlane et al. ${ }^{14}$ and Giddey et al. ${ }^{418}$ reviewed the potential for renewable energy production of ammonia and developments in fuel end use. Their end use options included the following: (1) transportation and internal combustion vehicle engines, (2) marine transportation, (3) power generation, (4) gas turbines/aviation, and (5) fuel cells.

6.1.4.1. Transportation and Internal Combustion Vehicle Engines. An overview of the use of ammonia fuel for transportation was included in the work of Zamfirescu and Dincer ${ }^{419}$ and Dincer and Bicer. ${ }^{420}$ They presented an economic analysis that lead to the conclusion that ammonia was the least expensive fuel in terms of U.S. \$/GJ and that ammonia was the lowest cost fuel. A comprehensive review of ammonia as a fuel for internal combustion engines was presented by Brohi. ${ }^{421}$ However, it was limited to the technical aspects (energy efficiency and emissions) but did include some economic cost aspects.

The potential use of ammonia fuel for U.S. transportation was reviewed by Kang and Holbrook. ${ }^{367}$ They concentrated on greenhouse gas emission reductions but did note that gasolinepowered vehicles (limited to light-duty vehicles) could be converted to run on mostly ammonia fuel. They also presented economic results via a cost-benefit analysis and concluded that ammonia-fueled vehicles could be a near-term alternative for light-duty vehicles. Dincer and Bicer ${ }^{422}$ evaluated ammonia production and transportation end-use application options, including ammonia cracking hydrogen vehicles. Their economic results compared various vehicle fuels in terms of energy cost per 
gigajoule and also compared the driving cost (100 km trip) for various fuels. In both cases, ammonia prevailed with the lowest costs.

6.1.4.2. Marine Transportation. An overall review of ammonia as a marine fuel was given by Alfa Laval, etc. ${ }^{423}$ The report discussed all aspects of the process, including conventional- and renewable-energy-based ammonia production. The results included an economic analysis for the cost of ammonia as a marine power source.

The economics of ammonia as a marine fuel was presented by Hansson et al. ${ }^{235}$ Their modeling results indicated that, for the long term, the use of hydrogen represented a more cost-effective marine option than ammonia. Dependent upon the solution of a number of technical issues, however, they also concluded that ammonia may be just as cost-effective.

Kim et al. carried out a detailed feasibility study on the use of ammonia for a ship propulsion system. ${ }^{424}$ Their work considered four different ammonia-fueled propulsion systems for a container feeder ship. These systems were compared (economically and environmentally) to a conventional heavy fuel oil fuel propulsion system. Their results showed that all of the ammonia-powered propulsion ships would require considerably more volume and weight than a conventional-powered ship. The ammonia systems reduced greenhouse gas emissions by $84-92 \%$ and cost 3.5-5.2 times more from a total life cycle cost analysis.

6.1.4.3. Power Generation. Yapicioglu and Dincer ${ }^{287}$ reviewed renewable-energy-produced ammonia as a potential fuel for industrial-scale applications. Their review discussed and compared methods for ammonia production on technical, economic, and environmental performance criteria. Furthermore, some potential methods to convert various types of commercially available generators for production of ammonia were proposed and discussed on the basis of the most recent work carried out in the field. The economic information, however, in this work is somewhat limited.

Rouwenhorst ${ }^{413}$ presented a comprehensive review of the technical and economic feasibility of power-to-ammonia-topower systems. His work contained economic details (capital costs, operating expenses, and revenue) of the components of such systems. Also included were summaries of the current technical progress for these systems as well as a discussion on their long-term feasibility. For non-grid-connected systems, as summarized in Rouwenhorst et al., ${ }^{17}$ their work was expanded to include non-grid-connected (islanded) ammonia power systems (with storage systems in the size range of 1-10 MW. They presented a process design method based on optimizing temperature and pressure levels of state-of-the-art and proposed technologies. For a generic location in northern Europe with renewable energy power sources, they concluded that its operational costs would be $0.30-0.35 € / \mathrm{kWh}$.

6.1.4.4. Gas Turbines/Aviation. Bicer and Dincer ${ }^{422}$ performed a life cycle evaluation of hydrogen and other fuels, including ammonia for aviation applications. The life cycle analysis of air transportation included the production of the aircraft and the construction, maintenance, and disposal for the ground infrastructure. Both conventional and renewable energy inputs for ammonia and hydrogen production were considered. This work calculated the cost for a $5600 \mathrm{~km}$ distance aircraft flight. Ammonia fuel would cost about U.S. \$30 000 compared to U.S. $\$ 18000$ for conventional jet fuel.

6.1.4.5. Fuel Cells. Lipman and $\operatorname{Shah}^{416}$ documented a research project that was designed to investigate the scientific and technical aspects of the potential use of ammonia and other carbon-free energy carriers for hydrogen fuel cell applications. Their research work had three primary tasks: (1) an extensive scientific and technical literature review on the subject, especially for stationary fuel cells, (2) a review of the current (2007) state-of-the-art technical performance and economics of ammonia supply for fuel cell applications, and (3) a recommended demonstration plan for an experimental ammonia/hydrogen fuel cell system.

The economic analysis part of this work centered on a comparison of ammonia cracking with other production methods and costs by the manufacturer of ammonia crackers.

Afif et al. ${ }^{288}$ gave a review of ammonia-fed solid oxide fuel cells. Their work included a comparative study of the working principles, analytical modeling, applications, advantages, and disadvantages as well as some cost data. They noted that, with regard to cost, fuel cells were more expensive per kilowatt of installed capacity than a conventional generator set; however, fuel cell systems were predicted to decrease in price in the near future.

The economics of ammonia (along with hydrogen and methanol) fuel cells for vehicle fuel cell applications was analyzed by Zhao et al. ${ }^{45}$ They summarized work on a highperformance direct ammonia fuel cell operating at $353 \mathrm{~K}$. Their summary concluded that ammonia had the lowest source-totank cost. Minutillo et al. ${ }^{417}$ presented an economic assessment of proposed refueling stations using ammonia and fuel cells to produce hydrogen, electricity, and heat on site. The ammonia directly feeds the solid oxide fuel cell that co-generates electricity and hydrogen coupled with hydrogen chemical storage. Their economic analysis was carried out for current and future cases and evaluated the levelized cost of hydrogen $(\mathrm{LCOH})$, the levelized cost of electricity (LCOE), and other economic performance parameters. The values of the $\mathrm{LCOH}$, for the proposed configurations and economic scenarios, were in the range of $6-10 € / \mathrm{kg}$, and the values of the LCOE ranged from 0.447 to $0.242 € / \mathrm{kWh}$.

Zhang et al. carried out a techno-economic analysis of a number of green ammonia production processes, including power to ammonia systems using solid oxide fuel cells. ${ }^{426}$ They concluded that the power to an ammonia fuel cell system was not economically competitive in 2020 but could become competitive (payback period of less than 5 years) with mass production of solid oxide fuel cells and reduced costs of renewable energy electric power costs.

This section of the review has shown that there has been significant work in the four economic areas previously defined. It has been found that the most common economic parameters have been the cost of ammonia production for fuel production, the cost of electricity for power-to-ammonia-to-power systems, and end use costs, such as transportation and storage. A summary of the range of some of these economic variables from the most recent (and most numerous) references is given in Table 8. One can also note a number of these studies have been based on the use of renewable energy sources to produce "green" ammonia or "green" electric power from ammonia systems. Most of the work shown here developed cost information on production to end use as a fuel or energy. It should be noted that the details of these end use costs (like transportation and storage) for a number of these references could be found in the publications of the authors, but some were very site-specific.

In general, ammonia presents a potential use because of not only its technical feasibility but also its economic features and 
Table 8. Summary of Some Economic Studies

\begin{tabular}{|c|c|c|c|c|}
\hline $\mathrm{NH}_{3}$ topic & $\begin{array}{l}\text { component model cost } \\
\text { details }\end{array}$ & $\begin{array}{c}\text { economic variable, U.S. \$ } \\
\text { (range) }\end{array}$ & $\begin{array}{l}\text { end use economics } \\
\text { (components) }\end{array}$ & reference \\
\hline green $\mathrm{NH}_{3}$ production & yes & $\$ /$ ton of $\mathrm{NH}_{3}(374-666)$ & no & 426 \\
\hline fuel cost of $\mathrm{CO}_{2}$-free ammonia & no & $\$ /$ ton of $\mathrm{NH}_{3}(276-300)$ & yes (transportation) & 409 \\
\hline small-scale Haber-Bosch process economics & yes & $\$ /$ ton of $\mathrm{NH}_{3}(494-720)$ & no & 412 \\
\hline floating offshore $\mathrm{NH}_{3}$ production & yes & $\$ /$ ton of $\mathrm{NH}_{3}(1556-1670)$ & yes (transport, storage) & 404 \\
\hline green $\mathrm{NH}_{3}$ marine fuel & no & $\$ /$ ton of $\mathrm{NH}_{3}(275-850)$ & yes (transpot, storage) & 423 \\
\hline power-to-ammonia-to-power & yes & $\$ / \mathrm{kWh}(0.22-0.55)$ & yes (storage) & 413 \\
\hline renewable energy $\mathrm{NH}_{3}$ production & yes & $\$ /$ ton of $\mathrm{NH}_{3}(390-762)$ & yes (transportation) & 420 \\
\hline $\mathrm{CO}_{2}$-free $\mathrm{NH}_{3}$ production & no & $\$ /$ ton of $\mathrm{NH}_{3}(638-1391)$ & yes (storage) & 399 \\
\hline offshore wind power $\mathrm{NH}_{3}$ & yes & $\$ /$ ton of $\mathrm{NH}_{3}(580-1224)$ & yes (transport, storage) & 403 and 411 \\
\hline
\end{tabular}

current global infrastructure. Furthermore, future systems that are currently under investigation might mitigate even further the costs of producing, storing, and using ammonia as a fuel.

\section{CONCLUSION AND FUTURE PERSPECTIVES}

Scenarios presented in this review show that ammonia can be effectively employed as an energy vector. However, further research is needed in all areas to improve production and efficiency, reduce emissions, and enable a clear path toward an economically viable use of the molecule to support the decarbonization of our highly energy-dependent culture. Thus, several points are addressed in this final section to improve these numbers and acknowledge the challenges for the use of ammonia as an energy vector.

7.1. Synthesis. In terms of synthesis processes, some strategies for improvement of the synthesis process consist of optimizing the heat recovery in the same form or using highpressure steam for power production to sustain the energydemanding compression. The development of alternative catalysts is also in place, allowing for higher conversion at the same pressure or lowering the pressure at equal productivity.

Considering that the catalyst cost impacts for $<1 \%$ of the production cost of $\mathrm{NH}_{3}$, ${ }^{39}$ the search for active materials, even if expensive, such as $\mathrm{Ru}$, would be justified: the reduction of the operating pressure down to 91 bar allows for $20 \%$ savings in equipment and piping.

Considering the process efficiency on the basis of the overall mass balance, $0.44 \mathrm{~mol}$ of $\mathrm{CH}_{4}$ are used per mole of liquid ammonia. Another efficiency measure is based on the computation of the energy or exergy balance. Exergy losses are mainly localized in the reforming section (60-70\%), particularly as a result of the low efficiency of combustion and process steam generation. $^{427}$

Strategies for process intensification of the current technologies are mainly based on the increase of the thermal efficiency of the high-temperature steps through accurate heat recovery, to save fresh fuel, particularly referring to the thermocatalytic hydrogen production section. As for the synthesis loop, attempts are proposed to reduce the temperature rise of the compressor (increasing efficiency) and decrease the temperature for reactor outlet streams. As for the whole integrated process, the lower the loop pressure or as well the lower the pressure difference between the synthesis gas production and the ammonia synthesis loop, the lower the energy input. The energy consumption for the production of 1 ton of $\mathrm{NH}_{3}$ has been reduced from 41.8 to $29.3 \mathrm{GJ}$ thanks to process intensification. ${ }^{39}$ Furthermore, the energy saving when decreasing the operating pressure was calculated: ${ }^{39}$ in the case of a $1000 \mathrm{t}$ /day size, lowering the synthesis pressure from 220 to 75 bar would decrease energy consumption by $1.3 \mathrm{GJ} / \mathrm{t}$.

Therefore, there is room for improvement of the current industrial processes for ammonia synthesis in the highlighted critical steps. However, the real difference would be a fully different process, and the search for alternative production paths for hydrogen, excluding thermochemical routes, is a high-impact action to make the process more sustainable. Also, ammonia synthesis strategies that may occur at lower pressure, ideally atmospheric, would be a real breakthrough. Nevertheless, it is very difficult to imagine an effective process based on renewables applicable to such a production size. This means that a significant downscaling of the ammonia synthesis plant is needed to match the hydrogen production capacity from renewables, which is expected to be orders of magnitude lower than what is needed for a current Haber-Bosch plant. Therefore, a limited advantage of scale can be expected with the need of a careful economic analysis to ensure the feasibility and remunerability of the investment.

Alternative strategies are currently in the experimental and conceptual design stages. For example, power-to-ammonia loops for use with the renewable energy supply characterized by intermittency have been considered, searching for the operating boundaries for steady-state operation of a three-bed autothermal ammonia synthesis reactor through a pseudohomogeneous model. $^{428}$

Furthermore, a solid oxide electrolyzer integrated with an ammonia synthesis reactor has been designed, claiming a reduction of $40 \%$ energy input. ${ }^{429}$ Similarly, air and water have been set as feeds with $\mathrm{N}_{2}$ separation from air through the Linde process and $\mathrm{H}_{2}$ production via water splitting. All of the duties for compression and electrolysis are designed from photovoltaic or wind sources. The estimated investment was huge, 1500 million $€$, but with a reasonable cost of ammonia of $1.35 € / \mathrm{kg}$. ${ }^{40}$

Ammonia synthesis has been around for over a century, but it is still modern while raising research and process design challenges. The process is very energy-intensive, and current efforts are pointing to the optimization of the whole process integration to decrease the net energy and raw material input. A $360^{\circ}$ strategy is needed because, on one hand, the development of more active catalysts can achieve higher productivity under the same conditions, while on the other hand, careful reengineering on the reactor and the whole loop is made effective enough toward the management of kinetic and thermodynamic limitations of the reaction.

Besides reworking conventional processes, mainly based on the Haber-Bosch scheme, attention is paid to novel raw materials (e.g., biomass-derived hydrogen and other renewable routes to $\mathrm{H}_{2}$, such as electrolysis through solar or wind power). 
This also opens the way to consider ammonia as an energy storage medium. Furthermore, fully unconventional routes, such as photocatalytic or electrocatalytic ammonia synthesis, are under development, although at the moment, the expected productivity is orders of magnitude lower than needed.

Overall, the main thermodynamic and kinetic features have been analyzed for commercial catalysts for ammonia synthesis. This analysis highlights that, to produce ammonia, a heterogeneous catalyst is needed to activate the $\mathrm{N}_{2}$ reactant and operation is accomplished around $670 \mathrm{~K}$ for kinetic reasons. This depresses the thermodynamics of this exothermal reaction, forcing an increase to the operating pressure to at least 9.0-10.0 $\mathrm{MPa}$, usually between 15.0 and $30.0 \mathrm{MPa}$. The ammonia synthesis loop is composed of a gas conditioning section (preheating and compression), the reactor, where the thermal management differentiates different layouts, and the product separation with reactant recycle. Although, in principle, simple, the need of integration with the upstream processes for the production of the synthesis gas poses many optimization challenges and opens the choice to many different design options.

7.2. Combustion. A further key development for ammonia combustion is the construction of comprehensive chemical kinetics models as well as skeletal versions for specific applications. The literature models should be improved for predicting the ignition delay and laminar burning velocity of ammonia-based fuel mixtures; especially, the cross reactions between $\mathrm{C}$ and $\mathrm{N}$ species need more investigation. To characterize the emissions from ammonia combustion numerically in case experimental measurements are not feasible (during combustor design), speciation measurements under controlled environments are desirable. These include (1) temperatureresolved measurements in flow and jet-stirred reactors as well as premixed flames, where the uncertainty of measurements must be strongly reduced along with consideration of surface reactions, and (2) time-resolved measurement in shock tubes and rapid compression machines, where reaction kinetics data can be obtained for validation of a single elementary reaction. Moreover, quantum chemical computational campaigns are beneficial for updating the rate constants of the key reactions for which rate constants and branching fractions are still in question.

As presented, ammonia is usually employed through co-firing applications. Therefore, future works in this area will be mainly focused on more detailed studies around the properties and characteristics of novel ammonia blends and the effect of a great variety of parameters that affect fundamental features of ammonia-based flames, such as the pressure, inlet temperature, ammonia concentration, etc. As for hydrogen, which is among the most promising co-fuels for ammonia combustion promotion, the areas of safety, combustion instabilities, "thermal plus fuel" $\mathrm{NO}_{x}$ emissions, etc. will be topics of research required to fully understand the behavior of nitrogen-based molecules and their performance on the reactivity of ammonia radicals. Practical conditions seen in engines and fuel cells will need more testing, with further studies conducted on operability, ignition, flame speed, etc., all critical parameters for the appropriate design of new units fueled with ammonia.

Despite the inherent challenges associated with the burning of ammonia and its blends with hydrogen or methane as a clean fuel powering gas turbine combustors, recent laboratory-scale and CFD research suggested innovative solutions that would guide industry to produce new burner generators using techniques devoted at widening the flame stability range and producing emissions within permissible environmental limits. The understanding of behavior, characteristics, and technical aspects of the multidisciplinary phenomena, including the thermochemical-turbulence interaction, will be facilitated by the aid of transient LES analysis validated through laser diagnostic and novel monitoring laboratory techniques. The recent development of detailed chemical kinetics of pure ammonia as well as different blends with methane and hydrogen is enabling a qualitative understanding of the formation and destruction of various radicals controlling the levels of $\mathrm{NO}_{x}$ and unburnt fuel by the exit of the combustors at different inlet conditions and premixing mechanisms. Staged combustion with rich-lean conditions, swirling to control CRZ sizes, and mixing inside the combustor as well as innovative burners controlling premixing levels are among the suggested solutions that are expected to allow for the sustainable and wide range operable use of ammonia for generations of economical clean combustion burners with high combustion efficiency and low pollutant levels. Further development of detailed chemical mechanisms in the near future is also expected to be reflected in more alternatives for the use of ammonia burner designs.

Therefore, the use of combustion and the understanding of its fundamental features are still under considerable research. For example, predictions of five selected recent ammonia oxidation mechanisms, Glarborg-2018, ${ }^{115}$ Li-2019, ${ }^{137}$ Mei-2019, ${ }^{91}$ Jiang$2019,{ }^{138}$ and Stagni-2020, ${ }^{103}$ have been compared to measured data from the literature on ignition delay times and flame speeds for ammonia, ammonia/hydrogen, and ammonia/methane mixtures. The evaluation has shown than none of the models are capable of accurate predictions over the range of conditions investigated, and further modeling development work is required. It is also recommended to expand the validation to include speciation data from flow reactors, jet-stirred reactors, and laminar premixed flames. Furthermore, it is desirable to obtain additional experimental data to validate particular subsets of the models.

The key reactions in the models depend upon both the reaction conditions and the model itself. To a significant extent, the IDT predictions are sensitive to other reactions than those important for the LBV calculations. The predicted ignition delays for RCM conditions are very sensitive to the reactions of $\mathrm{NH}_{2}$ with $\mathrm{NO}$ and $\mathrm{NO}_{2}$, in particular their branching fractions to a chain-branching product channel and a chain-terminating channel, respectively. Both of these reactions have been extensively characterized both experimentally and theoretically, and the uncertainties in rate constants are small. ${ }^{115}$ Other sensitive reactions are known less accurately. Of particular importance among these steps is the $\mathrm{NH}_{2}+\mathrm{HO}_{2}$ reaction, for which both the overall rate constant and the branching fraction is in discussion, ${ }^{103,134}$ with both experimental and theoretical results varying significantly. Also, reactions of $\mathrm{H}_{2} \mathrm{NO}$ show up as sensitive, and these have significant uncertainties. ${ }^{134}$

At the higher temperatures, typical of the shock tube experiments, reactions important for formation or consumption of atomic hydrogen show up. In addition to some of the steps discussed above, also dissociation of $\mathrm{NH}_{3}$ and its reaction with $\mathrm{H}$ show up in the analysis. Of particular note here is that several reactions in the $\mathrm{N}_{2}$-amine subset show up as bottlenecks; these steps are typically not well-known, and more work is desirable.

Similar to the high-temperature IDT predictions, flame speed calculations are particularly sensitive to formation and consumption of hydrogen atoms. In comparison to IDT predictions, radical-radical reactions of $\mathrm{NH}_{2}$ as well as reactions 
of $\mathrm{NH}$ with $\mathrm{O}_{2}$ and $\mathrm{NO}$ play a larger role. These are discussed in some detail elsewhere.

7.3. Applications. Potential systems fueled with ammonia through combustion in industrial and domestic sectors open many fields of discussion and investigation that, properly addressed, may even lead to a wider exploitation of ammonia as a fuel.

In the case of ammonia/solid fuel co-firing, sparse available data, discussed here for the coal case, suggest the need of systematic studies in controlled conditions that can further clarify the interaction of ammonia with the different stages of solid fuel transformation and conversion. In coal co-firing, this study can allow for the increase in the amount of ammonia that can be added to the coal. Besides coal co-firing, the status of knowledge on the interaction of ammonia oxidation with other solid fuel combustion processes, such as biomasses and waste of different nature, is still at an early stage. Also, in this case, a fundamental study that is even more complex as a result of the uncertainty on solid feedstock composition is required. On the other hand, better knowledge of these processes would open the real possibility to also strengthen the use of ammonia in the cement industry.

Moreover, it is worth noting that ammonia is often a waste in many production chains. Among the most interesting production chains, ammonia deriving from agriculture and animal manure could cover a primary role. The impact of agriculture and livestock on ammonia and GHG emission is a very relevant problem, which accounts for more than $50 \%$ of $\mathrm{NH}_{3}$ and about $40 \%$ of $\mathrm{CH}_{4}$ emissions in the atmosphere. These gaseous wastes, mainly coming from the organic decomposition of wastes from these chains can be used as low-calorific-value fuel in properly designed boilers to recover energy at the local level. Fuel-flexible advanced technologies, like MILD combustion, may represent a straightforward solution for burning such gaseous streams. The MILD combustion configuration, proven to be effective for ammonia conversion, also deserves further analysis for implementing scale-up strategies in terms of thermal power as well as power density.

As a general comment, suitable for any combustion system burning ammonia, it has to be noted that the change of flame characteristics and its reference parameters or the use of flameless combustion requires identification of new sensors and monitoring strategies for the progress of flame and reaction processes. This is a critical step in the setup of innovative digital techniques, inspired by the cyber-physical system concepts, aimed at improving system performances and sustainability by means of such innovative monitoring and control tools as, for instance, digital twins and advanced sensing schemes.

Ammonia engines, likely the first systems that will reach commercial maturity sooner, will receive considerable attention over the next decade, with studies that will be focused on the improvement of these units through modifications in the overall cycle, injection systems, and better reactivity of gasoline-based blends. These works will be followed by replacement of green fuels (i.e., methanol and hydrogen) in the ammonia blends, thus requiring robust programs to determine not only feasibility of these blends but also the most appropriate concentration of these doping agents, ignition requirements, and compressibility ratios. Furthermore, it is expected that other parameters, such as the introduction of novel technologies, will enhance the reactivity of ammonia, thus mitigating slip unburned streams. The technology will also be exposed to continuous scrutiny from environmental groups and decarbonization agendas, which will ensure that future ammonia-based engines not only mitigate unwanted emissions, such as $\mathrm{NO}_{x}$, but are also safe for both living species and the environment, with untraceable concentrations of unburned fuels. The marine industry, which is already leading the path toward these developments, will see the onset of the technology in the next couple of years, ensuring that ammonia engines secure a place in the energy mix of the near future.

Research of ammonia blends for stationary gas turbines has made remarkable progress over the past decade, but still various issues, like humidified RQL combustion, flame stability, emission reduction, suitable materials, cycle efficiencies, etc., need to be further addressed to have an industrial application. Industries in Japan have taken the lead for the use of various ammonia concentrations in their units, while European efforts have also started on the search of conditions, blends, and systems capable of using ammonia in combination of natural gas and as a hydrogen source for large power plants. ${ }^{11}$ With various research groups setting their focus on ammonia combustion, it is expected that many of the current problems will be addressed in the following decade, thus moving toward a "zero-carbon" energy grid. Furthermore, recent announcements by companies such as Reaction Engines ${ }^{431}$ that are now considering various ammonia blends for rocket engines are very encouraging, opening the possibility of using ammonia as an aerospace fuel, an idea discarded by the end of the last century. However, various issues need to be satisfied prior to having ammonia-fired propulsion engines in terms of loading, storage, stability, emissions, and environmental impacts.

In terms of fuel cells and their perspectives, fuel cells will be using ammonia extensively as a reliable source of hydrogen, although some factors, like production, storage, transport, cost, safety, etc., will need to be improved. The production cost of green ammonia is still much higher for the delivery of green hydrogen. ${ }^{266,291}$ At present, fuel cells are costlier than an electric generator running on natural gas or diesel, although the price of fuel cells is falling rapidly. Because power units running on combustion technology are mature, their installation costs will not decrease significantly. On the other hand, fuel cells are a technology for the future, which is developing fast to cope with demand and competition (i.e., low cost of combustion systems). If the trend of commercialization efforts continues, the fuel cell price will definitely be lower in the future and possibly replace many combustion generators. However, to reach this point, new materials need to be developed that ensure moderate temperatures with high efficiency, durability, flexibility, lower costs, and the potential of implementation in combined systems (i.e., hybrids). This work will ensure that fuel cells are part of the future, as expressed by many industries that are already looking into this technology for the use of ammonia, particularly in the marine sector. ${ }^{432}$

It is clear that, for combustion applications, ammonia is faced with several problems, such as low combustion speed, high ignition energy, narrow flammability range, and low flame temperature. Although ammonia has been demonstrated to burn in its pure form under successful scenarios, it is more common that dual-fuel co-firing strategies are employed for easier utilization. The most favorable choice according to previous studies is hydrogen, which is also a popular green fuel with excellent combustion properties when used as a promoter. Characteristics of ammonia/hydrogen fuel blend combustion have been widely studied in flame propagation, ignition, emissions, stability, etc. The performance of such fuel blends 
shows great potential for further applications. However, problems, such as $\mathrm{NO}_{x}$ emissions and flame instabilities, still need to be further optimized. In addition, hydrocarbon fuels also have good potential to be used as combustion promoters for ammonia. Methane, as a simple chemical, has been tested in several studies to enhance the combustion of ammonia. Other hydrocarbon fuels, such as diesel, gasoline, DME, etc., have also been widely studied for ammonia combustion promotion. The results have shown the feasibility of such co-firing technologies to some degree in combustion applications, especially in engine use. However, the fundamental combustion characteristics of such fuel blends are still not clear. Thus, more details of ammonia and its co-firing properties need to be investigated further.

Results obtained on furnaces and boilers, from large to small/ laboratory scale, satisfactorily prove that the use of ammonia as an energy carrier is a viable way to reduce the $\mathrm{CO}_{2}$ emission in several industrial sectors, especially in the most energy-intensive sectors. As a result of very peculiar ammonia combustion characteristics, the status of knowledge about ammonia combustion chemical kinetics and its unusual interplay with fluid dynamic and thermal fluxes need to be greatly improved. There are many applications that would potentially be a significant contribution to the consolidation of a significant role of ammonia in industry. However, in many cases, there are issues that deserve research and development efforts. For instance, it resulted that the limiting factors to ammonia use as an energy carrier in the industrial sector are the decrease of radiative heat transfer and the potential effect of a combustion atmosphere on material to be treated, in the case of furnaces for material production/transformation, as in the case of clinker production. In this and other cases, the design of industrial plants will have to be modified to prevent such issues. However, it has also been shown that development, optimization, and deployment of advanced, fuel-flexible, combustion technologies, such as MILD/flameless combustion, can synergistically support the penetration of ammonia as fuel. These techniques may significantly widen the useful working conditions, capable of preserving conversion efficiency and maintaining pollutant emissions at an acceptable level. As a consequence, the design of industrial plants exploiting ammonia as a fuel (or co-fuel) may be greatly simplified, and greater percentages of ammonia can be used with significant economical and maintenance savings.

Similarly, engines using ammonia will experience the first commercial application in the marine sector. Utilization of technologies that range from spark-ignition systems to compression-ignited devices will also enable the use of ammonia engines in sectors, such as automotives (i.e., for large trucks), trains, and stationary backup power. Innovative concepts, such as HCCI, will also be improved, ensuring that the delivery of fuel is attained with higher efficiency and lower losses. These developments will be accompanied by the understanding of new mechanisms, development of more robust components, storage facilities capable of supporting these sectors, novel multiphase injection systems, and the design of units with low pollution traces.

Ongoing studies around carbon-free power with ammonia blends have shown that the chemical can be fully implemented for the production of power at small and large scales. New developments in combustion systems, novel cycles, and reaction mechanisms have been proposed and tested to ensure the safe and efficient use of gas turbines fueled by ammonia. Even though most of the work has been performed using doping agents, such as methane, progress has been made toward using hydrogen as a combustion promoter, thus replicating the flame behavior of fossil fuel flames and enabling full reduction of carbon-based emissions. However, $\mathrm{NO}_{x}$ emissions, flame stability, material performance, and cycle efficiencies are still being studied by researchers, with the aim of large-scale power plants of $>100$ MW by 2030. These works have also spurred the interest of other sectors, such as the aerospace industry, which is now looking into the use of ammonia for propulsion purposes. It is expected that the near future will see more developments in the area, with cleaner, more efficient units that employ all of the benefits of ammonia (i.e., cooling, heating, and power).

As for fuel cells, current trends denote a fast progression into the development of materials that can operate at lower temperatures, thus making them more versatile for their use in energy and power systems. PEMs, SOFCs, AFCs, and other concepts are now under scrutiny across the world to ensure that ammonia can be easily used to produce energy while minimizing the corrosion that the chemical can produce on membranes and eletrolytic solutions. It has been demonstrated that fuel cells can produce significantly high power outputs (i.e., kilowatts when stacks are employed) with high efficiencies, thus presenting a novel solution to the use of combustion systems. However, it has also been conceived that fuel cells can be integrated with combustion systems, thus increasing power output and raising efficiencies, a concept that is now under research and that will lead to the development of innovative methods for the use of the molecule.

7.4. Safety. Ammonia has been considered a relatively safe chemical that now is positioned as the second most distributed and commercialized worldwide. Therefore, its presence in the global markets and its mature infrastructure make it a potential for fueling applications. However, it is clear that ammonia is a toxic chemical that needs to be treated with respect and, similar to other chemicals, requires proper training before it can be used on a global scale to decarbonize the energy and propulsion sector. Therefore, safety aspects will progress toward the creation of new standards and scientific/industrial exercises that will evaluate the potential of ammonia as a fuel in the transport, aerospace, and energy sectors. Furthermore, the introduction of engines and equipment using ammonia will also push domestic and international agendas for the proper legislation that will ensure minimum risks toward the use of the chemical. At the moment, conversations are taking place with the International Maritime Organization (IMO) to start conceiving the standards for the design of marine engines, with the countries involved already performing analyses and forecasts for the eventual implementation of ammonia in such a sector. These works will follow policy briefings worldwide that will ensure that politicians start debating the concept, thus introducing new legislation for the proper handling of ammonia. This will be accompanied by more public perception studies that will identify perception challenges of these new technologies, thus ensuring that the development leads to commercial applications.

In terms or corrosion, it is evident that new materials will be tested for the great variety of uses that ammonia can have. Novel high resistance materials will be assessed for combustion-based systems, while more robust, flexible, resistant membranes will also be developed for fuel cells. Coating processes with cheap materials will be evaluated, and the versatility of using posttreatment manufacturing processes to reduce residual stress and ammonia contamination will also be addressed in the near 
future, thus enabling the cost reduction of components with higher resistance to ammonia storage and handling.

In conclusion, it is clear that ammonia needs to be handled with care, because its toxicity and corrosivity are critical aspects to living species (including humans) and materials. The affinity of ammonia to water can lead to skin death while burning respiratory tracks in humans and animals. This is accompanied by severe corrosion toward copper-based materials, and some corrosivity to nickel-based alloys. However, similarly, this affinity can reduce cracking problems in storage and handling components (up to $0.2 \%$ by weight). Also, it is recommended that high-resistant steel $(>450 \mathrm{MPa})$ is not used, because this can be susceptible to corrosion under low stress. It is recommended that spray coatings (i.e., zinc) are used in welding areas. Also, good maintenance programs are required to ensure the integrity of components.

Therefore, it is essential that, for the use of ammonia, the correct procedures are followed not only for fueling purposes but also for the design of components, taking into consideration the conditions of operation, the concentration of the molecule in the solution/blend that will be used, and the manufacturing process of storage and handling components, to minimize residual stresses and further wearing. These aspects will mitigate risks toward people and equipment, minimizing costs and ensuring that ammonia is safely used.

7.5. Environment. As far as tailpipe emissions are concerned, ammonia offers the potential for eliminating the climate impacts associated with fossil-based fuel usage. However, there are some areas where further research is needed to be able to provide robust and comprehensive estimates of the potential environmental benefits of ammonia as a fuel and to inform technological decision making for ammonia engine development. For the former, the life cycle impacts of ammonia as a fuel need to be weighed, together with the implications of tailpipe emission changes. For the latter, a more comprehensive understanding of the potential emissions from using ammonia as a fuel and the resulting atmospheric implications would be needed. Improved characterization of emissions from research/ in development engines is critical in this effort. In addition, the investigation of trade-offs between the emission species from both an engine performance perspective and an environmental perspective can contribute toward setting an optimal balance. This could apply directly to emissions or help inform postcombustion control designs. Finally, given the atmospheric nonlinearities, the trade-offs between the emission species are likely to vary based on the potential application sector and engine type, and this should be taken into account in future analyses.

Ammonia is environmentally appealing as a fuel as a result of its carbon-free nature. However, the potential of unburned ammonia emissions ( $\mathrm{NH}_{3}$ slip) as well as remaining or increased $\mathrm{NO}_{x}$ emissions may lead to increased adverse air quality impacts and nitrogen deposition impacts. State-of-the-art atmospheric studies show that ammonia emissions in combination with emissions of $\mathrm{NO}_{x}$ and $\mathrm{SO}_{x}$ have an increased potential for forming air pollution. At the same time, on the engine level, there are fundamental trade-offs between $\mathrm{NO}_{x}$ and $\mathrm{NH}_{3}$ slip and against engine performance. Assessing the engine- and atmospheric-level trade-offs together provides the opportunity to inform engine designs and post-combustion control toward target settings for reduced environmental implications of ammonia as a fuel. This coupled with comprehensive life cycle analyses of the socioeconomic impacts of ammonia as a fuel will help establish robust outcomes on ammonia as a fuel source overall.

7.6. Legal Aspects. In terms of legalization, it seems that the path that will set the first international legislation toward the use of ammonia as a fuel will be based on the marine sector. Current developments critically request that international bodies, such as the IMO, reach consensus for the definition of codes and regulations to design, operate, and maintain ammonia-based engines. Although these technical codes will be relatively easy to implement, the human and environmental factors will be much trickier. The progression of ammonia into the global markets as a fueling vector will require that practices from countries with vast experience (i.e., the U.S.) in the use of pure ammonia are updated for fueling purposes while being integrated in standards and legal codes of other regions. Similarly, health and safety aspects will require further research and debate to reach norms that mitigate human impacts and environmental detriments (e.g., would an engine releasing $0.5 \mathrm{ppmv}$ be feasible in the U.S. and Europe, with different ammonia ceilings?), with large economic players heavily dependent upon ammonia-raising awareness of the environmental issues that ammonia emissions can cause. Finally, the progression in developing nations would need flexible approaches that combined with pragmatic practices and environmental/human impact awareness enable the fast transition to large deployment of the chemical as a fuel. Otherwise, the proposed implementations would not take place, in due course impacting the economy, while the lack of more rigor would also increase casualties when using ammonia. Therefore, it is foreseen that the most ammonia-intense economies will start talks and the debate to reach the safest, most practical, and easiest path to employ ammonia as a fuel on a global level in the following decade.

The legal aspect, critical for the transition to the use of ammonia as a largely deployed fuel, can be seen as a major challenge, especially for countries that have different approaches when it comes to health and safety and the environment. The U.S., a country highly dependent upon ammonia, has very pragmatic regulations that have enabled the adequate use of the molecule. However, their lack of environmental legislation presents a risk to the correct use of ammonia as a fuel. Similarly, the European approach is heavily focused on guaranteeing the integrity of living species (including humans) and the environment. However, such an approach can be detrimental to the fast transition for the implementation of the molecule in most sectors. Finally, the Chinese perspective shows a practical implementation to the growing use of ammonia, with the requirement of practices and methods for risk mitigation that can be implemented more easily than in the previously mentioned cases. However, the lack of rigor in health and safety practices is still paramount to reduce casualties while transporting or using the chemical. Furthermore, the U.S., similar to other developing nations, needs to become fully aware of the environmental impact that ammonia is causing, thus ensuring that a larger deployment will not have severely adverse effects at both local and global climatic scales.

7.7. Economics. The economic future of ammonia as a fuel will be influenced by developments in the two following areas: (1) the development of innovative and cost-effective ammonia fuel production techniques from renewable energy sources and (2) technical innovations and improvements in end systems that can use ammonia fuel.

Ammonia fuel production systems based on the HaberBosch (HB) process can be improved economically by the 
innovative use of all-electric systems driven from renewable energy sources, primarily wind and solar. Furthermore, one can expect other modifications to the $\mathrm{HB}$ ammonia production process or other types of production techniques using renewable energy that will be developed in the future. For example, one of these could include processes based on the electroreduction of $\mathrm{N}_{2}$ to ammonia by direct or other means.

In the future, the end uses of ammonia as a fuel are visualized as a direct transportation system fuel replacement for fossil fuels. Potential applications here include internal combustion engines (automobiles and trucks), power turbines, jet engine turbines, and marine propulsion power plants.

Overall and as reviewed and discussed in the Economics section, the current costs of ammonia as a fuel are generally higher than competing fossil fuels. Because environmental-based restrictions and the cost of carbon-based fuels are expected to increase in the future, there are numerous applications where the fuel costs of ammonia will be lower. This is especially true for cases where ammonia can be produced with only input from renewable energy resources (such as wind and solar). Specifically, the cost of electricity from renewable energy sources is expected to continue to decrease in the future as energy conversion efficiencies increase with technology innovations and scaling factors. It is also expected that the use of ammonia as a storage medium and as a cost-effective transportable energy source will further improve the economic viability of the renewable energy industry in general.

7.8. Final Remarks. It is clear that ammonia will be playing its part in the future energy mix. Current works at all levels and sectors will ensure that ammonia has a deep penetration in the energy market, thus enabling the use of stranded energy sources and decarbonization of the intermittent, renewable grid. However, there are still many challenges before ammonia is commercially deployed as a main energy vector. Challenges and works in the areas of synthesis, use, safety, and economics are all under scrutiny at various levels, thus ensuring that our understanding of the use of the molecule and its practical implementation are attained within the following decades.

\section{ASSOCIATED CONTENT}

\section{SI Supporting Information}

The Supporting Information is available free of charge at https://pubs.acs.org/doi/10.1021/acs.energyfuels.0c03685.

Additional material (i.e., laminar burning velocity and ignition delay times) generated to compare various mechanisms, experimental and numerical campaigns, and a variety of ammonia-based blends (PDF)

\section{AUTHOR INFORMATION}

\section{Corresponding Author}

A. Valera-Medina - College of Physical Sciences and Engineering, Cardiff University, Cardiff CF24 3AA, United Kingdom; (1) orcid.org/0000-0003-1580-7133; Email: valeramedinaa1@cardiff.ac.uk

\section{Authors}

F. Amer-Hatem - Ministry of Education, General Directorate of Education of Diyala, Diyala 32001, Iraq

A. K. Azad - Department of Chemical and Process Engineering, Faculty of Integrated Technologies, Universiti Brunei Darussalam, Gadong BE1410, Brunei Darussalam
I. C. Dedoussi - Section Aircraft Noise and Climate Effects, Faculty of Aerospace Engineering, Delft University of Technology, 2629 HS Delft, The Netherlands; (1) orcid.org/ 0000-0002-8966-9469

M. de Joannon - Istituto di Scienze e Tecnologie per l'Energia e la Mobilità Sostenibili (STEMS), Consiglio Nazionale delle Ricerche (CNR), 80125 Napoli, Italy; orcid.org/00000002-5182-5024

R. X. Fernandes - Department of Physical Chemistry, Physikalisch-Technische Bundesanstalt (PTB), 38116 Braunschweig, Germany

P. Glarborg - Chemical Engineering, Technical University of Denmark, DK-2800 Kongens Lyngby, Denmark; ○ orcid.org/0000-0002-6856-852X

H. Hashemi - Chemical Engineering, Technical University of Denmark, DK-2800 Kongens Lyngby, Denmark; (1) orcid.org/0000-0002-1002-0430

X. He - Department of Physical Chemistry, PhysikalischTechnische Bundesanstalt (PTB), 38116 Braunschweig, Germany

S. Mashruk - College of Physical Sciences and Engineering, Cardiff University, Cardiff CF24 3AA, United Kingdom

J. McGowan - Mechanical and Industrial Engineering, University of Massachusetts, Amherst, Massachusetts 01003-

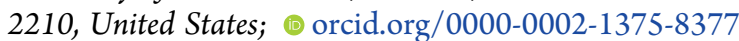

C. Mounaim-Rouselle - PRISME, University of Orleans, 45072 Orléans, France

A. Ortiz-Prado - UDIATEM, Faculty of Engineering, National Autonomous University of Mexico (UNAM), 04510 Mexico City, Mexico

A. Ortiz-Valera - UDIATEM, Faculty of Engineering, National Autonomous University of Mexico (UNAM), 04510 Mexico City, Mexico

I. Rossetti - Department of Chemistry, Università degli Studi di Milano, 20133 Milano, Italy; 이 orcid.org/0000-0001-58825011

B. Shu - Department of Physical Chemistry, PhysikalischTechnische Bundesanstalt (PTB), 38116 Braunschweig, Germany

M. Yehia - Department of Mechanical Power, Faculty of Engineering, Cairo University, Giza 12613, Egypt

H. Xiao - School of Naval Architecture and Ocean Engineering, Guangzhou Maritime University, Guangzhou, Guangdong 510725, People's Republic of China

M. Costa - IDMEC, Mechanical Engineering Department, Instituto Superior Técnico, Universidade de Lisboa, 1049-001 Lisboa, Portugal; (1) orcid.org/0000-0002-3118-2762

Complete contact information is available at:

https://pubs.acs.org/10.1021/acs.energyfuels.0c03685

\section{Notes}

The authors declare no competing financial interest.

\section{Biographies}

Agustin Valera-Medina is an associate professor at Cardiff School of Engineering. He has participated as principal investigator/coinvestigator on 23 industrial projects attracting approximately $£ 8.5$ million. He has published 145 papers ( $h$-index of 20), with 29 of these specifically concerning ammonia power. He has been part of various scientific boards, chairing sessions in international conferences and moderating large industrial panels on the topic of "ammonia for direct use". He supported the preparation of two Royal Society policy briefings on "green ammonia". 
Fares Amer-Hatem is a lecturer at the Iraqi Ministry of education/ Directorate Office of Education in Diyala, Iraq. He obtained his Ph.D. degree from Cardiff University, U.K. His area of research is thermal energy, renewable energy, and alternative fuels. He has published research concerning flame instabilities in complex fields. His expertise has supported the shaping of regulations in Divala for the use of advanced fueling technologies.

Abul Kalam Azad is an associate professor in chemical and process engineering at Universiti Brunei Darussalam. He obtained his Ph.D. degree from Gothenburg University, Sweden, and received postdoctoral experience at Uppsala University, Sweden, and the University of St. Andrews, U.K. His research expertise is on renewable and alternative fuels.

Irene Dedoussi is an assistant professor in the Faculty of Aerospace Engineering of Delft University of Technology (TU Delft) and a research affiliate of the Laboratory for Aviation and the Environment of Massachusetts Institute of Technology (MIT). Her research primarily focuses on combustion emissions, environmental impacts, and numerical methods. Dr. Dedoussi holds B.A. and M.Eng. degrees in engineering from the University of Cambridge, and S.M. and Ph.D. degrees in aeronautics and astronautics from MIT.

Mara de Joannon is senior researcher at the Institute of Science and Technology for Sustainable Energy and Mobility of the Italian National Research Council (CNR) in Napoli (Italy). She obtained her master's and Ph.D. degrees at University Federico II in Napoli. She is a fellow and member of the Board of Directors (2020-2026) of The Combustion Institute. Her main scientific interests are smart energy carriers and advanced/fuel-flexible combustion processes as MILD/ flameless/diluted combustion.

Ravi Fernandes is a professor at the Institute of Internal Combustion Engines of the Technical University of Brunswick and the head of the Department of Physical Chemistry at the National Metrology Institute of Germany (PTB). He obtained his Ph.D. degree at the Karlsruhe Institute of Technology in Germany. Thereafter, he was a researcher at the Max-Planck Institute in Germany, Sandia National Laboratories in the U.S.A., and Assistant Professor at RWTH Aachen University in Germany. His research expertise lies in reaction kinetics, renewable energy carriers, and advanced combustion.

Peter Glarborg is a professor of chemical engineering at the Technical University of Denmark, where he has taught since 1996. Peter has published more than 200 research articles in archival journals. He is working broadly in the field of combustion and harmful emission control, with special emphasis on developing detailed reaction mechanisms for high-temperature gas-phase processes.

Hamid Hashemi is a senior researcher at the Technical University of Denmark (DTU). His expertise is in chemical kinetic modeling of combustion and high-temperature processes. His recent work has focused on developing kinetic models for the oxidation of bio-derived fuels and novel energy carriers.

Xiaoyu $\mathrm{He}$ is an independent junior researcher at the National Metrology Institute of Germany (РTB) and the Institute of Internal Combustion Engines in the Technical University of Brunswick. He obtained his double master's degree at the Technical University of Brunswick in Germany and the Tongji University in China. His research focuses on the combustion chemistry of alternative fuels applying advanced mass spectrometry. Recently, he works intensively on the topic of ammonia combustion.

Syed Mashruk is a postdoctoral researcher at Cardiff University's School of Engineering. He has received his Ph.D. degree from Cardiff University and his M.Sc. and B.Eng. degrees with first class honors from
Cranfield University and University of Hertfordshire, respectively. His research is focused on experimental and numerical characterization of alternative, low-carbon fuels for power generation as well as in aviation and transport industries. He specializes in advanced optical and laser diagnostic systems.

Jon McGowan is a professor of mechanical engineering at the University of Massachusetts Amherst, where he has worked since 1967. He is a graduate of the Carnegie Institute of Technology (B.S. and Ph.D. degrees) and Stanford University (M.S. degree). His most recent research work has been in renewable energy systems (primarily wind) and thermodynamics. He has developed fundamental undergraduate/graduate engineering courses on energy conversion and renewable energy at the university and is editor of the Wind Engineering journal.

Christine Mounaim-Rousselle is a professor in mechanics in the topic of energy. She is a professor at the University of Orléans with expertise in combustion phenomena, in particular in internal combustion automotive engines, through the use of laser measurement techniques. She participates in numerous national and European research projects and carries out expertise in various international projects.

Armando Ortiz-Prado is a professor in mechanical engineering. $\mathrm{He}$ received his master's and Ph.D. degrees from the Autonomous National University of Mexico (UNAM). His area of expertise focuses on materials science, and he is director of the UDIATEM materials unit at UNAM's School of Engineering. Prof. Ortiz-Prado's principal research interests are around failure analysis, material degradation, atmospheric corrosion and corrosion in electronic equipment, deformable body mechanics, modeling of manufacturing processes, and mechanical behavior of biomaterials.

Armando Ortiz-Valera is a research associate in mechanical engineering. He received his master's degree in materials science from the Autonomous National University of Mexico (UNAM). He is currently finishing his Ph.D. degree in metal-cutting processes, and his areas of interest include material corrosion, deformable body mechanics, and metal-cutting processes.

Ilenia Rosseti is a professor at the University of Milan, Chemistry Department. She has been responsible for research contracts on behalf of important industries, such as ENI, Itelcond, BASF, etc. She was also national coordinator of different research projects granted by Regione Lombardia and Fondazione Cariplo. She was awarded the Chiusoli Medal in 2016 from the Industrial Chemistry Division of the Italian Chemical Society "for her multidisciplinary approach... in the field of hydrogen production and use".

Bo Shu is a senior researcher and the head of the Working Group "Reaction Kinetics" at the National Metrology Institute of Germany (PTB). He is a member of the Cluster of Excellence $\mathrm{SE}^{2} \mathrm{~A}-$ Sustainable and Energy-Efficient Aviation in the Technical University of Brunswick. He obtained his Ph.D. degree at the University of Duisburg-Essen in Germany. His research expertise is advanced optical diagnostics in reactive fluid and thermal-chemical conversion of low-carbon energy carriers.

Mohamed A. Yehia is a professor of combustion and energy at the Faculty of Engineering, Cairo University. He received his Ph.D. degree from the Imperial College, U.K., on the simulations of pulverized coal combustion. Prof. Yehia was a visiting academic in Loughborough University, U.K. He is currently the head of the combustion group and the coordinator of the Sustainable Energy Engineering program at the Faculty of Engineering, Cairo University. Research interests include deflagration, clean combustion, fire dynamics, and energy mix scenarios. 
Hua Xiao is an assistant professor at the School of Naval Architecture and Ocean Engineering, Guangzhou Maritime University, China. He has participated as first author and co-author of more than 15 publications related to ammonia gas turbines and improvement of chemical reaction models for the use of this chemical. He has worked in the topics of combined cycles, micro flame stability systems, power plants using heavy fuels, and waste utilization, among many other topics.

Mário Costa was a professor in the area of environment and energy at the Mechanical Engineering Department of Instituto Superior Técnico, University of Lisbon, where he taught several courses. He participated in more than 55 national and international projects and (co)authored one textbook on combustion and more than 320 journal articles. In 2020, he was elected fellow of the Combustion Institute "for innovative research on solid fuel combustion, formation and control of pollutants, and mild combustion".

\section{ACKNOWLEDGMENTS}

All of the authors acknowledge Prof. Mário Costa, whose initiative to work on this project led us to the production of a holistic document that includes the most relevant topics of ammonia as an energy vector. Unfortunately, Prof. Costa's last breath took place over the spring of 2020, leaving a tremendous gap in our scientific community. The authors hope that this review briefly praises his growing interest in the subject and its active research around ammonia, hoping that his perseverance and motivation remains alive through his work, students, and scientific legacy. Cardiff University thanks the Engineering and Physical Sciences Research Council (EPSRC) for the Grant Project SAFE (EP/T009314/1) and the Welsh European Funding Office (WEFO) through its Program "Flexible Integrated Energy Systems (FLEXIS)”, Project 80835. The Technical University of Denmark were supported by the AEngine project grant from Innovation Fund Denmark. The entire group also thanks Gina Goddard-Bell for the grammatical revision of this manuscript.

\section{REFERENCES}

(1) Allen, M.; Babiker, M.; Chen, Y.; Taylor, M.; Tschakert, P.; Waisman, H.; Warren, R.; Zhai, P.; Zickfeld, K.; Zhai, P.; et al. Summary for Policymakers-Global Warming of $1.5^{\circ} \mathrm{C}$; Intergovernmental Panel on Climate Change (IPCC): Geneva, Switzerland, 2018; https://www. ipcc.ch/sr15/chapter/spm/ (accessed Jan 19, 2021).

(2) Graziano, M.; Lecca, P.; Musso, M. Historic Paths and Future Expectations: The Macroeconomic Impacts of the Offshore Wind Technologies in the UK. Energy Policy 2017, 108, 715.

(3) International Energy Agency (IEA). Key World Energy Statistics; IEA: Paris, France, 2020; https://webstore.iea.org/download/direct/ 4093?fileName=Key_World_Energy_Statistics_2020.pdf (accessed Jan 19, 2021).

(4) Kabir, E.; Kumar, P.; Kumar, S.; Adelodun, A. A.; Kim, K. H. Solar Energy: Potential and Future Prospects. Renewable and Sustainable Energy Reviews 2018, 82, 894-900.

(5) International Energy Agency (IEA). Renewables; IEA: Paris, France, 2019; www.iea.org/renewables2019 (accessed Jan 19, 2021).

(6) International Energy Agency (IEA). Global Energy Review; IEA: Paris, France, 2020; www.iea.org/t\&c/ (accessed Jan 19, 2021).

(7) World Energy Council. World Energy Resources Marine Energy 2016; World Energy Council: London, U.K., 2016; https://www. marineenergywales.co.uk/wp-content/uploads/2016/01/WorldEnergy-Council-Marine-Energy-Resources-2016.pdf (accessed Jan 19, 2021).

(8) Elishav, O.; Mosevitzky Lis, B.; Miller, E. M.; Arent, D. J.; ValeraMedina, A.; Grinberg Dana, A.; Shter, G. E.; Grader, G. S. Progress and
Prospective of Nitrogen-Based Alternative Fuels. Chem. Rev. 2020, 120, $5352-5436$

(9) Gammon, R. The Role of Hydrogen \& Fuel Cells in Future Energy Markets. Proceedings of the Fuel Cell Early Markets 2007; Brussels, Belgium, June 11-12, 2007; p 23.

(10) The Royal Society. Ammonia: Zero-Carbon Fertiliser, Fuel and Energy Store.; The Royal Society: London, U.K., 2020.

(11) Valera-Medina, A.; Banares-Alcantara, R. Techno-Economic Challenges of Green Ammonia as an Energy Vector, 1st ed.; Academic Press: Cambridge, MA, 2021; DOI: 10.1016/c2019-0-01417-3.

(12) Djinović, P.; Schüth, F. Energy Carriers Made from Hydrogen. In Electrochemical Energy Storage for Renewable Sources and Grid Balancing; Elsevier: Amsterdam, Netherlands, 2015; Chapter 12, pp 183-199, DOI: 10.1016/B978-0-444-62616-5.00012-7.

(13) Brown, T. Updating the Literature: Ammonia Consumes 43\% of Global Hydrogen; Ammonia Energy Association: Brooklyn, NY, 2020; https://www.ammoniaenergy.org/articles/updating-the-literatureammonia-consumes-43-of-global-hydrogen/ (accessed Jan 19, 2021).

(14) MacFarlane, D. R.; Cherepanov, P. V.; Choi, J.; Suryanto, B. H. R.; Hodgetts, R. Y.; Bakker, J. M.; Ferrero Vallana, F. M.; Simonov, A. N. A Roadmap to the Ammonia Economy. Joule 2020, 4, 1186.

(15) Fujimura, Y. International Cooperation for Implementation of Green Ammonia. Proceedings of the $\mathrm{NH}_{3}$ Energy Implementation Conference; Pittsburgh, PA, Oct 31-Nov 1, 2018; https:// nh3fuelassociation.org/wp-content/uploads/2018/11/AEA-ImpCon-01Nov18-Yasushi-Fujimura-Session-6.pdf (accessed Jan 19, 2021).

(16) Bañares-Alcántara, R.; Dericks, G., III; Fiaschetti, M.; Grünewald, P.; Lopez, J. M.; Tsang, E.; Yang, A.; Ye, L.; Zhao, S. Analysis of Islanded Ammonia-Based Energy Storage Systems; University of Oxford: Oxford, U.K., 2015; pp 1-150.

(17) Rouwenhorst, K. H. R.; Van Der Ham, A. G. J.; Mul, G.; Kersten, S. R. A. Islanded Ammonia Power Systems: Technology Review \& Conceptual Process Design. Renewable Sustainable Energy Rev. 2019, 114, 109339.

(18) Wang, G.; Mitsos, A.; Marquardt, W. Conceptual Design of Ammonia-Based Energy Storage System: System Design and TimeInvariant Performance. AIChE J. 2017, 63, 1620.

(19) Bicer, Y.; Dincer, I. Life Cycle Assessment of Ammonia Utilization in City Transportation and Power Generation. J. Cleaner Prod. 2018, 170, 1594.

(20) Palys, M. J.; Daoutidis, P. Using Hydrogen and Ammonia for Renewable Energy Storage: A Geographically Comprehensive TechnoEconomic Study. Comput. Chem. Eng. 2020, 136, 106785.

(21) Financial Times. Japan Bets on Ammonia as the Fuel of the Future; Financial Times: London, U.K., 2020; https://www.ft.com/content/ 254e44c4-afec-11ea-94fc-9a676a727e5a (accessed Jan 19, 2021).

(22) NYK. Joint R\&D Starts for Use of Ammonia in Marine Transportation To Reduce GHG Emissions; NYK: Tokyo, Japan, 2020; https://www.nyk.com/english/news/2020/20200812_01.html (accessed Jan 19, 2021).

(23) Wärtsilä Corporation. World's First Full Scale Ammonia Engine Test-An Important Step towards Carbon Free Shipping; Wärtsilä Corporation: Wärtsilä, Finland, 2020; https://www.wartsila.com/ media/news/30-06-2020-world-s-first-full-scale-ammonia-enginetest---an-important-step-towards-carbon-free-shipping-2737809 (accessed Jan 19, 2020).

(24) Ammonia Energy Association. Viking Energy To Be Retrofit for Ammonia Fuel in 2024; Ammonia Energy Association: Brooklyn, NY, 2020; https://www.ammoniaenergy.org/articles/viking-energy-to-beretrofit-for-ammonia-fuel-in-2024/ (accessed Jan 19, 2021).

(25) MAN Energy Solutions. Engineering the Future Two-Stroke GreenAmmonia Engine; MAN Energy Solutions: Copenhagen, Denmark, 2019.

(26) BEIS. Storage at Scale UKRI; BEIS: London, U.K., 2019; https:// assets.publishing.service.gov.uk/government/uploads/system/ uploads/attachment_data/file/890168/Storage_at_ScaleCompetition_Guidance_Notes_March_2019_withdrawn_.pdf (accessed Jan 19, 2021). 
(27) ARENHA. Advanced Materials and Reactors for Energy Storage through Ammonia; ARENHA: Derio, Spain, 2020; https://arenha.eu/ content/home (accessed Jan 19, 2021).

(28) ETN. Flexnconfu; ETN: Brussels, Belgium, 2020; https:// flexnconfu.eu/ (accessed Dec 29, 2020).

(29) Ummary, S. Renewable Energy to Fuels Through Utilization of EnergyDense Liquids (REFUEL) Program Overview. ARPA-e 2016, $1-16$.

(30) Richard, E. Plans for Major Green Hydrogen and Ammonia Project in Australia Receive Crucial Boost; ICIS: London, U.K., 2020; https:// www.icis.com/explore/resources/news/2020/10/26/10567213/ plans-for-major-green-hydrogen-and-ammonia-project-in-australiareceive-crucial-boost (accessed Jan 19, 2021).

(31) Seznec, J.; Mosis, S. Will Saudi Arabia Build the World's Largest Green Hydrogen and Ammonia Plant?; Energy Post: Amsterdam, Netherlands, 2020; https://energypost.eu/will-saudi-arabia-build-theworlds-largest-green-hydrogen-and-ammonia-plant/ (accessed Jan 19, 2021).

(32) Ober, J. A. Mineral Commodity Summaries; U.S. Geological Survey: Reston, VA, 2016; DOI: 10.3133/70170140.

(33) Kandemir, T.; Schuster, M. E.; Senyshyn, A.; Behrens, M.; Schlögl, R. The Haber-Bosch Process Revisited: On the Real Structure and Stability of "Ammonia Iron" under Working Conditions. Angew. Chem., Int. Ed. 2013, 52 (48), 12723-12726.

(34) Cherkasov, N.; Ibhadon, A. O.; Fitzpatrick, P. A Review of the Existing and Alternative Methods for Greener Nitrogen Fixation. Chem. Eng. Process. 2015, 90, 24-33.

(35) Lan, R.; Irvine, J. T. S.; Tao, S. Ammonia and Related Chemicals as Potential Indirect Hydrogen Storage Materials. Int. J. Hydrogen Energy 2012, 37 (2), 1482-1494.

(36) Brown, D. E.; Edmonds, T.; Joyner, R. W.; McCarroll, J. J.; Tennison, S. R. The Genesis and Development of the Commercial BP Doubly Promoted Catalyst for Ammonia Synthesis. Catal. Lett. 2014, 144 (4), 545-552.

(37) Appl, M. Ammonia: Principles and Industrial Practice; WileyVCH: Weinheim, Germany, 1999; DOI: 10.1002/pauz.19970260615.

(38) Jennings, J. R. Catalytic Ammonia Synthesis: Fundamentals and Practice; Jennings, J., Ed.; Springer Science Business Media LCC: New York, 1994; DOI: 10.1007/978-1-4757-9592-9.

(39) Liu, H. Ammonia Synthesis Catalysts: Innovation and Practice; Chemical Industry Press and Wold Scientific: Beijing, China and Singapore, 2013; DOI: 10.1142/8199.

(40) Ammonia. Catalysis and Manufacture; Nielsen, A., Ed.; SpringerVerlag: Berlin, Germany, 1995; DOI: 10.1007/978-3-642-79197-0.

(41) Gaube, J. A. V. Slack and G. R. James (Eds.): Fertilizer science and technology series, vol. 2, Ammonia, part III. Marcel Dekker, Inc., New York, Basel 1977, 459 Seiten, Preis: SFr 222,-. Ber. Bunsen. Phys. Chem. 1980, 84 (7), 709-710.

(42) Pernicone, N.; Ferrero, F.; Rossetti, I.; Forni, L.; Canton, P.; Riello, P.; Fagherazzi, G.; Signoretto, M.; Pinna, F. Wustite as a New Precursor of Industrial Ammonia Synthesis Catalysts. Appl. Catal., A 2003, 251 (1), 121-129.

(43) Liu, H. Ammonia Synthesis Catalyst 100 Years: Practice, Enlightenment and Challenge. Chin. J. Catal. 2014, 1619-1640.

(44) Gillespie, L. J.; Beattie, J. A. The Thermodynamic Treatment of Chemical Equilibria in Systems Composed of Real Gases. II. A Relation for the Heat of Reaction Applied to the Ammonia Synthesis Reaction. The Energy and Entropy Constants for Ammonia. Phys. Rev. 1930, 36 (5), 1008-1013.

(45) Tempkin, M. I.; Pyzhev, V. Kinetics of Ammonia Synthesis on Promoted Iron Catalyst. Acta Phys. Chim. USSR 1940, 12 (12), 327356.

(46) Jennings, J. R. Catalytic Ammonia Synthesis; Springer: Boston, MA, 1991; p 451, DOI: 10.1007/978-1-4757-9592-9.

(47) Rossetti, I.; Pernicone, N.; Ferrero, F.; Forni, L. Kinetic Study of Ammonia Synthesis on a Promoted Ru/C Catalyst. Ind. Eng. Chem. Res. 2006, 45 (12), 4150-4155.
(48) Buzzi Ferraris, G.; Donati, G.; Rejna, F.; Carrà, S. An Investigation on Kinetic Models for Ammonia Synthesis. Chem. Eng. Sci. 1974, 29 (7), 1621-1627.

(49) Tripodi, A.; Conte, F.; Rossetti, I. Process Intensification for Ammonia Synthesis in Multibed Reactors with Fe-Wustire and $\mathrm{Ru} / \mathrm{C}$ Catalysts. Ind. Eng. Chem. Res. 2021, 60, 908.

(50) Rossetti, I. Reactor Design, Modelling and Process Intensification for Ammonia Synthesis. In Sustainable Ammonia Production. Green Energy and Technology; Inamuddin, B. R., Asiri, A., Eds.; Springer: Cham, Switzerland, 2020; pp 17-48, DOI: 10.1007/978-3-030-3510692.

(51) Nielsen, A. Chemical Kinetics and Transport Processes in Ammonia Synthesis. Chim. Ind. (Milan) 1969, 51, 1052.

(52) Jurgen, H. H. Process and Apparatus for Performing Reactions in the Gaseous Phase. U.S. Patent 3,372,988, 1968.

(53) Zardi, U.; Pagani, G. European Patent 287765, 1988.

(54) Li, Y.; Bi, M.; Li, B.; Gao, W. Explosion Behaviors of AmmoniaAir Mixtures. Combust. Sci. Technol. 2018, 190 (10), 1804-1816.

(55) Ronney, P. D. Effect of Chemistry and Transport Properties on Near-Limit Flames at Microgravity. Combust. Sci. Technol. 1988, 59 (13), 123-141.

(56) Pfahl, U. J.; Ross, M. C.; Shepherd, J. E.; Pasamehmetoglu, K. O.; Unal, C. Flammability Limits, Ignition Energy, and Flame Speeds in $\mathrm{H}_{2}-$ $\mathrm{CH}_{4}-\mathrm{NH}_{3}-\mathrm{N}_{2} \mathrm{O}-\mathrm{O}_{2}-\mathrm{N}_{2}$ Mixtures. Combust. Flame 2000, 123 (1-2), $140-158$.

(57) Zakaznov, V. F.; Kursheva, L. A.; Fedina, Z. I. Determination of Normal Flame Velocity and Critical Diameter of Flame Extinction in Ammonia-Air Mixture. Combust., Explos. Shock Waves 1978, 14, 710.

(58) Coward, H. F.; Jones, G. W. Limits of Flammability of Gases and Vapors; Bureau of Mines: Pittsburgh, PA, 1952.

(59) Xiao, H.; Lai, S.; Valera-Medina, A.; Li, J.; Liu, J.; Fu, H. Experimental and Modeling Study on Ignition Delay of Ammonia/ Methane Fuels. Int. J. Energy Res. 2020, 44 (8), 6939-6949.

(60) Yu, L.; Zhou, W.; Feng, Y.; Wang, W.; Zhu, J.; Qian, Y.; Lu, X. The Effect of Ammonia Addition on the Low-Temperature Autoignition of n-Heptane: An Experimental and Modeling Study. Combust. Flame 2020, 217, 4-11.

(61) Drummond, L. J. High Temperature Oxidation of Ammonia. Combust. Sci. Technol. 1972, 5 (1), 175-182.

(62) Wooldridge, S. T.; Mertens, J. D.; Hanson, R. K.; Bowman, C. T. A Shock Tube Study of the Reactions of $\mathrm{CN}$ and $\mathrm{NCO}$ with $\mathrm{NO}_{2}$. Symp. Combust., [Proc.] 1994, 25 (1), 983-991.

(63) Salimian, S.; Hanson, R. K.; Kruger, C. H. Ammonia Oxidation in Shock-Heated $\mathrm{NH}_{3} / \mathrm{N}_{2} \mathrm{O} /$ Ar Mixtures. Combust. Flame 1984, 56 (1), 83-95.

(64) Bull, D. C. A Shock Tube Study of the Oxidation of Ammonia. Combust. Flame 1968, 12 (6), 603-610.

(65) Soloukhin, R. I. High-Temperature Oxidation of Ammonia, Carbon Monoxide, and Methane by Nitrous Oxide in Shock Waves. Symp. Combust., [Proc.] 1971, 13 (1), 121-128.

(66) Takeyama, T.; Miyama, H. A Shock-Tube Study of the Ammonia-Oxygen Reaction. Symp. Combust., [Proc.] 1967, 11 (1), 845-852.

(67) Shu, B.; He, X.; Ramos, C. F.; Fernandes, R. X.; Costa, M. Experimental and Modeling Study on the Auto-Ignition Properties of Ammonia/Methane Mixtures at Elevated Pressures. Proc. Combust. Inst. 2020, DOI: $10.1016 /$ j.proci.2020.06.291.

(68) Pochet, M.; Dias, V.; Moreau, B.; Foucher, F.; Jeanmart, H.; Contino, F. Experimental and Numerical Study, under LTC Conditions, of Ammonia Ignition Delay with and without Hydrogen Addition. Proc. Combust. Inst. 2019, 37 (1), 621-629.

(69) Shu, B.; Vallabhuni, S. K.; He, X.; Issayev, G.; Moshammer, K.; Farooq, A.; Fernandes, R. X. A Shock Tube and Modeling Study on the Autoignition Properties of Ammonia at Intermediate Temperatures. Proc. Combust. Inst. 2019, 37, 205.

(70) Mathieu, O.; Petersen, E. L. Experimental and Modeling Study on the High-Temperature Oxidation of Ammonia and Related $\mathrm{NO}_{x}$ Chemistry. Combust. Flame 2015, 162 (3), 554-570. 
(71) He, X.; Shu, B.; Nascimento, D.; Moshammer, K.; Costa, M.; Fernandes, R. X. Auto-Ignition Kinetics of Ammonia and Ammonia/ Hydrogen Mixtures at Intermediate Temperatures and High Pressures. Combust. Flame 2019, 206, 189.

(72) Feng, Y.; Zhu, J.; Mao, Y.; Raza, M.; Qian, Y.; Yu, L.; Lu, X. LowTemperature Auto-Ignition Characteristics of $\mathrm{NH}_{3} /$ Diesel Binary Fuel: Ignition Delay Time Measurement and Kinetic Analysis. Fuel 2020, 281 (July), 118761.

(73) Issayev, G.; Giri, B. R.; Elbaz, A. M.; Shrestha, K. P.; Mauss, F.; Roberts, W. L.; Farooq, A. Combustion Behavior of Ammonia Blended with Diethyl Ether. Proc. Combust. Inst. 2020, 000, 1-8.

(74) Dai, L.; Gersen, S.; Glarborg, P.; Mokhov, A.; Levinsky, H. Autoignition Studies of $\mathrm{NH}_{3} / \mathrm{CH}_{4}$ Mixtures at High Pressure. Combust. Flame 2020, 218, 19-26.

(75) Drummond, L. J. High Temperature Oxidation of Ammonia. Combust. Sci. Technol. 1972, 5 (1), 175-182.

(76) Dai, L.; Gersen, S.; Glarborg, P.; Levinsky, H.; Mokhov, A. Experimental and Numerical Analysis of the Autoignition Behavior of $\mathrm{NH}_{3}$ and $\mathrm{NH}_{3} / \mathrm{H}_{2}$ Mixtures at High Pressure. Combust. Flame 2020, $215,134-144$.

(77) Ichikawa, A.; Hayakawa, A.; Kitagawa, Y.; Kunkuma Amila Somarathne, K. D.; Kudo, T.; Kobayashi, H. Laminar Burning Velocity and Markstein Length of Ammonia/Hydrogen/Air Premixed Flames at Elevated Pressures. Int. J. Hydrogen Energy 2015, 40 (30), 9570-9578.

(78) Lee, J. H.; Kim, J. H.; Park, J. H.; Kwon, O. C. Studies on Properties of Laminar Premixed Hydrogen-Added Ammonia/Air Flames for Hydrogen Production. Int. J. Hydrogen Energy 2010, 35 (3), 1054-1064.

(79) Takizawa, K.; Takahashi, A.; Tokuhashi, K.; Kondo, S.; Sekiya, A. Burning Velocity Measurements of Nitrogen-Containing Compounds. J. Hazard. Mater. 2008, 155, 144.

(80) Mei, B.; Ma, S.; Zhang, Y.; Zhang, X.; Li, W.; Li, Y. Exploration on Laminar Flame Propagation of Ammonia and Syngas Mixtures up to 10 Atm. Combust. Flame 2020, 220, 368-377.

(81) Han, X.; Wang, Z.; Costa, M.; Sun, Z.; He, Y.; Cen, K. Experimental and Kinetic Modeling Study of Laminar Burning Velocities of $\mathrm{NH}_{3} /$ Air, $\mathrm{NH}_{3} / \mathrm{H}_{2} /$ Air, $\mathrm{NH}_{3} / \mathrm{CO} /$ Air and $\mathrm{NH}_{3} / \mathrm{CH}_{4}$ / Air Premixed Flames. Combust. Flame 2019, 206, 214.

(82) Murray, R. C.; Hall, A. R. Flame Speeds in Hydrazine Vapour and in Mixtures of Hydrazine and Ammonia with Oxygen. Trans. Faraday Soc. 1951, 47, 743-751.

(83) Buckley, W. L.; Husa, H. Combustion Properties of Ammonia. Chem. Eng. Prog. 1962, 58, 84.

(84) Andrews, D. G. R.; Gray, P. Combustion of Ammonia Supported by Oxygen, Nitrous Oxide or Nitric Oxide: Laminar Flame Propagation at Low Pressures in Binary Mixtures. Combust. Flame 1964, 8 (2), 113126.

(85) Gray, P.; Mackinven, R.; Smith, D. B. Combustion of Hydrogen and Oxygen with Ammonia and Nitrous Oxide-Laminar Flame Speeds and Flammability Limits at Low Pressure for Ternary Mixtures. Combust. Flame 1967, 11 (2), 109-119.

(86) Hayakawa, A.; Goto, T.; Mimoto, R.; Arakawa, Y.; Kudo, T.; Kobayashi, H. Laminar Burning Velocity and Markstein Length of Ammonia/Air Premixed Flames at Various Pressures. Fuel 2015, 159, 98-106.

(87) Ku, J. W.; Ahn, Y. J.; Kim, H. K.; Kim, Y. H.; Kwon, O. C. Propagation and Emissions of Premixed Methane-Ammonia/Air Flames. Energy 2020, 201, 117632.

(88) Lhuillier, C.; Brequigny, P.; Lamoureux, N.; Contino, F.; Mounaïm-Rousselle, C. Experimental Investigation on Laminar Burning Velocities of Ammonia/Hydrogen/Air Mixtures at Elevated Temperatures. Fuel 2020, 263, 116653.

(89) Liang, M.; Luo, B.; Zhi, L. Application of graphene and graphenebased materials in clean energy-related devices Minghui. Int. J. Energy Res. 2009, 33, 1161-1170.

(90) Liu, Q.; Chen, X.; Huang, J.; Shen, Y.; Zhang, Y.; Liu, Z. The Characteristics of Flame Propagation in Ammonia/Oxygen Mixtures. J. Hazard. Mater. 2019, 363 (5), 187-196.
(91) Mei, B.; Zhang, X.; Ma, S.; Cui, M.; Guo, H.; Cao, Z.; Li, Y. Experimental and Kinetic Modeling Investigation on the Laminar Flame Propagation of Ammonia under Oxygen Enrichment and Elevated Pressure Conditions. Combust. Flame 2019, 210, 236-246.

(92) Okafor, E. C.; Naito, Y.; Colson, S.; Ichikawa, A.; Kudo, T.; Hayakawa, A.; Kobayashi, H. Experimental and Numerical Study of the Laminar Burning Velocity of $\mathrm{CH}_{4}-\mathrm{NH}_{3}$-Air Premixed Flames. Combust. Flame 2018, 187, 185-198.

(93) Okafor, E. C.; Naito, Y.; Colson, S.; Ichikawa, A.; Kudo, T.; Hayakawa, A.; Kobayashi, H. Measurement and Modelling of the Laminar Burning Velocity of Methane-Ammonia-Air Flames at High Pressures Using a Reduced Reaction Mechanism. Combust. Flame 2019, 204, 162-175.

(94) Wang, D.; Ji, C.; Wang, Z.; Wang, S.; Zhang, T.; Yang, J. Measurement of Oxy-Ammonia Laminar Burning Velocity at Normal and Elevated Temperatures. Fuel 2020, 279 (June), 118425.

(95) Wargadalam, V. J.; Löffler, G.; Winter, F.; Hofbauer, H. Homogeneous Formation of $\mathrm{NO}$ and $\mathrm{N}_{2} \mathrm{O}$ from the Oxidation of $\mathrm{HCN}$ and $\mathrm{NH}_{3}$ at $600-1000^{\circ} \mathrm{C}$. Combust. Flame 2000, 120 (4), 465-478.

(96) Bennett, A. M.; Liu, P.; Li, Z.; Kharbatia, N. M.; Boyette, W.; Masri, A. R.; Roberts, W. L. Soot Formation in Laminar Flames of Ethylene/Ammonia. Combust. Flame 2020, 220, 210-218.

(97) Hulgaard, T.; Dam-Johansen, K. Homogeneous Nitrous Oxide Formation and Destruction under Combustion Conditions. AIChE J. 1993, 39 (8), 1342-1354.

(98) Maclean, D. I.; Wagner, H. G. The Structure of the Reaction Zones of Ammonia-Oxygen and Hydrazine-Decomposition Flames. Symp. Combust., [Proc.] 1967, 11 (1), 871-878.

(99) Manna, M. V.; Sabia, P.; Ragucci, R.; de Joannon, M. Oxidation and Pyrolysis of Ammonia Mixtures in Model Reactors. Fuel 2020, 264, 116768.

(100) Nakamura, H.; Hasegawa, S.; Tezuka, T. Kinetic Modeling of Ammonia/Air Weak Flames in a Micro Flow Reactor with a Controlled Temperature Profile. Combust. Flame 2017, 185, 16-27.

(101) Okafor, E. C.; Somarathne, K. D. K. A.; Ratthanan, R.; Hayakawa, A.; Kudo, T.; Kurata, O.; Iki, N.; Tsujimura, T.; Furutani, H.; Kobayashi, H. Control of $\mathrm{NO}_{x}$ and Other Emissions in Micro Gas Turbine Combustors Fuelled with Mixtures of Methane and Ammonia. Combust. Flame 2020, 211, 406-416.

(102) Sabia, P.; Manna, M. V.; Cavaliere, A.; Ragucci, R.; de Joannon, M. Ammonia Oxidation Features in a Jet Stirred Flow Reactor. The Role of $\mathrm{NH}_{2}$ Chemistry. Fuel 2020, 276, 118054.

(103) Stagni, A.; Cavallotti, C.; Arunthanayothin, S.; Song, Y.; Herbinet, O.; Battin-Leclerc, F.; Faravelli, T. An Experimental, Theoretical and Kinetic-Modeling Study of the Gas-Phase Oxidation of Ammonia. React. Chem. Eng. 2020, 5 (4), 696-711.

(104) Tian, Z.; Li, Y.; Zhang, L.; Glarborg, P.; Qi, F. An Experimental and Kinetic Modeling Study of Premixed $\mathrm{NH}_{3} / \mathrm{CH}_{4} / \mathrm{O}_{2} / \mathrm{Ar}$ Flames at Low Pressure. Combust. Flame 2009, 156 (7), 1413-1426.

(105) Blint, R. J.; Dasch, C. J. Formation of no and $\mathrm{N}_{2}$ from $\mathrm{NH}_{3}$ in flames. ACS Symposium Series 1983, 249, 87-101.

(106) Dagaut, P. On the Oxidation of Ammonia and Mutual Sensitization of the Oxidation of NO and Ammonia: Experimental and Kinetic Modeling. Combust. Sci. Technol. 2019, 00 (00), 1-13.

(107) Dasch, C. J.; Blint, R. J. A Mechanistic and Experimental Study of Ammonia Flames. Combust. Sci. Technol. 1984, 41 (5-6), 223-244.

(108) Dean, A. M.; Chou, M.-S.; Stern, D. Kinetics of Rich Ammonia Flames. Int. J. Chem. Kinet. 1984, 16 (6), 633-653.

(109) Dean, A. M.; Hardy, J. E.; Lyon, R. K. Kinetics and Mechanism of $\mathrm{NH}_{3}$ Oxidation. Symp. Combust., [Proc.] 1982, 19 (1), 97-105.

(110) Dean, A. M.; Chou, M.-S.; Stern, D. Nitrogen Chemistry in Flames Observations and Detailed Kinetic Modeling. ACS Symp. Ser. 1983, 249, 71-86.

(111) Fenimore, C. P.; Jones, G. W. Oxidation of Ammonia in Flames. J. Phys. Chem. 1961, 65 (2), 298-303.

(112) Hasegawa, T.; Sato, M. Study of Ammonia Removal from CoalGasified Fuel. Combust. Flame 1998, 114 (1-2), 246-258.

(113) Wang, S.; Wang, Z.; Elbaz, A. M.; Han, X.; He, Y.; Costa, M.; Konnov, A. A.; Roberts, W. L. Experimental Study and Kinetic Analysis 
of the Laminar Burning Velocity of $\mathrm{NH}_{3}$ /Syngas/Air, $\mathrm{NH}_{3} / \mathrm{CO} /$ Air and $\mathrm{NH}_{3} / \mathrm{H}_{2} /$ Air Premixed Flames at Elevated Pressures. Combust. Flame 2020, 221, 270-287.

(114) Li, J.; Huang, H.; Kobayashi, N.; He, Z.; Nagai, Y. Study on Using Hydrogen and Ammonia as Fuels: Combustion Characteristics and $\mathrm{NO}_{x}$ Formation. Int. J. Energy Res. 2014, 38 (9), 1214-1223.

(115) Glarborg, P.; Miller, J. A.; Ruscic, B.; Klippenstein, S. J. Modeling Nitrogen Chemistry in Combustion. Prog. Energy Combust. Sci. 2018, 67, 31-68.

(116) Miller, J. A.; Bowman, C. T. Mechanism and Modeling of Nitrogen Chemistry in Combustion. Prog. Energy Combust. Sci. 1989, 15 (4), 287-338.

(117) Glarborg, P.; Jensen, A. D.; Johnsson, J. E. Fuel Nitrogen Conversion in Solid Fuel Fired Systems. Prog. Energy Combust. Sci. 2003, 29 (2), 89-113.

(118) Lucassen, A.; Zhang, K.; Warkentin, J.; Moshammer, K.; Glarborg, P.; Marshall, P.; Kohse-Höinghaus, K. Fuel-Nitrogen Conversion in the Combustion of Small Amines Using Dimethylamine and Ethylamine as Biomass-Related Model Fuels. Combust. Flame 2012, 159 (7), 2254-2279.

(119) Lyon, R. K. The $\mathrm{NH}_{3}-\mathrm{NO}-\mathrm{O}_{2}$ Reaction. Int. J. Chem. Kinet. 1976, 8 (2), 315-318.

(120) Lyon, R. K.; Hardy, J. E. Discovery and Development of the Thermal DeNO ${ }_{x}$ Process. Ind. Eng. Chem. Fundam. 1986, 25 (1), 1924.

(121) Dean, A. M.; Bozzelli, J. W. Combustion Chemistry of Nitrogen. Gas-Phase Combust. Chem. 2000, 125-341.

(122) Klippenstein, S. J.; Harding, L. B.; Glarborg, P.; Miller, J. A. The Role of NNH in NO Formation and Control. Combust. Flame 2011, 158 (4), 774-789.

(123) Lindstedt, R. P.; Lockwood, F. C.; Selim, M. A. A Detailed Kinetic Study of Ammonia Oxidation. Combust. Sci. Technol. 1995, 108 (4-6), 231-254.

(124) Lu, Z.-m.; Lu, J.-d. Influences of $\mathrm{O}_{2}$ Concentration on NO Reduction and $\mathrm{N}_{2} \mathrm{O}$ Formation in Thermal $\mathrm{DeNO}_{x}$ Process. Combust. Flame 2009, 156 (6), 1303-1315.

(125) Miller, J. A.; Smooke, M. D.; Green, R. M.; Kee, R. J. Kinetic Modeling of the Oxidation of Ammonia in Flames. Combust. Sci. Technol. 1983, 34 (1-6), 149-176.

(126) Skreiberg, Ø.; Kilpinen, P.; Glarborg, P. Ammonia Chemistry below $1400 \mathrm{~K}$ under Fuel-Rich Conditions in a Flow Reactor. Combust. Flame 2004, 136 (4), 501-518.

(127) Miller, J. A.; Glarborg, P. Modeling the Thermal De-NO Process: Closing in on a Final Solution. Int. J. Chem. Kinet. 1999, 31 (11), 757-765.

(128) Miller, J.; Branch, M.; Kee, R. A Chemical Kinetic Model for the Selective Reduction of Nitric Oxide by Ammonia. Combust. Flame 1981, 43, 81-98.

(129) Miller, J. A.; Glarborg, P. Gas Phase Chemical Reaction Systems. Springer Ser. Chem. Phys. 1996, 61, 318-333.

(130) Rota, R.; Antos, D.; Zanoelo, E. F.; Carrà, S. Experimental Study and Kinetic Modelling of Nitric Oxide Reduction with Ammonia. Combust. Sci. Technol. 2001, 163 (1-6), 25-47.

(131) Kilpinen, P.; Hupa, M.; Glarborg, P. Reburning Chemistry: A Kinetic Modeling Study. Ind. Eng. Chem. Res. 1992, 31 (6), 1477-1490.

(132) Glarborg, P.; Dam-Johansen, K.; Miller, J. A.; Kee, R. J.; Coltrin, M. E. Modeling the Thermal DeNO ${ }_{x}$ Process in Flow Reactors. Surface Effects and Nitrous Oxide Formation. Int. J. Chem. Kinet. 1994, 26 (4), 421-436.

(133) Glarborg, P.; Miller, J. a. Mechanism and Modeling of Hydrogen-Cyanide Oxidation in A Flow Reactor. Combust. Flame 1994, 99 (3-4), 475-483.

(134) Song, Y.; Hashemi, H.; Christensen, J. M.; Zou, C.; Marshall, P.; Glarborg, P. Ammonia Oxidation at High Pressure and Intermediate Temperatures. Fuel 2016, 181, 358-365.

(135) Zhang, Y.; Mathieu, O.; Petersen, E. L.; Bourque, G.; Curran, H. $\mathrm{J}$. Assessing the Predictions of a $\mathrm{NO}_{x}$ Kinetic Mechanism on Recent Hydrogen and Syngas Experimental Data. Combust. Flame 2017, 182 (x), 122-141.
(136) Shrestha, K. P.; Seidel, L.; Zeuch, T.; Mauss, F. Detailed Kinetic Mechanism for the Oxidation of Ammonia Including the Formation and Reduction of Nitrogen Oxides. Energy Fuels 2018, 32 (10), 1020210217

(137) Li, R.; Konnov, A. A.; He, G.; Qin, F.; Zhang, D. Chemical Mechanism Development and Reduction for Combustion of $\mathrm{NH}_{3} / \mathrm{H}_{2} /$ $\mathrm{CH}_{4}$ Mixtures. Fuel 2019, 257, 116059.

(138) Jiang, Y.; Gruber, A.; Seshadri, K.; Williams, F. An Updated Short Chemical-Kinetic Nitrogen Mechanism for Carbon-Free Combustion Applications. Int. J. Energy Res. 2020, 44 (2), 795-810.

(139) Otomo, J.; Koshi, M.; Mitsumori, T.; Iwasaki, H.; Yamada, K. Chemical Kinetic Modeling of Ammonia Oxidation with Improved Reaction Mechanism for Ammonia/Air and Ammonia/Hydrogen/Air Combustion. Int. J. Hydrogen Energy 2018, 43, 3004.

(140) Dagaut, P.; Glarborg, P.; Alzueta, M. The Oxidation of Hydrogen Cyanide and Related Chemistry. Prog. Energy Combust. Sci. 2008, 34 (1), 1-46.

(141) Konnov, A. A.; De Ruyck, J. A Possible New Route for NO Formation via ${ }_{\mathrm{N}} 2 \mathrm{H}_{3}$. Combust. Sci. Technol. 2001, 168 (1), 1-46.

(142) Dayma, G.; Dagaut, P. Effects of Air Contamination on the Combustion of Hydrogen-Effect of $\mathrm{NO}$ and $\mathrm{NO}_{2}$ Addition on Hydrogen Ignition and Oxidation Kinetics. Combust. Sci. Technol. 2006, 178 (10-11), 1999-2024.

(143) Goulay, F.; Osborn, D. L.; Taatjes, C. A.; Zou, P.; Meloni, G.; Leone, S. R. Direct Detection of Polyynes Formation from the Reaction of Ethynyl Radical $\left(\mathrm{C}_{2} \mathrm{H}\right)$ with Propyne $\left(\mathrm{CH}_{3}-\mathrm{C} \equiv \mathrm{CH}\right)$ and Allene $\left(\mathrm{CH}_{2}=\mathrm{C}=\mathrm{CH}_{2}\right)$. Phys. Chem. Chem. Phys. 2007, 9 (31), 4291-4300.

(144) Kéromnès, A.; Metcalfe, W. K.; Heufer, K. A.; Donohoe, N.; Das, A. K.; Sung, C. J.; Herzler, J.; Naumann, C.; Griebel, P.; Mathieu, O.; et al. An Experimental and Detailed Chemical Kinetic Modeling Study of Hydrogen and Syngas Mixture Oxidation at Elevated Pressures. Combust. Flame 2013, 160 (6), 995-1011.

(145) Mathieu, O.; Levacque, A.; Petersen, E. L. Effects of $\mathrm{N}_{2} \mathrm{O}$ Addition on the Ignition of $\mathrm{H}_{2}-\mathrm{O}_{2}$ Mixtures: Experimental and Detailed Kinetic Modeling Study. Int. J. Hydrogen Energy 2012, 37 (20), 1539315405.

(146) Mathieu, O.; Kopp, M. M.; Petersen, E. L. Shock-Tube Study of the Ignition of Multi-Component Syngas Mixtures with and without Ammonia Impurities. Proc. Combust. Inst. 2013, 34 (2), 3211-3218.

(147) Glarborg, P.; Kubel, D.; Kristensen, P. G.; Hansen, J.; DamJohansen, $\mathrm{K}$. Interactions of $\mathrm{CO}, \mathrm{NO}_{x}$ and $\mathrm{H}_{2} \mathrm{O}$ Under Post-Flame Conditions. Combust. Sci. Technol. 1995, 110-111 (1), 461-485.

(148) Ruscic, B.; Pinzon, R. E.; Morton, M. L.; Von Laszevski, G.; Bittner, S. J.; Nijsure, S. G.; Amin, K. A.; Minkoff, M.; Wagner, A. F. Introduction to Active Thermochemical Tables: Several "Key" Enthalpies of Formation Revisited. J. Phys. Chem. A 2004, 108 (45), 9979-9997.

(149) Lamoureux, N.; Merhubi, H. El; Pillier, L.; de Persis, S.; Desgroux, P. Modeling of NO Formation in Low Pressure Premixed Flames. Combust. Flame 2016, 163, 557-575.

(150) Lamoureux, N.; Desgroux, P.; El Bakali, A.; Pauwels, J. F. Experimental and Numerical Study of the Role of NCN in Prompt-NO Formation in Low-Pressure $\mathrm{CH}_{4}-\mathrm{O}_{2}-\mathrm{N}_{2}$ and $\mathrm{C}_{2} \mathrm{H}_{2}-\mathrm{O}_{2}-\mathrm{N}_{2}$ Flames. Combust. Flame 2010, 157 (10), 1929-1941.

(151) Mendiara, T.; Glarborg, P. Ammonia Chemistry in Oxy-Fuel Combustion of Methane. Combust. Flame 2009, 156 (10), 1937-1949.

(152) Bian, J.; Vandooren, J.; Van Tiggelen, P. J. Experimental Study of the Structure of an Ammonia-Oxygen Flame. Symp. Combust., [Proc.] 1988, 21 (1), 953-963.

(153) Homer, J. B.; Sutton, M. M. Nitric Oxide Formation and Radical Overshoot in Premixed Hydrogen Flames. Combust. Flame 1973, 20 (1), 71-76.

(154) Combustion Chemistry Centre $\left(\mathrm{C}^{3}\right)$, NUI Galway. AramcoMech 2.0; $\mathrm{C}^{3}$, NUI Galway: Galway, Ireland, 2016.

(155) Dally, B. B.; Karpetis, A. N.; Barlow, R. S. Structure of Turbulent Non-Premixed Jet Flames in a Diluted Hot Coflow. Proc. Combust. Inst. 2002, 29 (1), 1147-1154.

(156) Hashemi, H.; Christensen, J. M.; Gersen, S.; Glarborg, P. Hydrogen Oxidation at High Pressure and Intermediate Temperatures: 
Experiments and Kinetic Modeling. Proc. Combust. Inst. 2015, 35 (1), $553-560$.

(157) Zheng, J.; Rocha, R. J.; Pelegrini, M.; Ferrão, L. F. A.; Carvalho, E. F. V.; Roberto-Neto, O.; MacHado, F. B. C.; Truhlar, D. G. A Product Branching Ratio Controlled by Vibrational Adiabaticity and Variational Effects: Kinetics of the $\mathrm{H}+$ trans $-\mathrm{N}_{2} \mathrm{H}_{2}$ Reactions. J. Chem. Phys. 2012, 136 (18), 184310.

(158) Metcalfe, W. K.; Burke, S. M.; Ahmed, S. S.; Curran, H. J. A Hierarchical and Comparative Kinetic Modeling Study of $\mathrm{C}_{1}-\mathrm{C}_{2}$ hydrocarbon and Oxygenated Fuels. Int. J. Chem. Kinet. 2013, 45 (10), 638-675.

(159) Kumar, P.; Meyer, T. R. Experimental and Modeling Study of Chemical-Kinetics Mechanisms for $\mathrm{H}_{2}-\mathrm{NH}_{3}$-Air Mixtures in Laminar Premixed Jet Flames. Fuel 2013, 108, 166-176.

(160) Reiter, A. J.; Kong, S. C. Combustion and Emissions Characteristics of Compression-Ignition Engine Using Dual Ammonia-Diesel Fuel. Fuel 2011, 90 (1), 87-97.

(161) Xiao, H.; Valera-Medina, A.; Bowen, P. J. Modeling Combustion of Ammonia/Hydrogen Fuel Blends under Gas Turbine Conditions. Energy Fuels 2017, 31 (8), 8631-8642.

(162) Joo, J. M.; Lee, S.; Kwon, O. C. Effects of Ammonia Substitution on Combustion Stability Limits and $\mathrm{NO}_{x}$ Emissions of Premixed Hydrogen-Air Flames. Int. J. Hydrogen Energy 2012, 37 (8), 69336941.

(163) Westlye, F. R.; Ivarsson, A.; Schramm, J. Experimental Investigation of Nitrogen Based Emissions from an Ammonia Fueled SI-Engine. Fuel 2013, 111, 239-247.

(164) Mørch, C. S.; Bjerre, A.; Gøttrup, M. P.; Sorenson, S. C.; Schramm, J. Ammonia/Hydrogen Mixtures in an SI-Engine: Engine Performance and Analysis of a Proposed Fuel System. Fuel 2011, 90 (2), 854-864.

(165) Ciccarelli, G.; Jackson, D.; Verreault, J. Flammability Limits of $\mathrm{NH}_{3}-\mathrm{H}_{2}-\mathrm{N}_{2}$-Air Mixtures at Elevated Initial Temperatures. Combust. Flame 2006, 144 (1-2), 53-63.

(166) Ryu, K.; Zacharakis-Jutz, G. E.; Kong, S. C. Performance Enhancement of Ammonia-Fueled Engine by Using Dissociation Catalyst for Hydrogen Generation. Int. J. Hydrogen Energy 2014, 39 (5), 2390-2398.

(167) Frigo, S.; Gentili, R. Analysis of the Behaviour of a 4-Stroke Si Engine Fuelled with Ammonia and Hydrogen. Int. J. Hydrogen Energy 2013, 38 (3), 1607-1615.

(168) Choi, S.; Lee, S.; Kwon, O. C. Extinction Limits and Structure of Counterflow Nonpremixed Hydrogen-Doped Ammonia/Air Flames at Elevated Temperatures. Energy 2015, 85, 503-510.

(169) Woo, M.; Choi, B. C.; Ghoniem, A. F. Experimental and Numerical Studies on $\mathrm{NO}_{x}$ Emission Characteristics in Laminar NonPremixed Jet Flames of Ammonia-Containing Methane Fuel with Oxygen/Nitrogen Oxidizer. Energy 2016, 114, 961-972.

(170) Li, B.; He, Y.; Li, Z.; Konnov, A. A. Measurements of NO Concentration in $\mathrm{NH}_{3}$-Doped $\mathrm{CH}_{4}+$ Air Flames Using Saturated Laser-Induced Fluorescence and Probe Sampling. Combust. Flame 2013, 160 (1), 40-46.

(171) Sullivan, N.; Jensen, A.; Glarborg, P.; Day, M. S.; Grcar, J. F.; Bell, J. B.; Pope, C. J.; Kee, R. J. Ammonia Conversion and $\mathrm{NO}_{x}$ Formation in Laminar Coflowing Nonpremixed Methane-Air Flames. Combust. Flame 2002, 131, 285.

(172) Reiter, A. J.; Kong, S. C. Demonstration of CompressionIgnition Engine Combustion Using Ammonia in Reducing Greenhouse Gas Emissions. Energy Fuels 2008, 22, 2963.

(173) Ryu, K.; Zacharakis-Jutz, G. E.; Kong, S. C. Effects of Gaseous Ammonia Direct Injection on Performance Characteristics of a SparkIgnition Engine. Appl. Energy 2014, 116, 206-215.

(174) Grannell, S. M.; Assanis, D. N.; Bohac, S. V.; Gillespie, D. E. The Fuel Mix Limits and Efficiency of a Stoichiometric, Ammonia, and Gasoline Dual Fueled Spark Ignition Engine. J. Eng. Gas Turbines Power 2008, 130 (4), 1-8.

(175) Ryu, K.; Zacharakis-Jutz, G. E.; Kong, S. C. Performance Characteristics of Compression-Ignition Engine Using High Concen- tration of Ammonia Mixed with Dimethyl Ether. Appl. Energy 2014, $113,488-499$.

(176) Haputhanthri, S. O.; Maxwell, T. T.; Fleming, J.; Austin, C. Ammonia and Gasoline Fuel Blends for Spark Ignited Internal Combustion Engines. J. Energy Resour. Technol. 2015, 137 (6), 062201.

(177) Kurata, O.; Iki, N.; Matsunuma, T.; Inoue, T.; Suzuki, M.; Tsujimura, T.; Furutani, H. Power Generation by a Micro Gas Turbine Firing Kerosene and Ammonia. Proceedings of the International Conference on Power Engineering (ICOPE); Yokohama, Japan, Nov 30-Dec 4, 2015; DOI: 10.1299/jsmeicope.2015.12._ICOPE-15-_96.

(178) Yapicioglu, A.; Dincer, I. Performance Assesment of Hydrogen and Ammonia Combustion with Various Fuels for Power Generators. Int. J. Hydrogen Energy 2018, 43 (45), 21037-21048.

(179) Hayakawa, A.; Arakawa, Y.; Mimoto, R.; Somarathne, K. D. K. A.; Kudo, T.; Kobayashi, H. Experimental Investigation of Stabilization and Emission Characteristics of Ammonia/Air Premixed Flames in a Swirl Combustor. Int. J. Hydrogen Energy 2017, 42 (19), 14010-14018. (180) Somarathne, K. D. K. A.; C. Okafor, E.; Hayakawa, A.; Kudo, T.; Kurata, O.; Iki, N.; Kobayashi, H. Emission Characteristics of Turbulent Non-Premixed Ammonia/Air and Methane/Air Swirl Flames through a Rich-Lean Combustor under Various Wall Thermal Boundary Conditions at High Pressure. Combust. Flame 2019, 210, $247-261$.

(181) Xiao, H.; Valera-Medina, A.; Bowen, P.; Dooley, S. 3D Simulation of Ammonia Combustion in a Lean Premixed Swirl Burner. Energy Procedia 2017, 142, 1294.

(182) Valera-Medina, A.; Marsh, R.; Runyon, J.; Pugh, D.; Beasley, P.; Hughes, T.; Bowen, P. Ammonia-Methane Combustion in Tangential Swirl Burners for Gas Turbine Power Generation. Appl. Energy 2017, $185,1362$.

(183) Hussein, N. A.; Valera-Medina, A.; Alsaegh, A. S. AmmoniaHydrogen Combustion in a Swirl Burner with Reduction of $\mathrm{NO}_{x}$ Emissions. Energy Procedia 2019, 158, 2305.

(184) Vigueras-Zuniga, M. O.; Tejeda-Del-Cueto, M. E.; VasquezSantacruz, J. A.; Herrera-May, A. L.; Valera-Medina, A. Numerical Predictions of a Swirl Combustor Using Complex Chemistry Fueled with Ammonia/Hydrogen Blends. Energies 2020, 13, 288.

(185) Somarathne, K. D. K. A.; Hayakawa, A.; Kobayashi, H. Numerical Investigation on the Combustion Characteristics of Turbulent Premixed Ammonia/Air Flames Stabilized by a Swirl Burner. J. Fluid Sci. Technol. 2016, 11 (4), JFST0026-JFST0026.

(186) Somarathne, K. D. K. A.; Colson, S.; Hayakawa, A.; Kobayashi, H. Modelling of Ammonia/Air Non-Premixed Turbulent Swirling Flames in a Gas Turbine-like Combustor at Various Pressures. Combust. Theory Modell. 2018, 22, 973.

(187) Franco, M. C.; Rocha, R. C.; Costa, M.; Yehia, M. Characteristics of $\mathrm{NH}_{3} / \mathrm{H}_{2}$ /Air Flames in a Combustor Fired by a Swirl and Bluff-Body Stabilized Burner. Proc. Combust. Inst. 2020, DOI: $10.1016 /$ j.proci.2020.06.141.

(188) Okafor, E. C.; Somarathne, K. D. K. A.; Hayakawa, A.; Kudo, T.; Kurata, O.; Iki, N.; Kobayashi, H. Towards the Development of an Efficient Low- $\mathrm{NO}_{x}$ Ammonia Combustor for a Micro Gas Turbine. Proc. Combust. Inst. 2019, 37 (4), 4597-4606.

(189) Somarathne, K. D. K. A.; Hatakeyama, S.; Hayakawa, A.; Kobayashi, H. Numerical Study of a Low Emission Gas Turbine like Combustor for Turbulent Ammonia/Air Premixed Swirl Flames with a Secondary Air Injection at High Pressure. Int. J. Hydrogen Energy 2017, 42 (44), 27388-27399.

(190) Pugh, D.; Bowen, P.; Valera-Medina, A.; Giles, A.; Runyon, J.; Marsh, R. Influence of Steam Addition and Elevated Ambient Conditions on NO $x$ Reduction in a Staged Premixed Swirling NH 3 /H 2 Flame. Proc. Combust. Inst. 2019, 37 (4), 5401-5409.

(191) Zhu, X.; Khateeb, A. A.; Guiberti, T. F.; Roberts, W. L. NO and $\mathrm{OH}^{*}$ Emission Characteristics of Very-Lean to Stoichiometric Ammonia-Hydrogen-Air Swirl Flames. Proc. Combust. Inst. 2020, DOI: $10.1016 /$ j.proci.2020.06.275.

(192) Khateeb, A. A.; Guiberti, T. F.; Zhu, X.; Younes, M.; Jamal, A.; Roberts, W. L. Stability Limits and NO Emissions of Technically- 
Premixed Ammonia-Hydrogen-Nitrogen-Air Swirl Flames. Int. J. Hydrogen Energy 2020, 45 (41), 22008-22018.

(193) International Energy Agency (IEA). Energy Transitions; Penttinen, S.-L., Mersinia, I., Eds.; Intersentia: Cambridge, U.K., 2017; DOI: $10.1017 / 9781780685007$.

(194) Tamura, M.; Gotou, T.; Ishii, H.; Riechelmann, D. Experimental Investigation of Ammonia Combustion in a Bench Scale 1.2 MW-Thermal Pulverised Coal Firing Furnace. Appl. Energy 2020, 277, 115580.

(195) Zhang, J.; Ito, T.; Ishii, H.; Ishihara, S.; Fujimori, T. Numerical Investigation on Ammonia Co-Firing in a Pulverized Coal Combustion Facility: Effect of Ammonia Co-Firing Ratio. Fuel 2020, 267, 117166.

(196) Ishihara, S.; Zhang, J.; Ito, T. Numerical Calculation with Detailed Chemistry of Effect of Ammonia Co-Firing on NO Emissions in a Coal-Fired Boiler. Fuel 2020, 266, 116924.

(197) Akira Yamamoto Kimoto, M.; Ozawa, Y.; Hara, S. Basic CoFiring Characteristics of Ammonia with Pulverized Coal in a Single Burner Test Furnace. Proceedings of the 2018 AIChE Annual Meeting; Pittsburgh, PA, Oct 27-30, 2018.

(198) Kujiraoka, H.; Izumi, T.; Yoshizuru, Y.; Suemasy, T.; Ueda, M.; Niki, T.; Itou, T.; Nishio, M.; Murai, R.; Akamatsu, F. Evaluation of the cement clinker fired in the combustion furnace of heavy-oil and $\mathrm{NH}_{3}$. Proceedings of the 2018 AIChE Annual Meeting; Pittsburgh, PA, Oct 2730, 2018

(199) Sorrentino, G.; Cavaliere, A.; Sabia, P.; Ragucci, R.; de Joannon, M. Diffusion Ignition Processes in MILD Combustion: A Mini-Review. Front. Mech. Eng. 2020, 6, 10.

(200) Sorrentino, G.; Sabia, P.; Bozza, P.; Ragucci, R.; de Joannon, M. Low- $\mathrm{NO}_{x}$ Conversion of Pure Ammonia in a Cyclonic Burner under Locally Diluted and Preheated Conditions. Appl. Energy 2019, 254, 113676.

(201) de Joannon, M.; Sabia, P.; Sorrentino, G.; Bozza, P.; Ragucci, R. Small Size Burner Combustion Stabilization by Means of Strong Cyclonic Recirculation. Proc. Combust. Inst. 2017, 36, 3361.

(202) Ariemma, G. B.; Sabia, P.; Sorrentino, G.; Bozza, P.; de Joannon, M.; Ragucci, R. Influence of Water Addition on MILD Ammonia Combustion Performances and Emissions. Proc. Combust. Inst. 2020, DOI: $10.1016 /$ j.proci.2020.06.143.

(203) Sabia, P.; de Joannon, M. On $\mathrm{H}_{2}-\mathrm{O}_{2}$ Oxidation in Several Bath Gases. Int. J. Hydrogen Energy 2020, 45, 8151.

(204) Sabia, P.; Manna, M. V.; Ragucci, R.; de Joannon, M. Mutual Inhibition Effect of Hydrogen and Ammonia in Oxidation Processes and the Role of Ammonia as "Strong" Collider in Third-Molecular Reactions. Int. J. Hydrogen Energy 2020, 45 (56), 32113-32127.

(205) Bicer, Y.; Dincer, I. Clean Fuel Options with Hydrogen for Sea Transportation: A Life Cycle Approach. Int. J. Hydrogen Energy 2018, 43 (2), 1179.

(206) de Vries, N. Safe and Effective Application of Ammonia as a Marine Fuel. Master's Thesis, Delft University of Technology, Delft, Netherlands, 2019.

(207) Krejci, M. C.; Mathieu, O.; Vissotski, A. J.; Ravi, S.; Sikes, T. G.; Petersen, E. L.; Kérmonès, A.; Metcalfe, W.; Curran, H. J. Laminar Flame Speed and Ignition Delay Time Data for the Kinetic Modeling of Hydrogen and Syngas Fuel Blends. J. Eng. Gas Turbines Power 2013, 135 (2), 021503.

(208) Park, O.; Veloo, P. S.; Liu, N.; Egolfopoulos, F. N. Combustion Characteristics of Alternative Gaseous Fuels. Proc. Combust. Inst. 2011, 33, 887.

(209) Dirrenberger, P.; Glaude, P. A.; Bounaceur, R.; Le Gall, H.; Da Cruz, A. P.; Konnov, A. A.; Battin-Leclerc, F. Laminar Burning Velocity of Gasolines with Addition of Ethanol. Fuel 2014, 115, 162.

(210) Yu, H.; Hu, E.; Cheng, Y.; Zhang, X.; Huang, Z. Experimental and Numerical Study of Laminar Premixed Dimethyl Ether/MethaneAir Flame. Fuel 2014, 136, 37.

(211) Sileghem, L.; Alekseev, V. A.; Vancoillie, J.; Van Geem, K. M.; Nilsson, E. J. K.; Verhelst, S.; Konnov, A. A. Laminar Burning Velocity of Gasoline and the Gasoline Surrogate Components Iso-Octane, nHeptane and Toluene. Fuel 2013, 112, 355.
(212) Gray, J. T.; Dimitroff, E.; Meckel, N. T.; Quillian, R. D. Ammonia Fuel-Engine Compatibility and Combustion. SAE Tech. Pap. Ser. 1966, sdf DOI: 10.4271/660156.

(213) Sawyer, R. F.; Starkman, E. S.; Muzio, L.; Schmidt, W. L. Oxides of Nitrogen in the Combustion Products of an Ammonia Fueled Reciprocating Engine. SAE Tech. Pap. Ser. 1968, DOI: 10.4271/ 680401.

(214) Starkman, E. S.; Newhall, H. K.; Sutton, R.; Maguire, T.; Farbar, L. Ammonia as a Spark Ignition Engine Fuel: Theory and Application. SAE Tech. Pap. Ser. 1966, DOI: 10.4271/660155.

(215) Lamas, M. I.; Rodriguez, C. G. Numerical Model to Analyze $\mathrm{NO}_{x}$ Reduction by Ammonia Injection in Diesel-Hydrogen Engines. Int. J. Hydrogen Energy 2017, 42 (41), 26132-26141.

(216) Schramm, J.; Klüssmann, J. N.; Ekknud, L. R.; Ivarsson, A. Ammonia Application in IC Engines; Advanced Motor Fuels Technology Collaboration Programme, International Energy Agency (IEA): Paris, France, 2020.

(217) Mounaïm-Rousselle, C.; Brequigny, P. Ammonia as Fuel for Low-Carbon Spark-Ignition Engines of Tomorrow's Passenger Cars. Front. Mech. Eng. 2020, 6, 70.

(218) Dimitriou, P.; Javaid, R. A Review of Ammonia as a Compression Ignition Engine Fuel. Int. J. Hydrogen Energy 2020, 45, 7098.

(219) Lesmana, H.; Zhang, Z.; Zhu, M.; Zhang, D.; Li, X.; Xu, W. $\mathrm{NH}_{3}$ as a Transport Fuel in Internal Combustion Engines: A Technical Review. J. Energy Resour. Technol. 2019, 141 (7), 070703.

(220) Rehbein, M. C.; Meier, C.; Eilts, P.; Scholl, S. Mixtures of Ammonia and Organic Solvents as Alternative Fuel for Internal Combustion Engines. Energy Fuels 2019, 33 (10), 10331-10342.

(221) Woo, Y.; Jang, J. Y.; Lee, Y. J.; Kim, J.-N. Recent Progress on the Ammonia-Gasoline and the Ammonia-Diesel Dual Fueled Internal Combustion Engines in Korea. Proceedings of the 11th $\mathrm{NH}_{3}$ Fuel Conference; Des Moines, IA, Sept 21-24, 2014.

(222) Lhuillier, C.; Brequigny, P.; Contino, F.; Rousselle, C. Performance and Emissions of an Ammonia-Fueled SI Engine with Hydrogen Enrichment. SAE Tech. Pap. Ser. 2019, DOI: 10.4271/201924-0137.

(223) Koike, M.; Miyagawa, H.; Suzuoki, T.; Ogasawara, K. Ammonia as a Hydrogen Energy Carrier and Its Application to Internal Combustion Engines. Sustainable Vehicle Technologies: Driving the Green Agenda; Elsevier: Amsterdam, Netherlands, 2012; pp 61-70; DOI: $10.1533 / 9780857094575.2 .61$.

(224) Koike, M.; Suzuoki, T. In-Line Adsorption System for Reducing Cold-Start Ammonia Emissions from Engines Fueled with Ammonia and Hydrogen. Int. J. Hydrogen Energy 2019, 44 (60), 32271-32279.

(225) Lhuillier, C.; Brequigny, P.; Contino, F.; Rousselle, C. Combustion Characteristics of Ammonia in a Modern Spark-Ignition Engine. SAE Tech. Pap. Ser. 2019, DOI: 10.4271/2019-24-0237.

(226) Lee, D.; Song, H. Development of Combustion Strategy for the Internal Combustion Engine Fueled by Ammonia and Its Operating Characteristics. J. Mech Sci. Technol. 2018, 32 (4), 1905-1925.

(227) Wang, W.; Herreros, J. M.; Tsolakis, A.; York, A. P. E. Ammonia as Hydrogen Carrier for Transportation; Investigation of the Ammonia Exhaust Gas Fuel Reforming. Int. J. Hydrogen Energy 2013, 38 (23), 9907-9917.

(228) Wang, W.; Herreros, J. M.; Tsolakis, A.; York, A. P. E. Reducing $\mathrm{CO}_{2}$ Footprint through Synergies in Carbon Free Energy Vectors and Low Carbon Fuels. Energy 2016, 112, 976.

(229) Sittichompoo, S.; Nozari, H.; Herreros, J. M.; Serhan, N.; da Silva, J. A. M.; York, A. P. E.; Millington, P.; Tsolakis, A. Exhaust Energy Recovery via Catalytic Ammonia Decomposition to Hydrogen for Low Carbon Clean Vehicles. Fuel 2021, 285, 119111.

(230) Ryu, K.; Zacharakis-Jutz, G. E.; Kong, S.-C. Effects of Gaseous Ammonia Direct Injection on Performance Characteristics of a SparkIgnition Engine. Appl. Energy 2014, 116, 206-215.

(231) Sasaki, S.; Sarlashkar, J. Internal Combustion Engine with Ammonia Fuel. U.S. Patent 8,166,926 B2, May 1, 2012.

(232) Brown, T. University of Minnesota Demonstrates Efficient Ammonia Dual-Fuel Engine System; Ammonia Energy Association: 
Brooklyn, NY, 2019; https://www.ammoniaenergy.org/articles/ university-of-minnesota-demonstrates-efficient-ammonia-dual-fuelengine-system/ (accessed Jan 19, 2021).

(233) Boretti, A. A. Novel Heavy Duty Engine Concept for Operation Dual Fuel $\mathrm{H}_{2}-\mathrm{NH}_{3}$. Int. J. Hydrogen Energy 2012, 37, 7869.

(234) Boretti, A. Novel Dual Fuel Diesel-Ammonia Combustion System in Advanced TDI Engines. Int. J. Hydrogen Energy 2017, 42 (10), 7071-7076.

(235) Hansson, J.; Brynolf, S.; Fridell, E.; Lehtveer, M. The Potential Role of Ammonia as Marine Fuel-Based on Energy Systems Modeling and Multi-Criteria Decision Analysis. Sustainability 2020, 12 (8), 3265.

(236) Laursen, R. Ship Operation Using LPG and Ammonia as Fuel on MAN B\&W Dual Fuel ME-LGIP Engines. Proceedings of the $\mathrm{NH}_{3}$ Fuel Conference; Pittsburgh, PA, Oct 31-Nov 1, 2018.

(237) Brown, T. MAN Energy Solutions: An Ammonia Engine for the Maritime Sector; Ammonia Energy Association: Brooklyn, NY, 2019; https://www.ammoniaenergy.org/articles/man-energy-solutions-anammonia-engine-for-the-maritime-sector/ (accessed Jan 19, 2021).

(238) Pochet, M.; Dias, V.; Jeanmart, H.; Verhelst, S.; Contino, F. Multifuel CHP HCCI Engine towards Flexible Power-to-Fuel: Numerical Study of Operating Range. Energy Procedia 2017, 105, 1532-1538.

(239) Pochet, M.; Jeanmart, H.; Contino, F. A 22:1 Compression Ratio Ammonia-Hydrogen HCCI Engine: Combustion, Load, and Emission Performances. Front. Mech. Eng. 2020, 6, 43.

(240) Blarigan, P. V. Advanced Internal Combustion Engine Research. Proceedings of the 2000 DOE Hydrogen Program Review; San Ramon, CA, May 9-11, 2000.

(241) Schönborn, A. Aqueous Solution of Ammonia as Marine Fuel. Proc. Inst. Mech. Eng., Part M 2020, 235 (1), 147509022093715.

(242) Frigo, S.; Gentili, R. Further Evolution of an Ammonia Fuelled Range Extender for Hybrid Vehicles. Proceedings of the $\mathrm{NH}_{3}$ Fuel Association; Des Moines, IA, Sept 21-24, 2014.

(243) Horlock, J. H. Aero-Engine Derivative Gas Turbines for Power Generation: Thermodynamic and Economic Perspectives. J. Eng. Gas Turbines Power 1997, 119 (1), 119-123.

(244) Kailos, N. C. Utilization of Ammonia as an Alternative Fuel in Army Aircraft Engines; U.S. Army Aviation Materiel Laboratories: Fort Eustis, VA, 1966; USAAVLABS Technical Report 66-52.

(245) Verkamp, F. J.; Hardin, M. C.; Williams, J. R. Ammonia Combustion Properties and Performance in Gas-Turbine Burners. Symp. (Int.) Combust., [Proc.] 1967, 11, 985-992.

(246) Pratt, D. T. Performance of Ammonia-Fired Gas-Turbine Combustors; University of California, Berkeley: Berkeley, CA, 1967; Report TS-67-5.

(247) Newhall, H. K.; Starkman, E. S. Theoretical Performance of Ammonia as a Gas Turbine Fuel. SAE Tech. Pap. Ser. 1966, DOI: $10.4271 / 660768$

(248) Bull, M. G. Development of an Ammonia-Burning Gas Turbine Engine; U.S. Army Engineer Research and Development Laboratories; Fort Belvoir, VA, 1968; DOI: 10.21236/AD0671667

(249) Wiswell, R. L. X-15 Propulsion System. Proceedings of the 33rd Joint Propulsion Conference and Exhibit; Seattle, WA July 6-9, 1997; DOI: 10.2514/6.1997-2682.

(250) Walker, J.; Weil, J. The X-15 Program; Proceedings of the Heterogeneous Combustion Conference; Palm Beach, FL, Dec 11-13, 1963; DOI: 10.2514/6.1963-1440.

(251) Dydek, Z. T.; Annaswamy, A. M.; Lavretsky, E. Adaptive Control and the NASA X-15 Program: A Concise History, Lessons Learned, and a Provably Correct Design. In Proceedings of the American Control Conference 2008, 2957-2962.

(252) Goldmann, A.; Sauter, W.; Oettinger, M.; Kluge, T.; Schröder, U.; Seume, J.; Friedrichs, J.; Dinkelacker, F. A Study on Electrofuels in Aviation. Energies 2018, 11 (2), 392.

(253) Haar, L. Thermodynamic Properties of Ammonia as an Ideal Gas. J. Res. Natl. Bur. Stand., Sect. A 1968, 72A (2), 207.

(254) Ball, M.; Wietschel, M. The Future of Hydrogen - Opportunities and Challenges. Int. J. Hydrogen Energy 2009, 34 (2), 615-627.
(255) Balestri, M.; Cecchini, D.; Cinti, V. Unconventional Fuels Experimental Campaigns in Gas Turbine Combustor at Enel Sesta Facility. Proceedings of the ASME Turbo Expo 2004: Power for Land, Sea, and Air; Vienna, Austria, June 14-17, 2004; DOI: 10.1115/gt200453274.

(256) Karabeyoglu, A.; Evans, B. Fuel Conditioning System for Ammonia-Fired Power Plants. Proceedings of the 9th Annual $\mathrm{NH}_{3}$ Fuel Association Conference; San Antonio, TX, Sept 30-Oct 3, 2012.

(257) Meyer, T.; Kumar, P.; Li, M.; Redfern, K.; Diaz, D. Ammonia Combustion with Near-Zero Pollutant Emissions; Iowa State University: Ames, IA, 2012; http://www.rsof.org/images/NO CO2 FLAME CONSTRUTION NH3.pdf (accessed Oct 12, 2020).

(258) Iki, N.; Kurata, O.; Matsunuma, T.; Inoue, T.; Tsujimura, T.; Furutani, H.; Kobayashi, H.; Hayakawa, A.; Arakawa, Y.; Ichikawa, A.. Micro Gas Turbine Firing Ammonia. Proceedings of the ASME Turbo Expo 2016: Turbomachinery Technical Conference and Exposition; Seoul, South Korea, June 13-17, 2016; DOI: 10.1115/GT2016-56954.

(259) Iki, N.; Kurata, O.; Matsunuma, T.; Inoue, T.; Tsujimura, T.; Furutani, H.; Kobayashi, H.; Hayakawa, A. Operation and Flame Observation of Micro Gas Turbine Firing Ammonia. Proceedings of the ASME Turbo Expo 2017: Turbomachinery Technical Conference and Exposition; Charlotte, NC, June 26-30, 2017; DOI: 10.1115/GT201764250

(260) Iki, N.; Kurata, O.; Matsunuma, T.; Inoue, T.; Suzuki, M.; Tsujimura, T.; Furutani, H. Micro Gas Turbine Firing Kerosene and Ammonia. Proceedings of the ASME Turbo Expo 2015: Turbine Technical Conference and Exposition; Montreal, Quebec, Canada, June 15-19, 2015; DOI: $10.1115 /$ GT2015-43689.

(261) Somarathne, K. D. K. A.; Hatakeyama, S.; Hayakawa, A.; Kobayashi, H. Numerical Study of a Low Emission Gas Turbine like Combustor for Turbulent Ammonia/Air Premixed Swirl Flames with a Secondary Air Injection at High Pressure. Int. J. Hydrogen Energy 2017, 42 (44), 27388-27399.

(262) Valera-Medina, A.; Morris, S.; Runyon, J.; Pugh, D. G.; Marsh, R.; Beasley, P.; Hughes, T. Ammonia, Methane and Hydrogen for Gas Turbines. Energy Procedia 2015, 75, 118.

(263) Xiao, H.; Valera-Medina, A. Chemical Kinetic Mechanism Study on Premixed Combustion of Ammonia/Hydrogen Fuels for Gas Turbine Use. J. Eng. Gas Turbines Power 2017, 139 (8), 081504.

(264) Pugh, D.; Valera-Medina, A.; Bowen, P.; Giles, A.; Goktepe, B.; Runyon, J.; Morris, S.; Hewlett, S.; Marsh, R. Emissions Performance of Staged Premixed and Diffusion Combustor Concepts for an $\mathrm{NH}_{3} /$ Air Flame with and without Reactant Humidification. J. Eng. Gas Turbines Power 2020, 1-10.

(265) Xiao, H.; Howard, M. S.; Valera-Medina, A.; Dooley, S.; Bowen, P. Reduced Chemical Mechanisms for Ammonia/Methane Co-Firing for Gas Turbine Applications. Energy Procedia 2017, 105, 1483-1488.

(266) Xiao, H.; Howard, M.; Valera-Medina, A.; Dooley, S.; Bowen, P. J. Study on Reduced Chemical Mechanisms of Ammonia/Methane Combustion under Gas Turbine Conditions. Energy Fuels 2016, 30 (10), 8701-8710.

(267) Honzawa, T.; Kai, R.; Okada, A.; Valera-Medina, A.; Bowen, P. J.; Kurose, R. Predictions of NO and CO Emissions in Ammonia/ Methane/Air Combustion by LES Using a Non-Adiabatic Flamelet Generated Manifold. Energy 2019, 186, 115771.

(268) Valera-Medina, A.; Gutesa, M.; Xiao, H.; Pugh, D.; Giles, A.; Goktepe, B.; Marsh, R.; Bowen, P. Premixed Ammonia/Hydrogen Swirl Combustion under Rich Fuel Conditions for Gas Turbines Operation. Int. J. Hydrogen Energy 2019, 44 (16), 8615-8626.

(269) Valera-Medina, A.; Pugh, D. G.; Marsh, P.; Bulat, G.; Bowen, P. Preliminary Study on Lean Premixed Combustion of AmmoniaHydrogen for Swirling Gas Turbine Combustors. Int. J. Hydrogen Energy 2017, 42, 24495.

(270) Pugh, D.; Runyon, J.; Bowen, P.; Giles, A.; Valera-Medina, A.; Marsh, R.; Goktepe, B.; Hewlett, S. An Investigation of Ammonia Primary Flame Combustor Concepts for Emissions Reduction with $\mathrm{OH}^{*}, \mathrm{NH}_{2}{ }^{*}$ and $\mathrm{NH}^{*}$ Chemiluminescence at Elevated Conditions. Proc. Combust. Inst. 2020, DOI: 10.1016/j.proci.2020.06.310. 
(271) Law, C. K. Combustion Physics; Cambridge University Press: Cambridge, U.K., 2010.

(272) da Rocha, R. C.; Costa, M.; Bai, X.-S. Chemical Kinetic Modelling of Ammonia/Hydrogen/Air Ignition, Premixed Flame Propagation and NO Emission. Fuel 2019, 246, 24-33.

(273) Xiao, H.; Wang, Z.; Valera-Medina, A.; Bowen, P. J. Study on Characteristics of Co-Firing Ammonia/Methane Fuels under Oxygen Enriched Combustion Conditions. J. Therm. Sci. 2018, 27, 270.

(274) Mashruk, S.; Xiao, H.; Valera-Medina, A. Rich-Quench-Lean Model Comparison for the Clean Use of Humidified Ammonia/ Hydrogen Combustion Systems. Int. J. Hydrogen Energy 2021, 46 (5), $4472-4484$.

(275) Okafor, E. C.; Yamashita, H.; Hayakawa, A.; Somarathne, K. D. K. A.; Kudo, T.; Tsujimura, T.; Uchida, M.; Ito, S.; Kobayashi, H. Flame Stability and Emissions Characteristics of Liquid Ammonia Spray CoFired with Methane in a Single Stage Swirl Combustor. Fuel 2021, 287, 119433.

(276) Keller, M.; Koshi, M.; Otomo, J.; Iwasaki, H.; Mitsumori, T.; Yamada, K. Thermodynamic Evaluation of an Ammonia-Fueled Combined-Cycle Gas Turbine Process Operated under Fuel-Rich Conditions. Energy 2020, 194, 116894.

(277) Guteša Božo, M.; Vigueras-Zuniga, M. O.; Buffi, M.; Seljak, T.; Valera-Medina, A. Fuel Rich Ammonia-Hydrogen Injection for Humidified Gas Turbines. Appl. Energy 2019, 251, 113334.

(278) Guteša Božo, M.; Mashruk, S.; Zitouni, S.; Valera-Medina, A. Humidified Ammonia/Hydrogen RQL Combustion in a Trigeneration Gas Turbine Cycle. Energy Convers. Manage. 2021, 227, 113625.

(279) Gutesa-Bozo, M.; Valera-Medina, A. Trigeneration Humidified Gas Turbine Cycles for Ammonia/Hydrogen. Proceedings of the 14th International SDEWES Conference; Dubrovnik, Croatia, Oct 1-6, 2019.

(280) Ito, S.; Uchida, M.; Onishi, S.; Kato, S.; Fujimori, T.; Kobayashi, H. Performance of Ammonia-Natural Gas Co-fired Gas Turbine for Power Generation. Proceedings of the 15th Annual $\mathrm{NH}_{3}$ Fuel Conference; Pittsburgh, PA, Oct 31-Nov 1, 2018; https://nh3fuelassociation.org/ 2018/12/07/performance-of-ammonia-natural-gas-co-fired-gasturbine-for-power-generation/ (accessed Oct 12, 2020).

(281) Abdalla, A. M.; Hossain, S.; Azad, A. T.; Petra, P. M. I.; Begum, F.; Eriksson, S. G.; Azad, A. K. Nanomaterials for Solid Oxide Fuel Cells: A Review. Renewable Sustainable Energy Rev. 2018, 82, 353-368.

(282) Steele, B. C. H.; Heinzel, A. Materials for Fuel-Cell Technologies. Nature 2001, 414, 345-352.

(283) Møller, K. T.; Jensen, T. R.; Akiba, E.; Li, H. Hydrogen-A Sustainable Energy Carrier. Prog. Nat. Sci. 2017, 27 (1), 34-40.

(284) Nikolaidis, P.; Poullikkas, A. A Comparative Overview of Hydrogen Production Processes. Renewable Sustainable Energy Rev. 2017, 67, 597-611.

(285) Simon Araya, S.; Liso, V.; Cui, X.; Li, N.; Zhu, J.; Sahlin, S. L.; Jensen, S. H.; Nielsen, M. P.; Kær, S. K. A Review of the Methanol Economy: The Fuel Cell Route. Energies 2020, 13 (3), 596.

(286) Ni, M.; Leung, D. Y. C.; Leung, M. K. H. A Review on Reforming Bio-Ethanol for Hydrogen Production. Int. J. Hydrogen Energy 2007, 32 (15), 3238-3247.

(287) Yapicioglu, A.; Dincer, I. A Review on Clean Ammonia as a Potential Fuel for Power Generators. Renewable Sustainable Energy Rev. 2019, 103, 96.

(288) Afif, A.; Radenahmad, N.; Cheok, Q.; Shams, S.; Kim, J. H.; Azad, A. K. Ammonia-Fed Fuel Cells: A Comprehensive Review. Renewable Sustainable Energy Rev. 2016, 60, 822-835.

(289) Ma, Q.; Peng, R. R.; Tian, L.; Meng, G. Direct Utilization of Ammonia in Intermediate-Temperature Solid Oxide Fuel Cells. Electrochem. Commun. 2006, 8 (11), 1791-1795.

(290) Fournier, G. G. M.; Cumming, I. W.; Hellgardt, K. High Performance Direct Ammonia Solid Oxide Fuel Cell. J. Power Sources 2006, 162 (1), 198-206.

(291) Boggs, B. K.; King, R. L.; Botte, G. G. Urea Electrolysis: Direct Hydrogen Production from Urine. Chem. Commun. (Cambridge, U. K.) 2009, No. 32, 4859-4861.

(292) Kordali, V.; Kyriacou, G.; Lambrou, C. Electrochemical Synthesis of Ammonia at Atmospheric Pressure and Low Temperature in a Solid Polymer Electrolyte Cell. Chem. Commun. 2000, No. 17, $1673-1674$

(293) Miyaoka, H.; Miyaoka, H.; Ichikawa, T.; Ichikawa, T.; Kojima, Y. Highly Purified Hydrogen Production from Ammonia for PEM Fuel Cell. Int. J. Hydrogen Energy 2018, 43 (31), 14486-14492.

(294) McFarlan, a.; Pelletier, L.; Maffei, N. An IntermediateTemperature Ammonia Fuel Cell Using Gd-Doped Barium Cerate Electrolyte. J. Electrochem. Soc. 2004, 151 (6), A930.

(295) Araya, S. S.; Zhou, F.; Liso, V.; Sahlin, S. L.; Vang, J. R.; Thomas, S.; Gao, X.; Jeppesen, C.; Kær, S. K. A Comprehensive Review of PBIBased High Temperature PEM Fuel Cells. Int. J. Hydrogen Energy 2016, 41 (46), 21310-21344.

(296) Jeppesen, C.; Araya, S. S.; Sahlin, S. L.; Thomas, S.; Andreasen, S. J.; Kær, S. K. Fault Detection and Isolation of High Temperature Proton Exchange Membrane Fuel Cell Stack under the Influence of Degradation. J. Power Sources 2017, 359, 37-47.

(297) Thomas, S.; Vang, J. R.; Araya, S. S.; Kær, S. K. Experimental Study to Distinguish the Effects of Methanol Slip and Water Vapour on a High Temperature PEM Fuel Cell at Different Operating Conditions. Appl. Energy 2017, 192, 422-436.

(298) Cinti, G.; Liso, V.; Sahlin, S. L.; Araya, S. S. System Design and Modeling of a High Temperature PEM Fuel Cell Operated with Ammonia as a Fuel. Energies 2020, 13 (18), 4689.

(299) Hossain, S.; Abdalla, A. M.; Jamain, S. N. B.; Zaini, J. H.; Azad, A. K. A Review on Proton Conducting Electrolytes for Clean Energy and Intermediate Temperature-Solid Oxide Fuel Cells. Renewable Sustainable Energy Rev. 2017, 79 (May), 750-764.

(300) Radenahmad, N.; Afif, A.; Petra, P. I.; Rahman, S. M. H.; Eriksson, S.-G.; Azad, A. K. Proton-Conducting Electrolytes for Direct Methanol and Direct Urea Fuel Cells-A State-of-the-Art Review. Renewable Sustainable Energy Rev. 2016, 57, 1347-1358.

(301) Azad, A. K.; Kruth, A.; Irvine, J. T. S. Influence of Atmosphere on Redox Structure of $\mathrm{BaCe}_{0.9} \mathrm{Y}_{0.1} \mathrm{O}_{2.95}$-Insight from Neutron Diffraction Study. Int. J. Hydrogen Energy 2014, 39, 12804.

(302) Pelletier, L.; McFarlan, A.; Maffei, N. Ammonia Fuel Cell Using Doped Barium Cerate Proton Conducting Solid Electrolytes. J. Power Sources 2005, 145 (2), 262-265.

(303) Farr, R. D.; Vayenas, C. G. Ammonia High Temperature Solid Electrolyte Fuel Cell. J. Electrochem. Soc. 1980, 127 (7), 1478-1483.

(304) Maffei, N.; Pelletier, L.; Charland, J.; Mcfarlan, A. An Intermediate Temperature Direct Ammonia Fuel Cell Using a Proton Conducting Electrolyte. J. Power Sources 2005, 140 (2), 264-267.

(305) Ni, M.; Leung, D. Y. C.; Leung, M. K. H. Electrochemical Modeling of Ammonia-Fed Solid Oxide Fuel Cells Based on Proton Conducting Electrolyte. J. Power Sources 2008, 183 (2), 687-692.

(306) Ni, M.; Leung, D. Y. C.; Leung, M. K. H. Thermodynamic Analysis of Ammonia Fed Solid Oxide Fuel Cells: Comparison between Proton-Conducting Electrolyte and Oxygen Ion-Conducting Electrolyte. J. Power Sources 2008, 183 (2), 682-686.

(307) Lan, R.; Tao, S. Direct Ammonia Alkaline Anion-Exchange Membrane Fuel Cells. Electrochem. Solid-State Lett. 2010, 13 (8), B83.

(308) Cairns, E. J.; Simons, E. L.; Tevebaugh, A. D. Ammonia-Oxygen Fuel Cell. Nature 1968, 217 (5130), 780-781.

(309) Ganley, J. C. An Intermediate-Temperature Direct Ammonia Fuel Cell with a Molten Alkaline Hydroxide Electrolyte. J. Power Sources 2008, 178 (1), 44-47.

(310) Hejze, T.; Besenhard, J. O.; Kordesch, K.; Cifrain, M.; Aronsson, R. R. Current Status of Combined Systems Using Alkaline Fuel Cells and Ammonia as a Hydrogen Carrier. J. Power Sources 2008, 176 (2), 490-493.

(311) Lan, R.; Tao, S. Ammonia as a Suitable Fuel for Fuel Cells. Front. Energy Res. 2014, 2, 35.

(312) Suzuki, S.; Muroyama, H.; Matsui, T.; Eguchi, K. Fundamental Studies on Direct Ammonia Fuel Cell Employing Anion Exchange Membrane. J. Power Sources 2012, 208, 257-262.

(313) Zhang, X.-B.; Han, S.; Yan, J.-M.; Chandra, M.; Shioyama, H.; Yasuda, K.; Kuriyama, N.; Kobayashi, T.; Xu, Q. A New Fuel Cell Using Aqueous Ammonia-Borane as the Fuel. J. Power Sources 2007, 168 (1), $167-171$. 
(314) Zhang, X.-B.; Yan, J.-M.; Han, S.; Shioyama, H.; Yasuda, K.; Kuriyama, N.; Xu, Q. A High Performance Anion Exchange MembraneType Ammonia Borane Fuel Cell. J. Power Sources 2008, 182 (2), 515519.

(315) Cisar, A.; Withers-Kirby, S.; Heselmeyer, E. Direct Ammonia Borane Alkaline Fuel Cell with In-Situ Electrolyte Replacement. ECS Trans. 2008, 12 (1), 737-742.

(316) Wojcik, A.; Middleton, H.; Damopoulos, I.; Van Herle, J. Ammonia as a Fuel in Solid Oxide Fuel Cells. J. Power Sources 2003, $118,342-348$.

(317) Staniforth, J.; Ormerod, R. M. Clean Destruction of Waste Ammonia with Consummate Production of Electrical Power within a Solid Oxide Fuel Cell System. Green Chem. 2003, 5 (5), 606-609.

(318) Hossain, S.; Abdalla, A. M.; Zaini, J. H.; Savaniu, C. D.; Irvine, J. T. S.; Azad, A. K. Highly Dense and Novel Proton Conducting Materials for SOFC Electrolyte. Int. J. Hydrogen Energy 2017, 42 (44), 27308-27322.

(319) Radenahmad, N.; Afif, A.; Abdalla, A. M.; Saqib, M.; Park, J.-Y.; Zaini, J.; Irvine, J.; Kim, J. H.; Azad, A. K. A New High-Performance Proton-Conducting Electrolyte for Next-Generation Solid Oxide Fuel Cells. Energy Technol. 2020, 8, 2000486.

(320) Afif, A.; Radenahmad, N.; Lim, C. M.; Petra, M. I.; Islam, M. A.; Rahman, S. M. H.; Eriksson, S.; Azad, A. K. Structural Study and Proton Conductivity in $\mathrm{BaCe} 0.7 \mathrm{Zr} 0.25-\mathrm{xYxZn} 0.05 \mathrm{O} 3$ ( $\mathrm{x}=0.05,0.1,0.15,0.2$ \& 0.25). Int. J. Hydrogen Energy 2016, 41 (27), 11823-11831.

(321) Meng, G.; Jiang, C.; Ma, J.; Ma, Q.; Liu, X. Comparative Study on the Performance of a SDC-Based SOFC Fueled by Ammonia and Hydrogen. J. Power Sources 2007, 173 (1), 189-193.

(322) Demin, A. Thermodynamic Analysis of a Methane Fed SOFC System Based on a Protonic Conductor. Solid State Ionics 2002, 152$153,555-560$.

(323) Assabumrungrat, S.; Sangtongkitcharoen, W.; Laosiripojana, N.; Arpornwichanop, A.; Charojrochkul, S.; Praserthdam, P. Effects of Electrolyte Type and Flow Pattern on Performance of MethanolFuelled Solid Oxide Fuel Cells. J. Power Sources 2005, 148, 18-23.

(324) Chellappa, A. S.; Fischer, C. M.; Thomson, W. J. Ammonia Decomposition Kinetics over Ni-Pt/ $\mathrm{Al}_{2} \mathrm{O}_{3}$ for PEM Fuel Cell Applications. Appl. Catal., A 2002, 227, 231.

(325) Yin, S. F.; Xu, B. Q.; Zhou, X. P.; Au, C. T. A Mini-Review on Ammonia Decomposition Catalysts for on-Site Generation of Hydrogen for Fuel Cell Applications. Appl. Catal., A 2004, 277 (1-2), 1-9.

(326) Demin, A. Thermodynamic Analysis of a Hydrogen Fed Solid Oxide Fuel Cell Based on a Proton Conductor. Int. J. Hydrogen Energy 2001, 26 (10), 1103-1108.

(327) Ishak, F.; Dincer, I.; Zamfirescu, C. Thermodynamic Analysis of Ammonia-Fed Solid Oxide Fuel Cells. J. Power Sources 2012, 202, 157165.

(328) Valera-Medina, A.; Xiao, H.; Owen-Jones, M.; David, W. I. F.; Bowen, P. J. Ammonia for Power. Prog. Energy Combust. Sci. 2018, 69, 63-102.

(329) Perry, S. C.; Gateman, S. M.; Stephens, L. I.; Lacasse, R.; Schulz, R.; Mauzeroll, J. Pourbaix Diagrams as a Simple Route to First Principles Corrosion Simulation. J. Electrochem. Soc. 2019, 166, C3186.

(330) Groysman, A. Physicochemical Behavior of Engineering Materials in Ammonia and Its Derivatives. Proceedings of the "New and Old in the Ammonia World" 2017 Conference; Technion, Haifa, Israel, Nov 15-16, 2017; http://eurocorr.efcweb.org/2018/abstracts/ 7/101877.pdf (accessed Jan 19, 2021).

(331) Pedeferri, P. Corrosion Science and Engineering; Springer: Cham, Switzerland, 2018; DOI: 10.1007/978-3-319-97625-9.

(332) NACE International. NACE Publication 5A192-2004-SGIntegrity of Equipment in Anhydrous Ammonia Storage and Handling; NACE International: Houston, TX, 2004.

(333) Hamidah, I.; Solehudin, A.; Hamdani, A.; Hasanah, L.; Khairurrijal, K.; Kurniawan, T.; Mamat, R.; Maryanti, R.; Nandiyanto, A. B. D.; Hammouti, B. Corrosion of Copper Alloys in $\mathrm{KOH}, \mathrm{NaOH}, \mathrm{NaCl}$, and $\mathrm{HCl}$ Electrolyte Solutions and Its Impact to the Mechanical Properties. Alexandria Eng. J. 2021, 60, 2235.
(334) Valera-Medina, A.; Roldan, A. Ammonia from Steelworks. Sustainable Ammonia Production; Springer International Publishing: Cham, Switzerland, 2019; p 136, DOI: 10.1007/978-3-030-35106-9.

(335) Crolius, S.; Pugh, D. G.; Morris, S.; Valera-Medina, A. Safety Aspects. Techno-Economic Challenges of Ammonia as an Energy Vector; Academic Press: Cambridge, MA, 2020; p 37, DOI: 10.1016/c2019-001417-3.

(336) American Industrial Hygiene Association (AIHA). Current ERPG Values; AIHA: Falls Church, VA, 2015; https://www.aiha.org/ ge t - involved/A I H A Guideline Foundation/ EmergencyResponsePlanning Guidelines / Documents / 2015ERPGLevels.pdf (accessed Jan 19, 2021).

(337) Michaels, R. A. Emergency Planning and the Acute Toxic Potency of Inhaled Ammonia. Environ. Health Perspect. 1999, 107, 617.

(338) Pedersen, F.; Selig, R. S. Predicting the Consequences of ShortTerm Exposure to High Concentrations of Gaseous Ammonia. J. Hazard. Mater. 1989, 21, 143.

(339) Ten Berge, W. F.; Zwart, A.; Appelman, L. M. ConcentrationTime Mortality Response Relationship of Irritant and Systemically Acting Vapours and Gases. J. Hazard. Mater. 1986, 13, 301.

(340) Pauluhn, J. Acute Inhalation Toxicity of Ammonia: Revisiting the Importance of $\mathrm{RD}_{50}$ and $\mathrm{LCT}_{01 / 50}$ Relationships for Setting Emergency Response Guideline Values. Regul. Toxicol. Pharmacol. 2013, 66, 315.

(341) Silverman, L.; Whittenbbrger, J. L.; Muller, J. Physiologieal Response of Man to Ammonia in Low Concentrations. J. Ind. Hyg. Toxicol. 1949, 31 (2), 74-78.

(342) Amshel, C. E.; Fealk, M. H.; Phillips, B. J.; Caruso, D. M. Anhydrous Ammonia Burns Case Report and Review of the Literature. Burns 2000, 26 (5), 493-497.

(343) Changes in Atmospheric Constituents and in Radiative Forcing. In Climate Change 2007. The Physical Science Basis; Forster, P., Ramaswamy, V., Artaxo, P., Berntsen, T., Betts, R., Fahey, D. W., Haywood, J., Lean, J., Lowe, D. C., Myhre, G., Nganga, J., Prinn, R., Raga, G., Schulz, M., Van Dorland, R., Miller, H. L., Eds.; Cambridge University Press: Cambridge, U.K., 2007; Vol. 39.

(344) Mauzerall, D. L.; Sultan, B.; Kim, N.; Bradford, D. F. NO $\mathrm{NO}_{x}$ Emissions from Large Point Sources: Variability in Ozone Production, Resulting Health Damages and Economic Costs. Atmos. Environ. 2005, 39, 2851.

(345) Coghlan, A. Nitrogen Oxides in Car Exhaust Kill Tens of Thousands in UK; New Scientist: London, U.K., 2015; https://www. newscientist.com/article/dn28245-nitrogen-oxide-is-not-so-harmlessand-could-damage-human-health/ (accessed Jan 19, 2021).

(346) Kurvits, T.; Marta, T. Agricultural $\mathrm{NH}_{3}$ and $\mathrm{NO}_{x}$ Emissions in Canada. Environ. Pollut. 1998, 102, 187.

(347) Lelieveld, J.; Evans, J. S.; Fnais, M.; Giannadaki, D.; Pozzer, A. The Contribution of Outdoor Air Pollution Sources to Premature Mortality on a Global Scale. Nature 2015, 525 (7569), 367-371.

(348) Anenberg, S. C.; Horowitz, L. W.; Tong, D. Q.; West, J. J. An Estimate of the Global Burden of Anthropogenic Ozone and Fine Particulate Matter on Premature Human Mortality Using Atmospheric Modeling. Environ. Health Perspect. 2010, 118 (9), 1189-1195.

(349) United States Environmental Protection Agency (U.S. EPA). The Benefits and Costs of the Clean Air Act from 1990-2020. Better Air: Benefits and Costs of the Clean Air Act; U.S. EPA: Washington, D.C., 2011; pp 1-201.

(350) Héroux, M.-E.; Anderson, H. R.; Atkinson, R.; Brunekreef, B.; Cohen, A.; Forastiere, F.; Hurley, F.; Katsouyanni, K.; Krewski, D.; Krzyzanowski, M.; et al. Quantifying the Health Impacts of Ambient Air Pollutants: Recommendations of a WHO/Europe Project. Int. J. Public Health 2015, 60 (5), 619-627.

(351) Heeb, N. V.; Forss, A.-M.; Brühlmann, S.; Lüscher, R.; Saxer, C. J.; Hug, P. Three-Way Catalyst-Induced Formation of AmmoniaVelocity- and Acceleration-Dependent Emission Factors. Atmos. Environ. 2006, 40 (31), 5986-5997.

(352) Johnson, T. V. Review of Diesel Emissions and Control. Int. J. Engine Res. 2009, 10 (5), 275-285. 
(353) Dedoussi, I. C.; Barrett, S. R. H. Air Pollution and Early Deaths in the United States. Part II: Attribution of $\mathrm{PM}_{2.5}$ Exposure to Emissions Species, Time, Location and Sector. Atmos. Environ. 2014, 99, 610.

(354) Holt, J.; Selin, N. E.; Solomon, S. Changes in Inorganic Fine Particulate Matter Sensitivities to Precursors Due to Large-Scale Us Emissions Reductions. Environ. Sci. Technol. 2015, 49 (8), 4834-4841.

(355) Dedoussi, I. C.; Eastham, S. D.; Monier, E.; Barrett, S. R. H. Premature Mortality Related to United States Cross-State Air Pollution. Nature 2020, 578 (7794), 261-265.

(356) Chossière, G. P.; Malina, R.; Ashok, A.; Dedoussi, I. C.; Eastham, S. D.; Speth, R. L.; Barrett, S. R. H. Public Health Impacts of Excess $\mathrm{NO}_{x}$ Emissions from Volkswagen Diesel Passenger Vehicles in Germany. Environ. Res. Lett. 2017, 12, 034014.

(357) Quadros, F.; Snellen, M.; Dedoussi, I. C. Regional Sensitivities of Air Quality and Human Health Impacts to Aviation Emissions. Environ. Res. Lett. 2020, 15, 105013.

(358) Fu, X.; Wang, S.; Xing, J.; Zhang, X.; Wang, T.; Hao, J. Increasing Ammonia Concentrations Reduce the Effectiveness of Particle Pollution Control Achieved via $\mathrm{SO}_{2}$ and $\mathrm{NO}_{x}$ Emissions Reduction in East China. Environ. Sci. Technol. Lett. 2017, 4 (6), 221227.

(359) Lee, C. J.; Martin, R. V.; Henze, D. K.; Brauer, M.; Cohen, A.; van Donkelaar, A. Response of Global Particulate-Matter-Related Mortality to Changes in Local Precursor Emissions. Environ. Sci. Technol. 2015, 49 (7), 4335-4344.

(360) Pinder, R. W.; Adams, P. J.; Pandis, S. N. Ammonia Emission Controls as a Cost-Effective Strategy for Reducing Atmospheric Particulate Matter in the Eastern United States. Environ. Sci. Technol. 2007, 41 (2), 380-386.

(361) Sun, K.; Tao, L.; Miller, D. J.; Pan, D.; Golston, L. M.; Zondlo, M. A.; Griffin, R. J.; Wallace, H. W.; Leong, Y. J.; Yang, M. M. Vehicle Emissions as an Important Urban Ammonia Source in the United States and China. Environ. Sci. Technol. 2017, 51 (4), 2472.

(362) Guo, H.; Otjes, R.; Schlag, P.; Kiendler-Scharr, A.; Nenes, A.; Weber, R. J. Effectiveness of Ammonia Reduction on Control of Fine Particle Nitrate. Atmos. Chem. Phys. 2018, 18 (16), 12241-12256.

(363) Heald, C. L.; Collett, J. L.; Lee, T.; Benedict, K. B.; Schwandner, F. M.; Li, Y.; Clarisse, L.; Hurtmans, D. R.; Van Damme, M.; Clerbaux, C.; et al. Atmospheric Ammonia and Particulate Inorganic Nitrogen over the United States. Atmos. Chem. Phys. 2012, 12, 10295-10312.

(364) Gaffney, J. S.; Marley, N. A. The Impacts of Combustion Emissions on Air Quality and Climate - From Coal to Biofuels and Beyond. Atmos. Environ. 2009, 43 (1), 23-36.

(365) Myhre, G.; Shindell, D.; Bréon, F.-M.; Collins, W.; Fuglestvedt, J.; Huang, J.; Koch, D.; Lamarque, J.-F.; Lee, D.; Mendoza, B.; et al. Anthropogenic and Natural Radiative Forcing. Climate Change 2013: The Physical Science Basis. Contribution of Working Group I to the Fifth Assessment Report of the Intergovernmental Panel on Climate Change; Cambridge University Press: Cambridge, U.K., 2013.

(366) Shindell, D. T. The Social Cost of Atmospheric Release. Clim. Change 2015, 130 (2), 313-326.

(367) Kang, D. W.; Holbrook, J. H. Use of $\mathrm{NH}_{3}$ Fuel to Achieve Deep Greenhouse Gas Reductions from US Transportation. Energy Reports 2015, 1, 164-168.

(368) Dedoussi, I. C.; Allroggen, F.; Flanagan, R.; Hansen, T.; Taylor, B.; Barrett, S. R. H.; Boyce, J. K. The Co-Pollutant Cost of Carbon Emissions: An Analysis of the US Electric Power Generation Sector. Environ. Res. Lett. 2019, 14 (9), 094003.

(369) Thompson, T. M.; Rausch, S.; Saari, R. K.; Selin, N. E. A Systems Approach to Evaluating the Air Quality Co-Benefits of US Carbon Policies. Nat. Clim. Change 2014, 4 (10), 917-923.

(370) Driscoll, C. T.; Buonocore, J. J.; Levy, J. I.; Lambert, K. F.; Burtraw, D.; Reid, S. B.; Fakhraei, H.; Schwartz, J. US Power Plant Carbon Standards and Clean Air and Health Co-Benefits. Nature Climate Change 2015, 535-540.

(371) Nemet, G. F.; Holloway, T.; Meier, P. Implications of Incorporating Air-Quality Co-Benefits into Climate Change Policymaking. Environ. Res. Lett. 2010, 5 (1), 014007.
(372) Grobler, C.; Wolfe, P. J.; Dasadhikari, K.; Dedoussi, I. C.; Allroggen, F.; Speth, R. L.; Eastham, S. D.; Agarwal, A.; Staples, M. D.; Sabnis, J.; et al. Marginal Climate and Air Quality Costs of Aviation Emissions. Environ. Res. Lett. 2019, 14 (11), 114031.

(373) Lamarque, J.-F.; Dentener, F.; McConnell, J.; Ro, C.-U.; Shaw, M.; Vet, R.; Bergmann, D.; Cameron-Smith, P.; Dalsoren, S.; Doherty, R.; et al. Multi-Model Mean Nitrogen and Sulfur Deposition from the Atmospheric Chemistry and Climate Model Intercomparison Project (ACCMIP): Evaluation of Historical and Projected Future Changes. Atmos. Chem. Phys. 2013, 13 (16), 7997-8018.

(374) Bobbink, R.; Hicks, K.; Galloway, J.; Spranger, T.; Alkemade, R.; Ashmore, M.; Bustamante, M.; Cinderby, S.; Davidson, E.; Dentener, F.; et al. Global Assessment of Nitrogen Deposition Effects on Terrestrial Plant Diversity: A Synthesis. Ecol. Appl. 2010, 20 (1), 30-59.

(375) Paulot, F.; Jacob, D. J.; Henze, D. K. Sources and Processes Contributing to Nitrogen Deposition: An Adjoint Model Analysis Applied to Biodiversity Hotspots Worldwide. Environ. Sci. Technol. 2013, 47 (7), 3226-3233.

(376) Arrow, K. J.; Cropper, M. L.; Gollier, C.; Groom, B.; Heal, G. M.; Newell, R. G.; Nordhaus, W. D.; Pindyck, R. S.; Pizer, W. A.; Portney, P. R. How Should Benefits and Costs Be Discounted in an Intergenerational Context? The Views of an Expert Panel. SSRN Electron. J. 2013, 12-53.

(377) Tan, J.; Fu, J. S.; Seinfeld, J. H. Ammonia Emission Abatement Does Not Fully Control Reduced Forms of Nitrogen Deposition. Proc. Natl. Acad. Sci. U. S. A. 2020, 117 (18), 9771-9775.

(378) Heer, M. de; Roozen, F.; Maas, R. The Integrated Approach to Nitrogen in the Netherlands: A Preliminary Review from a Societal, Scientific, Juridical and Practical Perspective. J. Nat. Conserv. 2017, 35, $101-111$.

(379) Sutton, M.; Howard, C.; Erisman, J. The European Nitrogen Assessment: Sources, Effects and Policy Perspectives; Cambridge University Press: Cambridge, U.K., 2011.

(380) Bicer, Y.; Dincer, I.; Vezina, G.; Raso, F. Impact Assessment and Environmental Evaluation of Various Ammonia Production Processes. Environ. Manage. 2017, 59 (5), 842-855.

(381) Service, R. Ammonia-A Renewable Fuel Made from Sun, Air, and Water-Could Power the Globe without Carbon. Science 2018, DOI: $10.1126 /$ science.aau 7489 .

(382) Currie, D. P. OSHA. Law Soc. Inq. 1976, 1 (4), 1107-1160.

(383) Tanner Industries, Inc. Storage and Handling of Anhydrous Ammonia; Tanner Industries, Inc.: Southampton, PA, 2020; http:// www.ammoniapro.com/AmmoniaLibrary/TechDataBooklets/ Tanner NH3Storage\&Handling.pdf (accessed Jan 19, 2021).

(384) Baybutt, P. Process Safety Management. Process Saf. Prog. 2014, $33(4), 407$.

(385) Occupational Safety and Health Administration (OSHA). Air Contaminants-1910.1000; OSHA: Washington, D.C., 2016; https:// www.osha.gov/pls/oshaweb/owadisp.show_document?p_table= STANDARDS\&p_id=9991 (accessed Jan 19, 2021).

(386) European Parliament and the Council of the European Union. Seveso III Directive; European Parliament and the Council of the European Union: Brussels, Belgium, 2012 https://eur-lex.europa.eu/ eli/dir/2012/18/oj (accessed Jan 19, 2021).

(387) European Commission. Directive 2000/39/EC; European Commission: Brussels, Belgium, 2000; https://eur-lex.europa.eu/ legal-content/en/ALL/?uri=CELEX\%3A32000L0039 (accessed Jan 19, 2021).

(388) Chemical Inspection and Regulation Service (CIRS). GBZ 2.12007 Occupational Exposure Limits for Hazardous Agents in the Workplace/Chemical Hazardous Agents; Chemical Inspection and Regulation Service (CIRS): Hangzhou, China, 2007; https://www. chinesestandard.net/PDF.aspx/GBZ2.1-2007 (accessed Nov 25, 2019).

(389) China Planning Press. GB 50016-2014-Code for Fire Protection Design of Buildings; China Planning Press: Beijing, China, 2014.

(390) United States Environmental Protection Agency (U.S. EPA). Risk Management Plan (RMP) Rule; U.S. EPA: Washington, D.C., 2018; 
https://www.epa.gov/rmp/risk-management-plan-rmp-rule-overview (accessed Jan 19, 2021).

(391) United States Environmental Protection Agency (U.S. EPA). Significant New Alternatives Policy (SNAP) Program; U.S. EPA: Washington, D.C., 2020; https://www.epa.gov/snap (accessed Jan 19, 2021).

(392) European Parliament and the Council of the European Union. Directive 2008/1/EC; European Parliament and the Council of the European Union: Brussels, Belgium, 2008; http://data.europa.eu/eli/ dir/2008/1/oj (accessed Jan 19, 2021).

(393) Ministry of Ecology and Environment. Discharge Standard of Water Pollutants for Ammonia Industry (GB 13458-2013); Ministry of Ecology and Environment: Beijing, China, 2013; http://www.mee.gov. $\mathrm{cn} /$.

(394) Task Force on Integrated Assessment Modelling (TFIAM); Centre for Integrated Assessment Modelling (CIAM). Review of the Gothenburg Protocol; United Nations Economic Commission for Europe (UNECE): Geneva, Switzerland, 2007; https://unece.org/ fileadmin//DAM/env/lrtap/TaskForce/tfiam/TFIAM ReportReviewGothenburgProtocol.pdf (accessed Jan 19, 2021).

(395) Thomas, G.; Parks, G. Potential Roles of Ammonia in a Hydrogen Society; $\mathrm{NH}_{3}$ Fuel Association: Pittsburgh, PA, 2006; https:// nh3fuelassociation.org/2006/02/01/potential-roles-of-ammonia-in-ahydrogen-economy/ (accessed Jan 19, 2021).

(396) Bartels, J. R. A Feasibility Study of Implementing an Ammonia Economy. M.S. Thesis, Iowa State University, Ames, IA, 2008.

(397) Leighty, B.; Holbrook, J. Transmission and Firming of GWScale Wind Energy via Hydrogen and Ammonia. Wind Eng. 2008, 32, 45.

(398) Philibert, C. Producing Ammonia and Fertilizers: New Opportunities from Renewables. IEA Rep. 2017, 1-6.

(399) Institute for Sustainable Process Technology (ISPT). Power to Ammonia; ISPT: Amersfoort, Netherlands, 2017; http://www.ispt.eu/ media/ISPT-P2A-Final-Report.pdf (accessed Jan 19, 2021).

(400) Iijama, M.; Susaki, M.; Furuichi, H.; Yonekawa, T.; Senba, N.; Nagayusu, $\mathrm{H} . \mathrm{CO}_{2}$-Free Energy (Ammonia). Mitsubishi Heavy Ind. Tech. Rev. 2019, 56 (1), 1-6.

(401) Morgan, E. R. Techno-Economic Feasibility Study of Ammonia Plants Powered by Offshore Wind Recommended Citation. Ph.D. Thesis, University of Massachusetts Amherst, Amherst, MA, 2013.

(402) United Nations Industrial Development Organization; International Fertilizer Development Center. The Fertilizer Manual; Kluwer Academic Publishers: Dordrecht, Netherlands, 1998.

(403) Morgan, E. R.; Manwell, J. F.; McGowan, J. G. Sustainable Ammonia Production from U.S. Offshore Wind Farms: A TechnoEconomic Review. ACS Sustainable Chem. Eng. 2017, 5 (11), 95549567.

(404) Parmar, V.; Manwell, J.; McGowan, J. Ammonia Production from a Non-Grid Connected Floating Offshore Windfarm. J. Phys.: Conf. Ser. 2020, 1452, 012015.

(405) Morgan, E.; Manwell, J.; McGowan, J. Wind-Powered Ammonia Fuel Production for Remote Islands: A Case Study. Renewable Energy 2014, 72, 51-61.

(406) Vrijenhoef, J. Decentralised Ammonia Production in the Netherlands. Proceedings of the $\mathrm{NH}_{3}$ Fuel Conference; Los Angeles, CA, Sept 18-21, 2016.

(407) Bicer, Y.; Dincer, I.; Zamfirescu, C.; Vezina, G.; Raso, F. Comparative Life Cycle Assessment of Various Ammonia Production Methods. J. Cleaner Prod. 2016, 135, 1379-1395.

(408) Boulamanti, A.; Moya, J. A. Production Costs of the Chemical Industry in the EU and Other Countries: Ammonia, Methanol and Light Olefins. Renewable Sustainable Energy Rev. 2017, 68, 1205.

(409) Shiozawa, B. The Cost of $\mathrm{CO}_{2}$-free Ammonia; Ammonia Energy Association: Brooklyn, NY, 2020; https://www.ammoniaenergy.org/ articles/the-cost-of-co2-free-ammonia/ (accessed Jan 19, 2021).

(410) International Energy Agency (IEA). Future of Hydrogen; IEA: Paris, France, 2019; https://www.iea.org/hydrogen2019/ (accessed Jan 19, 2021).
(411) Morgan, E. R.; Manwell, J. F.; McGowan, J. G. Opportunities for Economies of Scale with Alkaline Electrolyzers. Int. J. Hydrogen Energy 2013, 38, 15903.

(412) Lin, B.; Wiesner, T.; Malmali, M. Performance of a Small-Scale Haber Process: A Techno-Economic Analysis. ACS Sustainable Chem. Eng. 2020, 8, 15517.

(413) Rouwenhorst, K. Power-to-Ammonia-to-Power (P2A2P) for Local Electricity Storage in 2025: Current Developments, Process Proposal \& Future Research Required. M.S. Thesis, University of Twente, Enschede, Netherlands, 2018.

(414) Wang, Y.; Zheng, S.; Chen, J.; Wang, Z.; He, S. Ammonia $\left(\mathrm{NH}_{3}\right)$ Storage for Massive PV Electricity. Energy Procedia 2018, 150, 99.

(415) Siddiqui, O.; Dincer, I. Development and Performance Evaluation of a Direct Ammonia Fuel Cell Stack. Chem. Eng. Sci. 2019, 200, 285.

(416) Lipman, T.; Shah, N. Ammonia as an Alternative Energy Storage Medium for Hydrogen Fuel Cells: Scientific and Technical Review for NearTerm Stationary Power Demonstration Projects; University of California, Berkeley: Berkeley, CA, 2007; https://escholarship.org/uc/item/ 7z69v4wp (accessed Jan 19, 2021).

(417) Minutillo, M.; Perna, A.; Di Trolio, P.; Di Micco, S.; Jannelli, E. Techno-Economics of Novel Refueling Stations Based on Ammonia-toHydrogen Route and SOFC Technology. Int. J. Hydrogen Energy 2020, DOI: $10.1016 /$ j.ijhydene.2020.03.113.

(418) Giddey, S.; Badwal, S. P. S.; Munnings, C.; Dolan, M. Ammonia as a Renewable Energy Transportation Media. ACS Sustainable Chem. Eng. 2017, 5 (11), 10231-10239.

(419) Zamfirescu, C.; Dincer, I. Ammonia as a Green Fuel and Hydrogen Source for Vehicular Applications. Fuel Process. Technol. 2009, 90, 729.

(420) Dincer, I.; Bicer, Y. Comprehensive Evaluation of $\mathrm{NH}_{3}$ Production and Utilization Options for Clean Energy Applications. Liaison Functions 2017-Core Programming Area at the 2017 AIChE Annual Meeting; Ontario, Canada, Oct 29-Nov 3, 2017; Mitacs Accelerate Final Report Application IT08015, pp 398-531.

(421) Brohi, E. A. Ammonia as Fuel for Internal Combustion Engines? Master's Thesis, Department of Applied Mechanic, Division of Combustion, Chalmers University of Technology, Göteborg, Sweden, 2014.

(422) Bicer, Y.; Dincer, I. Life Cycle Evaluation of Hydrogen and Other Potential Fuels for Aircrafts. Int. J. Hydrogen Energy 2017, 42, 10722

(423) Alfa Laval; Hafnia; Haldor Topsøe; Vestas; Siemens Gamesa. Ammonfuel-An Industrial View of Ammonia as a Marine Fuel; Hafnia: Singapore, 2020; https://hafniabw.com/news/ammonfuel-anindustrial-view-of-ammonia-as-a-marine-fuel/ (accessed Jan 19, 2021).

(424) Kim, K.; Roh, G.; Kim, W.; Chun, K. A Preliminary Study on an Alternative Ship Propulsion System Fueled by Ammonia: Environmental and Economic Assessments. J. Mar. Sci. Eng. 2020, 8, 183.

(425) Zhao, Y.; Setzler, B. P.; Wang, J.; Nash, J.; Wang, T.; Xu, B.; Yan, Y. An Efficient Direct Ammonia Fuel Cell for Affordable CarbonNeutral Transportation. Joule 2019, 3 (10), 2472-2484.

(426) Zhang, H.; Wang, L.; Van herle, J.; Maréchal, F.; Desideri, U. Techno-Economic Comparison of Green Ammonia Production Processes. Appl. Energy 2020, 259, 114135.

(427) Liu, H.; Hu, Z.; Li, X.; Cen, Y.; Fu, G. Optimal Operation Conditions of Ammonia Synthesis and Catalytic Activity for A301 Catalyst. Chem. React. Eng. Technol. 2001, 17 (1), 28-34.

(428) Cheema, I. I.; Krewer, U. Operating Envelope of Haber-Bosch Process Design for Power-to-Ammonia. RSC Adv. 2018, 8 (61), 34926-34936.

(429) Cinti, G.; Frattini, D.; Jannelli, E.; Desideri, U.; Bidini, G. Coupling Solid Oxide Electrolyser (SOE) and Ammonia Production Plant. Appl. Energy 2017, 192, 466-476.

(430) Sánchez, A.; Martín, M. Optimal Renewable Production of Ammonia from Water and Air. J. Cleaner Prod. 2018, 178, 325-342.

(431) Brown, T. Zero Emission Aircraft: Ammonia for Aviation; Ammonia Energy Association: Brooklyn, NY, 2020; https://www. 
ammoniaenergy.org/organization/reaction-engines/ (accessed Jan 19, 2021).

(432) Brown, T. Ammonia-Fueled Ships: Entering the Design Phase; Ammonia Energy Association: Brooklyn, NY, 2019; https://www. ammoniaenergy.org/articles/ammonia-fueled-ships-entering-thedesign-phase $/$ mc_cid $=9926 \mathrm{ad} 8 \mathrm{~cd} 1 \& \mathrm{mc}$ eid $=81 \mathrm{~cd} 7 \mathrm{~b} 883 \mathrm{e}$ (accessed Jan 19, 2021). 